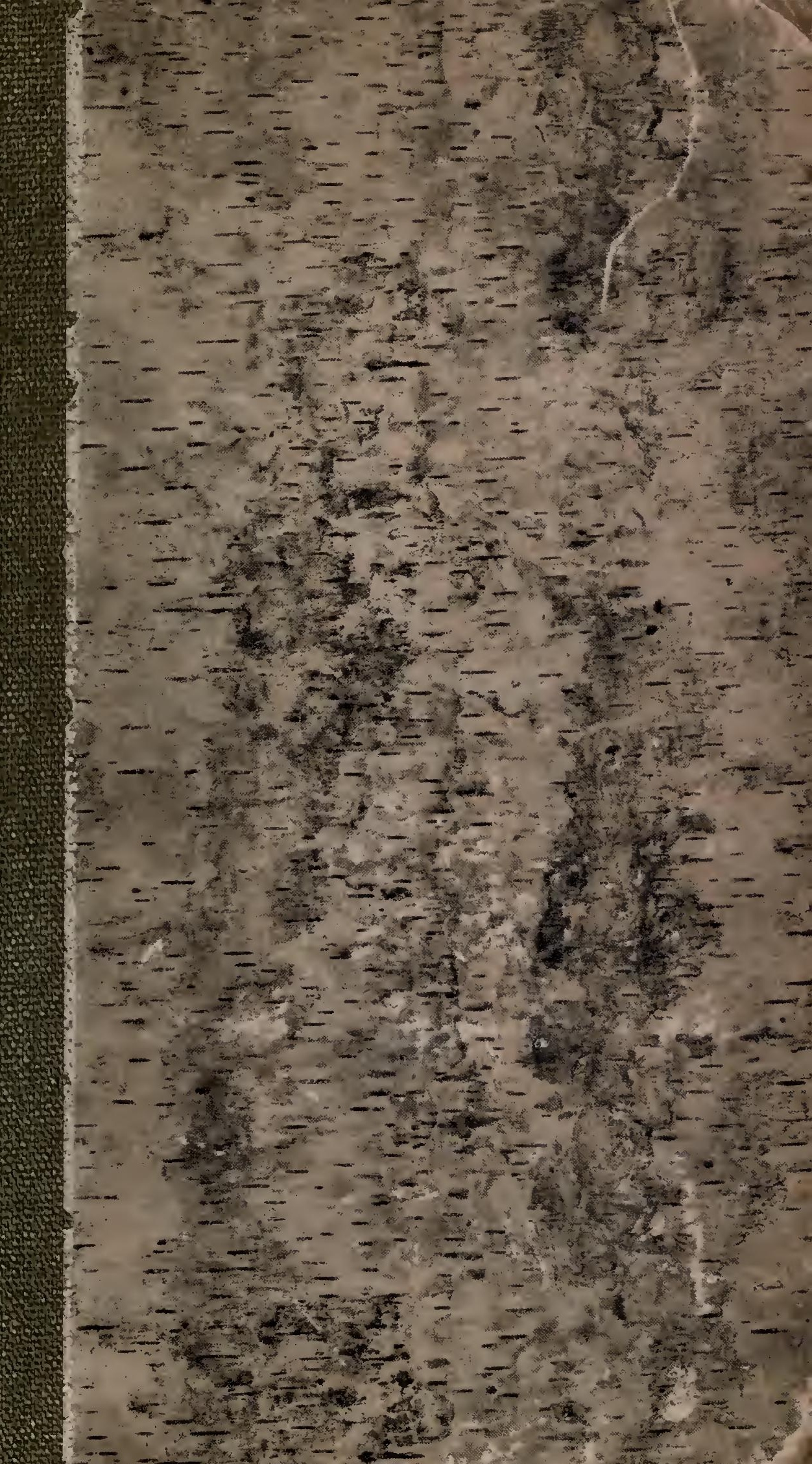



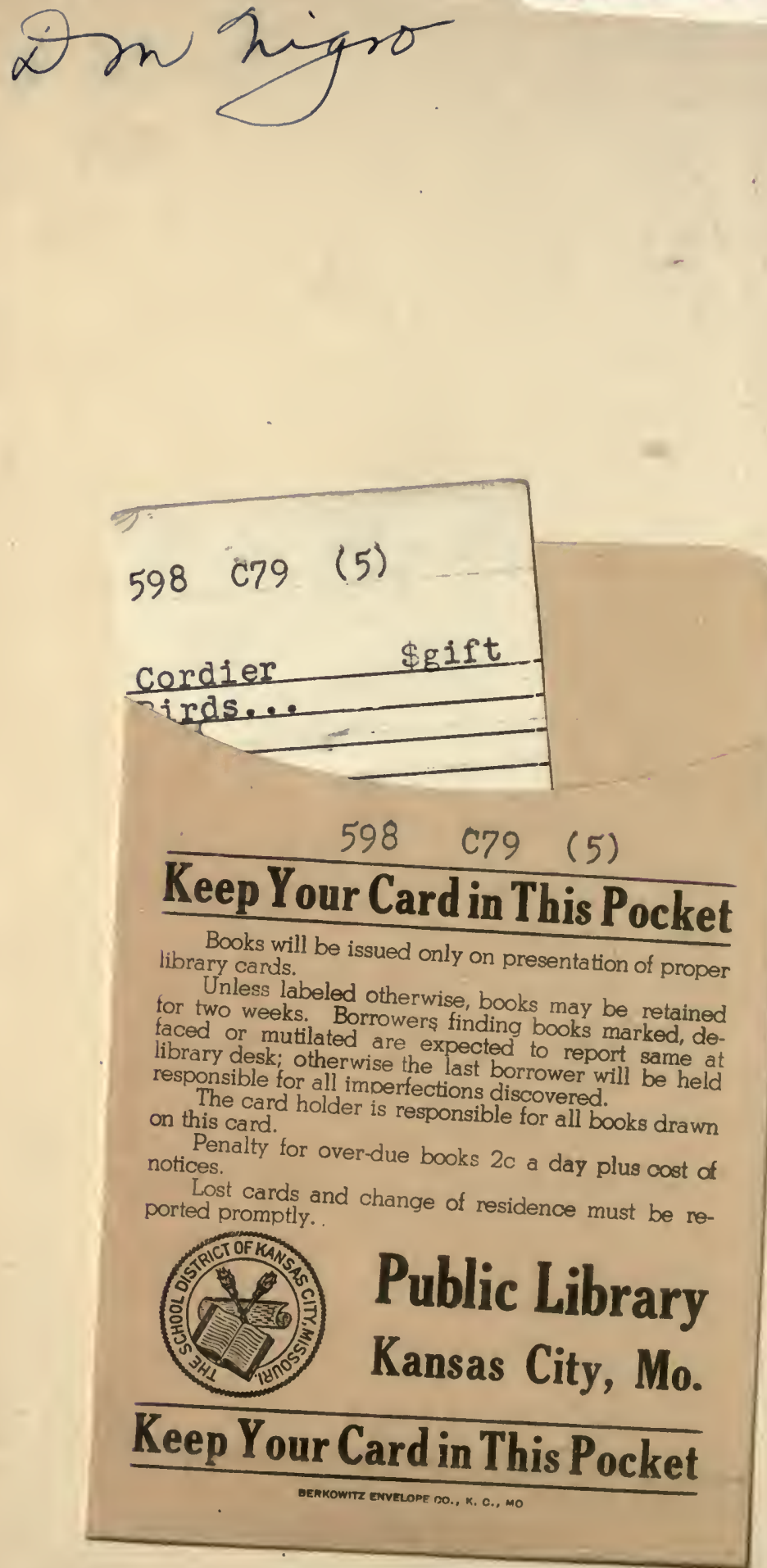


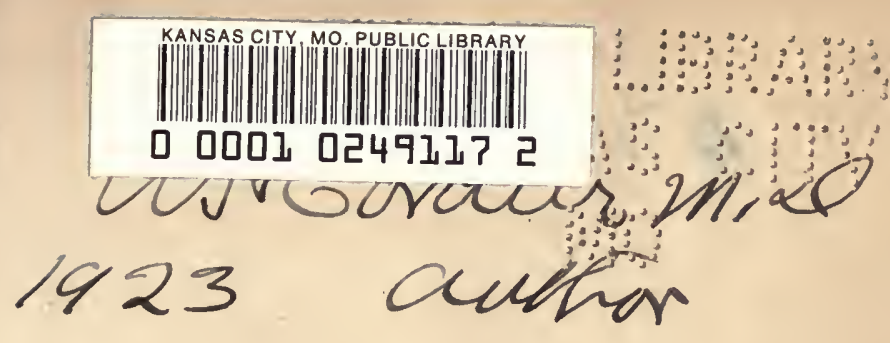

SATE: DUL

\section{7 i2}

From the collection of the

- Prefinger $\int_{\text {Library }}^{{ }^{2}}$

t

$\mathrm{p}$

San Francisco, California 2006 


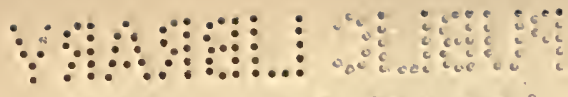

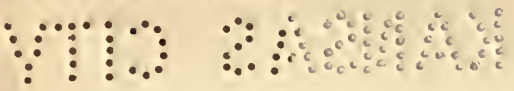

$\vdots: \vdots:: \vdots$ 


\section{BIRDS \\ THEIR PHOTOGRAPHS AND HOME LIFE}

A. H. CORDIER, M.D. 
Mao 9 ant

Wa nom

m. 


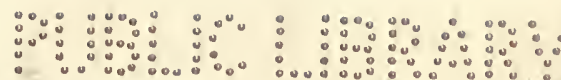

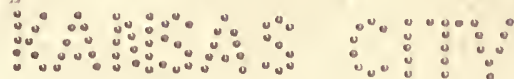

$\stackrel{\circ}{\because} \because \because 0$ 


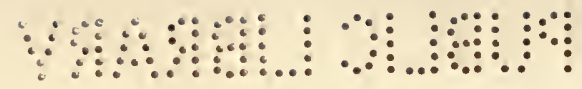

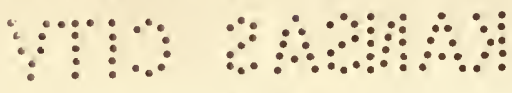

:

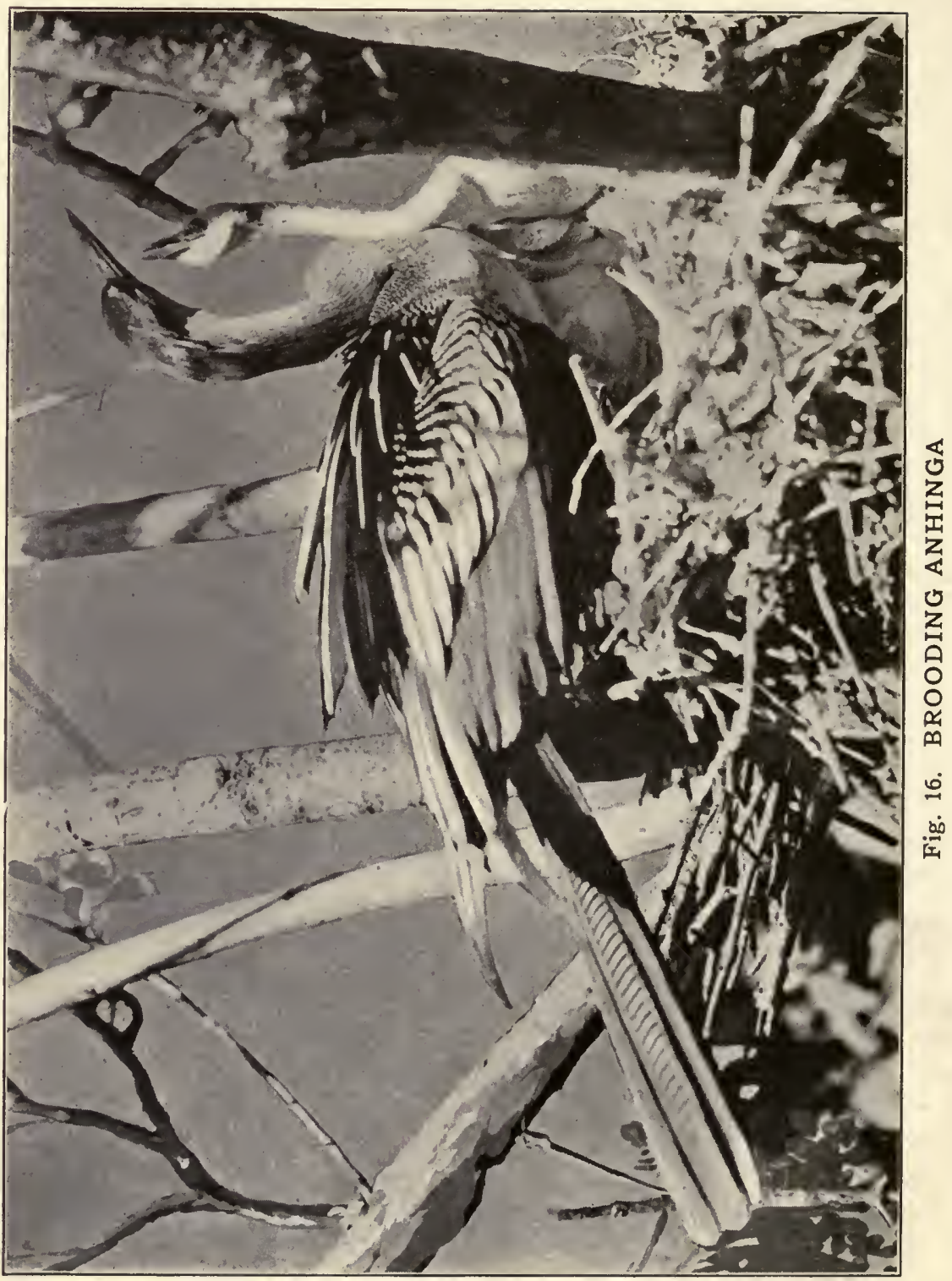




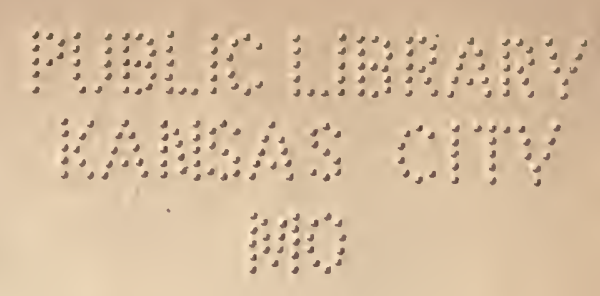

\section{B I R D S}

\section{Their Photographs and Home Life}

\section{BY}

\section{A. H. CORDIER, M.D.}

Former Professor of the Principles and Practice of Surgery in the University Medical College of Kansas City, Mo.; Former

President of the Mississippi Valley Medical Association;

Former Chairman of the Section of Gynecology of the American Medical Association; Author of SOME BIG GAME HUNTS; Associate

Member of American Ornithologists' Union, etc., etc.

With 145 Illustrations from Photographs of Wild Birds, by the Author

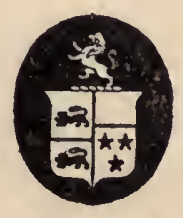

Publishers DORRANCE Philadelphia 


\section{Copyrizht 1923 \\ Dorrance \& Compeny Ine All Righta Recerved \\ Published in September \\ Socond Printing Septomber}




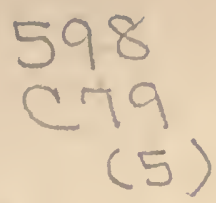

AFFECTIONATELY DEDICATED

TO

VIRGINIA CORDIER NELLIS

AND

ALBERT PRICE CORDIER, JR. 



\section{CONTENTS}

Preface $\ldots \ldots \ldots \ldots \ldots \ldots \ldots \ldots \ldots \ldots \ldots \ldots \ldots \ldots \ldots \ldots, \quad 11$

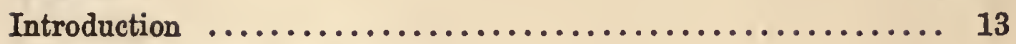

Bird Personalities and Habits $\ldots \ldots \ldots \ldots \ldots \ldots \ldots \ldots \ldots \ldots, 17$

Bird Migration ............................... 19

Identification, Nest-building, General Field Observations ...... 22

Photographing Birds ............................ 29

Photographic Equipment ........................ 39

The Umbrella Tent ............................. 43

The Great Bird-Breeding Rookeries .................. 46

Big Bird Island: Laguna de la Madre ................. 51

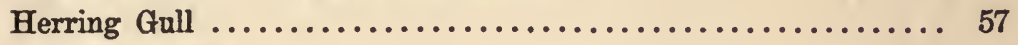

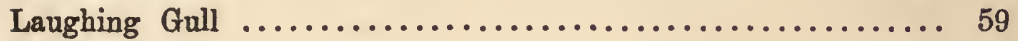

Least Tern .................................. 61

Black Skimmer ............................... 63

Snake-Bird ................................. 65

Cormorant .................................. 70

American Brown Pelican .......................... 72

Roseate Spoonbill ........................... 76

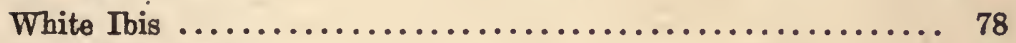

Great Blue Heron ............................ 80

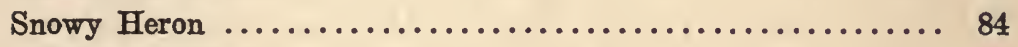

Louisiana Heron ............................. 88

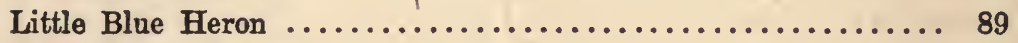

Little Green Heron ............................ 91

Limpkin .................................... 93

Bob-White .................................. 94

Passenger Pigeon ............................. 96

Mourning Dove ............................. 97

Black Vulture $\ldots \ldots \ldots \ldots \ldots \ldots \ldots \ldots \ldots \ldots \ldots \ldots \ldots \ldots \ldots \ldots \ldots$

Golden Eagle .................................. 102

Bald Eagle .................................... 104

Sparrow Hawk ............................. 107

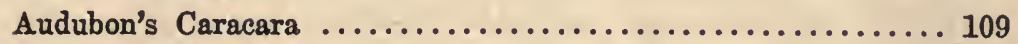

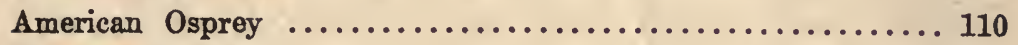

Long-eared Owl ............................... 111 


\section{CONTENTS-(Contimued)}

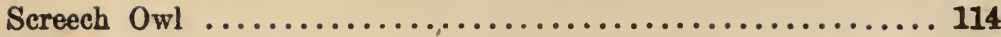

Yellow-billed Cuckoo ........................... 116

Kingfisher .................................. 120

Downy Woodpecker .......................... 122

Pileated Woodpecker ............................ 124

Red-headed Woodpecker ........................ 127

Red-bellied Woodpecker ........................... 129

Flicker ......................................... 131

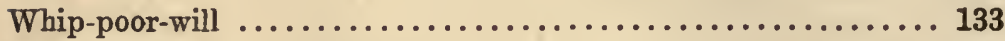

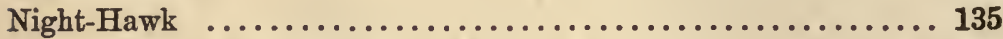

Ruby-throated Hummingbird ..................... 138

Kingbird .................................. 142

Great Crested Flycatcher ....................... 144

Phobe ....................................... 146

Prairie Horned Lark ......................... 148

Blue Jay ................................... 150

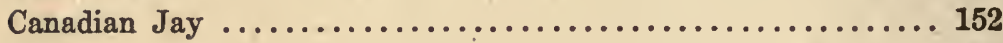

Crow ......................................... 154

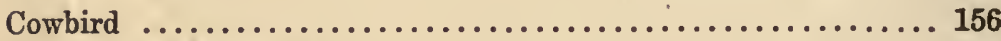

Red-winged Blackbird ........................... 159

Meadowlark .................................. 163

Baltimore Oriole ............................... 165

Bronzed Grackle ............................. 167

Great Boat-tailed Grackle ........................ 169

American Goldfinch ........................... 171

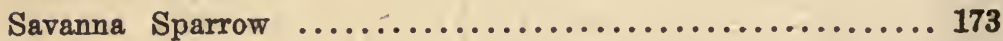

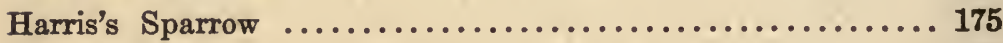

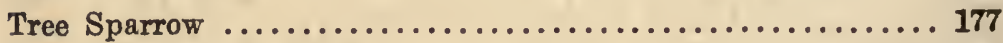

White-throated Sparrow ....................... 179

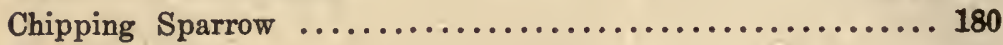

Field Sparrow ............................... 181

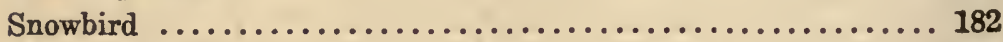

Song Sparrow ............................... 184

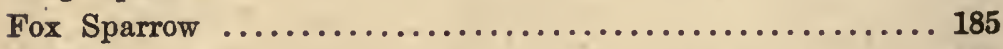

Towhee .................................... 187

Redbird .................................... 189

Rose-breasted Grosbeak .......................... 192

Indigo Bunting .............................. 194

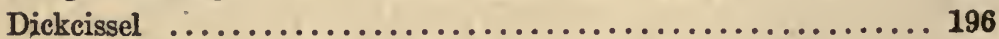

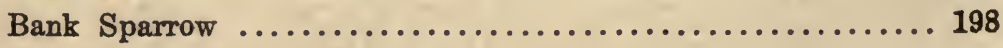




\section{CONTENTS-(Continued)}

Migrant Shrike ............................. 200

Red-eyed Vireo ............................... 203

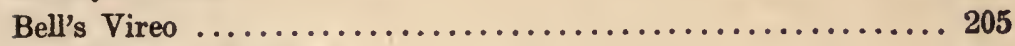

Prothonotary Warbler ......................... 207

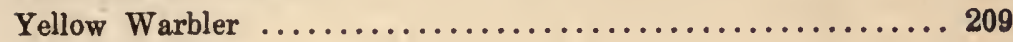

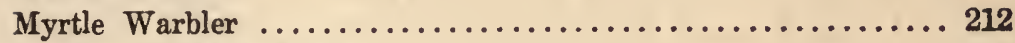

Maryland Yellow-Throat ........................ 214

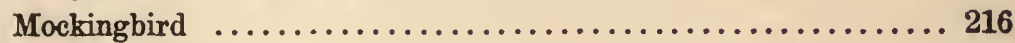

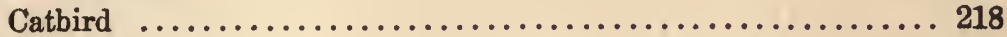

Brown Thrasher .............................. 220

Western House Wren .......................... 223

Brown Creeper ............................... 226

Tufted Titmouse ............................... 228

Chickadee ................................. 230

Blue-Gray Gnatcatcher ......................... 232

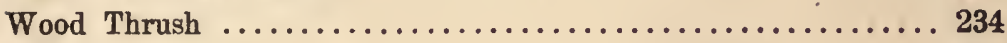

American Robin ............................. 237

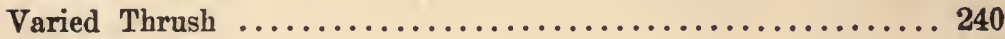

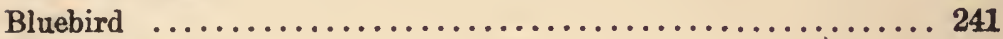

Water Ouzel ................................ 242 



\section{ILLUSTRATIONS}

FIG.

1. Teaching the Cat a Wrong Lesson ................. 18

2. Arsenated Skins ........................... 18

3. Comparative Size Pictures Made with Various Lenses ..... 19

4. Umbrella Tent ............................... 20

5. Diamond-backed Rattlesnake .................... 20

6. Hudson Bay Indian Guide .................... 21

7. Animated Lines ............................ 21

8. Impenetrable Mangrove Roots .................. 22

9. Brown Pelican Breeding Colony .................. 22

- 10. Nest and Eggs of Reddish Egret ................. 23

11. Great Blue Heron Ground Nest .................. 23

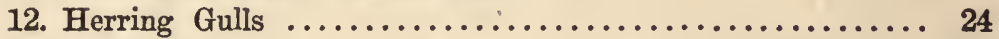

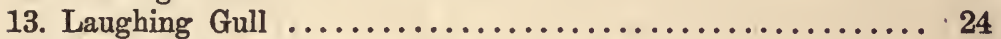

14. Eggs of Least Tern and Nest .................. 25

15. Black Skimmers ........................... 25

16. Brooding Anhinga ...................... Frontispiece

17. Male and Female Anhinga .................... 30

18. Mexican Cormorant ....................... 30

19. Man-o-War Birds ........................... 31

20. Brown Pelican .............................. 31

21. Brown Pelicans Flying ...................... 38

22. Brown Pelican's Nest and Eggs .................. 38

23. White Ibis's Nest and Eggs .................... 39

24. White Ibis's Head and Bill .................... 39

25. Great Blue Heron ............................ 42

26. Great Blue Heron at Nest ................... 42

27. Great Blue Heron with Plume-Crested Head ........... 43

28. Snowy Heron, Mother Bird .................. 43

29. The Two Orphans .......................... 58

30. Young Snowy Herons ..................... 58

31. Snowy Herons in Missouri ................... 59

32. Limpkin $\ldots \ldots \ldots \ldots \ldots \ldots \ldots \ldots \ldots \ldots \ldots \ldots \ldots \ldots \ldots \ldots \ldots \ldots \ldots \ldots$

33. Little Blue Heron Nest and Eggs ................ 62

34. Louisiana Heron ........................... 62

35. Eggs of Bob-White ........................63

36. The Last Passenger Pigeon ...................... 63

37. Mourning Doves .......................... 70

38. Black Vulture's Nest and Egg .................. 70

39. Harris Hawk ........................... 71

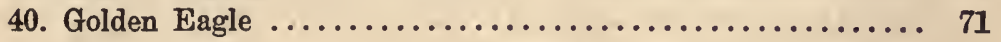




\section{ILLUSTRATIONS-(Continuod)}

Fia.

PAG:

41. Bald Eagle's Nest .......................... 74

42. Audubon's Caracara ......................... 74

43. Sparrow Hawk Egg.$\ldots \ldots \ldots \ldots \ldots \ldots \ldots \ldots \ldots \ldots \ldots \ldots \ldots$

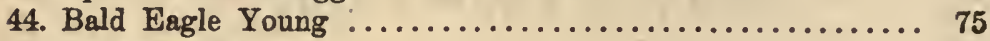

45. Osprey's Nest .......................... 90

46. Screech Owl .............................. 90

47. Long-Eared Owl's Young ...................... 91

48. Long-Eared Owl's Nest and Eggs .................. 91

49. Yellow-billed Cuckoo ......................... 94

50. Yellow-billed Cuckoo Young at 9 A. M. ............. 94

51. Yellow-billed Cuckoo Young at 3 P. M. .............. 95

52. Yellow-billed Cuckoo Young at 4 P. M. ............. 95

53. Belted Kingfisher's Nest and Eggs ............... 102

54. Belted Kingfisher Young ...................... 102

- 55. Belted Kingfisher Makes His Picture ................. 103

56. Downy Woodpecker ......................... 103

57. Pileated Woodpecker Chippings ................ 106

58. Pileated Woodpecker at Nest .................. 106

59. Pileated Woodpecker at Nest $\ldots \ldots \ldots \ldots \ldots \ldots \ldots \ldots \ldots \ldots . \ldots \ldots$

60. Pileated Woodpecker Young ..................... 107

61. Red-headed Woodpecker Young ................... 122

62. Red-headed Woodpecker at Nest ................. 122

63. Red-bellied Woodpecker ....................... 123

64. Flicker ................................ 123

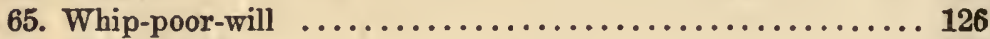

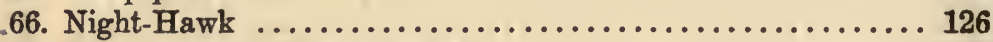

67. Ruby-throated Hummingbird .................. 127

68. Ruby-throated Hummingbird .................. 127

69. Kingbird .................................. 134

70. Kingbird Young ..................................

71. Great Crested Flycatcher ..................... 135

72. Prairie Horned Lark Incubating ................ 135

73. Phobe Young $\ldots \ldots \ldots \ldots \ldots \ldots \ldots \ldots \ldots \ldots \ldots \ldots \ldots \ldots \ldots \ldots \ldots \ldots$

74. Prairie Horned Lark's Nest and Eggs ............. 138

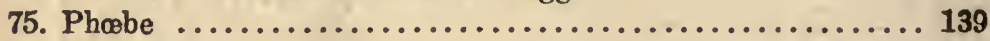

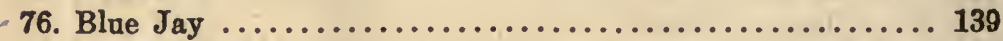

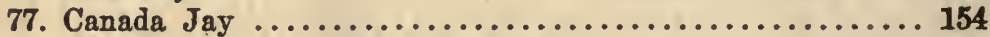

78. American Crow's Nest and Young ............... 154

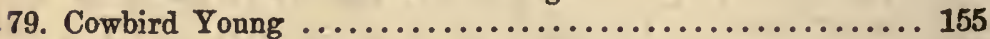

80. Red-winged Blackbird's Nest and Young ............ 155

81. Red-winged Blackbird Brooding ................. 158

82. Red-winged Blackbird Young .................... 158

83. Meadowlark's Nest and Eggs $\ldots \ldots \ldots \ldots \ldots \ldots \ldots \ldots \ldots \ldots \ldots \ldots$

84. Meadowlark Incubating ..................... 159

85. Baltimore Oriole's Nest ......................... 186

86. Baltimore Oriole Young ..................... 166 


\section{ILLUSTRATIONS-(Continued)}

FIG.

87. Bronze Grackle Young ...................... 167

88. Boat-tailed Grackle's Nest and Eggs ............... 167

89. Great Boat-tailed Grackle's Nest and Egg ............. 170

90. Great Boat-tailed Grackle Incubating ................ 170

91. American Goldfinch ....................... 171

92. Savanna Sparrow .......................... 171

93. Lark Sparrow's Nest and Eggs ................. 186

94. Lark Sparrow Incubating .................... 186

95. Harris's Sparrow ........................... 187

96. Harris's Sparrows at Feeding Station .............. 187

97. Tree Sparrow ............................. 190

98. White-Throated Sparrow ..................... 190

99. Chipping Sparrow ....................... 191

100. Slate-Colored Junco ............................ 191

101. Field Sparrow ............................. 198

102. Song Sparrow ................................. 198

103. Fox Sparrow ................................... 199

104. Towhee .................................. 199

105. Cardinal's Nest and Eggs ...................... 204

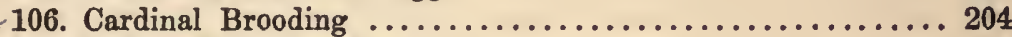

107. Rose-breasted Grosbeak ........................ 205

108. Indigo Bunting's Nest and Eggs .................. 205

109. Indigo Bunting Young. Note Cowbird Egg ............ 206

110. White-Rumped Shrike's Nest and Eggs ............... 206

111. Bank Swallow Nest Sites ..................... 207

112. Dickcissel's Nest ........................... 207

113. Young Shrike ............................ 208

114. Shrike at Nest ............................. 208

115. Shrike-Impaled Bluebird ...................... 209

116. Red-eyed Vireo's Nest. Note Cowbird Egg .............. 209

117. Red-eyed Vireo Incubating ................... 210

118. Young Cowbird in Vireo's Nest . . . . . . . . . . . . 210

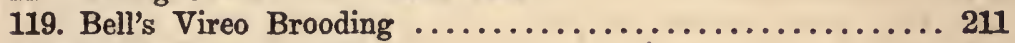

120. Bell's Vireo Brooding ....................... 211

121. Prothonotary Warbler Nesting Sites . . . . . . . . . . . . . 212

122. Yellow Warbler's Nest with Walled-off Cowbird Egg . . . . 212

123. Yellow Warbler's Nest and Young ................ 213

124. Myrtle Warbler .......................... 213

125. Maryland Yellow-throat's Nest and Eggs ............. 214

126. Mockingbird Young ......................... 214

127. Mockingbird at Nest ............................ 215

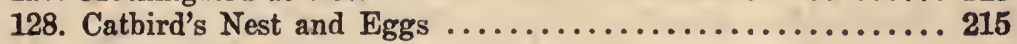

129. Brown Thrasher ............................ 216

130. Brown Thrasher Young ....................... 216

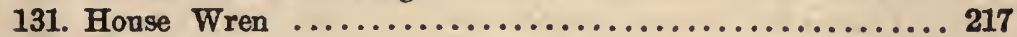

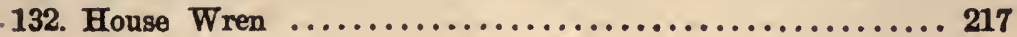




\section{ILLOSTRATIONS-(Continued)}

FIG.

133. Brown Creeper .......................... 220

134. Tufted Titmouse ........................... 220

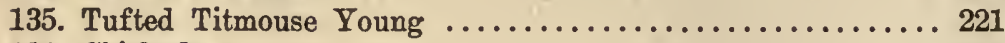

136. Chickadee .................................. 221

137. Blue-Gray Gnateateher ....................... 224

- 138. Wood Thrush at Nest ........................ 224

139. Blue-Gray Gnateatcher's Nest. Note Cowbird Egg ....... 225

-140. Robin at Nest, Male ......................... 225

141. Robin at Nest, Female ........................ 230

142. Water Ouzel's Nest $\ldots \ldots \ldots \ldots \ldots \ldots \ldots \ldots \ldots \ldots \ldots . \ldots \ldots$

143. Varied Thrush .............................. 231

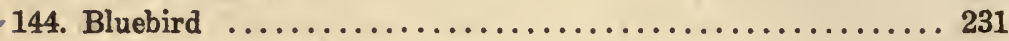




\section{PREFACE}

The author makes no claim that this book is a complete treatise on all the birds of a given locality. Only those with which he has come in photographic contact in their natural feeding and breeding haunts are considered.

Personal observations and conclusions of the author, while making these pictures, are the basis of the subject matter. Many of the photographs have been taken under trying circumstances, almost insurmountable difficulties and discouraging outlooks. This has been the experience of all bird photographers. Those who have preceded me in this work have covered the field thoroughly and have left very little new to discuss.

The work of the many world-renowned ornithologists, Audubon, Coues, Wilson, Chapman, Reed, Job and others, has blazed the way and made the labors of those who follow less arduous; but no thoroughfare was ever traveled without presenting some new phase worth recording by the late arrival.

The author hopes that the lay reader will find much of interest in this book of birds, as it deals largely with that phase of bird life observed about their homes. The writer trusts that the technical ornithologist, he who by his untiring efforts has elevated this subject to its present high standard, will find in some of the author's personal observations here recorded, points of value.

The author has faithfully endeavored briefly to record the behavior and personalities of the birds with which he has come in contact. The scientific nomenclature has been gleaned by reading and copying from the books of recognized authorities at command.

For various courtesies and valuable assistance the writer is under many obligations to: T. Gilbert Pearson, President, National Association of Audubon Soeities; E. W. Nelson, Chief of Bureau of Biological 


\section{PREFACE}

Survey ; Frank Hodges, Purd B. Wright, Librarian, Kansas City Public Library; Caryl De Voe; to Professor A. A. Allen, Cornell University, for the illustration numbered 133; and to Professor A. E. Shirling for illustrations $63,64,96$ and 107. 


\section{INTRODUCTION}

Some persons go through life surrounded by nature's rarest gems without taking any interest or observing them. A tree is a tree, a bird a "sparrer," a rock is a rock!

One of my acquaintances was curious to know what I got out of my bird experiences that he had not also received. As an illustration, I said to him:

"You do not know that a Blue Jay belongs to the Crow family."

He replied: "No, I don't, and I don't give a damn."

There is quite a gap between this friend and another, who is a scientific ornithologist and who told me when I appealed to him to classify a Savanna Sparrow, as to whether it was just a common Savanna or the Western subspecies, that it would be utterly impossible, unless he had before him for examination a hundred specimens collected from a given locality.

Poor Western Savanna! It were better to remain in unclassified obscurity than to become exterminated by "scientific classification" methods.

Reed, one of our very best and most learned ornithologists, says: "To identify the various subspecies of the Red-winged Blackbird would require micrometer calipers and the services of the man who separated them."

"Many subspecies are recognized only by the expert with the specimens in hand and under favorable light conditions," says another.

Between my Blue Jay friend and these scientists there is a vast chasm, and somewhere within that gap I am content to remain. The technical field has been thoroughly covered. What the general bird-lover enjoys most is a true picture of birds, and an account of their daily doings afield and at home.

It is not necessary to know that water is composed of two parts of hydrogen and one of oxygen, in order to enjoy to the fullest the grandeur of a Niagara or of a Yellowstone waterfall; neither is it essential for one exploring an untraveled mountain range to be a learned 


\section{INTRODUCTION}

geologist, in order to glorify and become enthusiastic on the beauties and magnitude of a towering obsidian or basaltic uplift. Most of our real pleasures come through the special senses of sight and hearing, and not through a knowledge of their source based on prior conception.

While the minute anatomy of birds, in relation to osteology, muscular distribution and function, is of much scientific interest and practical value to the serious bird student, it is not at all necessary to one who enjoys observing the home life of birds, and coming into actual contact with them in their freedom. The dissecting knife and the laboratory are of inestimable value to science, and may be compared to the pick and chemistry in the study of the geology of a vast mountain range; yet, without all this knowledge, the surface beauties of high altitudes, rugged precipices and unharnessed waterfalls may be photographed, and their beauties accurately portrayed, so that those who cannot visit the scenes may witness them in fancy.

I do not wish to be understood as placing a stamp of depreciation upon the serious and scientific study of ornithology, botany or geology; it is a noble work and is the prime essential along all lines of investigation. Those who engage in it are the trail-blazers and pioneers. Few persons have the time or inclination to pursue so diffcult a task. Too much praise and credit cannot be given such workers as Chapman, Reed, Forbush, Job, Findley, T. Gilbert Pearson and many others.

One cannot come in intimate contact with birds, and study them, without becoming broader in his knowledge of trees, vines, flowers, soil, insects and many other allied subjects. To the busy man, a trip into the field, bird-hunting with pen and camera, will give a vacation; to the man who has nothing to do, it will give pleasant occupation.

Rather than go afield with a gun, collecting hundreds of specimens, I am content to view the fruits of the labor of the scientists who delve into osteology and minute measurements of the toes and other anatomical features of birds. As a rule the general reader is not so much interested in the number of bones in the head as in the color and general exterior appearance of a bird, 


\section{INTRODUCTION}

its habits at home and afield, and the range and beauty of its song.

Osteology, like geology, is permanent. Bird habits and bird behavior present great flexibility in mannerism, and a careful observer may see new stories in any day's visit with his feathered friends. Those true to types set by learned ornithologists, only prove that there are exceptions: hence, credence should be given to investigators who find and recognize those exceptions.

Many birds, by force of circumstances, change their habits and extend or vary their diet, as may be seen when the Osprey's nest, or that of the Great Blue Heron, is found upon the ground; or when the Cardinal, looked upon as a seed and grain eating bird, does not taboo a nice fat angleworm; and since the automobile has supplanted the horse in our cities, the English Sparrow has changed its dietetic requirements and busies itself collecting foliage-destroying pests, or, perchance, stealing the angleworms from the bill of the industrious Robin. 



\section{BIRDS}

THEIR PHOTOGRAPHS AND HOME LIFE 



\section{Bird Personalities and Habits}

Practically every human emotion is manifested in the life histories of birds. Pride, generosity, jealousy, anger, fear, love, shyness, caution, shrewdness and suspicion are only a few of the traits and actions observed in our feathered friends. I see no object in calling these sentiments human, since they are all expressed in the most forceful manner. Why not call them bird traits? They are also found in man, it is true, but are not birds entitled to their own personalities?

Because a bird will fight in defense of its young, or act as though crippled in order to entice you, as you chase it, from the vicinity of its nest, or because it will feign death on your approach, is no reason why these acts should be called human traits. In the interpretation of them we may use our thoughts and human words, and apply them with justice to bird thoughts and bird actions.

Many writers do not give birds sufficient credit for possessing an intelligence of their own, peculiar to the species, or acquired by adaptability to new or varied surroundings. Birds accomplish many things easily where we would make dismal failures.

Personal contact with wild birds ofttimes gives varying experiences, probably as a result of difference of environment, failure of the powers of observation, or inability to record the results correctly at the time the observations are made. The habits of a bird in a cage and the behavior of a bird in its wild, unhampered state may differ materially and with a casual observer may lead to wrong deductions. Some birds may, by force of surroundings, merge their natural traits into those of others, nest-building in unusual places and adopting a diet foreign to their usual one; yet these birds do not, in the main, lose their personality, for once their natural surroundings have been re-established, their broods 
quickly pursue the line peculiar to the species. Whether one calls this new adaptability to unusual conditions, or a resumption of the old, or instinct or reason, is of little consequence to the general bird-lover.

The individual who does not care to enter into the minute scientific details of ornithology may find in the study of the personal or individual peculiarities of birds in their home lives much of interest. For instance, the male Rose-breasted Grosbeak is the ideal bird husband and his mate, I take for granted, is the original suffragette. Think of a husband who patiently remains at home attending to all the household duties while his wife is away at the club or voting-place! Just think of it! $\mathrm{He}$ is so happy while attending to these same home duties that he actually sings, as he incubates, morning, noon and night. Is not that a lovely bird personality? It is, with a vim!

Of all birds who possess a despicable personality the Cowbird is the limit: it does not mate, is polygamous in its breeding habits, builds no nest of its own, lays its egg in some small bird's nest and abandons the egg and the hatched young to the tender mercies of fosterparents. Whether the small bird whose nest is despoiled by this slacker, is unsuspecting or is filled with a parental love so strong that it fails to detect the fraud, I do not know. At all events, the intruder in the family circle of the small bird receives the same parental care as her own brood. 


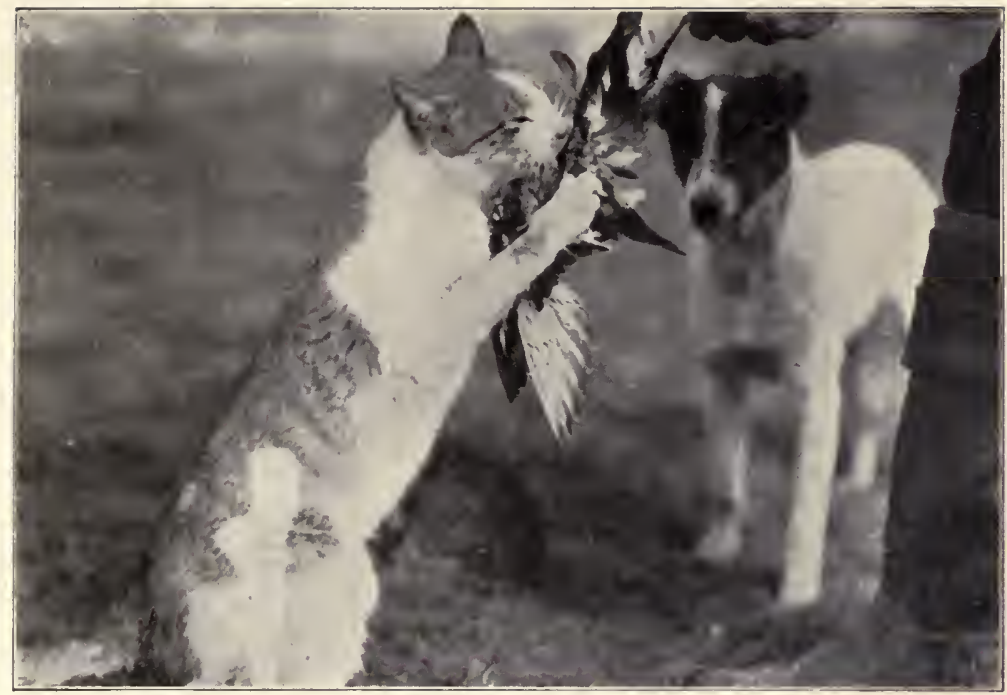

Fig. 1. TEACHING THE CAT A WRONG LESSON

(page 28)

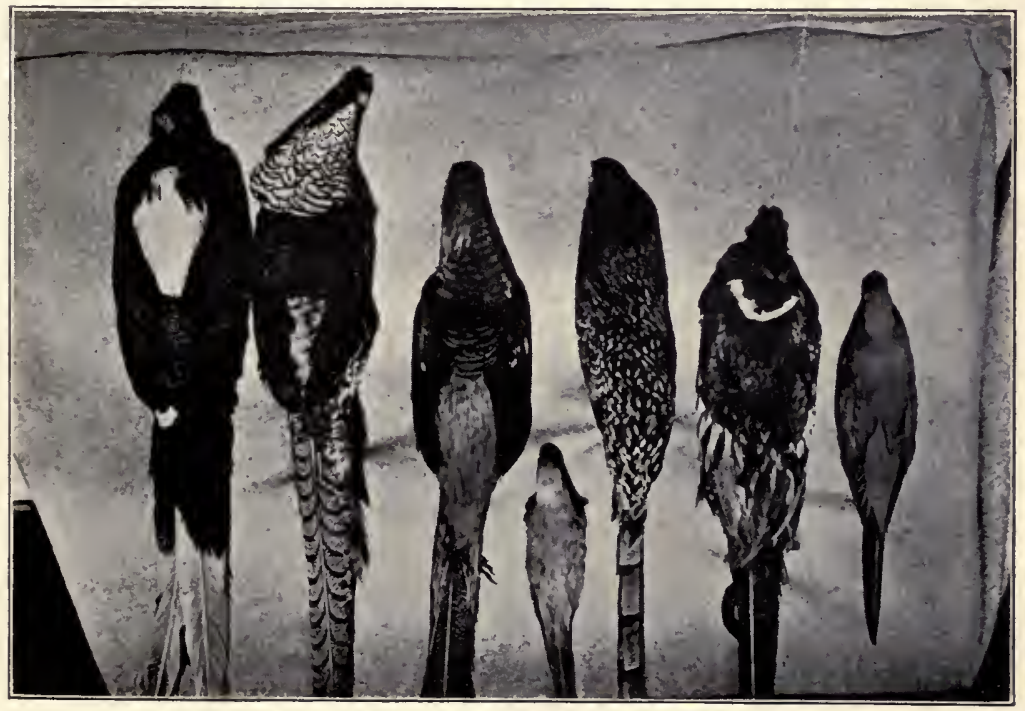

Fig. 2. ARSENATED SKINS 


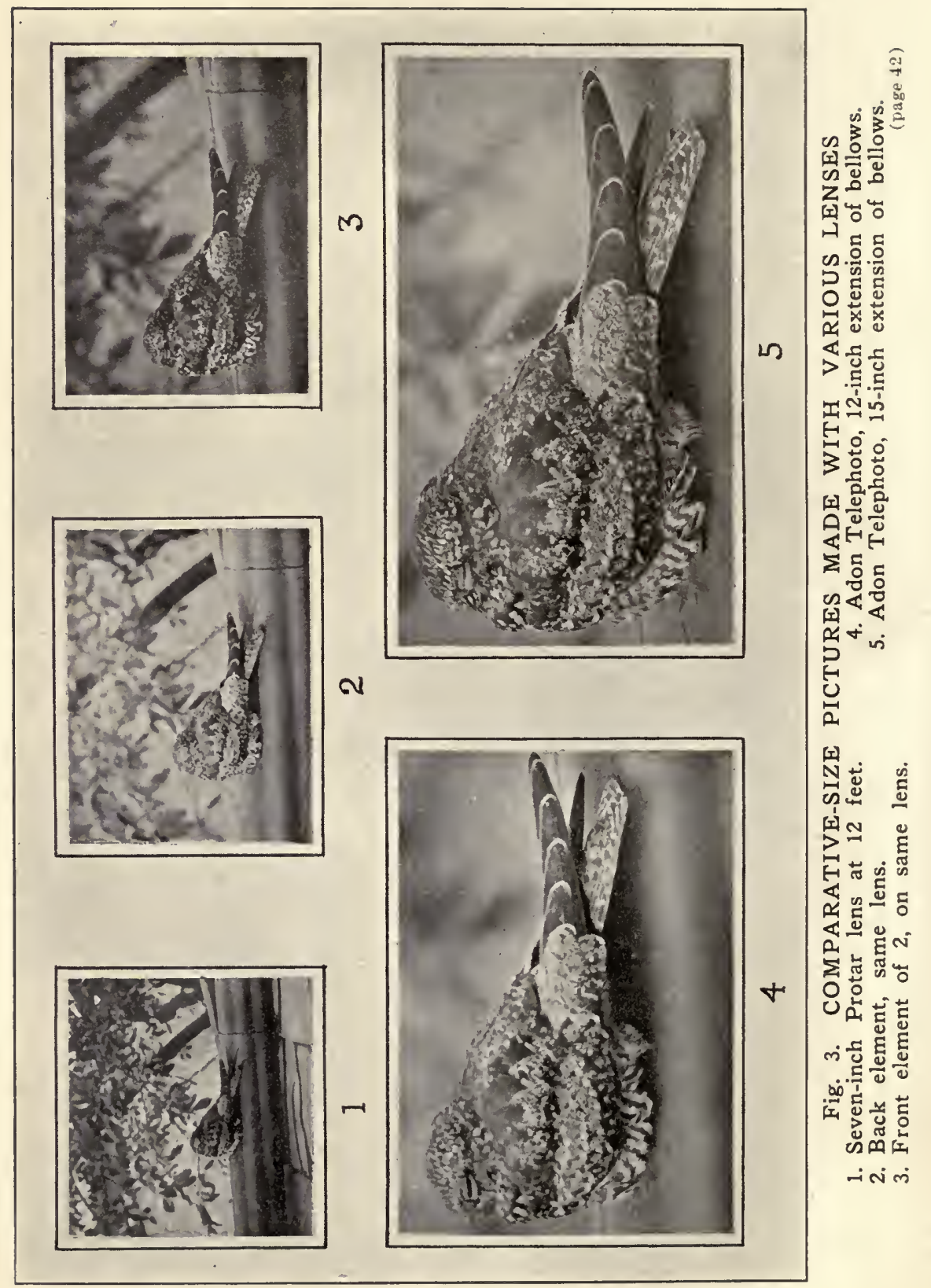




\section{Bird Migration}

In any given locality, so regular is the date of the return of the migratory birds in their flight from nesting site or winter resort that the exact time may be predicted as accurately as an eclipse of the moon or sun.

Migration is a kind of marathon in which all the birds of a species are entered. This race is run twice each year and is attended by many difficulties, almost insurmountable, that only the healthy and strong can conquer. By day and by night the procession wings its semi-annual flight along unmarked aerial trails, just a few miles, or hours, in the advance southward before the chilly blast of approaching winter, pausing here and there just long enough to rest a tired wing, or gather a few seeds or other provender. Storms and man with his automatic shotgun make great inroads on these travelers.

During the glacial period, when the central part of the United States was under an ice-cap, the birds existing at that time had, in all probability, as their northern limit of migration, the southern extremity of the glacial area, in about the same latitude as Kansas City, Missouri, and Cincinnati, Ohio. This gap between the southern and northern migratory points has, by the retreat of the ice sheet, been extended to the Arctic Ocean and to the islands farther north.

I have often wished I could join the bird frontiersmen as they go to their unsettled territory in the Far North. What could be more enjoyable than to follow a trail not even blazed by human hand! Yet for ages these winged travelers have followed an imaginary thoroughfare without leaving a footprint or a sign-board, guided only by that something in their make-up which is more accurate than the stars or the mariners' compass. Day and night the right of way is cleared from Brazil to Point Barrow. 
It has been said that river courses and mountain ranges act as sign-posts for birds in migration. This may be true of some water birds, but many other species disregard all surface markings and fly across rivers, lakes and mountain ranges. The Arctic Tern is the champion of all long-distance migratorial birds, as it nests within a few degrees of the North Pole and, on its southern journey each season, travels eleven thousand miles to the border of the Antarctic Circle, making this round trip of twenty-two thousand miles in twenty weeks. The Golden Plover, nesting north of the Arctic Circle, on its southern journey flies across the Atlantic Ocean from Nova Scotia to South America, a distance of two thousand five hundred miles, without a pause to feed or to rest its tired wings.

The most pessimistic individual becomes an optimist when he looks from his window on a cold, bleak March day and beholds on his front lawn the first spring messengers of the season. A Robin or a Bluebird in March suggests glorious sunshine, warm balmy air, blooming tulips and grassy lawns.

During the late fall and winter the Kingbird and flycatchers, feeders on the moth and other flying insects, must go far south, where delicate winged insects are not killed by the cold.

Seed and grain eating birds may and do remain many degrees farther north, and many do not migrate at all; for instance, the Quail, Wild Turkey and Downy Woodpecker.

Birds of prey, or those depending on capturing living things, as mice and other birds, are governed wholly by their food supply. With their ability to cover a large scope of territory while hunting, they manage to pick up a meagre food supply the year round in almost any locality.

The southern migration cannot be for food-seeking reasons alone. You have only to watch the congregating of the Redwinged Blackbirds or of the Grackles in October to appreciate the unity of purpose existing in all migrants of any species as the time approaches for their journey to the South. 

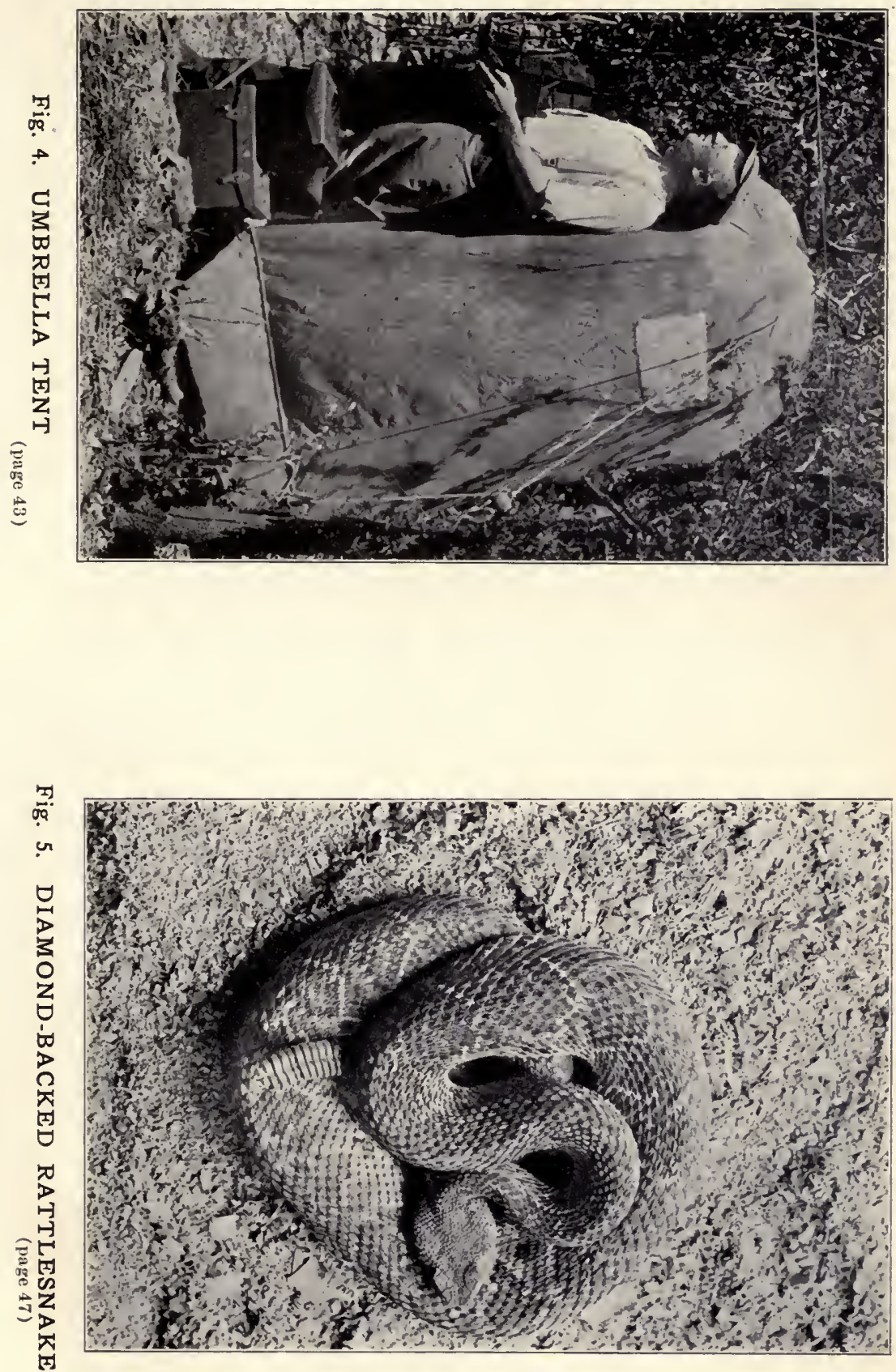


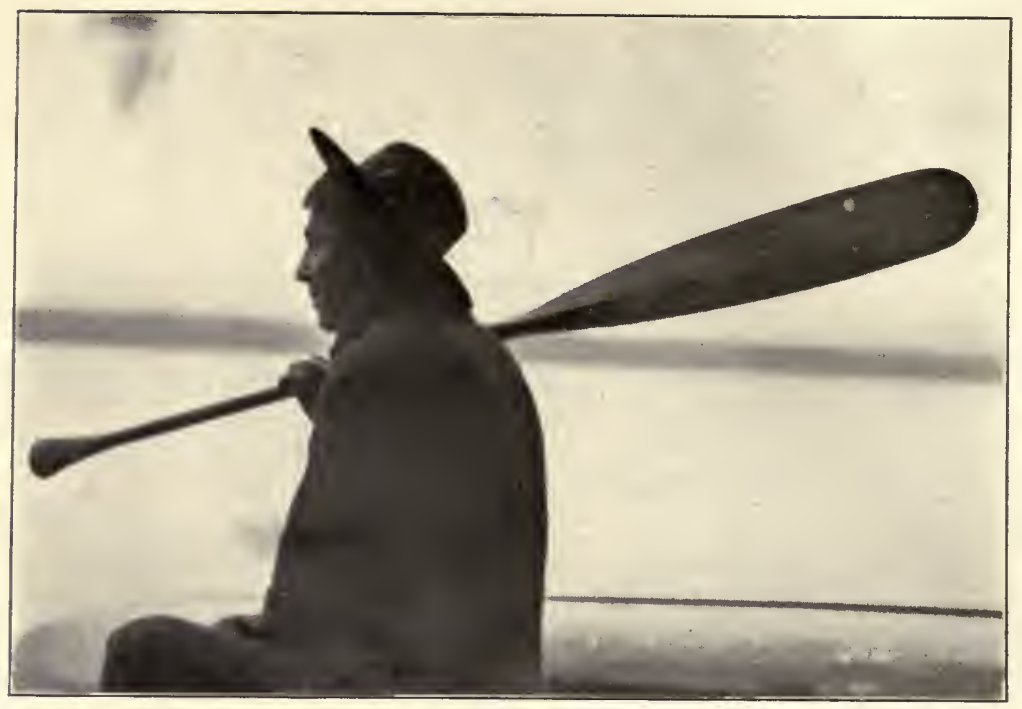

Fig. 6. HUDSON BAY INDIAN GUIDE

(page 38 )

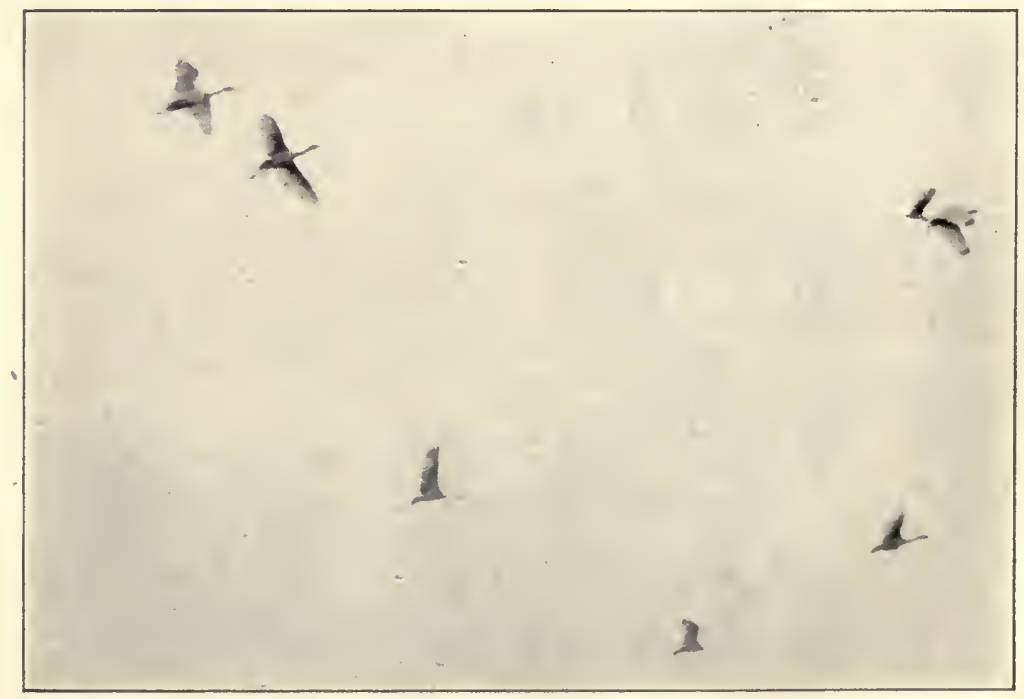

Fig. 7. ANIMATED LINES 
Just imagine the vastness of the unknown and unexplored territory north of the Great Lakes and south of the Arctic Ocean, and the number and kinds of our feathered friends that annually rear their young there; then it is possible to appreciate the unlimited number of migrants. Of all that countless throng only a scattering few sojourn in the Arctic regions during the prolonged boreal night. Millions upon millions annually make the southern journey.

The northward trip is marked by depletion in ranks and is a journey made in response to the breeding instinct. The survival of the fittest is the rule in this northward rushing horde.

During the seasonal migration many surprises and pleasurable moments await those who go into the fields and woods for a day's outing. A traveler from the Mackenzie River delta may sing you a polar ditty, or a visitor may bring you a song from a South American winter resort. Or a tourist from the shores of Hudson's Bay may pause near you to gather a few seeds from a weed stalk or a cedar tree in your front yard. During the night these travelers of the dark may be faintly heard as they pursue their journey along the unblazoned aerial highways. With a unified purpose they pursue their course year after year. Their hazardous trips should be made without additional risk through man's predatory inclinations. 
Identification, Nest-Building, General Findd

When one goes afield he should carry with him pencil and paper for recording his observations on the spot. Memory is fickle and what one sees today may be soon forgotten. When you go bird-hunting armed with only a pencil and paper, a camera and some one of the standard books on bird identification you are sure not to be met by the landowner and ordered from his premises. Therefore, take your time.

For comparison in size I know of no better way than to think of the familiar Robin as being ten and the Crow, twenty inches long. For color estimates the task is more difficult, as the plumage of a given bird as in the young or the sexual difference often varies greatly. Make note of the following:

1. Where nest is located.

2. Of what nest is made.

3 . Whether old or new nest is made.

4. Time of year.

5. Whether both birds assist in building.

6. Number of eggs, size and color.

7. Incubation periods.

8. If both birds incubate.

9. If both birds feed the young.

10. How long the young remain in nest.

11. How fed at nest and after leaving it.

12. Plumage of young as compared to that of old birds.

13. How nest is cleaned.

14. If young returned to nest after leaving it.

16. When they arrive and depart, if migratory.

17. If residents, where they reside and feed.

18. If both birds fight in defending the young.

19. Color of young as compared to that of old birds.

20. What young birds are fed and how often. 


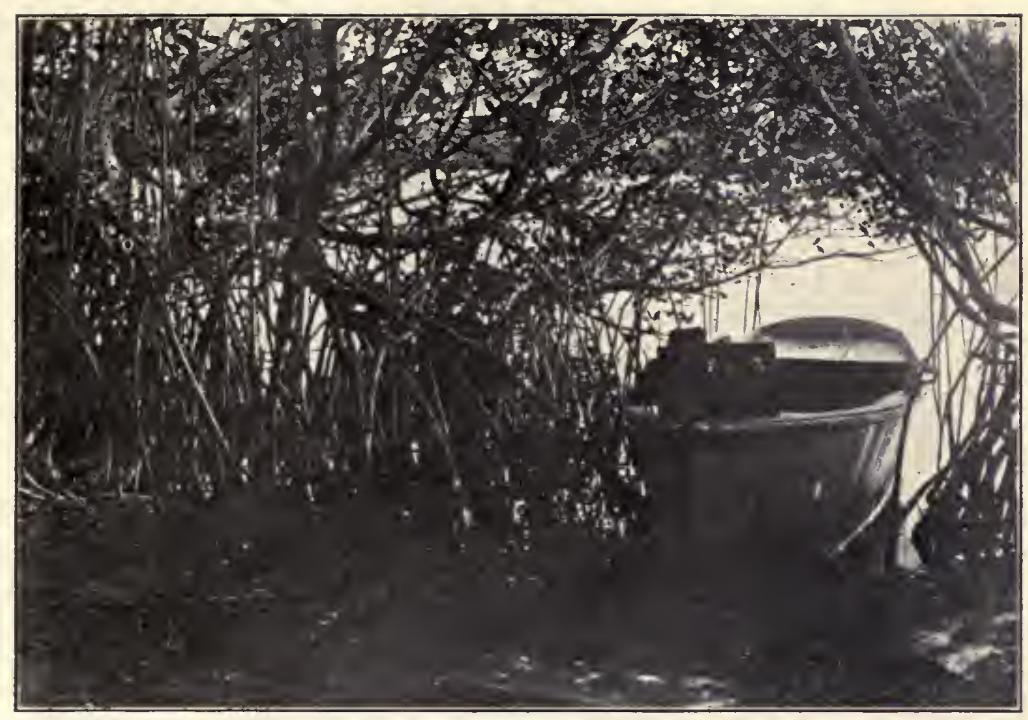

Fig. 8. IMPENETRABLE MANGROVE ROOTS

(page 50)

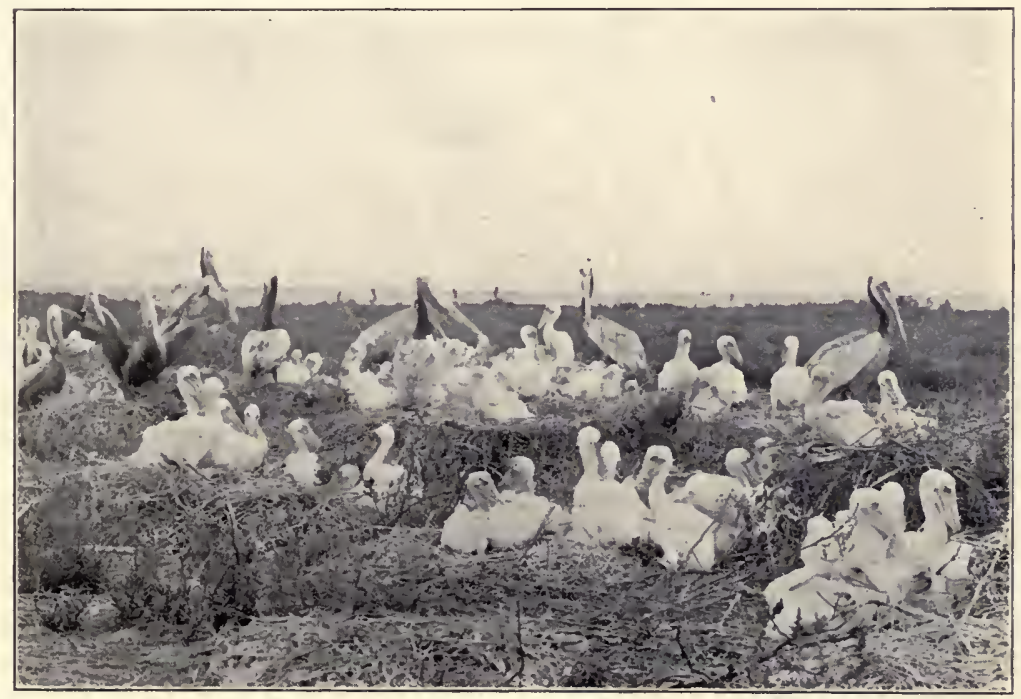

Fig. 9. BROWN PELICAN BREEDING COLONY

(page 53) 


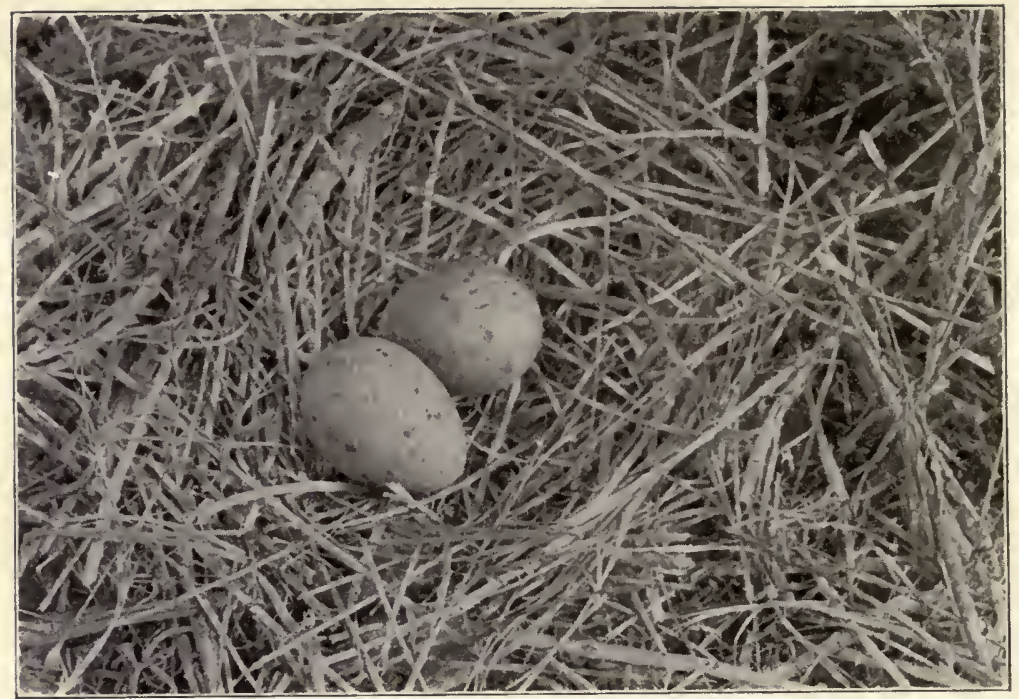

Fig. 10. NEST AND EGGS OF REDDISH EGRET

(page 54)

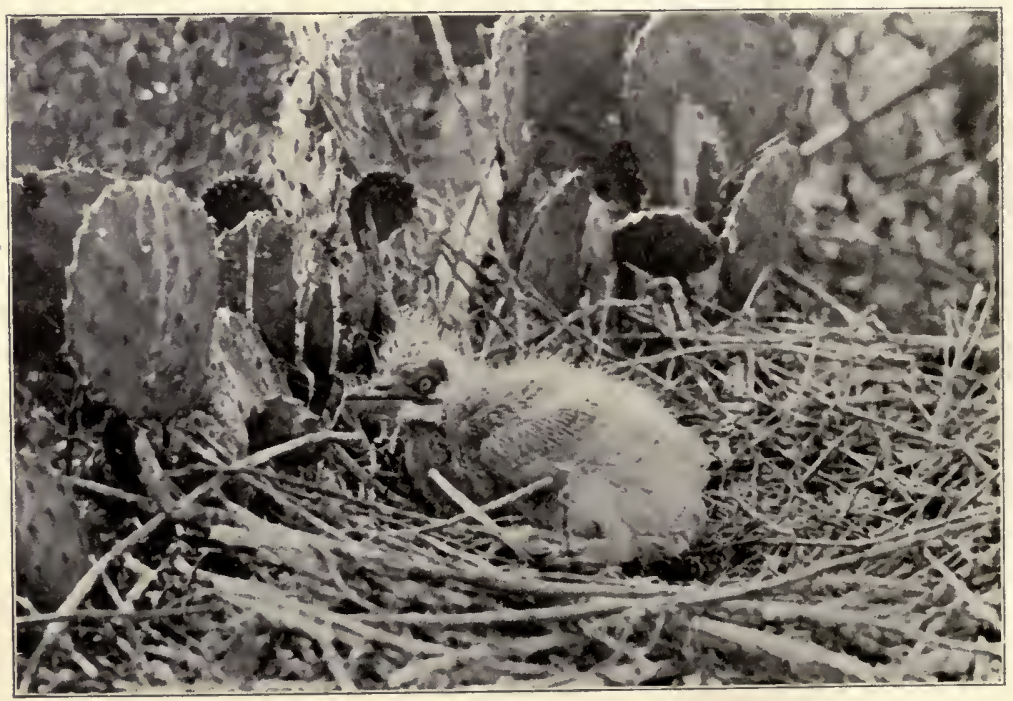

Fig. 11. GREAT BLUE HERON, GROUND NEST

(page 55) 
To this list should be added the list of the general nest-building materials, as:

1. Lint-like strippings from plants.

2. Twigs of vines.

3. Fragmentary substances of plants.

4. Old leaves.

5. Snake skins.

6. Feathers.

7. Hair.

8. Spider-webs.

9. Lichens.

10. Rabbit fur.

11. Cotton-like plant substances.

12. Strings.

13. Paper.

14. Roots.

15. Mud.

16. Mosses.

17. Pine needles.

18. Bare ground.

19. Shell heaps.

20. Down from parents' breasts.

The preceding tables will be of much assistance in the identification of the owners of any nest found when the builders are not at home; and the comparison of the familiar Robin and Crow will be an aid in identifying birds by size comparison, when referring to the field guide-book.

Birds are more easily approached during the nesting, incubating and brooding periods, not that they appreciate our presence close to their homes at these times, but because they loose their usual caution and timidity and are drawn closer to their eggs and young by their own home ties and parental feelings.

Some birds seem to seek nesting sites near to man's habitation, not because they recognize man and desire his companionship but because they seek favorable conditions that man has brought about; orchards and open spaces for Bluebirds and Flickers, hanging and uncrowded elm branches for Orioles, bunches of lilacs for Brown Thrashers and climbing vines for Chipping Sparrows. 
Like that of human home-builders bird architecture presents many phases, from the Kingfisher's "dug-out," the Yellow-billed Cuckoo's mere platform, the Oriole's beautifully woven basket and the Osprey's skyscraper, to the Condor's cliff dwelling. In size and material used the scale is equally diversified, as may be seen in the nest of the Ruby-throated Humming-bird, with its plantsilk and spider-web lining, that of the Night-hawk, with only a bare rock or the ground, or the nest of the Bald Eagle, with its pile of driftwood six or seven feet in diameter, the home of a permanently mated pair for many years.

Much confusion in the identification of birds is brought about by dissimilarity in the size of the bird and the character of the plumage in the male and the female of a given species, as well as the juvenile plumage of those birds that are slow in taking on the permanent garb. Should one point out a female Red-wing Blackbird to a beginner in bird study, and at the same time show him the male, it would be hard for him to accept the statement that they are male and female of the same species. Who would believe, without being told, that the long-legged bird wading in the slough near the roadside is only a Little Blue Heron in its white juvenile plumage, or that the dark grey bird, larger than its feeding parents, is none other than a young bird of the beautiful Indigo Bunting?

Of much assistance in identification is the presence of the parent birds in their fixed plumage, in company with the young. Seasonal and mating plumage, or even that of the moulting period, may be very confusing.

The identification of a bird is usually possible by the aid of its song, its location, its methods of flight, its associates and its recognized personality, even under adverse conditions. The breeding plumage of the Skylark and the juvenile markings of the Robin and other birds are typical illustrations of the difficulties often encountered in bird identification with the appearance of the plumage as guide. Unfortunately, the beautiful plumes of many of our birds are at their height of perfection only during the love-making, nesting and brood- 


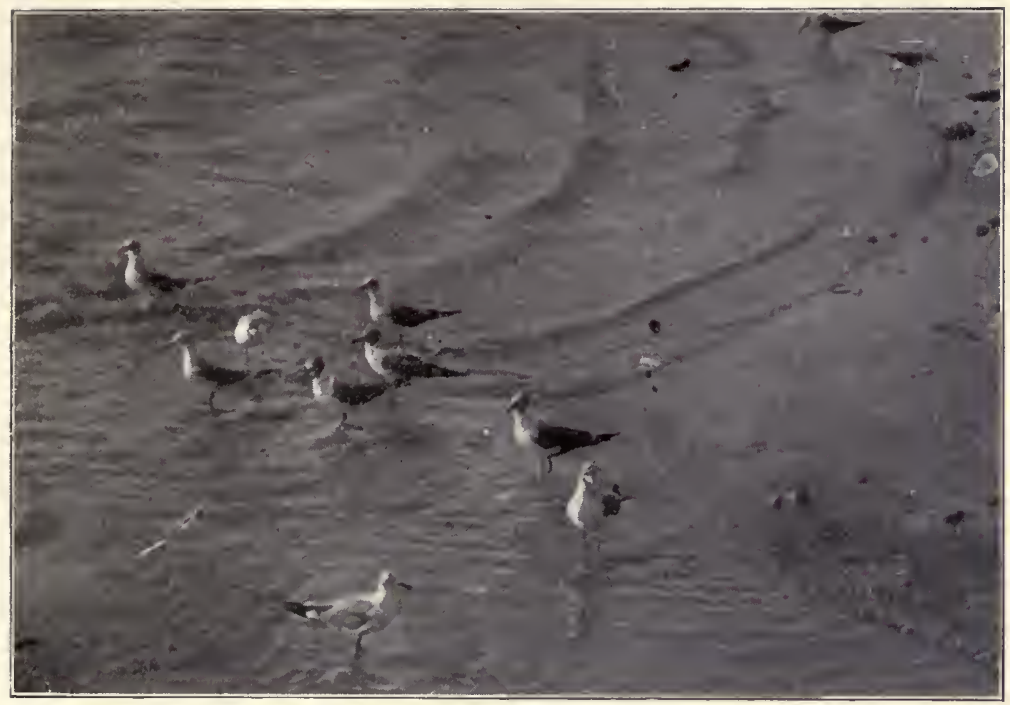

Fig. 12. HERRING GULLS

(page 57)

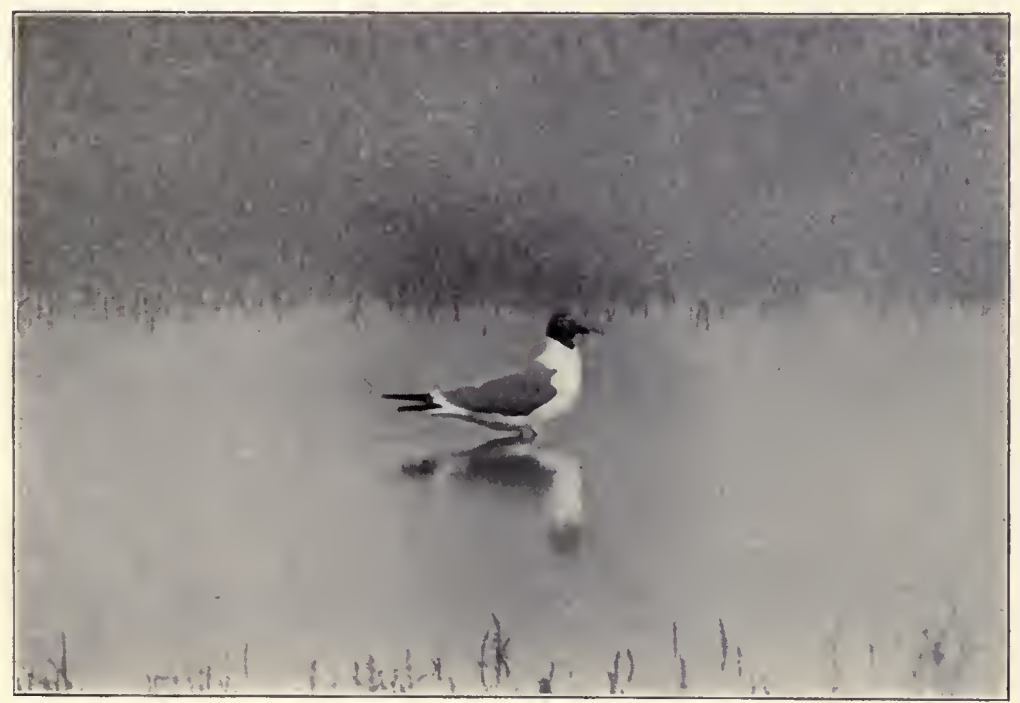

Fig. 13. LAUGHING GULL 


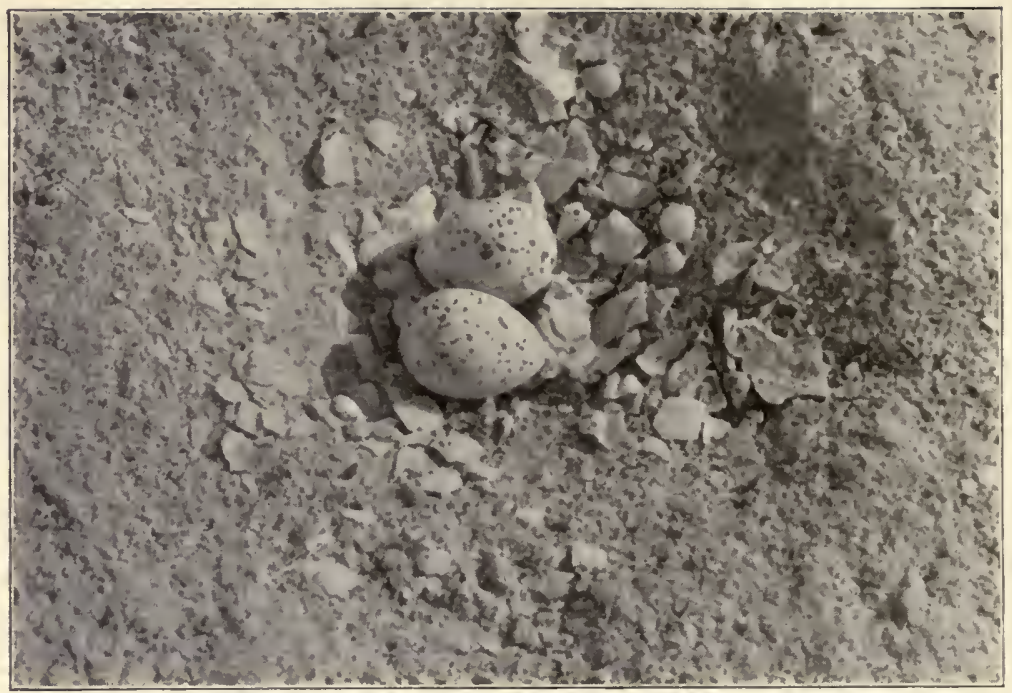

Fig. 14. EGGS OF LEAST TERN

(page 61)

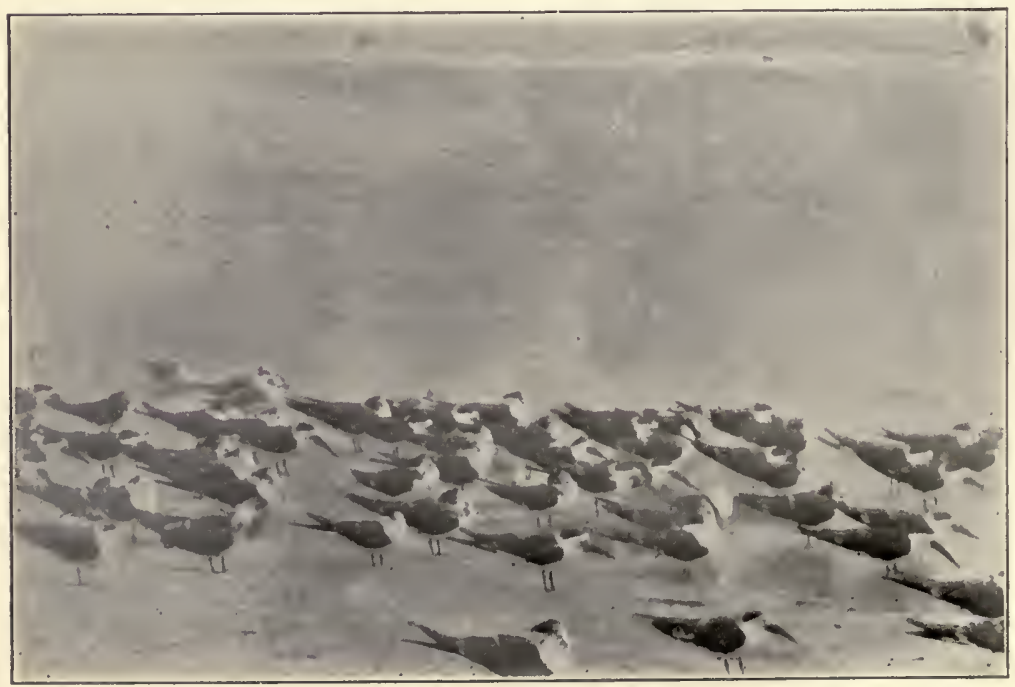

Fig. 15. BLACK SKIMMER

(page 63) 
ing periods, at which times they are easily approached and killed by "plumers."

The parental love and affection in most birds is not surpassed by that of any other warm-blooded animal. I know of no mother more affectionate or solicitous of her young than a bird mother. Observe the patient resignation of the incubating Robin as it sits day after day in the scorching sun; or of the Kingfisher in its dark and ill-ventilated recesses. Notice the reckless disregard for its personal safety of the Shrike in its valiant attack on the disturber of its home and young; or the sad and pathetic appeal of the Mockingbird as you survey its nest and babies. Hardened indeed must be the heart of the individual who would hear these appeals and not be touched by a bond of sympathy.

If you have never stood near a nest of young birds and timed the parents in their feeding trips, you can form no conception of the devotion of the old birds nor of the amount of food a brood of young requires for healthy existence and rapid growth. For the first few days a well-fed, healthy, young Kingbird or Sparrow will increase from fifty to sixty per cent in weight, while the feathers, as in the case of the Cuckoo and Kingfisher, seem actually to burst into existence.

As with all accurate observations on any subject, it is an exacting and interesting work to keep tab on the doings in a bird dining-room and nursery. The semidowny stage of these animated little bodies is to me the most beautiful period in the life of many birds; there is a delicacy in the neutral tints of grays and browns never found in the plumage of mature birds. The peculiarly delicate silvery sheen on the back, the modest gray of the breast, the innocence and confiding appearance of the little fellows, as they sit as still as miniature statues, must elicit the admiration and sympathy of all birdlovers.

The poor attempts at flight of the young birds seem to put disgust and consternation into their parents as they follow the little ones from limb to limb, either scolding or praising the feeble efforts.

Should you return to a nest and find that the young birds have left it, wait patiently near by and you will 
surely see the old birds endeavoring to attract your attention away from the location of the young. You will hear the protest and see the excitement of the parents when you come near the hiding young birds. Then, if you remain quiet, you will hear the youngsters calling their faint, "peep, peep!" and, if you hunt carefully, you may find the little fellows sitting on a limb near the body of the tree, close to the ground, or peering at you from behind a leaf or tuft of grass.

The language of birds is expressed in a few words, easily understood by their kind. Some of the sounds uttered are like the Indian sign language, understood by all birds of any species within hearing.

The alarm note of the Robin, or the screaming of the female Red-winged Blackbird as you disturb her brood, instantly arouses every feathered denizen of that vicinity to battle for a common cause, the protection of the helpless young. The limited vocabulary of the Water Turkey is in striking contrast wtih that of the Mockingbird or the Brown Thrasher, yet the former succeeds in making itself understood by its kind, as I have frequently witnessed while working in the bird rookeries of the Everglades of Florida.

Did you ever hunt Wild Geese? After manoeuvering for a place of vantage on a flock of feeding geese, and after crawling on your stomach for a half-mile, all the while barely keeping your eyes above the grass, you hear a signal from the old sentinel gander and see the whole flock take wing in an opposite direction from your hidingplace; then you understand the goose language, and conclude that a goose is not such a goose, after all.

The alarm-call of the barnyard hen, as she suddenly ceases her scratching for her brood, sends all the chickens, as a similar warning sends the wild birds, scurrying to a place of safety.

Many composers of the world's masterpieces of music have tried to reproduce the songs of our best bird musicians; their efforts have been notes of mockery reproduced on instruments foreign to the delicately attuned reeds or vocal cords of birds, and are as expressionless as the monotonous tones of a bagpipe. One who has heard the tones of the Wood-Thrush in the stillness 
of approaching twilight or early dawn must appreciate the futility of man's puny efforts at reproducing its notes.

The marvels of the protective coloring of the birds are a constant source of wonder to all bird-lovers. One would think that the Meadow-lark, with its beautiful goldenyellow breast, would be conspicuous; however, it is amply cared for by its ground-feeding and nesting habits. As it sits on the nest its gray and dark striped back blends with its surroundings so accurately that its body is hard to detect a few feet away. The same is true of practically all ground-nesting birds-_Sparrows, Quails, Grouse, and others of like habits. The Ptarmigan, with gray summer and pure white winter plumage, is an illustration of the seasonal protective plumage of birds.

The American Bittern, its neck and beak extended as it stands motionless in a bunch of dry or dead slough grass, is almost indistinguishable from its surroundings, even though you are only a few feet from the bird and saw it when you first approached its location.

The Black Skimmer and a few other birds are exceptions to the rule of plumage mimicry of natural surroundings.

The better acquainted we become with birds, their habits and home lives, the more we realize the benefit they are to civilization and the firmer our affections are cemented to them. The birds are ever reducing the number of harmful bugs, moths, worms, rodents and weed seeds, regardless of their location. Whether these pests are beneath the water; under the bark of trees, on the leaves or in the air, there exist birds whose feeding habits are such as to lead them to seek and destroy these pests.

We have been too slow to recognize bird benefactors, and in enacting laws for their protection. The great Audubon Society, and other organizations, are carrying on propaganda of inestimable value along this line.

Two of the birds' most civilized enemies are house cats and lovable, tender-hearted and sympathetic women. I am sure that if every woman who wears a stuffed bird, or the feathers of one, could have a true picture presented to her of the sacrifice of life made in order that her hat 
may be decorated, she would at once discontinue their use; then the shameful traffic in decorations that cost life would cease. She who demands such sacrifice of bird life places herself on an equal footing with house cats, snakes, red squirrels, skunks and other enemies of birds and their preservation. (Fig. 1.)

The evil spirit of egg-collecting has never taken possession of me. My dominating sentiment has been to let nature take its full course in the life history of birds. One of my long bird-picturing trips was ruined by my extending an invitation to a casual acquaintance to accompany me. My opportunities to pursue my harmless picture-taking of the birds was thwarted by this fellow's going ahead of me and, when we arrived at the rookery, disturbing the birds and robbing their nests of eggs. Whether the eggs were fresh or incubated it was all the same to him. I trust he found out the difference between a good and a bad egg, later. In disgust, I took my departure, a wiser, more experienced man.

An acquaintance of mine visited the celebrated Cuthbert Rookery in Southern Florida a few years ago. $\mathrm{He}$ told me he saw piles of the American Egret ten feet high, where the plume hunters had piled the birds after stripping them of their beautiful nuptial and brooding aigrettes-a disgrace to our civilization. 


\section{IV}

\section{Photographing Birds: The Principles Involved in THE WORK}

The interest I had always felt in nature studies received a new enthusiasm when I beheld the beauties of my first bird photograph-that of the Prairie Horned Lark. The impression it made upon me has been so lasting and the memories connected with it have been so pleasant, that my zeal has not been diminished by time. There is an enticing thrill in every prospective excursion to a bird home or rookery. Coming in contact with wild life, be it mammal or bird, is to me the very climax of pioneer history-making.

If you would not make bird pictures, study geology or go fishing; cultivate the habit of going into the fields and woods. Nature's lures will sooner or later catch you at some point and hold you fast. You will learn that all of nature's handiwork is of much more interest than the company of some human beings. Your bird-picturing trips do not end with your return home. The possessive instinct is a great and dominant feature of our make-up; if you are the possessor of a good picture you are far wealthier than if you owned the skin and feathers of that bird. The latter are the personal property of the bird, and you have no right to covet them.

The commercial value of a good bird picture may not be worth so much on the market as a mounted bird, or a bird's skin; but to the future generation the value of a live bird in the bush is greater than that of two dead ones in the hands of a commercial ornithologist. I am not decrying the works of the museum collectors, but the amateur who has the hobby of collecting bird eggs and bird skins, trading and selling them, or who goes through life perched on this bird-carcass hobby, deserves all of the censure bestowed on him by the conservationists.

The average bird-lover gets far more actual knowledge from a picture true to life than from a bunch of 
feathers and skins preserved in arsenic and protected by the fumes of bisulphid of carbon. If you are an amateur I beg of you to remain as such. The tang of the outdoors, with its glorious sunshine and pure, health-giving air, is more seductive than glass cases and drawers filled with specimens and noxious gases. I gladly relegate to the scientist my interest in the laboratory division of ornithology, and am content with hearing the unbottled sweet songs and with seeing the bright natural plumage and the unsurpassed poses and graceful flights of the living birds.

While I have, in a few instances, killed a rare migratory bird in order to procure a good picture of it, I must admit that in every instance this desperate procedure robbed me of all pleasure in the work, as I have invariably had a feeling of guilt, remorse and shame, until I have resolved not to repeat the practice. Although I say that I detest the practice of killing large numbers of birds for their skins, I understand the necessity of such a course to procure specimens in order to fill a gap in a public museum or in an educational institution. But the same methods should not be tolerated in amateurs and commercial skin and egg collectors.

With the works of some of the famous ornithologists before me-works that will live throughout all time-I find in one this statement: "Begin by shooting every bird you see." Bird life is too beautiful to destroy to no purpose. Yet, as if that were not enough, the writer adds, "Endeavor to kill as many females as males," and continues: "Fifty birds shot and skins preserved in a day is a very good day's work."

I say it is horrible butchery. Some are obeying the injunction at the present time, or at least it would appear so, when one reads in a late issue of a magazine devoted to ornithology that eighty-seven specimens of one species were killed that the juvenile plumage of the species might be studied.

An ornithologist, in a conversation last spring, told me that he had over thirty thousands bird skins. His field outfit consisted of a cheap camera, no tripod, a pair of tree climbers and a small bore shotgun. He said he had located a small flock of Carolina Paro- 


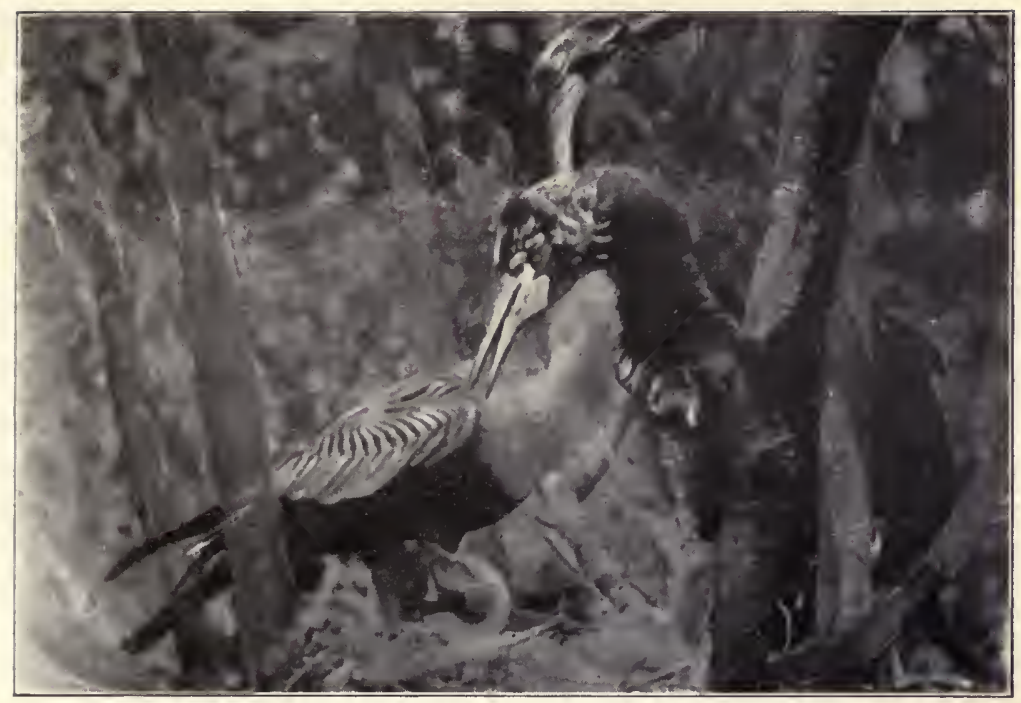

Fig. 17. MALE AND FEMALE ANHINGA

(page 68)

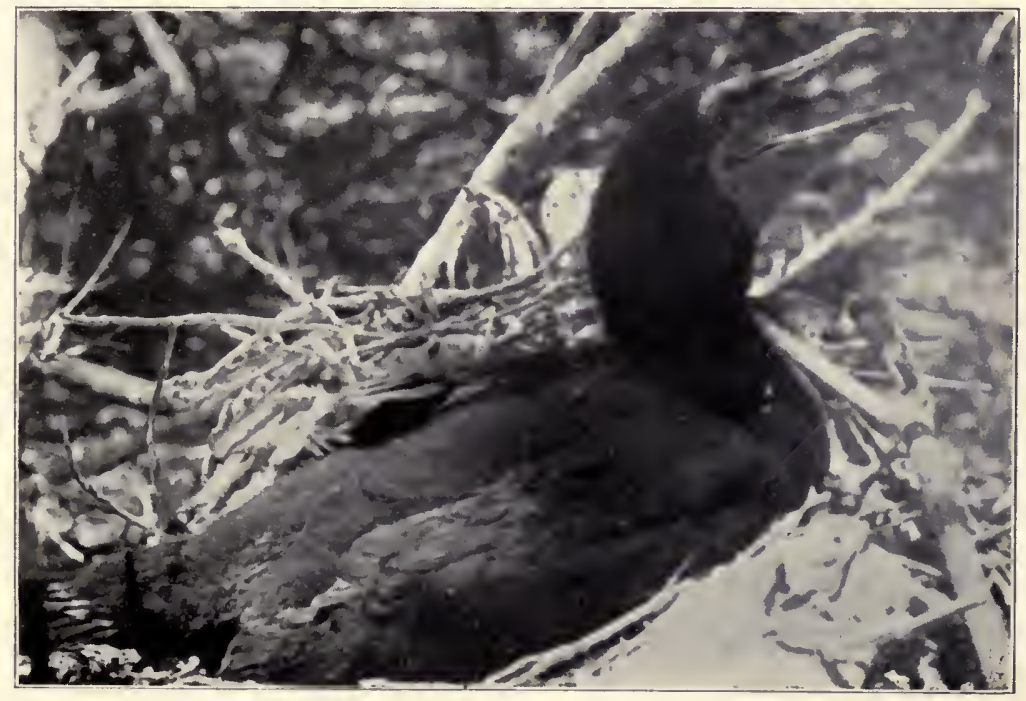

Fig. 18. MEXICAN CORMORANT

(page 70) 


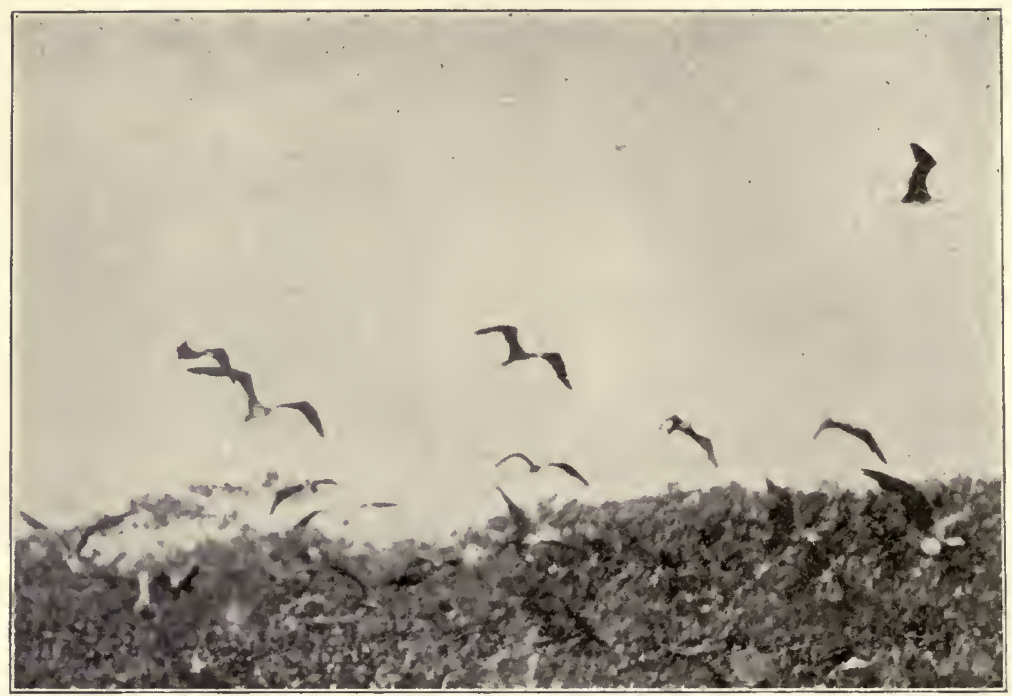

Fig. 19. MAN-O'-WAR BIRDS

(page 72$)$

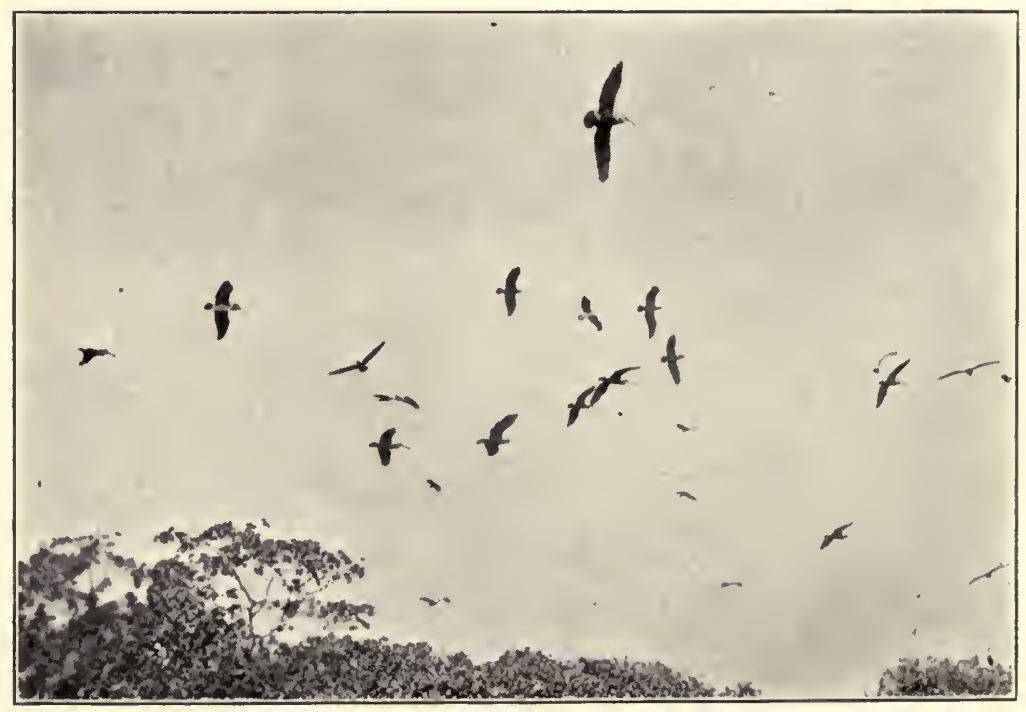

Fig. 20. BROWN PELICAN

(1age $7: 3)$ 
quets, probably the last of the kind. Poor Paroquets! I saw their finish.

With few exceptions the illustrations in this book are photographs, made by the writer, of living wild birds in their natural surroundings, in full possession of their freedom and uninjured before or after the pictures were procured. The picturing of two or three small migrants was made possible by trapping the birds, administering chloroform to keep them quiet while the pictures were being taken, then resuscitating them and returning them to their freedom, none the worse for their forced chemical restraint. I have repeatedly resorted to this same procedure with poisonous reptiles, minus the resuscitation.

No permanent resident or brooding or feeding bird, has ever sustained an injury from my association with it, or making pictures of it.

It is no easy task to make good photographs of birds, as all who have seriously taken up this work will testify. It may be an easy thing to get a picture of a Robin on the lawn in your front yard, but the taking of a "closeup" of a Bald Eagle at the nest-side is fraught with diffculties and dangers not easily avoided.

Far more skill is required, and a greater feat is accomplished, in getting a close-up bird picture than in killing that same bird with a gun, at a distance of a hundred yards.

In order to be of educational value a picture of a bird must be an actual photograph showing details, and can be made only in close proximity to the subject. I trust that every bird picture in this volume will act as a true-to-life pictorial appeal in behalf of the conservation of these, our feathered friends.

There is no limit to the "bag" or law violations by gunners in trespassing on "No hunting" posted estates. In fact, the landowner welcomes you and your camera, as he realizes you are his and his bird-tenants' best friend.

The enthusiasm engendered by the taking of a series of successful bird pictures is far more pleasurable and lasting than the memory of a ruthless slaughter of these harmless and beneficial little creatures. After the photo- 
graphic exposure of a rare bird has been made and you enter your dark-room to develop the plate-with a feeling of some uncertainity as to the results-I know of nothing that gives greater thrills than beholding, in the dim, soft, ruby light, the chemical transformation taking place on that plate, as on its blank, cream-colored pictureless surface an image slowly grows into an exact likeness of the bird, just as your eyes and the lens of the camera saw it at the instant of exposure. No skinning of the lifeless bird and no taxidermy can produce such thrills or lifelike reproductions.

It is an easy matter to take your photographic outfit and under favorable light conditions secure a good landscape picture. But when it comes to making a good photograph of a living bird in its native haunts many entirely different problems confront the camera man. "Birds have no interest in any device that assists in their identification, and due recognition should be given their protest by avoiding all unnecessary exposure of their eggs and young to unfavorable climatic and other dangers. Undue exposure to the burning rays of the sun may prove fatal to a young bird, or the fertility of eggs may be so destroyed."

In after years, in reviewing your labors, your thoughts will be of light values, time of exposure, developers and good pictures, and not of the size of the shot, the distance from the gun and the mangled bodies of birds.

I detest the idea and practice of photographing dead bodies of birds, yet there are occasions when one is justified by force of circumstances in resorting to the procedure. One of our most readable books on birds has its beauty marred and its value depreciated by the illustrations, which, without exception, are photographs of mummified museum specimens. The listless eyes, the rickety legs, the moth-eaten appearance and the unnatural surroundings and postures on pedestal perches, all proclaim in pathetic language a funeral oration on the defenseless original owners of the arsenated skins. (Fig. 2.)

No country has ever enacted a law restricting "camera shooting" of any of its birds, at any season, and in unlimited numbers. By painstaking care and persistent 
effort most bars to good pictures can be surmounted and a good photograph secured, although geographical distribution, or inaccessible nesting-places or the shyness of the birds, make it impossible in some instances. However, it requires time, caution, experience and a good working knowledge of how to use a photographic outfit to the best advantage to secure first-class pictures of some birds in their natural surroundings.

I have resorted to practically all kinds of devices or blinds, as natural foliage, pits, caves and the umbrella tent. I have found the latter to be the most efficient, convenient and easily transported.

All birds, from tradition or inheritance, have a deeply-rooted fear of mankind. However, their parental instinct has remained strong and the bird photographer may utilize it in overcoming that timidity and fear, and thus be enabled to come in close touch with them during the brooding period. Birds, even of the same species, manifest much diversity of temperament, so you cannot tell in advance how any bird will behave at the nest in the presence of the camera. The use of the tent, in such cases, will be of great assistance. From this private box the naturalist may observe minutely every mood and act of both old and young birds in their unhampered surroundings, an advantage that can be secured in no other manner.

Proximity to birds is best obtained by letting them approach you, waiting patiently in the vicinity of their known resting places, feeding grounds, watering places and nest-sites. The larger birds, as Hawks, Ducks and Herons have a "pursued alertness," while smaller birds, as Warblers, Vireos and others, are possessed of a "natural timidity." Every effort should be made to rob the birds of all alarm and catch them in their natural poses. This requires a knowledge of the birds' usual temperament. Avoid all quick motions of the body and hands, or the breaking of dead twigs, when near birds. When the incubating instinct is fully established the setting bird will permit of close approach and thus even time exposures may be made. In many timid birds parental love is so firm that it completely overshadows fear and all sense of danger. 
I have repeatedly noticed the remarkable sense shown by parent birds in protecting their offspring from heary rains and the sun's hot rays by spreading the wings in such a position as to shield and cast the shadow of the body and wings on the young. This has been especially true when I have tied aside the limbs shading the nest, to get better light for photographing the youngsters in the nursery. I am always careful to replace the protecting foliage as soon as possible.

It is desirable in picturing birds to be as nearly on a level with the subjects as possible, as the actinic rays of the clear sky act so quickly on the sensitive plate, when full time is given, that on the side next to the camera, the sky is so over-exposed that the plate is fogged. By selecting the time of day and placing the camera in the best spot available, a fairly good or first-class picture may be obtained. The use of a ray-filter, or screen, is desirable, but unfortunately it increases the time of exposure so much that its utility is doubtful.

In making a picture of a nesting bird a side view with a quartering illumination, if in sunlight, is desirable. The eggs and young should be pictured just as the old birds placed them. Avoid handling the eggs and exposing them to the hot sun's rays, all that is possible.

Pictures at the nest show the rapidity of growth of the young and the variety and amount of food furnished by the old birds. The breathing of birds on hot, sultry days is rapid and requires, if the camera is within a few feet of the birds, a quick exposure. By quick exposure I mean using stop F. $8,1 / 25$ to $1 / 100$ of a second, and light conditions must be favorable to get full-timed negatives at these speeds.

The force of habit in birds is beautifully amplified in the feeding parents in their manner of approaching the nest. The exact lighting spot near the nest and the direction of approach are so frequently followed that one may with assurance focus on some particular place with a good chance that the bird will pursue the route, as observed before placing the camera in position. This knowledge of bird habits often prevents failure through having the subjects out of focus.

If in doubt as to whether there is sufficient light to secure a good picture I have, on many occasions, resorted 
to the use of the Imp flash-gun and secured good fully timed negatives. This is a very ingenious little affair arranged so that the cable release may be attached in such a manner that when the flash takes place the shutter is sprung. I have repeatedly used this method to obtain pictures in dark ravines and at night. By a simple attachment of my own application the gun may be sprung by the bird. This consists of a five-cent mouse-trap attached to one leg of the tripod; from the trap spring that catches the mouse is a string that is fastened to a lever on the gun, that throws the exploding hammer. This requires more pressure to release than the bird would make, so to overcome that, a string is fastened to the delicate little trigger to which, when mouse-baiting, the cheese is fastened. This string is passed to a point over the nest or across the entrance hole and the least pressure from the bird's body or feet throws the mouse-trap spring, which in turn jerks the gun lever that explodes the magnesium powder. At the same time a plunger presses on the wire release to the shutter and the picture is made at 1/100 of a second. All this is done so quickly that the bird's actions do not blur the picture. The contrivance is much simpler and easier to work than to explain. The pictures of the Wood Thrush, the Flicker and the Kingfisher in this book were made by this magnesium flash method.

A photograph of a living bird is a picture true to life, and no artist can duplicate it with pen or brush. The artistic work of some of our bird artists is truly marvelous; the poses, however, are imaginary and rather fixed in types, like museum specimens. Many of the pictures in this book are of young birds and portray phases of bird life as truly as do the pictures of fully grown birds : for example, the early plumage of the young, their positions in perching and their hiding positions are clearly shown. Many of the young birds pictured are practically full-grown birds that had broken home ties before I discovered them and made their pictures in exactly the locality in which I found them. Careful handling of a full-grown young bird inspires confidence and dispels fear. It will remain in the position in which you place it, and various beautiful natural poses can thus be obtained. No rough handling or undue restraint must 
be indulged in after pursuing and capturing young birds that have left the nest, if you wish them to pose for you. Having selected the site for making the picture, focus on the spot where you expect to perch the captured young bird. Then gently and loosely hold the bird in the whole hand, so its neck and head are not restrained, place the hand over the selected spot and let the bird find its own footing; it will usually grasp the perch as soon as the feet touch it. Now quietly hovering the hand for a few seconds, remove it slowly and press the bulb or shutter release, with the other hand. Be sure that no part of your body or your shadow is in the camera's range. As to the immediate surroundings in the picture your personal taste and judgment will dictate.

Oftentimes bird pictures are ruined by bird motion, and sometimes they are ruined by a shaking of the camera or by under-exposures, but rarely by too much time. My best endeavors to obtain the pictures of full-grown young birds have often been thwarted by the parent birds' giving warning of danger and causing an excitement in the youngsters that human efforts could not appease.

A good contrast developer should be used on birdexposed plates. One containing pyro and metol meets the requirement.

I always use plates by preference, as they are more reliable than films, giving a more accurate and smooth surface, while films often buckle and make uneven and out-of-focus surfaces. It is true the plates are heavier and more easily destroyed than films, but this drawback is more than counterbalanced by other good qualities. I develop most of my plates by the tray method, but unless one is qualified to do his own developing in this way I should advise the use of the tank, following the instructions enclosed with the developing powders. Careful fixing and washing should be carried out regardless of the methods used in the developing of the plate or film.

If you have a friend who wishes to accompany you on a bird-picturing trip I should advise you to leave him at home, unless he is thoroughly in sympathy with the work, lest you tax his patience beyond the endurance point and he spoil your entire trip by getting tired and pleading to go home. It is better to go it alone. But to 
the patient worker and bird-lover loneliness is impossible while with such good entertainers as the birds.

"One must be full to the brim of bird enthusiasm to enjoy the many things encountered on a trip through the Everglades of Florida, surrounded by sharp-pointed, unyielding forests of palmetto, thorny-leafed clusters of beautiful Spanish daggers and meadows of rasping-edged saw-grass." The travel over, under and through these obstacles is anything but conducive to good cheer and bodily comfort. Then add to these drawbacks a pair of hip waders, a Graflex camera, a 4x5 plate camera and a few other necessities, free both hands to ward off the windtossed foliage and myriads of mosquitoes and you are fairly busy. Such is the experience of the photographer in the Everglades. One does not have to go through these hardships from choice, since in every city suburb, golf course and park there are always to be found many birds to study. On the farm, on old brush-grown abandoned fields, birds congregate in sufficient numbers during migration and nesting time to offer a rich pictorial yield to anyone who will take the time to reap the ornithological harvest.

It is a comparatively easy matter whenever a live bird is found to procure a bird's skin with the assistance of a shotgun. The instant a bird's life is sacrificed its body ceases to be a thing of much interest to anyone except the scientist for compilation or for the preservation of a rare or almost extinct species. Many have become extinct from this very cause. I know a number of collectors who look forward to the semi-annual migration of rare birds and never fail to aid in the extermination by collecting specimens, or by stealing eggs during the nesting time.

"By following the subdued and sweet refrain of some mother bird, I have often been led to beautiful and enchanting woodland nooks." Birds are by nature romantic and poetical, temperamentally speaking. Their nesting sites are so well hidden and often so remote that one must have special inducements to visit and locate these isolated beauty-spots.

I can no better illustrate some of the pleasant features of remote bird picture hunting than by quoting from my field notes, made on a trip to the Arctic Ocean 
watershed. After an active and successful day's work, I wrote:

"I capped my lens, folded my tripod, boxed my camera and took my departure. I soon reached the edge of the small lake near my camp, where I found my Hudson's Bay Indian guide with the canoe, waiting for me. (Fig. 6.) We soon rowed across the narrow stretch of water to my quarters. When I retired to my bed of pine boughs, an evening farewell-look from my tent showed, standing by the dying embers of the campfire, this perfect physical specimen of an Indian, in the midst of his solemn appeal to the Great Spirit. As I closed my eyes in the slumber that comes to him whose labors have been pleasant, I thought, 'twas the 'end of a perfect day." ", 


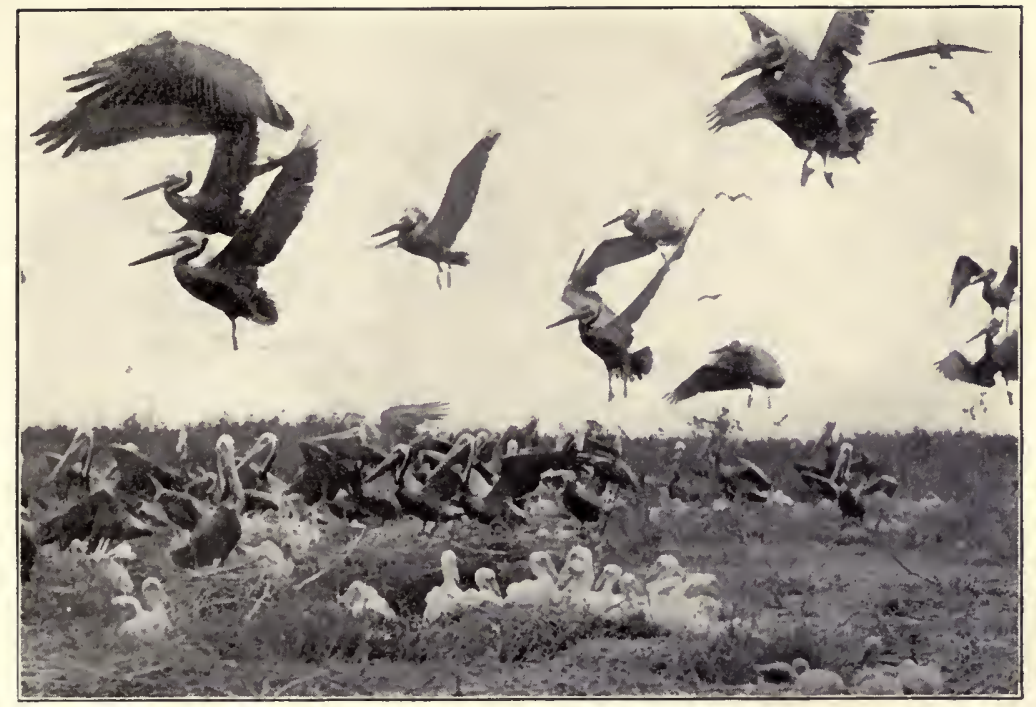

Fig. 21. BROWN PELICANS FLYING

(page 74)

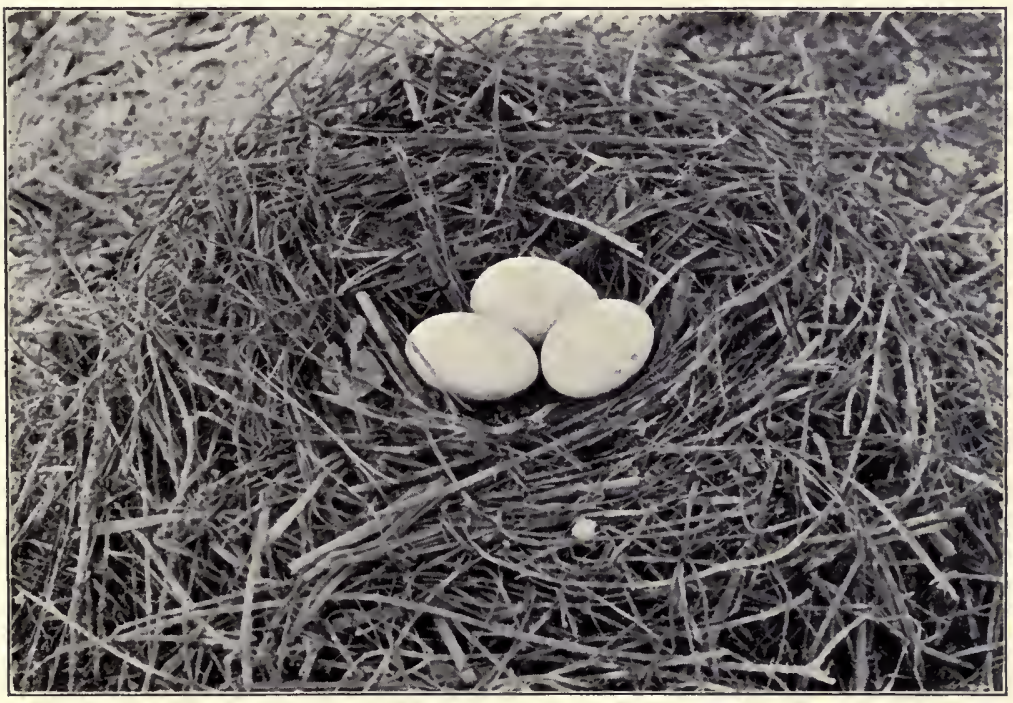

Fig. 22. BROWN PELICAN'S NEST AND EGGS

(page 75) 


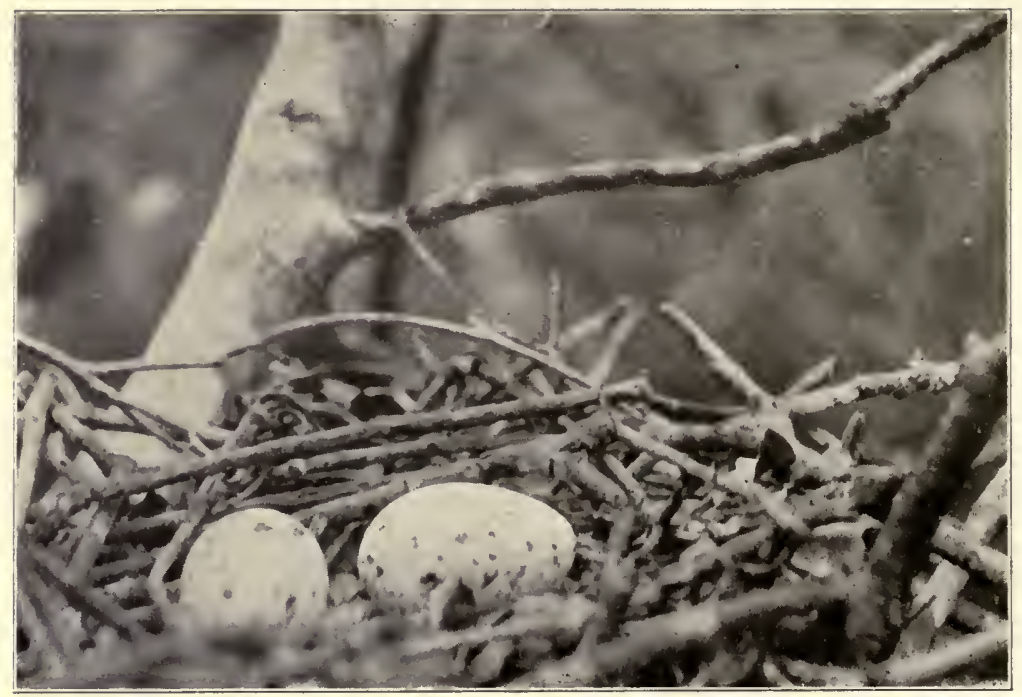

Fig. 23. WHITE IBIS'S NEST AND EGGS

(page 78)

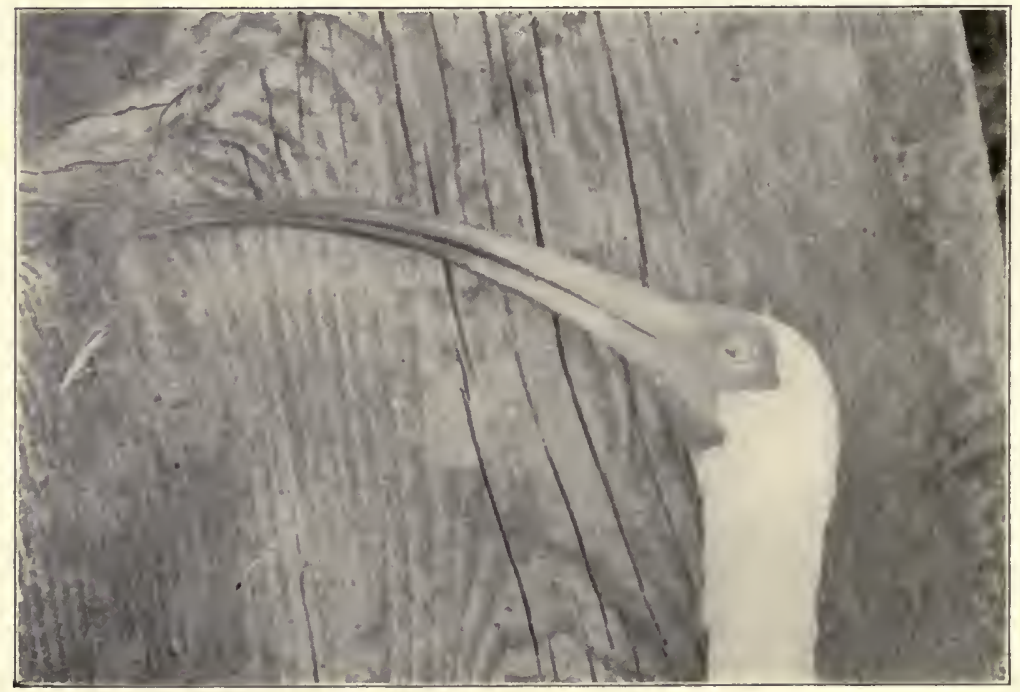

Fig. 24. WHITE IBIS'S HEAD AND BILL

(page 79) 


\section{V \\ Photographic Equipment}

Photography, with its far-reaching and accurate records, has invaded every department of scientific investigations. Whether it be the farthest star, millions of miles away in unlimited space, or the microscopical death-dealing microbe, this aid to the investigator has made possible permanent records for future workers.

The improvement made in lenses and shutters in this department of science has reached a perfection thought impossible up to a few years ago. From the single meniscus, concavo-convex lens with all possible errors and slowly working powers, to the single achromatic with its partial chromatic correction, to the rapid rectilinear corrected for most errors except curvature of field and astigmatism and, finally, to the fast-working anastigmat with its full correction for all optical errors, is quite a gap and represents the very climax in lens-making.

The anastigmat is a fast-working lens, giving critical definition at full apertures of F. 3.5 to F. 6.3, and smaller. Many of these lenses have symmetrical front and back elements and may be used singly at the expense of lengthened focus and much increase in the time of exposure, but with marked increase in the size of the image on the ground glass. In photographing birds rapid working is a most essential quality of any lens, yet depth of field and speed, when near an object, are of equal importance. By depth of field is meant the distance from the nearest object to the farthest in focus. Depth of focus is the distance ground glass may be moved, when the object is in focus, without blur. All lenses, regardless of make, of the same focal length and the same stop or aperture, are of the same depth of field and focus and of equal speed. The shorter the focus the deeper the field. The longer the focus length the larger the image.

The speed at which the various lenses work may be stated as follows: 
The cheap meniscus.................F. 16 .

Single Achromatic .................... 11.

Rapid Rectilinear ................... 8.

Anastigmat..$\ldots \ldots \ldots \ldots \ldots \ldots \ldots \ldots \ldots$. 4 .

Thus the F. 4 lens works at about four times the speed of the F. 8. In other words, if an exposure with an anastigmat lens working at F. 4 required one second, using the rapid rectilinear would require four seconds, at its largest working aperture, or F. 8.

The rapid rectilinear lens consists of two single elements, which may be used separately with about double the focal length and size of the image. This type of lens requires a smaller diaphragm opening than the anastigmat to secure sharp definition in the negative, hence is a much slower lens than the anastigmat. The latter lens is a more expensive one.

While the anastigmat lens is fully corrected and is nearly as perfect as a lens can be made, under some light conditions and extensions of bellows it occasionally develops a flare spot, and either destroys the negative or reduces its brilliancy. All shining metal surfaces within the camera and shutter should be given a coat of black finish.

The cheap fixed focus cameras, while giving great depth of field, have uncorrected lenses and should not be used for this work.

If you are going to make pictures of birds worth while you must expect to devote much time and have unlimited patience; added to these must be a practical working knowledge of how to use a first-class photographic equipment. My equipment consists of three cameras, a number of the best anastigmat lenses and a telephoto lens with about a nine magnification, as compared to an ordinary 6-inch focus lens. All the cameras are equippod with a ground glass for accurate focusing and a good firm wooden tripod, to which is fixed a tilling tripod head for use in picturing on the ground and in trees.

One of my cameras is a Gundlac $4 \times 5$ revolving back plate-using machine, fitted with a front and back extension of 22 inches. This long bellows is used in connection with the telephoto lens. To this camera I have fitted a number of lens boards. The lens I use for ground, tent 
and field work in general is a 71/2-inch Protar F. 7. convertible anastigmat with a $113 / 4$-inch back and a $133 / 4$-inch front element focus, this fitted to a volule shutter working from time to $1 / 150$ second, with thumb, bulb and pull release.

I use the telephoto lens on this camera. This lens is an Adon, working at F. 15 with a bellows extension of 5 inches and giving a magnification of three times at this extension as compared to a lens of 5-inch focus, or the equivalent focus of a lens of 13 -inch focus. When at 22 -inch focus, it gives an $\mathrm{F}$. value of 55 , an equivalent focus of F. 45 and a magnification of 9 diameter.

The Adon telephoto lens is composed of a front cemented doublet of $41 / 2$-inch positive focal length, and a back negative cemented doublet of 2 -inch focal length. The separation of the elements is governed by a rack and pinion movement. This lens is complete within itself; hence it requires no other lens and thus gives better illumination and more speed than if used as an attachment to another lens.

The entire Adon weighs only five ounces. In brief, this lens gives a picture three times the size of any other lens at an equal bellows extension. For the benefit of anyone who may wish to purchase an Adon the following table is inserted:

\begin{tabular}{|c|c|c|c|c|c|c|}
\hline $\begin{array}{c}\text { Camera } \\
\text { Extension }\end{array}$ & $\begin{array}{c}\text { Focal } \\
\text { Length }\end{array}$ & F. No. & $\begin{array}{l}\text { Lin. mag. } \\
\text { as comp. } \\
\text { with } \\
\text { 5-in. Lens }\end{array}$ & $\begin{array}{l}\text { As comp. } \\
\text { with } \\
\text { 8-in. Lens }\end{array}$ & $\begin{array}{c}\text { Time Reg. } \\
\text { Camera }\end{array}$ & $\begin{array}{l}\text { Adon } \\
\text { Stop 4 }\end{array}$ \\
\hline $\begin{array}{c}\text { Inches } \\
6\end{array}$ & $\begin{array}{l}\text { Inches } \\
18\end{array}$ & 15 & Diameter & Diameter & $\begin{array}{r}\text { Sec. } \\
1 / 11\end{array}$ & Sec. \\
\hline 9 & 24.5 & 21 & $5^{72}$ & $31 /$ & $1 / 8$ & $4 / 5$ \\
\hline 11 & 29 & 24 & 6 & 4 & $1 / 4$ & 1 \\
\hline 14 & 36 & 30 & 7 & & $1 \%$ & 2 \\
\hline 16 & 40 & 34 & 8 & 5 & & \\
\hline 18 & 45 & 38 & 9 & & $3 / 4$ & 3 \\
\hline 20 & 49 & 39 & 10 & & & \\
\hline 22 & 54 & 45 & 11 & 8 & 1 & 4 \\
\hline
\end{tabular}

All shutters used with any lens should be as free from noise as possible.

In using the Adon with this long bellows extension there must be no vibration of the camera, either from a shaking tripod or jarring shutter blades, as the exposures are from two to eight seconds long. This lens can be 
used only on birds that are incubating or are perfectly still and in good light. Many of the pictures used in illustrating this book were made with the Adon, at moderate magnification. (Fig. 3.)

For speed pictures of birds flying or moving, a revolving back Graflex with its focal plane shutter and rapid $\mathrm{F}$. 4.5 Tessar lens meets all the requirements. It cannot be dispensed with. Its hood and ground glass permit you to see the object photographed up to the instant of the exposure, and thus make it possible to get good pictures of all moving or restless birds. Its rapid F. 4.5 lens makes quick exposure possible on dark days. The focal plans shutter works from time to $1 / 1000$ of a second. A 4x5 inch revolving back Graflex is a good size to use and is the one usually employed.

For tree or other climbing work where the camera must be carried to great heights and anchored, a small $31 / 4 \times 51 / 2$ Tenax metal camera fitted with a Goerz Dagor F. 6.8, six and one-half inch focus lens in a compound shutter, is easily carried up to the vicinity of the nest and is quickly anchored to a limb or the body of the tree by fastening it snugly to the tripod. The focusing cloth may be fixed over the camera and a few green leaves and limbs quickly tied over it.

I prefer plates to films for this work; the Standard Orthonon and Hammer Extra Fast ortho are both to be endorsed as they give beautiful tone values. But there are a number of other equally as efficient plates on the market. 

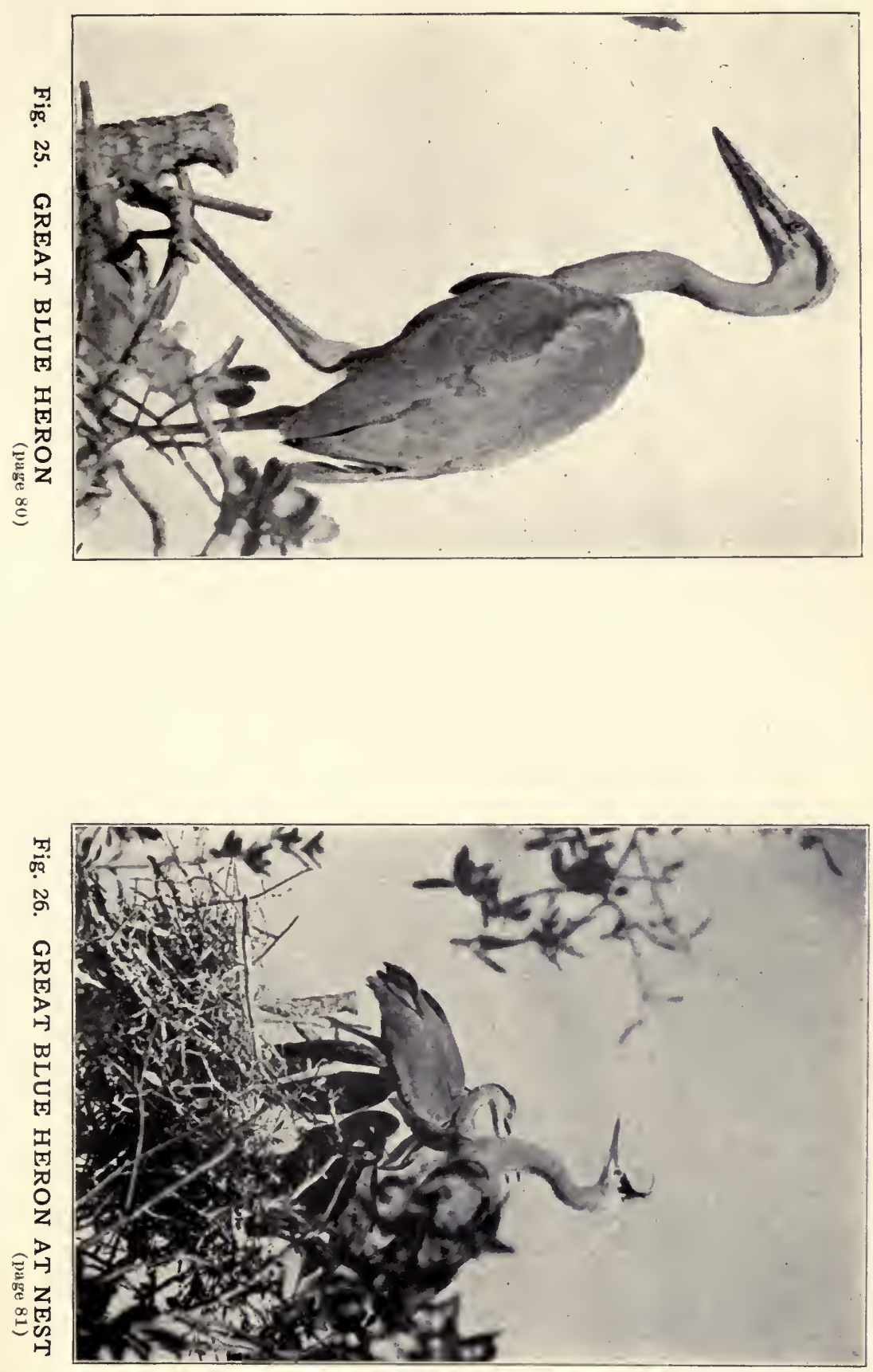


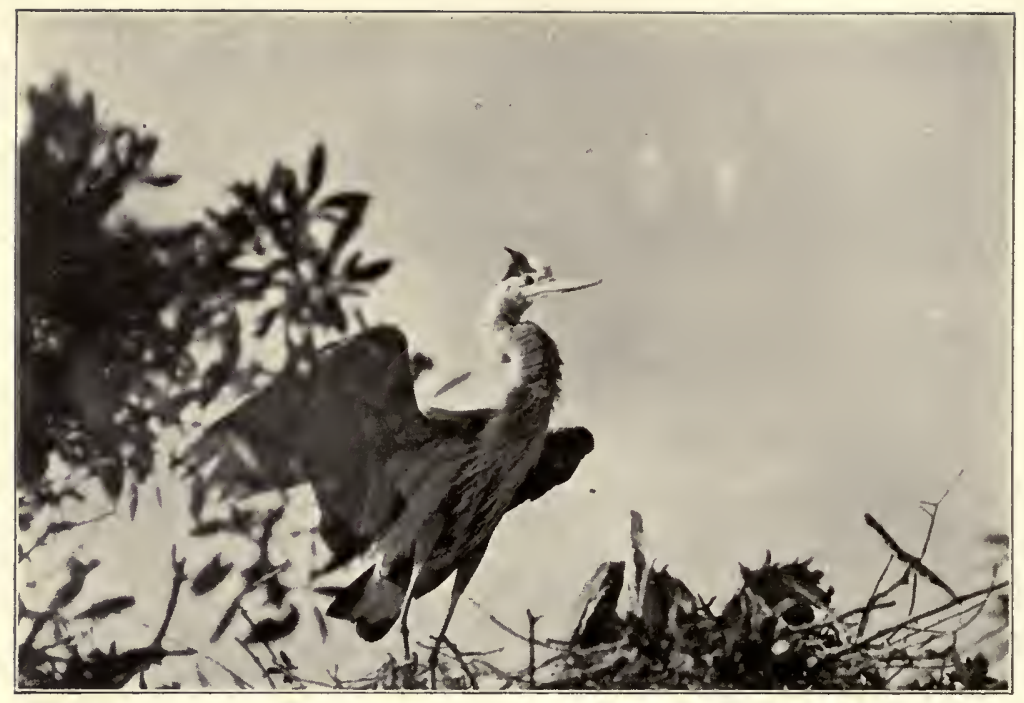

Fig. 27. GREAT BLUE HERON WITH PLUME-CRESTED HEAD (page 83)

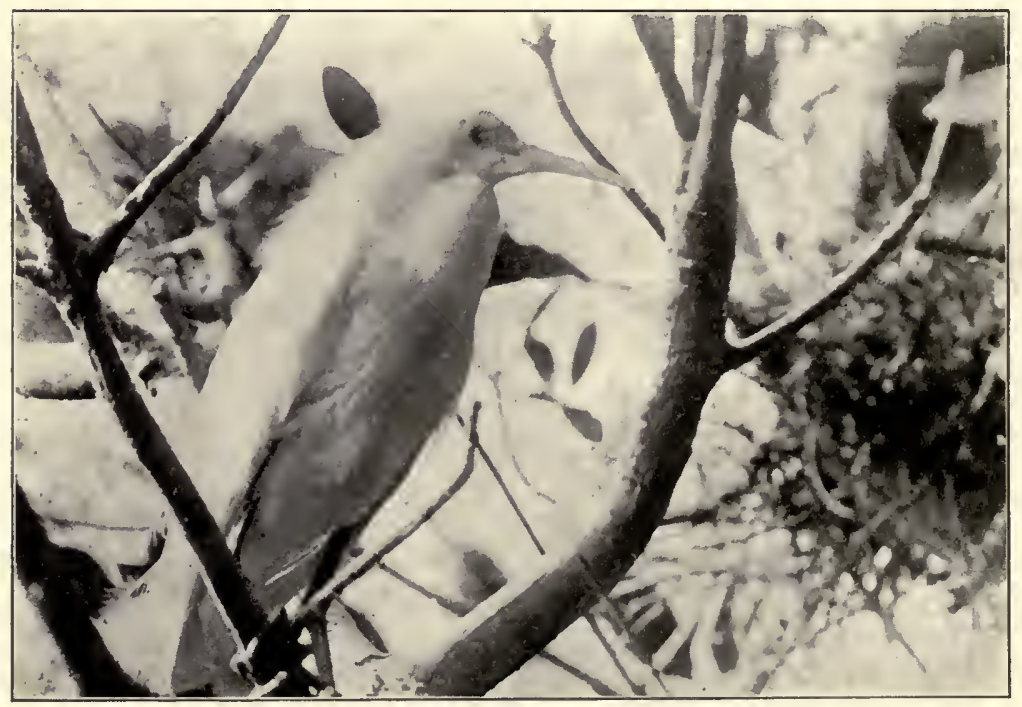

Fig. 28. SNOWY HERON, MOTHER BIRD 


\section{The Umbrelua Tent}

The bird tent is indispensable to the bird investigator and photographer. When once used it will not be discarded. It is light and is quickly erected. The one I prefer and use is of the umbrella variety; it weighs only four pounds, complete, and can be erected in thirty seconds. No blind of any kind can be made practical and at the same time convenient and comfortable, for all blinds prohibit free air circulation, restrict freedom of movement and limit your equipment. Anyone who does bird photography seriously does not expect or exact the comforts of a wind-swept front porch. (Fig. 4.)

This tent is easily made, is inexpensive and meets all the requirements necessary for thorough work. It consists of three very thin pieces of hollow iron tubing, graduated to telescope snugly. This tubing should be one-half inch in diameter for the bottom joint, and in the end of this piece a solid bolt, sharpened at its end, should be screwed so that it may be pushed into the ground easily, while in use. Each joint should be from two to three feet in length. Little clips can be arranged to grip the segments to govern the height, and the depth it is pushed into the ground will also determine the height of the tent. Let the top segment be the exact inside measurement of the iron rod to an ordinary full-sized umbrella handle. Now make a sack of some firm muslin, about seven feet long, the diameter of which exactly fits the size of the umbrella when stretched. The top of this sack is more easily made separately, as it must fit the raised umbrella snugly. One side of the sack is left open up to the end of the umbrella ribs when stretched. About one foot from the bottom of the sack, make a tuck around it just large enough to take a one-quarter inch rope, and at four equal distant points tie to this girdling rope, pieces of rope two feet long, to be used in holding the edge of the tent close to the ground and to keep it from 
flapping in the wind. A similar rope must be run around the sack at its junction with the ribs of the umbrella and three or four pieces, each ten or fifteen feet long, tied to it, these to be used as guy ropes to anchor the tent to stakes, roots or any immovable objects.

On two or three sides of the tent, on a level with your eyes when standing, cut windows one foot by eight inches, leaving the flap attached at the top side. Now in these openings sew two thicknesses of green mosquito bar. The tent should then be dyed a drab-green. At three points cut vertical slits in the sides to correspond with the size of the camera bellows and height of lens when in use, and the tent is completed. Have plenty of safety pins stuck into the goods for use while in the field.

When taken down, the tent makes a small roll about as long as an umbrella. All the parts should be kept in one bundle by a couple of firm rubber bands. If you so desire the umbrella cover may be removed, using only the frame, and a circular hole left in the dome of the tent for a ventilating flue.

I have found that the umbrella, complete, has saved me from several good soakings when I was overtaken by rain storms while working in the field or woods.

There can be no practical set rules governing the location of the tent at all nest-sites. The judgment of the individual at the time must decide that problem. This much, however, it is safe to say! Place the tent in such proximity to the nest or bird as to insure a good-sized picture, showing details on your ground glass. The location and character of light must always enter into the decision. The focal length of the lens in use will govern the distance. The longer the focal length of lens the greater the distance from which you may get a good picture.

Some birds disregard the presence of the tent, while others are slow to accept its intrusion without much protesting. Occasionally a bird is found that even abandons its nest; especially is this true soon after the first or second egg has been laid, or during early incubation.

No detailed instructions are necessary on how to put up the tent. Anybody can raise an umbrella. Then, since it is an object that neither moves nor resembles any known bird enemy, and is silent, it is soon accepted as a 
part of the natural landscape, confidence is restored, and the actions of the birds at the nest become true to their usual habits. The alarm, when the tent is first erected, bidding the young birds to "lay low" and keep quiet, is soon replaced by the assurance that all is safe. The youngsters resume their positions at the festive board, with gaping mouths ready to be fed, while in the tent the photographer in joyous anticipation awaits the return of the feeding parents. Every call and response may be distinctly heard and the minutest details of the feeding and brooding or the cleaning of the nest, are plainly seen and recorded by the camera.

When the nest containing the young is in a location where it cannot be photographed-as the perch of a Redwinged Blackbird anchored to cattails in deep water, or a muddy bottom, or the basket of an Oriole swinging on a limb too high for the tent-the nest with its natural surroundings may be moved to a nearby and suitable locality in which the work can be carried on from the tent. The original natural surroundings should be preserved as nearly as possible if the picture is to be of much value.

A canvas background should never be used. A fresh bunch of natural foliage is preferable. The moving of the nest should be resorted to only in extreme cases as the foliage soon withers after being cut and thus leaves the young exposed to the sun and rain.

When it has been photographed, the nest should be returned near its former position and securely anchored in a shaded spot. The parent birds soon find the nest in its new location and renew their feeding and brooding as though the nest had not been disturbed or moved.

In the absence of the tent an improvised blind will be of much help. This may be either a pit dug in a bank or the ground, or the material at hand, as grasses, green leaves of the palmetto or ferns. All these substitutes, however, are hard to erect or devise and are not so efficient as the tent. If two persons go to the tent and one enters and remains hidden while the other retires, the watching birds, unable to count two, decide that the tent is vacant and soon return to the nest. 


\section{VII}

The Great Bird-Breeding Rookeries Along the Florida, Atlantic and Gulf Coasts

The United States, Florida, other States and the National Association of the Audubon Societies, have very wisely set apart a number of islands and other suitable locations for the exclusive use of the shore birds as breeding rookeries. These reservations are under the supervision of game wardens who have, in a measure, checked the shameful and ruthless slaughter of birds and the sale of their plumage. A special permit must be secured before one is allowed to visit or land on the reservations. Through the courtesy of Mr. E. W. Nelson, Chief of the Bureau of the United States Biological Survey; Mr. T. Gilbert Pearson, President of the National Association of Audubon societies, and Mr. B. J. Pacette, Inspector of Federal Reservations, I was granted the privilege of visiting these vast rookeries for the purpose of studying their population and making photographs.

Early in March, 1920, I made a trip to Florida, planning to visit Pelican Island, in the Indian River. Two days before my arrival a five-inch rain and an adverse wind caused the flooding of the island and the destruction of over three thousand nests and their eggs. I returned to Kansas City at once, resolving to make a second visit later in the season.

On May 20, 1920, as I took my departure for my second trip that year to the big bird rookeries along the Florida Coast, I recalled my former visit and the seeming sadness and lonely aspect of the Pelican population, as they aimlessly sat around on the sand or floated on the water near by, their incubating destroyed for the season. I contrasted them with their long-necked and slenderlegged, graceful bird neighbors a few miles from there, at another rookery. I thought of the brackish tide-water flowing through the mangrove swamps; of the countless peace-destroying and disease-breeding Florida mos- 
quitoes; of the swamp diamond-backed rattlesnakes-the most deadly of all American reptiles-and of the lazy cotton-mouth water moccasin, sunning himself on the dead and fallen timber and lily pads (Fig. 5); of the myriad birds with their babel of tongues- to me an unknown language; of the beautiful white-plumed American Egret and the gracefully-formed Snowy Heron. I remembered the ideal May weather we were having at Kansas City; yet there was something indescribable saying to me: "Florida and its haunts of untrammelled nature are calling to you." And I was happy in the thought that I had heard the summons and was obeying.

On this trip I visited reservations on both the Atlantic and the Gulf coasts and found them very much alike, as far as their citizens are concerned.

I succeeded in getting good comfortable quarters within a few miles of the rookeries. As twilight drew near, looking out across the vast expanse of water beyond the bird islands with their fringe of low, mangrovecovered shores, I was often reminded, by the disappearing sun with its play of subdued multi-colored light, of a vast art-glass memorial window, placed there by unseen hands in commemoration of the departure of another day. The long, solemn procession of home-coming birds with their vesperal chantings completed a picture of enchanting and inspiring beauty. What a glorious privilege to behold nature's handiwork in all its splendor!

If you have never visited a large shore bird-breeding rookery and have never been enthused by the doings of their busy residents, you have missed many a pleasurable surprise.

The dark-colored birds, the Louisiana Heron, the Little Blue Heron, the Water Turkey and the Cormorant, are inconspicuous while perched in the trees among the foliage of the densely-studded mangrove islands, and correct estimate cannot be made, from a distance, of the number of tenants occupying a given rookery. Then, as you draw near, each leaf seems to take on life, as the unseen birds, with mingled screams, make their hasty exits from their resting places.

The white birds, the Snowy Heron and the White Ibis, can be seen from afar, for their color stands out in marked contrast to the green leaves. 
With each revolution, the "chug! chug!" of my gasoline engine brought to view above the treetops thousands of heads on snake-like craning necks, unlike anything to be seen elsewhere. As the boat drew up to the water's edge and the anchor was thrown overboard the noise produced by its accidentally striking the edge of the boat, acted as a signal of universal alarm and thousands of big birds took wing, screaming and flying in all directions. How they avoided collisions I do not understand. The Cormorants and Anhingas darted hither and thither on a horizontal plane, at lightning speed; the Pelicans, with awkward beating of wings, flew in frantic confusion, while many of the marvelous flyers, the Man-owar birds with their small bodies and eight feet of wing-spread, ascended higher and higher in airplane-like circles until almost lost to view.

The ocean and gulf island rookeries are comparatively easy for the photographer, as there are no tall trees to climb, or cypress swamps to splash through for miles, before reaching them. All of the Everglade cypress swamp and ocean and gulf breeding grounds are invariably located on islands, or their equivalent. The birds have learned that they are safe there from the invasion of skunks, wildeats and other bird-destroying animals. That ever-present villain, the Fish Crow, I found to be these birds' worst enemy.

The activities and noises in a mixed rookery of Water Turkeys, Little Blue Herons, Louisiana Herons, with the Fish Crows flying overhead, may be compared to those of a public market square, where the salesmen are made up of many nationalities, all crying their wares at the same time, each in his native tongue. Side by side, the Turk, the Italian and the Greek, each patronized by his kind, shows due consideration and a let-alone policy to the stall adjoining.

During the morning and evening feeding periods great animated lines keep coming and going, as if from a central telephone station, all with messages to craws' capacity. No mother or father dares to return to the hungry young without bringing a "full dinner pail." (Fig. 7.) 
Many of the trees in Florida are covered with poisonoak vines and I should advise him whose skin is susceptible to the baneful influence not to visit a Florida Herony. Again, the mosquitoes have no respect for formality and unceremoniously introduce their germ-laden bills into one's anatomy on any and all occasions.

The long-legged waders and quick-diving birds manifest none of the combative traits of the land tree-dwellers, an example of which is the bullet-like swoop of the Migrant Shrike or the Robin.

Long persecution and destruction by game birds or by "game-hog" plume hunters has instilled a fear of man and his loud noise of destruction. This is seen in the wild commotion that is set up by the quick snapping of a twig, when one is walking through a protected bird colony. With one acclaim all birds able or old enough to fly take wing the instant a dry twig is broken.

It is nothing unusual to see several dead birds hanging by the feet or neck where they have slowly died while dangling, held fast by the imprisoned member in the crotch of a mangrove limb. All young birds that fall from the nest to the ground starve, for the old birds never descend to feed them. Like monkeys, the young birds climb from limb to limb and tree to tree, making it very difficult to capture them for close picture-making.

On arrival at the rookery I carefully surveyed my surroundings and selected the most favorable location for my blind, amidst the most populous portion of the island. Within a very few moments the tent was in place and I was securely hidden and awaiting the return of the birds that had been frightened away by my appearance.

Someone has said that in a bird tent you don't have to sit as still as a stone dog on a lawn. The scene from the tent was truly like a great steaming hot-house in this mangrove morass, with cider-colored water on every side, filled with alligators, reptiles and other things that crawl, while the steaming air was dense with flying pests. Looking from the blind into the almost impenetrable roots of mangrove $I$ was reminded of a vast monkey cage, so much do these young birds resemble the monkey, as they crawl over the limbs of the trees. Add to this, 
the noise of the coming and going of the feeding birds, and you have a true picture with a jungle setting. (Fig. 8.)

I soon learned not to set up my tent or to stand directly underneath a nest full of young Herons or Cormorants. It is decidedly unsanitary and unwholesome to do so.

Even one's usual dread of poisonous reptiles is, in a measure, overcome by his eagerness to picture some of these birds. Such was my experience while making the Anhinga picture. While I was in the blind of palmettoes, with my rubber-boot encased feet and legs buried in the mud to my knees, a large water moccasin slowly crawled within a few inches of my leg and a twelve-foot alligator sunned himself close by on a mud bank. I secured the Anhinga pictures by keeping still. 


\section{VIII}

\section{Big Bird Island: Laguna de la Madre}

Mr. T. Gilbert Pearson, President of the National Audubon Societies, related, in a communication to me, his experience while on a visit to Big Bird Island and Laguna de la Madre. This decided me as to where I should go next. I made arrangements by letter for a guide and a boat to take me from Corpus Christi, Texas, to Big Bird Island, a distance of about fifty miles. When I arrived I found the boat on the skids undergoing repairs and waiting for replacement of parts broken. The latter never came. After waiting seven days I employed another boatman. His boat drew nearly three feet of water.

The Laguna de la Madre is a very shallow stretch of partly land-locked salt water about four miles across, extending from Corpus Christi to the mouth of the Rio Grande. The island is located in this lagoon. To reach it requires a boat of a very shallow draft, not over two feet. Our craft, drawing, as it did, three feet of water, gave us much trouble. In fact, we made much of the journey by land, using the bottom of the lagoon as the road-bed. Sometimes, for a mile at a stretch, two or three of our party were in the water, generating manpower to assist the splendid forty horsepower, six cylinder engine in its work of plowing a furrow as the boat was shoved along on the bottom of the lagoon. This was truly working one's passage.

We passed numerous small shallow-bottomed fishing sailboats, manned by Mexicans. The lagoon abounds in splendid edible game fish, as the red fish, sea trout and others. A few hours' run brought us in sight of the island, which is a mere sand spit, a few inches above the shallow tide limit, covered in part with coarse stem grass and weeds. Not a tree is found on its soil. Boggy places a few feet in extent and filled with salt water abound, and the whole shore line is one of sand and broken shells. 
The water in the little pools over the islands is one mass of bubbling gasses that abound in sulphurated hydrogen, as distinguished by the sense of smell.

Owing to the depth of the water we had to anchor the boat a half-mile from the shore off the island and use a rowboat to land us.

As we approached the low, shell-strewn shore line, the gulls began rising, first in pairs, then in scores, hundreds and thousands, all the while with screaming laughter circling about our heads and threatening to do us bodily injury. They would form in great flying squadrons and after turning and revolving close over us a number of times return to the island and drop down in the little open brackish pools or in the grass, their black heads and white necks and breasts forming conspicuous objects as they stood motionless, viewing our approach.

When I landed and began my search for nests the throng again took wing and continued the screaming until I moved to another section of the island. Those first disturbed then dropped back to their nests, while those under my feet were constantly rising, only to return as soon as I passed on. Many of the birds did not appear at all frightened at my presence.

The men who were assisting me had been in the terrible tidal wave of 1916 , and again in 1919, and had been compelled to wade, swim and battle with the awful death-dealing salt-water demon for hours to save their lives. Their homes and all other property were destroyed. They are naturally uneasy, therefore, when storms threaten, and their restlessness does not add to the feeling of safety of a newcomer, or tenderfoot, when a few thunderheads arise on the northeastern horizon.

We had anchored the boat on the northeastern shore of the island, in plain view. After working all day picturing and taking field notes, I was surprised, on returning to the spot where the boat had been left, to find that it was nowhere to be seen. It was just at dark, and I was hungry and very thirsty, and for a few minutes a little alarmed; however, I soon discerned it on the opposite side of the island, where the boatman had removed it for protection, in case of storm. We rowed out to the boat, had supper and then retired for the night. 
While we were lying on the bottom of the boat, with the star-studded dome above us, all the horrors of the last tidal wave were gone over in detailed conversation by the two men, for my comfort, I presume, as they frequently referred to the sinister appearance of the cloudrimmed eastern horizon, where forked streaks of lightning zigzagged through space, to be followed by the distant rumblings of thunder, the forerunners of a storm that never materialized.

During the night I awakened and for an instant thought we were on the verge of being engulfed by an approaching tidal wave. However, when I recalled that the distant low rumbling was the pounding of the surf of the Gulf of Mexico on the shore of Padre Island that for two miles separates Laguna Madre from the gulf, all of my fears vanished and I dropped into sleep, such as one gets only when he breathes the purest air and knows that all is well.

The next day, as I neared the farther end of the Island, I was gratified to see what on casual view appeared to be a vast garden of large, full-blooming, white flowers. This, I at once recognized as a Brown Pelican breeding colony in full bloom. (Fig. 9.) The big, comically solemn-looking birds were there by the hundreds and presented all phases of Pelican home life. The nests were large structures, on the ground, made of dried grass, weeds and sticks, all mud-plastered into a conical mass a foot or more in height and two feet across, with a slight depression in the center.

These nests were promiscuously scattered over several acres of ground and in many instances were so closely studded that their walls were in contact with those of the next-door neighbors. From my tent I witnessed some very amusing incidents while I was making pictures of the parent birds and taking field notes of my close-up observations.

The old birds have a persistent longing for the nestbuilding material of their nearest friends, and do not hesitate to steal a few sticks or blades of grass and appropriate them to the beautifying of their own domiciles, all of which is sure to bring a vigorous protest and corporal punishment from the rightful owners, together 
with a return of the stolen building material and a little bit more.

The young birds in most of the nests were large enough to tumble out and waddle in an awkward way to the yard next door and beg to be fed by the first old bird returning. These visitors were quickly reprimanded and sent home squawking to their parents.

The big birds become, under the parental feeling, very tame and permit of a close approach during the period of feeding and caring for their young.

When the parent bird arrives from the fishing grounds and drops down by the nest with extended wings and dangling feet the young birds at once begin their pleading to be fed by pecking at the old birds' breasts and bill, all the while making a noise such as can be made by a young Pelican, only. The parent bird, with its strong bill drooping on its breast, and its large yellow eyes looking nowhere in particular, yet everywhere, seems to say by its stoical attitude, "Just you wait a minute." But all the while the young bird keeps up its persistent pleading.

When the psychological moment arrives the parent bird raises the upper mandible and the young, their necks stretched to their fullest and bills extended, fight for first choice, shoving each other as they push their bills, heads and even part of their necks through the old bird's mouth into the "dinner pail"' and proceed to help themselves to the partly digested fish.

This scene was being enacted all around me the whole time I was an observing, photographing and recording visitor to the large nursery of the Brown Pelicans.

- One of the rare birds of our southern shoreline is the Reddish Egret. (Fig. 10.) I was fortunate in finding a few of this species nesting on the island. They may easily be mistaken for the Little Blue Heron, as their general size, color and habits are similar to those of this Heron, but the color of the bill and the reddish ruffled neck of the Reddish Egret is different. This bird was frequently seen in company with the Louisiana and Little Blue Herons; on approach, however, the latter were sure to remain for a short period after the former had flown away. Their nests were on the ground and 
were built of grass; each contained three pale bluish eggs, larger than those of the Little Blue Heron.

I found several nests of the Big Blue Herons on this island. They were voluminous structures, each containing three eggs or three young birds. When one realizes the fondness of this Big Heron for a nest-site in the tallest of trees, he cannot fail to appreciate the adaptability of nature's subjects to conditions as they find them, when he sees a Great. Blue Heron's nest on the ground, surrounded by grass and cactus. (Fig. 11.) Most of the nest-building material, except the coarse grass for the Heron and Pelican nests, must be carried from the mainland three miles away. I saw one of these big birds flying with a two-foot piece of brush to be used in constructing its home.

Many of the Pelican nests contained only one egg, although the usual quota is three; in some the young were just leaving the shell, and in others they were covered with pin-feathers and were half-grown, showing that these birds have a variable laying and hatching period.

The year before, as I have stated, I had visited the great Pelican ground on the nesting island in the Indian River, Florida; but a few days before my arrival a flood had washed the nests and eggs away and I found only the dejected and sad-looking birds, waddling aimlessly about the island, as though they thought, "Well, what's the use?" So I congratulated myself on my good fortune in finding this big colony in the full period of incubating and feeding the young. I spent many hours with these birds.

There were probably eight or ten thousand Laughing Gulls on the island; their nests of grass and dead weeds were on the ground, everywhere. I could hardly step without disturbing an incubating or laying Gull. The eggs, two to four in number, were of a muddy brown, with drab-colored spots. There were no young Gulls in any of the nests, as the season had been one of unusual lateness with many cold spells.

These Gulls, like all of their kind, are inveterate thieves. When I approached the Pelican nesting site and some of the old birds flew away from their young, they did not dare to remain away long, for the Laughing 
Gulls collected in screaming masses over the Pelicans' nests. Every morsel of food lying about or in a nest was quickly seized by a Gull, who was promptly pursued by those less fortunate and made either to swallow the stolen fish or drop it to be caught by some one of the pursuers. A very young Pelican is not eschewed by these brigands.

Pelicans do not collect their food from the ground when once disgorged or dropped during the feeding process, so I presume the Gulls are a benefit to the Pelicans' surroundings because they remove decaying fish.

The year before I visited the island, Mr. T. Gilbert Pearson had found on Little Bird Island, a mile away, forty of the Great White Pelicans, nesting-a rare find, indeed, as these birds do not, as a rule, nest south of Utah and Wyoming. But not a vestige did I find of a nest of these birds on either Little Bird Island or Big Bird Island. In fact, Little Bird Island was practically deserted, for I found only a few Boat-tailed Graeckles' and two or three Big Blue Herons' nests on the whole island.

On Big Bird Island the Black Skimmers were beginning to arrive in large numbers and their sand-excavated nests were just being formed. I found only one egg of these peculiar birds. They were flying up and down the shoreline with their long lower mandibles skimming the water, picking up minnows, occasionally, as they flew; and all the while some were objecting to my presence by their usual bark-like voices and by sudden dartings around my head.

One day, as I was walking through the grass, a Purple Gallinule flew up from beneath my feet and joining the throng of Gulls in the air was soon lost to view.

The sky and sun were behind masses of heavy clouds most of the time I was on the island, thus hampering my efforts at good speed flight pictures with the Graflex, but affording ideal conditions for tripod work on nest and eggs. 


\section{IX}

\section{HERRING GULA \\ 51. Larus argentatus}

The Herring Gull is the largest and most widely distributed of the Gulls; it is twenty-four inches long. With its mantle of deep pearl gray or gull blue, its breast and the rest of its body pure white, and its black-tipped wings, this bird is the most beautiful of its family. Owing to its wide distribution and semi-domestic traits it is also the best known of the Gulls. Its breeding range extends over a large area of the United States and as far north as portions of Alaska and British Columbia. Very few are the seaside and lakeshore resorts that do not have a flock of these big Gulls frequenting their water fronts. (Fig. 12.) They become very tame and may be seen perched on the piling and sand spits, patiently waiting for the cooks on the anchored boats to toss overboard the crumbs and scraps from the tables. Herring Gulls are not so numerous on the Pacific as on the Atlantic coast.

The nest is beautiful and both birds take active part in nest-building. It is made of miscellaneous material, including grass, weeds, chips of wood and feathers, and is built on the ground from choice, but often in trees.

A last year's nest is sometimes utilized by repairing it. Like many land birds, Gulls shape the nest by moulding it to fit the builder's breast. After the nest is completed, or even at times when the birds are incubating, they have a habit of carrying around and collecting building material. Whether this is a prolonged building instinct or a permanent habit, naturalists have been unable to decide.

These birds are persistent fighters among themselves. Often, during an encounter, they will suddenly cease their combat and in an indifferent manner peck at any object near by, or pick up pieces of grass or sticks. 
The Herring Gull does not dive for its food and is a poor swimmer, yet no bird floats more gracefully on the water, or is more skillful in catching food tossed to it. If the morsel is missed, the Gull picks it from the surface of the water, without alighting. These Gulls may frequently be seen dozing, like a domestic hen, with heads snugly tucked beneath their feathers.

The young retain their juvenile plumage for the first year. This may lead to confusion in identification.

Gulls like to loaf around man's abode, where they can reap a rich harvest of food with less labor than from the open ocean. They are not particular in regard to their diet list. Garbage, sewerage, and dead fish all look alike to a hungry Gull.

With its beautiful white plumage this bird appears out of its sphere when seen feeding on a ship's refuse or on city garbage. The Gull does not look like a scavenger. I have stood on a steamer's deck, when out of sight of land, and watched a flock of them as they followed in the wake of the boat. They would come screaming and begging for more refuse to be cast upon the waters. How they kept up with the ship was a wonder to me. Regardless of the fact that the vessel was making fifteen miles per hour in the face of quite a gale, these big Gulls kept close, seemingly without winged or other effort. With their wings in graceful, cup-like curves, they bored into the air currents.

While I was big game hunting on the Aleutian Peninsula, the Pacific type of these Gulls was to be found there in great numbers. The natives told me that they collected large quantities of Gull's eggs each year during the nesting period.

On Kodiak Island I saw these birds at low tide, feeding on clams and other moluscae, which are abundant there. I saw a Gull pick up a large clam, fly with it to a height of twenty feet, and drop it on a pile of glacial boulders. If the shell was broken the clam was greedily eaten; but if the drop failed to smash the shell, the Gull picked it up and from a greater height dropped the clam again. This was repeated until the objective was attained, of ten requiring many efforts.

Is this reasoning? If not, what is it? 


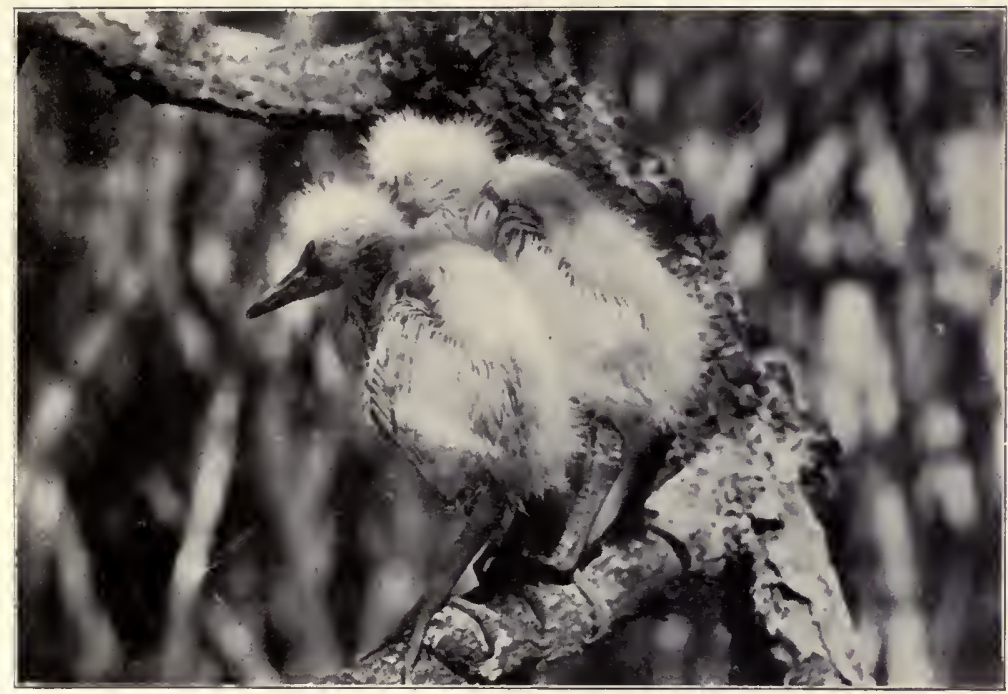

Fig. 29. THE TWO ORPHANS

(page 85)

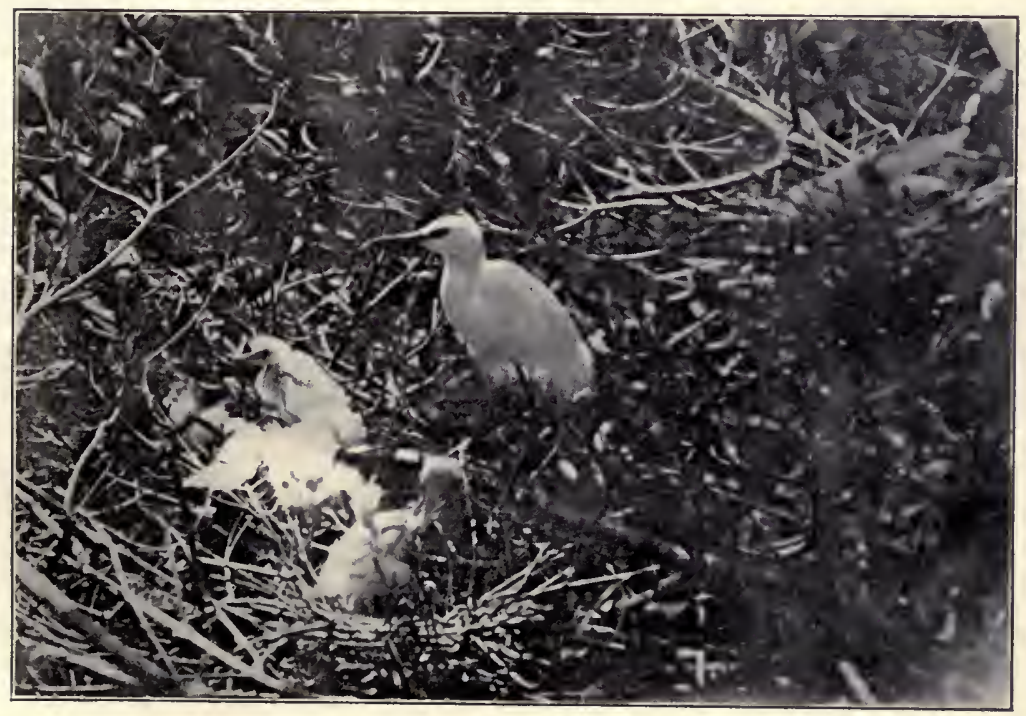

Fig. 30. YOUNG SNOWY HERONS 


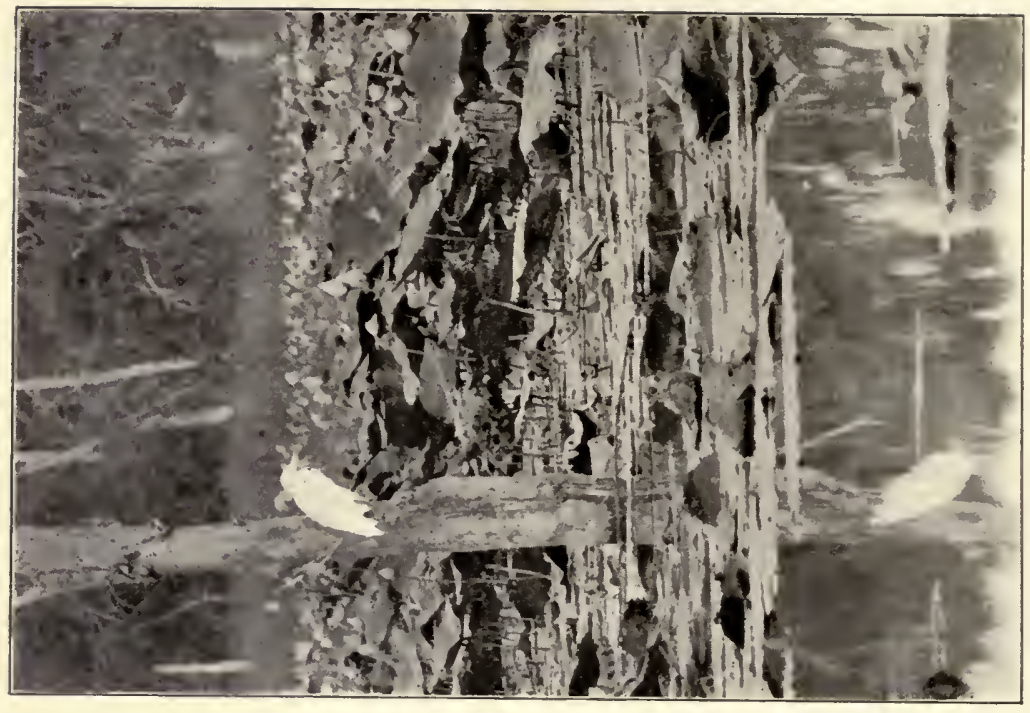



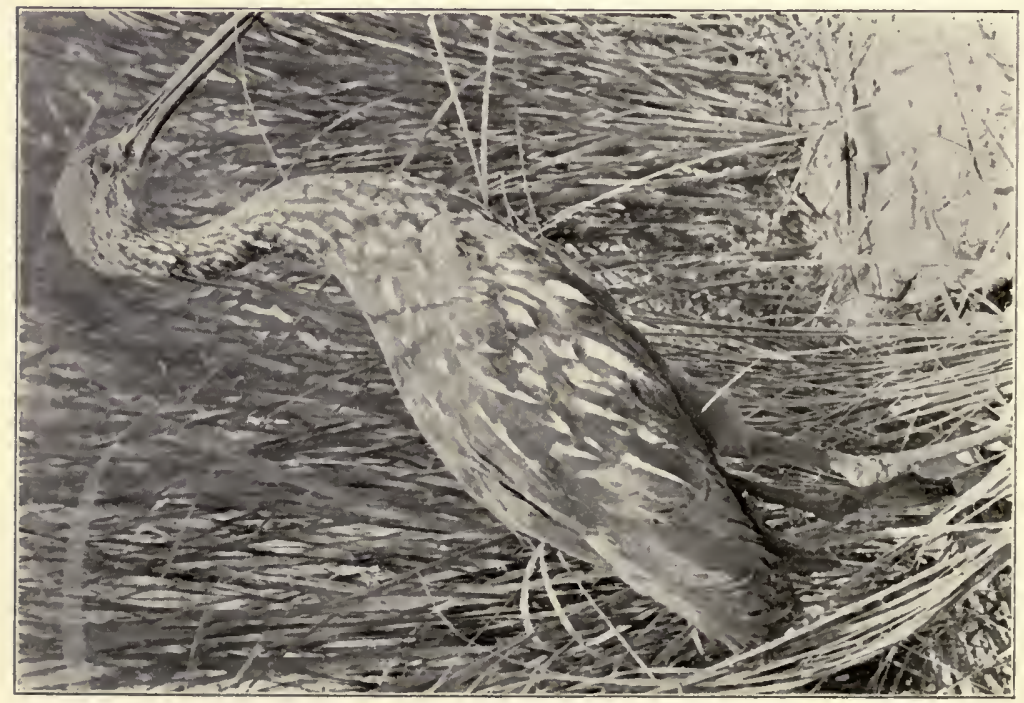




\section{$\mathrm{X}$}

\section{Laughing Gull; Black-Headed Gull}

58. Larus atricilla (Linn.)

This beautiful and noisy Black-headed Gull is found all over temperate North America. Its breeding range is practically confined to the coast of the Gulf of Mexico and the South Atlantic Ocean.

Laughing Gulls congregate in vast numbers during the breeding season. Their nests are built on the ground and are constructed of coarse sea-grass and weeds. The eggs are usually three in number and are of an olive shade mixed with splotches of brown. The bird is about sixteen inches long. The name, Laughing Gull, was given it because of its peculiar and persistent laughter-like call.

This Gull is marked by a black head, the black extending farther on the chin and throat than on the nape. There is a white spot back of the eye. The general marking is whitish, the mantle grayish. The outer six primaries are black with white tips; the bill, eyes and feet are carmine. The Franklin, Bonaparte and Laughing Gull are marked somewhát similarly.

While I was working on an island in the Laguna de la Madre, in the last weeks in May, the vast throng of these feathered hosts began to arrive. They at once got busy building nests on the ground. A few days later great numbers of Royal and Cabot Terns made their appearance. The island was now covered with an evermoving mass of feathers and the air was full of mingled screams and laughter.

The Terns pre-empted the sandy, shell-strewn beaches, while the Laughing Gulls preferred the grassy stretches between the many little brackish, sulphurated gas-charged pools.

I found hundreds of nests scattered all through the grass. In fact, I had to be ever on the alert to keep from stepping on the eggs. Most of the nests contained three brownish ones, but there were no young birds in any 
of the nests. The breeding birds did not manifest much fear, as they were constantly flying around me and hovering near my head. I repeatedly walked within a few feet of a Gull, while it stood knee-deep in a brackish little pool, complacently viewing the intruder. (Fig. 13.) As I walked across the island hundreds of these birds arose a few feet or yards in front of me, circled and dropped into the grass as soon as I passed. In numbers, like those of a great grasshopper pestilence, they seemed to spring from every blade of grass. Such a laughing chorus one will rarely hear elsewhere. I could scarcely hear my own voice, so loud and constant was the screaming laughter about my head. This noise was truly a great treat to the ears of an ornithologist. 


\section{XI}

Least Tern; Sea Swallow

74. Sterna antillarum

This is the smallest of the Terns and is popularly known as the Sea Swallow. Having once seen the bird, with its trim wings and forked tail, in flight, one can readily see the resemblance to a Swallow. The upper surface of the Least Tern is of a delicate pearl gray. The bird has a black cap, and is pure white on its under surface; it shows much docility in disposition, when not disturbed, and its ferocity in protesting your presence in its nesting domain is equally marked.

These Terns nest over a large area of the United States, and are about nine inches long, or the same size as the Robin. Their bills are tipped with black, and led me, when I first saw one, to believe, as it flew over me, that it was carrying a small mollusk.

The nest of the Sea Swallow is like that of the Black Skimmer and many other shore birds, being simply a depression in the sandy beach or a broken shell heap above high tide. Most of the nests I have found have contained only two eggs. (Fig. 14.) The nest is made in an isolated locality away from those of other Terns and Gulls. The eggs are of a whitish-brown, with minute chocolate-colored specks all over the surface.

These birds feed from a height, from which, as soon as they have discovered it, they hover over a school of minnows, which they capture, not by diving like the Pelican, but by a skimming process with the bill barely touching the water.

While I was walking along the shore of the Laguna de la Madre, on the Texas Gulf Coast, two of these graceful Terns flew over my head, screaming as if they were being tortured by some unseen hand. It was in their nesting season and I understood the meaning of all their noise and confusion-I was near their nest; they were protesting against the intrusion on their shell-strewn, 


\section{BIRDS}

sandy nesting beach. I looked for an hour before I located the nest, with its two brownish chocolate-spotted eggs. All the while the birds were screaming and darting at my head and kept it up until I had made the picture and taken my departure.

They are beautiful little birds and are on the verge of shameful extermination, through the demands of our fair sex for hat and other decorations. Mr. T. Gilbert Pearson, President of the National Audubon Societies, says :

"The beauty of plumage, the ease with which they might be killed and their vast numbers all contributed to their popularity with the feather trade, and during the eighties, before the Audubon work became effective, their slaughter constituted one of the blotches on our American life, ten thousand being taken on Cobb Island in one season."

These birds are now under United States protection, and are said to be on the increase. 


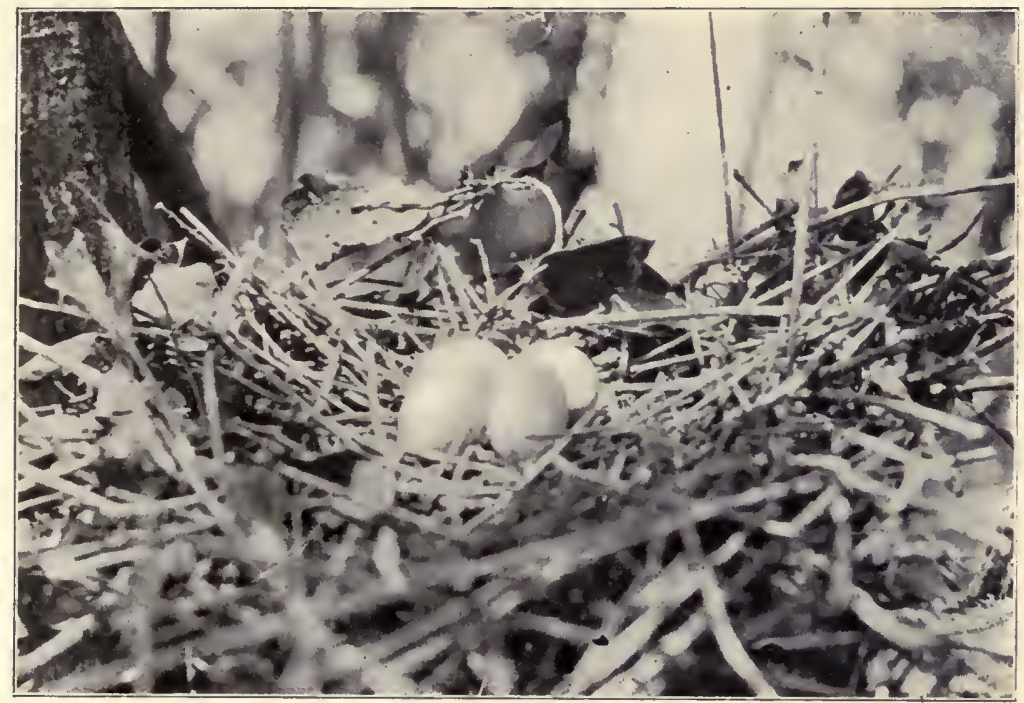

Fig. 33. LITTLE BLUE HERON NEST AND EGGS

(page 89)

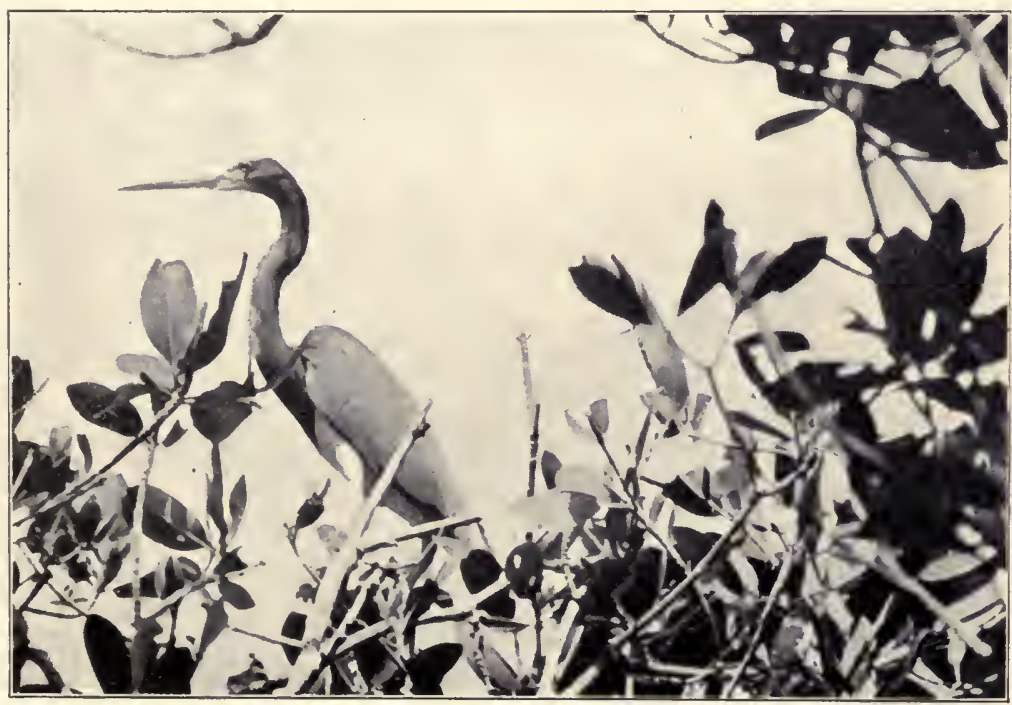

Fig. 34. LOUISIANA HERON 


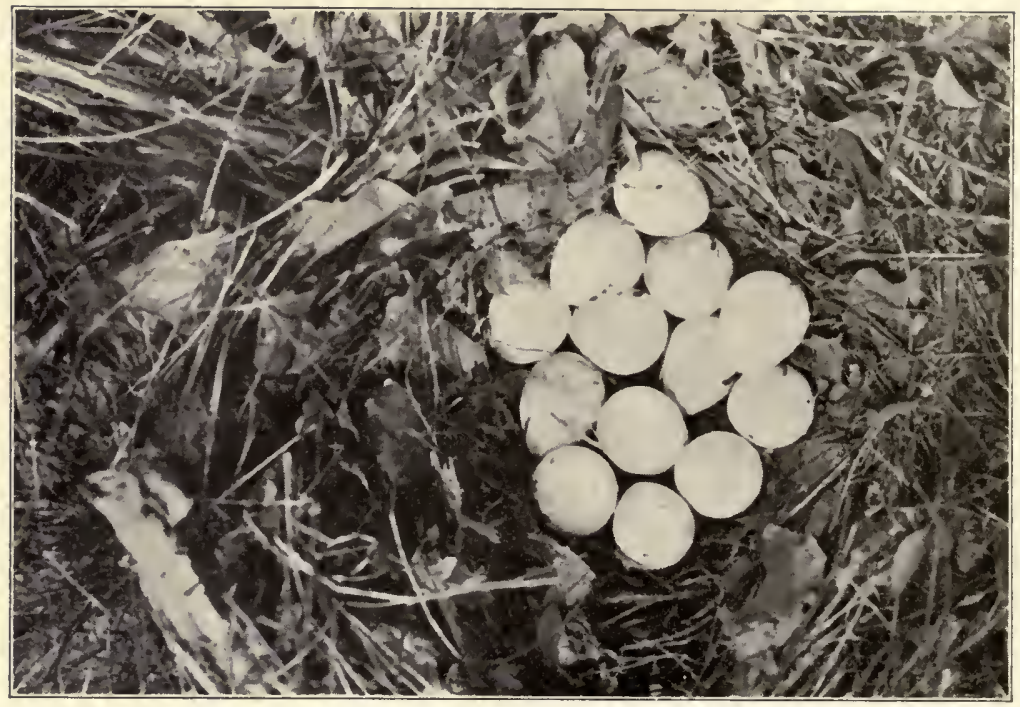



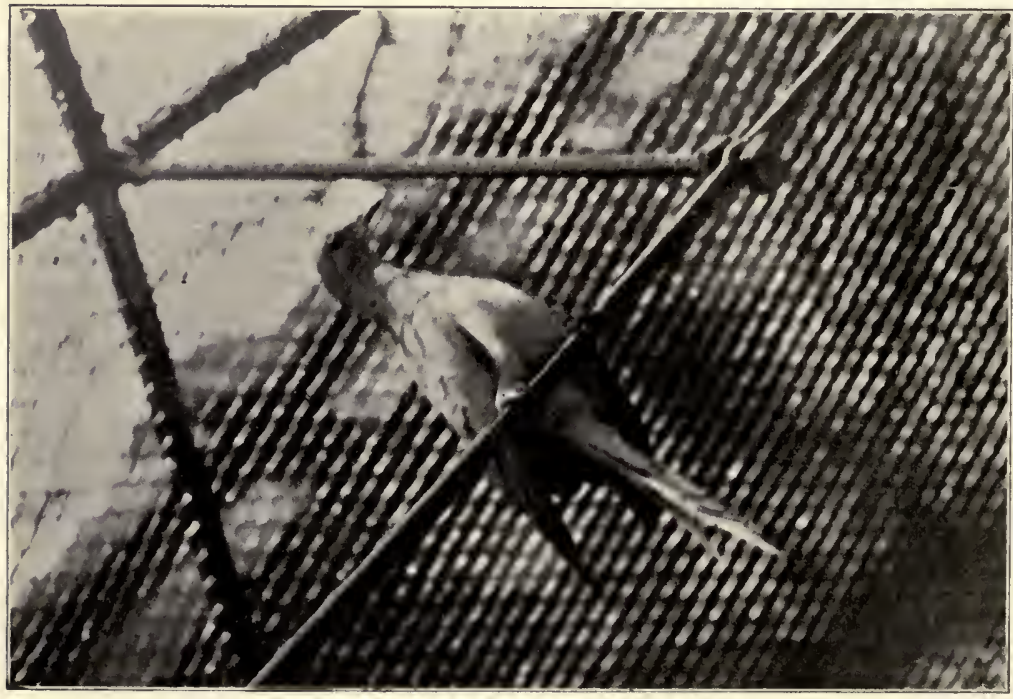

Z 


\section{XII}

\section{Black Skimmer; Scissor-Bill; Cut-Water \\ 80. Rynchopsnigra}

This freakish-looking bird is marked by a black back, white outer tail feathers and belly, and under mandible an inch or more longer than the upper; its lower bill, legs and feet are bright carmine. It is about nineteen inches long and its nest is a rounded excavation made by the bird's moulding its body into the yielding sand. Four cream-colored eggs with dark brown splotches are laid in the sand spit. A barren sand spit is selected for a nesting site. (Fig. 15.)

The Black Skimmer is strictly maritime and is rather abundant along the Florida and Texas gulf coastline, breeding in large numbers near Corpus Christi, on the low, sandy beaches in the Laguna de la Madre. The bird is a typical migrant, appearing along our southern coast in May and breeding in colonies.

Chapman, in his admirable description of the Black Skimmer, says: "On Cobb's Island, when the nests were reached, the uproar increased and with it the excitement and boldness of the particular bird whose eggs or nest I chanced to be standing near." They repeatedly charged him.

The early ornithologist maintained that these birds incubate only during the night and in stormy weather. This has been proved to be a mistake, as both birds have repeatedly been seen on the nest at all hours of the day or night. They have a harsh voice of a scolding character. As they feed they skim along the shoreline, the lower mandible plowing a furrow through the shallow water, the mouth open to pick up surface minnows and other edible things, as small crabs and crustaceous denizens of the seashore.

One day in March, while bird-picturing along a sandy beach of Tampa Bay, Florida, I discovered a flock of one hundred or more of these remarkable and unusual look- 
ing birds, standing on a partly submerged spit. They were all facing one way and with their freakish-looking bills and definite black, white and red coloring, presented an unusual and interesting picture. After careful stalking, I got within picture range and secured a fair photograph of the group. I met this bird on more intimate terms in the Laguna de la Madre two years later, near Corpus Christi, Texas. 


\section{XIII}

Snake-BIrd; Darter; Water Turkey; Anhinga 118. Anhinga anhingá (Linn.)

This bird is a native of the tropics and semi-tropics of most countries of the earth. Having once seen it in the water, with its small head and waving neck, one can easily understand why it is often called "Snake-bird." Then, when the same bird is perched awkwardly in the top of a dead tree or on the high limbs of a tall cypress, its fan-shaped tail, ladder-bar black markings and wings with black and white bars, make its resemblance to a Wild Turkey truly striking; hence the name, "Water Turkey." Its torpedo-shaped body and the wonderful webbing of its front and back toes make the Anhinga one of the fastest diving birds. It is said to pursue and capture fish under the water by its rapid swimming, using its wings to increase its speed, but of the truth of this statement I am in doubt, as the bird's wings are large and not shaped for use under water. However, a fish once within the grasp of its long, sharp, backward, serrated, teeth-like bill has indeed very little chance of escape.

Of all birds with which I am acquainted this one presents the most varied coloring. Joseph of old, with his coat of many colors, had nothing on the Anhinga, with its mane of black feathers and side plumes of purple and whitish-brown; its breast of fawn-color with a rich chestnut border, and its back feathers of brown with edges and centers of black; its neck of grayish-brown to reddish, iris red, its bill yellow with green edges, the bare skin about its eyes livid green, its nucal sac yellow and its feet olive or yellow with black claws.

The parental instinct is very strong in these big birds while incubating and rearing their offspring. The young require much protection from the cold rains at night and from the mid-day heat of the burning tropical sun. The female is often seen standing over the nest 
with wings half drooping and feet far apart, head erect and mouth open, panting for breath, while the young lie snugly placed in the cool shadow of the parent bird's body, fresh from the water. It was during one of these brooding periods that I secured my best picture of the Snake-bird.

The nest is composed of coarse sticks and is a large, compactly built structure, placed, usually, from ten to fifteen feet over the water. The number of eggs is from two to four. The full-grown bird measures about thirtysix inches.

It was while photographing in the big bird rookeries of Florida that I found my first Snake-bird's nest, which was located twenty feet from the water in a mangrove tree. In order to photograph the birds at close range it was necessary for me to devise some method of steadying the ever-moving treetop and anchoring my camera close to the nest. This I did by running many ropes from one tree to another, until I had the swaying boughs snugly fastened. Then I left the camera, or rather the focusing cloth, for three days at the point where $I$ had decided to anchor the camera. When the birds had ceased to take notice of it I securely fastened my camera in position and tied the focusing cloth over it, focused sharply on the spot which the old bird occupied while feeding and brooding. Then I dropped a fishing line to the ground and trailed it one hundred feet into the mangrove and palmetto snake-ridden swamp. Returning to the tree, I climbed to the camera and set the shutter at 1/25 second with an F.8 diaphragm opening, after which I went back to my muddy hiding-spot to await the return of the old birds. It was then that I was enabled to make my first Snake-bird picture.

The old birds, craning their necks from the tops of the tall trees four hundred yards away, had been watching my every movement; they now began to rush backwards and forwards over the nest-site, their heads turned sidewise. After several skirmishing flights the female lighted in the mangrove near the nest and remained perfectly quiet for half an hour. She then moved down the limb toward the begging young, until she was within two feet of the nest, but out of focus-and in this posi- 
tion she tantalizingly remained for two long hours. All of that time I was cramped up in my palmetto blind with the villainous mosquitoes taking every advantage of my enforced non-combative attitude toward them. With my fish line grasped expectantly in wait for a proper position of the bird, I passed those two hours under a nervous tension rarely experienced, even on some of $\mathrm{my}$ big game hunts.

During the prolonged absence of the parent birds, caused by the presence of the focusing cloth, the young kept up a most persistent "skeek, skeek, skeek!" waving their snake-like necks, while their gular sacs oscillated with the rapidity of an electric buzzer. With the old birds within a few feet of the nest the pleadings and begging were pathetic. This continued until the old birds responded by feeding the young.

The Snake-bird comes in with the blustering noise of a Wild Turkey, lighting awkwardly and making a great noise with its wings, while its actual perching is ungainly and clumsy to a marked degree.

Every day as I approached the nest tree, the old birds flew a few hundred yards away from me, then suddenly wheeled about and at great speed returned, passing over me and repeating their rapid flights, each time rising higher than before, until they were several hundred feet high, when they soared in vast circles, with outspread wings, all the while ascending until they became mere circling specks of black in the dome of the sky.

Now, after I had concealed myself for a short time, they came tumbling back, without any preliminary skirmishes, and landed in the tops of the mangrove trees near the nests. Thence, with much fuss, they waddled down the limbs toward their long-necked, pleading young.

The male, as he approached the nest containing the young, presented a formidable appearance, with his jetblack rigid neck, his bristling plumage and open mouth, all the while producing sounds like the striking of two pebbles together, alternating with sounds like the squeaking of a new leather riding saddle. The female was far more tractable, in both appearance and action. The male reminded me of a maddened baboon with all his hair turned the wrong way. (Fig. 16. Frontispiece.) 
The female finally reached the nest, and from the instant of perching to the time she settled by the side of the two ugly, leathery-looking. young birds, her attitude was one of extreme caution and suspicion, as the camera was tied to the tree within six feet of the nest. The male put in his appearance with a great bluster of apparent courage, lighting within two feet of the female.

With their snaky necks craning and waving in all directions, their rat-like eyes searching every nook and cranny for possible enemies or suspicious dangerous movements, while their acute hearing gave an alarm at the snapping of every twig, each seemed to await the advance of the other. First one and then the other, with cautious and awkward waddles, went down the limb leading to the nest, all the while giving vent in protesting Anhinga to disapproval of the presence of that black something with the big, staring, glass eye too near the domicile.

The female, after reaching the nest, spread her wings so as to protect the young from the glare of the sun. First one young bird and then another received a portion of pre-digested food from the mother's beak, the mother all the while keeping the young in the shade, without letting her body touch them. I watched this performance for several minutes with unbounded interest before I pulled the line on the camera shutter and made my first Anhinga photograph. Then the tired, muddy, patient and anxious camera man folded his tent, so to speak, and hiked to other parts of the rookery.

Although I lived in doubting anticipation of the result of my efforts, I was sure that the light conditions and time of exposure were correct and that proved to be the case, as the frontispiece in this book testifies.

Many a naturalist has spent weeks in the vicinity of the nesting site of the Snake-bird without securing a good picture. (Fig. 17.) My own pictures were obtained after much painstaking effort and patience. "The Brooding Anhinga" is probably the best photograph ever made of this shy bird. In the grouping is contained a complete record of the household doing of the Anhinga nursery. The brooding attitude of the mother, the plead- 
ing of the one hungry young bird, the satisfied composure of the one last fed is plainly shown.

I have never made a bird picture that required more caution or greater patience than this one, but it is worth all it cost me. 


\section{XIV}

Cormorant: Nigger Goose

121. Phalacrocorax dilophus floridanus

This big black bird is about thirty inches long and is easily identified if one will only remember that no other water bird resembles it closely, save the Water Turkey, or Anhinga. The Cormorant is sometimes incorrectly called "Water Turkey."

The Double Crested Cormorant is the bird usually seen passing through the central part of the United States to its northern nesting grounds, while the other variety is found in the great rookeries along the Gulf coast.

While on a hunting trip to Kodiak Island, Alaska, I frequently saw at close range specimens of the Redfaced Cormorant, and of the Violet Shag, the largest of the family. They are beautiful birds with richly iridescent greenish plumage. All of this family fish either from the surface or from a perch on a rock or post. They do not dive, like the Brown Pelican and Kingfisher, from a height while flying over the water. With their great strength of body and rapid swimming ability these big birds pursue and capture fish as they dart through the water, and the fish have little chance of escape when once captured by their hooked, serrated bills which, with their dilatable gular sacs, can swallow a fish a foot long, a pound in weight, and larger than the neck of the birds. (Fig. 18.)

I spent a part of several days in a Cormorant rookery on an island in the Gulf of Mexico, off the west coast of Florida. This rookery, with its closely and roughly built nests of coarse sticks, reminded me of a vast hive of giant, black-feathered bees. So closely packed were the nests in some of the live oak trees that their sides overlapped. In an area of twenty by thirty feet I pictured sixty-two nests, all occupied by young Cormorants. Just imagine a spectator's predicament under- 


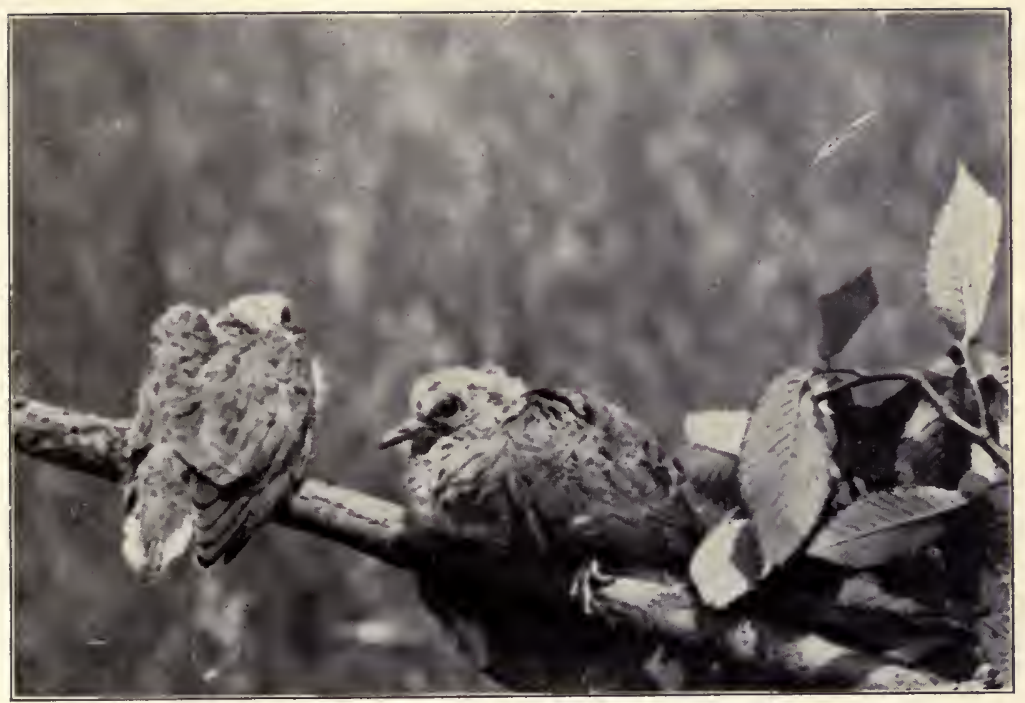

Fig. 37. MOURNING DOVES

(page 97)

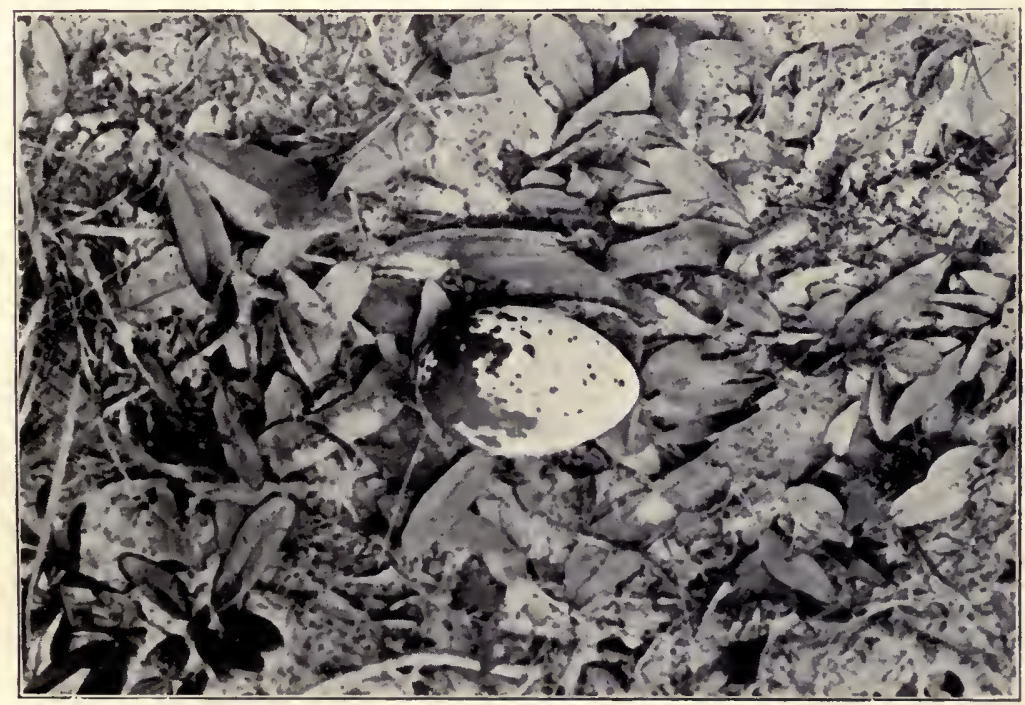

Fig. 38. BLACK VULTURE'S NEST AND EGG

(page 99) 


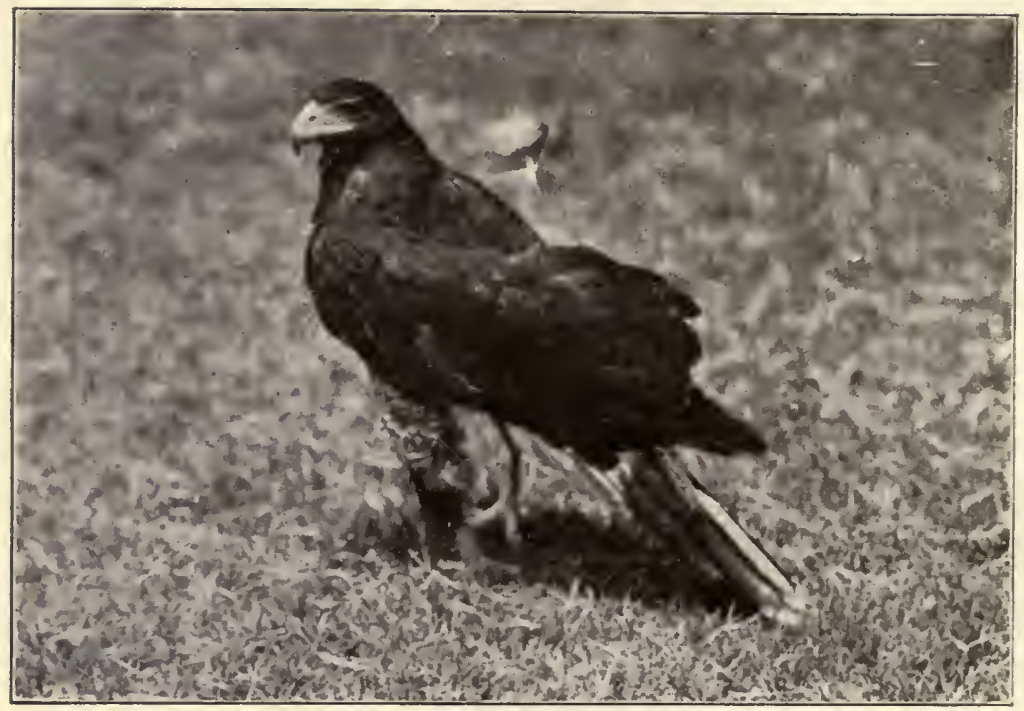

Fig. 39. HARRIS HAWK

(page 102)

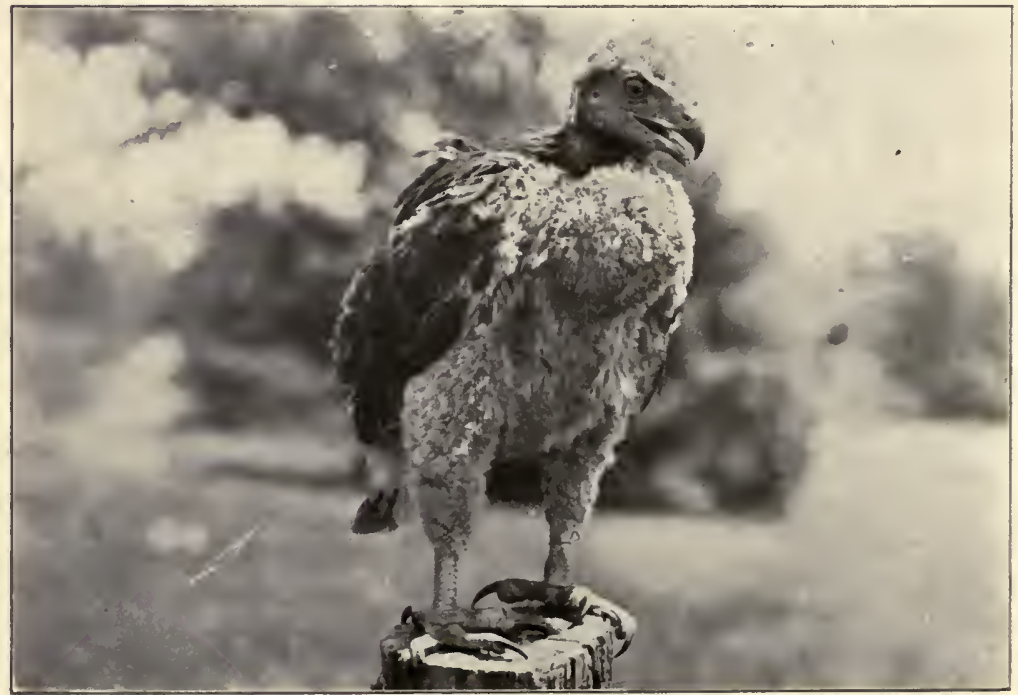

Fig. 40. GOLDEN EAGLE

(page 102) 
neath one of these trees! It was no place for a full-dress suit and a plug hat. Of all the bird rookeries, that of the Cormorant is undoubtedly the filthiest. It reeks in filth; the ground beneath is moist and muddy, and is covered with excrement and partly digested and decayed fish, while all around are scattered the mouldering bodies of dead birds that have either died in the nest and been pushed out, or have fallen and been killed by the fall, or have starved to death after falling, since the old birds do not come to the ground to feed the fallen young. The trees are thoroughly calcimined and myriads of small red bird-lice are to be found on every leaf or floating in the air. Add to all this the dense foliage and prisonlike bars of mangrove bordering the water's edge of the island, the mosquitoes with rapacious appetites and the humid atmosphere and you have some idea of the abundance of the inducements offered one to stay away from these rookeries and let the birds enjoy to their fullest their freedom and home comforts.

I have seen an old bird disgorge a fish ten or twelve inches long-one that must weigh fully a pound-into a nest beside the young and then depart, as if to say, "There you are! Help yourself!" That, however, is a task not always easily accomplished by the young birds; hence every few minutes a big juicy fish finds its way to the ground. This must account for the number of Mano-war birds that I saw sitting on the edge of the Cormorants' nests, for the Man-0-war birds are great flyers and secure their food by attacking other birds and taking their meal from them. Evidently, the long-winged birds were eating the disgorged fish by the side of the young Cormorants. (Fig. 22.)

The old Cormorants, in a moment of surprise or excitement, will divide their last meal with the man under the tree, with reckless disregard of the features of the visitor and his wearing apparel. I can testify to the fact. The last day I put in at this rookery I was forced to wade into the Gulf of Mexico and launder my outer and under clothing before I was in a fit condition to return to civilization or could be passed on favorably by the Board of Health. 


\section{XV}

\section{American Brown Pelican 126. Pelicanus fuscus}

This remarkable-looking big water bird, with its bill several times the length of its head and a "dip net" holding a gallon attached to the under side of its bill, is represented in the United States by two varieties of sub-genus, the White Pelican and its lesser brother, the Brown Pelican. Both are fish eaters, the Brown securing its fish by diving from a height into a school of surface-swimming minnows. The White Pelican, the skin of which is filled with air cells, cannot dive but must patiently wait for its food supply to come within reach of its beak, to be scooped up by a quick stroke, the wideopen bill and sac forming a semi-vacuum into which fishladen water rushes. With a rapid closure the fish are imprisoned, while the water is gradually forced from the sac along the edges of the bill; then the fish are swallowed.

The White Pelican is a bird of the middle and western United States; it breeds both along the seashore and along inland fresh water lakes, as in the Yellowstone and the Klamath lakes.

The Brown Pelican is maritime and abounds along the Gulf of Mexico from the Rio Grande to Key West and up the Atlantic shore to South Carolina. Both species are gregarious and gather in untold thousands in some localities, to breed. (Fig. 19.)

On beholding these awkward-looking birds as, with ministerial mien, they pose, seemingly for their pictures, one could hardly believe with what grace and ease they can soar to great heights and hover there for hours, with the facility of an Eagle or a Condor.

When a Brown Pelican discerns a school of Menhaden minnows near the surface it instantly strikes out after them with a Pelican scream, which every bird within hearing interprets as the call, "Dinner is now 
being served!" Down comes each to join in the feast, pitching from a height of thirty or more feet, headlong into the water, with open beak and breast, so hard and fast that it reminds one of a heavy stone tossed into the water from an equal height. When the bird rights itself it presents a ridiculous and comical picture as, with much seeming dignity, it gradually forces the water from the distended sac and tosses its head upward to swallow the imprisoned prey. If the fish is five or more inches long and turned tail downward the bird skilfully maneuvers until the head points toward its stomach before swallowing the victim.

All of this time you are amused to see one or more Gulls following in the wake of the feeding Pelicans and picking up the crumbs from the latter's table, or even alighting on the Pelicans' backs or heads, screaming, quarreling and begging for food, often actually seizing the tails of protruding fish from between the lightlyclasped bills of the Pelicans and holding on so persistently that the big birds, as if in disgust, relax their hold and seem to say: "Take it, you beggar. Thief!"

Birds that swim and dive for their food are all awkward and ugly on land, while those that wade are the emblems of poise and beauty, as personified in the Great Whooping Crane, and the Great Blue Heron.

One of the best known and most accessible large breeding places of the Brown Pelican is on Pelican Island, in the Indian River, on the east coast of Florida. (Fig. 20.) This island of only three acres is the breeding place each season for four thousand pairs of Pelicans. The general surface of the island is only three feet above the water line at the usual stage; therefore, a heavy rain with a strong wind from the north may flood the entire surface, except a little knoll on the eastern side of the island. A few years ago the island was studded with stunted mangrove trees, but at the time of my visit only two or three dead stumps remained.

The river at this point is about three miles wide, the 1sland being within half a mile of the eastern shoreline. A very rich deposit of guano makes up the surface of the island. I was told by someone while visiting in the vicinity that much of this guano had been removed and 
used for fertilizer on nearby farms. As to the truth of this I cannot vouch.

The island had been flooded a few days before my visit and thousands of eggs and destroyed nests were piled in promiscuous heaps at various points. Great numbers of the old birds were sitting on the water near the island in a most pensive and solemn mood, if one could judge from their actions and appearance. Some of the birds had taken to the nearby Long Island, separating the river from the Atlantic, and I could plainly see their white heads as they perched in the mangrove trees.

A few years ago the Pelicans tried to rear their young on Long Island but the mosquitoes were so bad that the birds had to abandon the venture, at the expense of thousands of young that were literally killed by the pests. Mosquitoes do not thrive or remain on the treeless, wind-blown and isolated small islands in the river; hence the tortured birds soon returned to their old haunts. These particular Pelican Island birds prefer terrestrial nest-sites, as was illustrated when they moved to the wooded island before mentioned, where most of the nests were built on the ground. (Fig. 21.)

On the west coast of Florida I have seen thousands of nests in trees and not a single one on the ground. I presume that if all the trees were removed the birds would gladly accept the new conditions and adopt the ground-nesting habit. One would suppose that this awkward big bird would have much difficulty in alighting, balancing and feeding its young from the small branches surrounding the arboreal nest-site, and such is the case; however, a very small percentage of the young birds wander far enough from the nest to fall to the ground or to be out of reach of the parent bird at meal-time.

I have, for hours, stood in my tent within twenty feet of fifteen Pelicans' nests, each containing two or three young birds, and watched the movements of the old ones while they were feeding the young, and I have never seen a nestling fail to get its rations. But I did see some dead young birds hanging in the trees and a very few on the ground, for the old birds do not go to the ground to feed fallen young. 

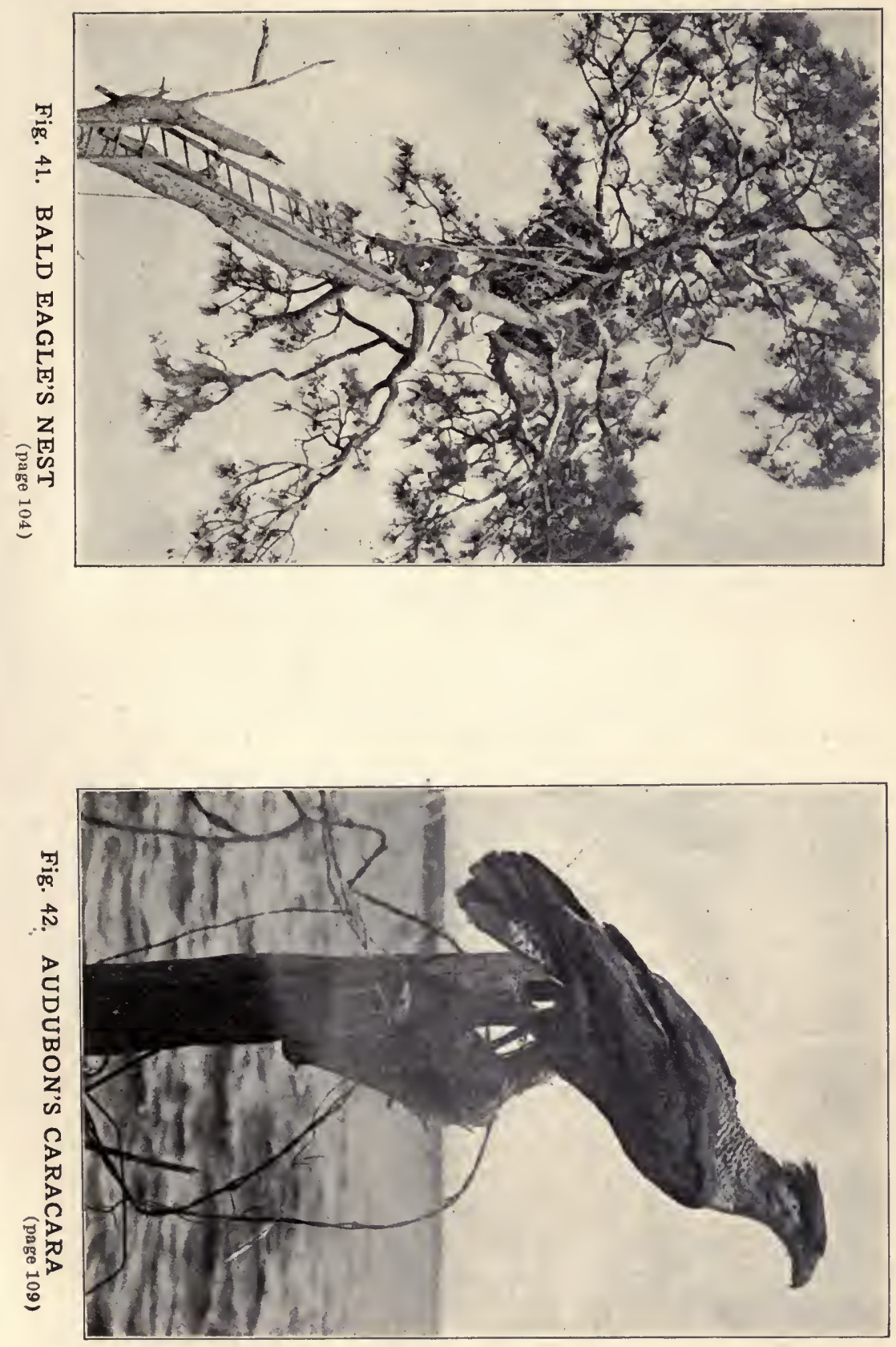


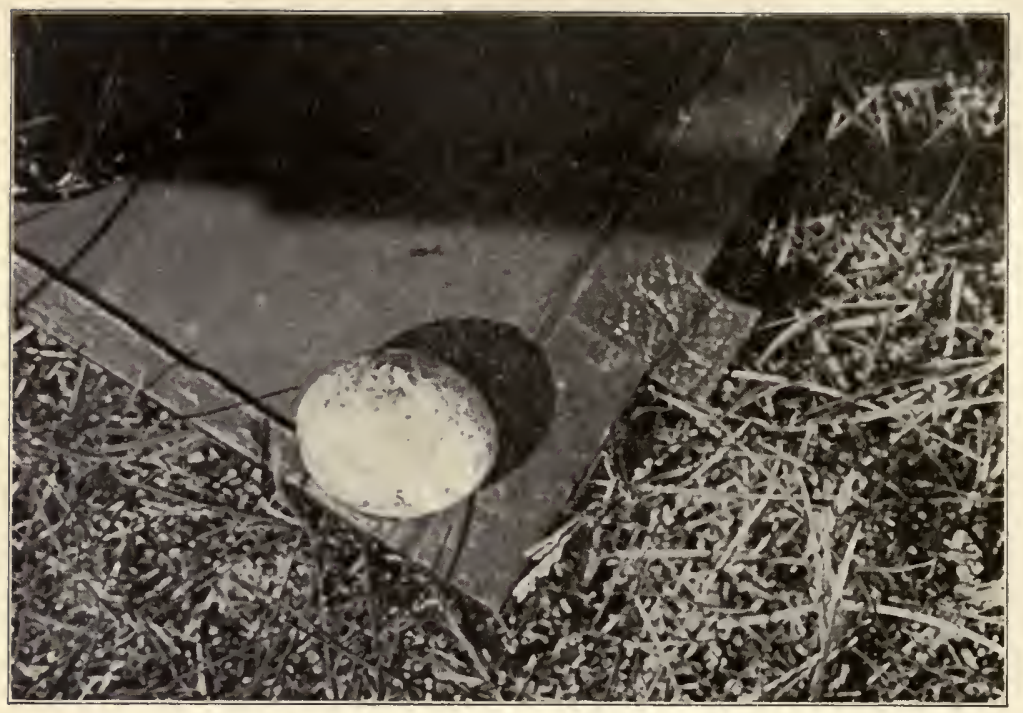

Fig. 43. SPARROW HAWK EGG

(page 107)

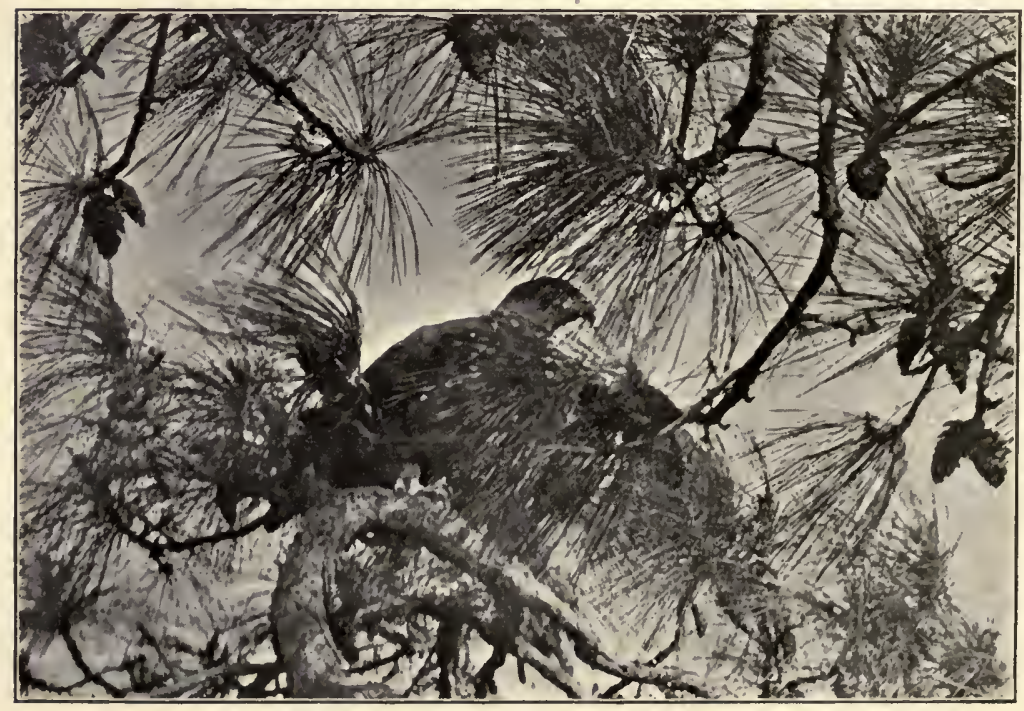

Fig. 44. BALD EAGLE YOUNG

(page 106) 
The Brown Pelicans soon accept man's presence as something not to be dreaded and become very tame. I have repeatedly had them, near the winter resorts in Florida, take food from my hand, or rather catch the food tossed to them, while within three feet of me. (Fig. 22.)

Fish Crows, large Gulls and mosquitoes are the principal enemies of the water-surrounded nest-sites of the rooking birds. Man is the only destroyer of living things who has no special motive save a selfish and useless one.

An additional handicap under which these birds labor in rearing their young on the ground is the habit of the full-grown young birds of devouring the less matured nestlings of their neighbors. The parent birds do not, as do our Robins and Wood Thrushes, show parental love and affection. Seemingly, home duties cease with the supplying of food.

Brown Pelicans are very ungainly in their efforts to pick anything from the ground, but their headlong diving is the very climax of grace and accuracy.

There does not appear to be any neighborly or friendly intercourse between the water birds that colonize at the breeding places. In fact, I witnessed many a fight between next door neighbors on Big Bird Island, in the Laguna de la Madre, when an over-zealous bird tried to steal a stick from the side walls of a neighbor's nest. A flock of breeding Pelicans undoubtedly devours large numbers of fish in a season, but from all reliable sources it is understood that their food consists of the unsavory Menhaden, or mullet. Far more than I relish a tasteless baked or fried mullet, I enjoy seeing a Pelican catch one. The birds are welcome to my share of these fish. 


\section{XVI}

\section{Roseate Spoonbill 188. Ajaja ajaja}

While viewing the surroundings on the first afternoon after my arrival on the shore of the Laguna de la Madre, I beheld a sight that would thrill any naturelover, especially an ornithologist. I saw approaching a rose-colored streak, like those of the rays of the setting sun on the top of a distant lofty mountain peak or cloud bank.

It was my first view of the Roseate Spoonbill, a bird once plentiful but now rarely seen on our coastline. There were twenty-three in this flock. I watched them with my glasses until they lighted on a sand spit a mile away, where I frequently observed them, afterward, as long as I remained in that vicinity.

A few miles west and south of this point, in Old Mexico, there is a large breeding ground occupied by these birds.

Like the Egrets, they have been killed for their beautiful-colored plumage, practically to the point of extermination. One view of this flock was more refreshing to me than to stand on a busy thoroughfare and watch a long parade of women wearing ornaments made from the feathers of the birds.

Even when they were two miles away, on a sandy beach, the beautiful rose-red line could be plainly seen. How I longed to be within photographing distance of them! I trust our United States bird-killing restrictions may become more firm and that the Roseate Spoonbills will return in large numbers to decorate our gulf shores, and not some fair lady's head-wear.

Late one morning I tried to get within picturing distance of this flock. When I had approached to within one hundred yards of them they took flight. I stood watching the procession, as with measured wing-beats it slowly made its way toward an island in the Gulf of Mexico. 
The setting sun, playing with rich, mellow rays on the big, roseate birds, made a picture of incomparable beauty. Enchanted by the sight I kept my eyes on the flock until the last glow of rose and gold had vanished in the distance. 


\section{XVII}

\section{White Ibis; Spanish Curlew 184. Guara alba}

With exception of the longest wing feathers, which are glossy black, the plumage of the White Ibis is a pure white. Its legs, feet, bill and bare face are orange red. The bill is sickle-shaped and is about six inches long; hence the resemblance to the Curlew and the popular name. The sexes are alike in color and the length of the bird is twenty-four inches; it is a permanent resident of the South Atlantic and Gulf states, rarely. visiting the Central United States, and breeds in communities along with other shore birds. The nest, placed a few feet from the ground, is composed of coarse twigs. The White Tbis lays from three to five chalky-white eggs, splotched with brown. (Fig. 23.) The feet of the birds are not webbed; hence they are poor swimmers, feeding on frogs, crayfish and other kinds of fish that are easily accessible.

These birds prefer to "rook" by themseles, but when their nests are disturbed will colonize with Herons, Anhingas and other birds of like species.

On one island in Florida I saw three thousand White Ibis' nests, and every nest had been robbed by the Fish Crows. The poor birds had finally abandoned the nesting place and sought new quarters with the Herons on another island a mile away. The villains-the Fish Crows-had followed and were flying over the rookery, looking for more nests to plunder. I repeatedly witnessed the act of robbing a nest. The black burglar would light nearby and sit there with its complaining "caw, caw!" waiting for the incubating or the laying bird to leave the nest; the instant this occurred the Crow would hop or light on the edge of the nest and proceed to peck holes in the eggs and suck them dry, or, as was the case in some instances, deliberately throw two or three eggs out of the nest on the ground, and fly away 
with one in its thieving bill. Not a protest was offered by the Ibis or Herons, while they sat quietly near and saw their homes pillaged by the renegades. There should be a special bounty placed on the scalp of the Fish Crow by the states where it thrives from its ill-gotten gains.

On nearing a rookery, one day, I saw a great fluttering of white wings in a mangrove tree. On going nearer, I found that a White Ibis had by some means caught its foot in the fork of a small limb and was dangling head downward. I released the bird but its leg was badly fractured. The bones were protruding from the lacerated flesh and skin. Here I brought to bear my professional skill, by anaesthetizing the bird, amputating its leg and fixing it up, surgically speaking. I then made a close-up photograph of its long, decurved, sickle-shaped bill and turned the bird loose. (Fig. 24.) Six months later, I received a letter from Mr. Ashburner, the warden, telling me that my one-legged patient was, to all appearance, well and thriving. Because of the habit these birds have of resting on one leg, let it be hoped that my patient will manage to get along, in the years to come, with its remaining support. 


\section{XVIII}

\section{Great Blue Heron; Blue Crane 194. Ardea herodias}

The Great Blue Heron has a wide range and breeds over the same territory, usually nesting in tall trees, but often on the ground, and laying from three to six dull greenish-blue eggs. It is a bird forty-two inches long, and is found in flocks only at the nesting sites. The male and female divide household duties and are mated for the season; they fight faithfully for their home rights, and are patient, accurate and quiet fishers.

The nest is a piece of coarse, rickety architecture. No lichen upholstery is put into this nursery and no burnishing of the wicker-work outer walls is found.

While working in a Cormorant rookery in the Gulf of Mexico, off the coast of Florida, one hot May day, I discovered, much to my surprise, a full-grown Blue Heron perched on top of a dead tree stump thirty feet from the ground and almost directly over me. (Fig. 25.) It was posed as gracefully as any etching on a bronze vase, and its seeming indifference to my approach led me to conclude that it was a young bird. However, it was an old bird that was taking a much-needed rest after the morning meal had been served. I had made no effort at secret approach or stalking, and I was heavily loaded with a Graflex and a $4 \times 5$ plate camera, extra lenses and a carrying case filled with loaded plate-holders and a tripod. I deliberately deposited my load in a selected dry spot, set up my tripod, mounted the long bellows camera, carefully focused on the bird statuary and made two exposures of three seconds each. I used an Adon telephoto lens. All this time the bird was practically motionless. Finally I decided I wanted a different pose, so I called up to the Heron to change its position, whereupon, much to my surprise and chagrin, it deliberately straightened its neck to full length, gave one beat with 
its powerful wings and then, with beautifully curved neck and extended rudder-like legs, flew away.

It is indeed a rare opportunity for the bird photographer to have such good luck as to have a full-grown Blue Heron pose for its picture within thirty feet of the camera. On looking for the source of attraction I discovered, within ten feet of the dead tree, a large openwork nest, and sitting in it a full-grown young Big Blue Heron, fully feathered, but with weak legs and untried wings. To secure a good picture of the young in the top of the wind-blown mangrove, surrounded, as it was, with green leaves, was impossible. I decided to climb the tree and bring the bird to the ground, picture it there and return it to its perch.

I climbed the fresh guano-frescoed tree to within reach of the bird, but $I$ soon found that a four-inch bill projected two feet with the power and rapidity of an arrow was something to be reckoned with, when holding to a waving tree with one hand and reaching for a long shinbone of a young Great Blue Heron with the other.

I persisted in my efforts but each time I thought I could secure a hold the young bird climbed a little farther out on the limb, until I could go no farther; then down the tree I climbed, or slid, and up another I went. Each time the bird kept beyond my reach. I finally secured a ten-foot pole to which I fastened a loop of soft twine, and by this method I was able to bring the young bird to the ground without injury and photograph it. It fought to the last trench and I returned it to the perch temperamentally unconquered, but photographed.

While on a trip to the Laguna de la Madre, near Corpus Christi, I heard of a Big Blue Heron breeding rookery a few miles back in shore. (Fig. 26.) Taking my bird tent, two cameras, tripod and field glasses, I struck out to work my way to the place. That part of the Texas gulf shoreline had been under the awful tidal wave of two years before. Driftwood and sea-weed were piled everywhere on the ground and in the mesquite trees, many of which had been killed by the salt water. Dead mesquite trees are just about as unyielding as barbed wire entanglements. Add to this many bunches of cacti with the probability of a Texas diamond-backed rattle- 
snake being hidden under a cactus and ready to strike at any time, and you have an idea of the many pleasures one must miss, as he worms his passage two or three miles through this mess.

My bird enthusiasm and clothing were somewhat dampened long before I heard, smelled or saw the breeding grounds. I arrived at last with my skin and clothing somewhat the worse for wear, but my enthusiasm was renewed as soon as I beheld the size of the rookery and the number of its inhabitants. There were about three hundred big waders nesting in the tops of the low mesquite trees. Many of the nests were empty, as the young had grown to the size of full-grown birds and were away, feeding in the lagoons. Others, full-grown young, were in the nests. At my approach, the old birds arose from every treetop while many of the young began screaming from fright and others kept on begging for food. The old birds, with folded necks and outstretched legs, were flying in confusion over my head, dropping a chalk line at every post and disgorging partly-digested catfish or mullet at every turn.

There were three young birds in most of the nests, and three fresh eggs in those of incubating birds. One youngster had a wing off at the elbow but was perfectly well and active. Near the rookery I saw a Large White Heron associating with the Big Blues. A Mr. Watson, living near the rookery, told me that this white bird was often in the blue rookery, and had been visiting there four years. It was very wild and hard to approach. This was probably a hybrid or an albino phase of the Big Blue.

I found one full-grown bird dead, hanging head down, with a foot grasping a limb in a death grip. These birds are good climbers and will return to the nest if by chance they should tumble to the ground.

I selected a nest with three young in it, located favorably for picturing, and erecting the umbrella tent within fifteen feet of the spot I entered the hot-air prison to await the return of the old birds.

While the sun was streaming its torrid rays, the three little Herons, with pulsating gular sacs and perspiration in great drops dripping from their yellow and black bills, patiently awaited the return of the food-pro- 
viding parents. The sight of the latter was the signal for great commotion on the part of the young, who, with craning necks and a "kek, kek, kek!" rapidly repeated, made wild rushes about the nest.

With great wing expanse the immense and handsome parent birds floated on the air currents, as they drew near the nest, and alighted gracefully and gently as a falling autumn leaf. Their departure was of equal charm and free from winged noise. In fact, were it not for the excited, hungry pleadings of the young, as the parents approached, the old birds could have come to the nest and departed without being heard by one concealed within ten feet of it. $\mathrm{He}$ who has never had a close-up view of a Big Blue Heron, except in a glass museum case, or behind the wire netting of a park aviary, can form no idea of the real beauty of the big and graceful birds until he comes in contact with them during the rearing of the young. While standing on the edge of the nest with its three full-grown young birds around it, the parent Heron presents a picture of statuesque beauty beheld in no other bird that I have seen. (Fig. 27.) With its plumecrested head and rapier-like bill, its streaming nuptial breast plumes, its graceful neck, trim legs, and shapely body silhouetted against a sky of pure azure, this bird stands out sharply like a clear-cut medallion by a master of his art. However, when the actual feeding process is in full action all graceful lines are broken into a confused mass of fluttering wings and jumbling beaks, mixed with what appears to be the agony of death from strangulation, and the performance looks like a wrestling match with no holds barred.

The full-grown young birds are unable to fly after a hearty meal of two pounds of mullet, but they often, in a moment of excitement and fear, disgorge the partly. digested fish and thus lightened of their load of ballast, make an awkward but sure getaway. It is not unusual for such young birds to donate their last meal of partly digested fish to the visitor beneath the nest tree.

These Texas birds were the Wards Heron, a little larger than the usual run of Big Herons, and measuring forty-eight inches, while the ordinary Big Blue Heron measures forty-two inches. 


\section{XIX}

Snowy Heron; Little White Egret; Bonnet Martyr 197. Egretta candidissima

This pure white bird is about twenty-four inches long and is marked by beautiful crest and back feathers during the breeding period. The eyes and toes of the Snowy Heron are yellow; the bill is yellow at the base and black the rest of the way; the lower part of the black legs are also yellow; the claws are black. The bird is a permanent resident of the Southern United States, on the Gulf and Atlantic sides of Florida, occasionally wandering into the central states during August. It lays from three to five eggs of a bluish color. The nest is a rather poor specimen of a bird's home, built of coarse sticks and located five or more feet from the ground. These birds breed in communities; since they are generally recognized as the birds furnishing plumes for the milliners, these Herons are popularly known as the "Bonnet Martyrs." (Fig. 28.)

With its dorsal train and decomposed crest of head feathers and general plumage of the purest white, this little Heron symbolizes innocence and purity. So pure is the white of the bird's plumage that against the blue of the Florida midday sky it is almost lost to view because of its blending with the actinic rays. It is, therefore, difficult to make a good picture of the bird.

The Snowy Herons have been hounded from island to island by plume hunters. The birds were on the verge of extinction, at one time; however, by a rigid enforcement of the laws protecting them, they are now on the increase. Of Florida's assets these birds are high in the list.

Within my umbrella tent, with the Herons all round me, I had ample opportunities to study their every trait while nesting.

Once, two tiny half-naked baby Herons stood on a limb within five feet of my tent, waiting patiently for the 
parents that never came; the young birds were doomed to death by starvation, while, in all probability, some woman who thinks more of pet cats and of feathers than of mother birds with starving babies, was displaying the nuptial and breeding plumes of the dead parents of these little Snowy Herons. (Fig. 29.) If no market were created by women wearing such plumes, there would be no incentive to hunt and destroy these birds during their breeding lives.

One female had evidently lost her mate. I photographed her frequently from the tent for several days. At no time did the male come to the nest to assist the little mother in appeasing the hunger of her two fledglings. I named her" The Young Widow Ardea Candidissima," and like all young widows she was the very essence of beauty and propriety. When she came to the nest to feed, her manners were those of a modest, solicitous, loving parent, whose thoughts were centered on the duty of caring for her brood. The feeding act was not one of a perfunctory character, performed because nature demanded it; it was done from a truly motherly instinct. As she approached the young her attitude was one of enthusiastic anticipation. Look how she clucks with glee, as she strolls down a nearby limb toward the nest, with its anxious, hungry babies, whose calls are always, "more, more, more!" (Fig. 30.) See how she displays her lovely nuptial plumage! How each delicate feather vibrates, like nothing else of which one can think! Shame on any woman whose vanity would create a market for this Heron's maternity garments! Just watch this bird as she gently steps upon the threshold of her brood! Her steps are queenly and dignified! Observe how she impartially distributes a little to this one and to that: no favors shown; all must be served alike. Even though the mother has fished all day in some distant shallow pond she must disgorge from her meager supply, food probably needed for her own sustenance.

On one occasion, a young bird had left the nest a few feet. The mother came, fed those that had remained in the nest, but refused to feed the disobedient one until it had returned. On another, after feeding, she caressed her brood, brushed her pearly white feathers until they 
were immaculately clean, posed for her picture, yawned a few times as though the tent and its occupant made her weary, then let herself down gently upon her brood, with her bosom of soft whiteness, and dropped to sleep -all this within six feet of me and my camera.

No theatre, with its dazzling electric-lighted splendor, its upholstery of the finest plush and its tapestries of high price, can, to my mind, be compared, for real enjoyment, to my bird tent in the days I spent in the mangrove swamp with these island actors.

If any of the young birds happen to be away from home, playing or visiting their neighbors, they make a bee-line for the nest the minute they hear the call, "Dinner is served!' If neighbors' children accompany them home, the outsiders are sure to be unceremoniously sent away, hungry, and with a good sound flogging from the feeding parent. Although the nests of other Herons are often within two feet of a feeding bird, the young make no effort to intrude or plead for what does not belong to them.

In the Gulf of Mexico, near the Mexican border, I saw these birds feeding along the shallow shore line. They have a peculiar way of doing a species of buck dancing, or scraping with their feet, to dislodge hidden food particles in the sandy or muddy bottom, then jumping three or four feet into the air, as if some invisible mollusk or crab had seized their toes and they were trying to shake the creature off. (Fig. 31.)

On a shooting preserve in Bates County, Missouri, there is a large swampy section of ground, covered with weeds of various kinds. This place is ideal for water birds, as myriads of small fish and frogs are to be found in its morasses. In August, 1921, I saw and pictured there six beautiful white Herons which remained about the body of water for six weeks. They were genuine Snowy Herons, and not Little Blues in the white phase. I made the pictures with the camera within sixty feet of the birds as they perched on the dead tree stumps in the water. I was told by the keeper that these birds come to the place yearly. I had studied and pictured these beautiful Little Herons in their homes on the islands in the Gulf of Mexico, and elsewhere, where they are found 


\section{SNOWY HERON}

in yearly increasing numbers since the Federal restrictions were placed on their being killed and on the wearing of their plumage, and I estimated that there was sufficient food in this one swamp for the sustenance of a thousand of these birds. 


\section{$\mathrm{XX}$}

Louistana Heron; Lady of the Waters; Louisiana Egret 199. Hydranassa tri-color ruficollis

The Louisiana Heron is slaty-black on its back and wings, with a whitish streak down the throat. It has a reddish crest and back of neck, white crest feathers, and some white on the rump. Long whitish feathers extend from the back over the tail. The bill in general is black; the feet are bluish-iris red.

This Heron is about twenty-six inches long and is found along our southern shore with other Herons, but is rarely seen far from the seashore. It has no plumes, except in the breeding period. The young do not have the juvenile white stage as the Little Blue Herons do. (Fig. 34.)

The nest and eggs of the Louisiana Heron are similar to those of the Snowy Heron. I have seen the homes of these two birds within three feet of one another, and the only way in which I could distinguish them apart was to see the rightful owner on its nest, or leaving or coming to it. The general habits of the two are so similar that no additional description is necessary. 


\section{$\mathrm{XXI}$}

\section{Little Blue Heron ; Little White Heron 200. Ardea caerulea (Linn.)}

This Heron is about twenty-four inches long and is of a general slate-bluish color, with a maroon-colored neck and head. The basal half of its upper bill is of a greenish black and the lower mandible is yellow. The nest is composed of sticks and a few leaves placed ten or more feet from the ground, frequently on limbs of the mangrove, overhanging the water. The Little Blue Heron lays four bluish-green eggs and breeds in vast numbers along with other Herons. In some instances it retains the juvenile white plumage up to or through the first breeding period, but there is no excuse for confusing it with the beautiful Snowy Heron. The general contour is different and the individual plumage does not look like that of the other Heron, except in general color; the actions about the nest are very different, and the color of the feet and bill of the two birds does not correspond. It is only necessary to come into close contact with both to differentiate, while the Little Blue Heron is in its juvenile white phase.

The Little Blue Heron is more restricted in its breeding range than the Great Blue Heron and is a diurnal feeder, roosting with large flocks of its kind and feeding near the shore of small lakes or shallow sloughs, being a patient fisher, but not so accurate as the Snowy Heron.

Near a rookery in Florida I witnessed a Little Blue building its nest of fine twigs, gathered from a burnedover area. Each twig was carefully selected from the dead limbs of the same bush, and was broken off and carried to the nest. The trips were made on an average of every seven minutes and the nest was completed and contained one egg at the end of forty-eight hours. (Fig. 33.)

The feeding note of these birds as they approach the nest is much like that of a guinea fowl; the fighting, or 
quarreling note resembles the scream of a parrot when it sees a dog coming around a corner toward its perch.

When the young birds have been fed the parent frequently stands by the nest for an hour or more, all the while uttering a contented note, much like that of a barnyard hen as she struts around the yard with her halfgrown brood following her. The owner of a nest near my tent had the habit of descending to the ground and eating bill after bill-full of the mud so abundant under the trees, continually dancing and jumping around as if enjoying the feast.

The actual act of feeding is, to say the least, a vicious and terrible affair. The parent bird stands by the nest in a seemingly indifferent mood, while the young are screaming and fighting for the best position. Each time the parent's bill is within reach, a young bird seizes it crosswise at the base and jerks violently, while there is much protesting noise from the other less fortunate youngsters. The old bird may, with stoical indifference, refuse to feed for some time, during which the young bird continues, with bull dog tenacity, to pull and jerk at the parent's beak, getting nearer and near to the tip. When the psychological moment for regurgitation arrives the partly digested fish is either forced down the throat of the nestling or, perchance, it may light on the interested photographer's head or camera outfit.

Such are the doings in a Heron-breeding rookery at meal time. The proceedings are not an appetizing affair from a human point of view, but they are of absorbing interest to the naturalist, and of vital importance to the young Herons. 

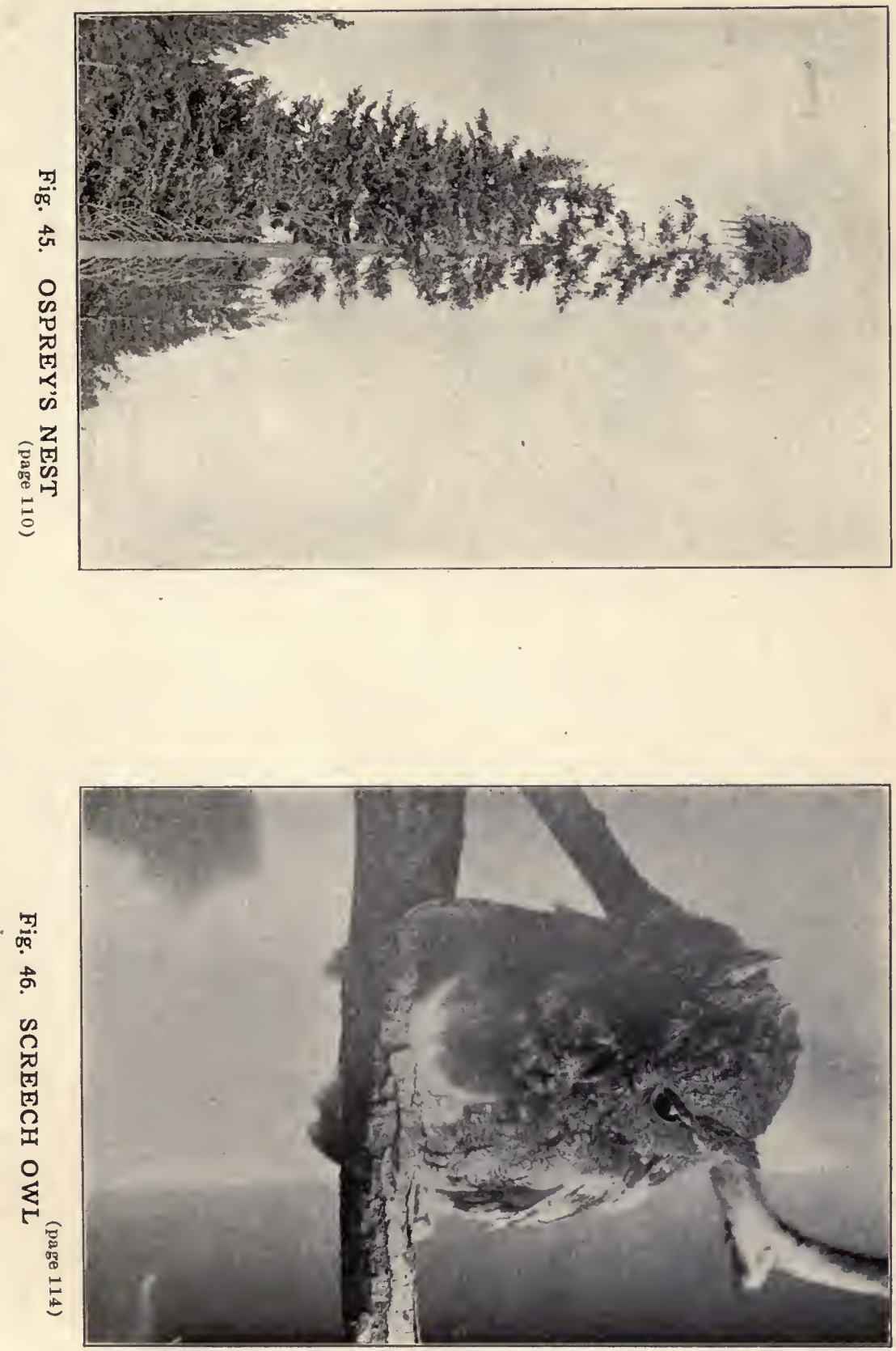


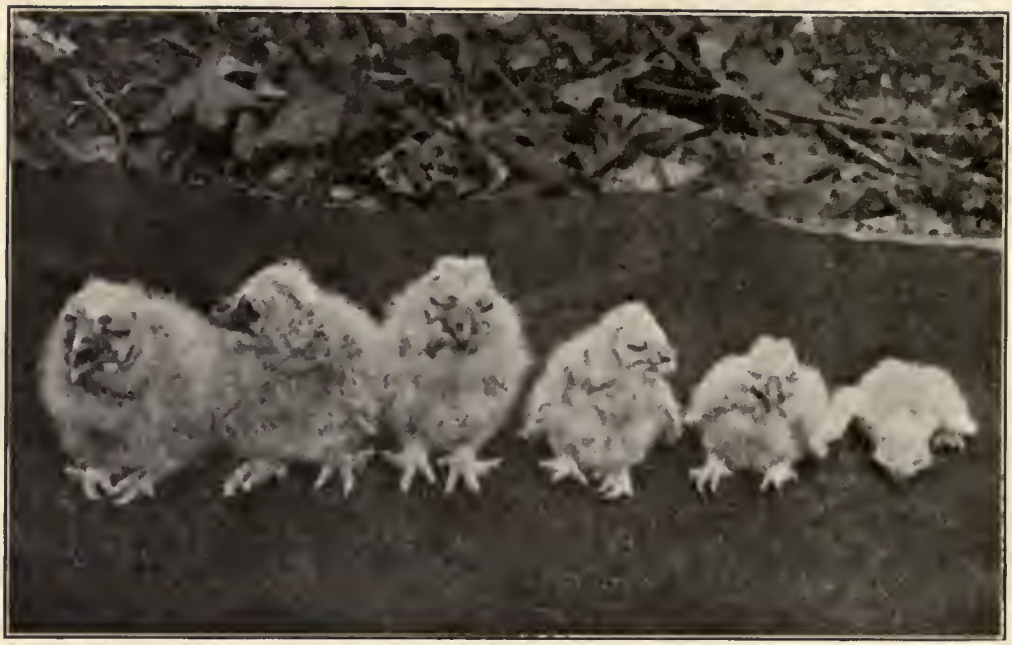

Fig. 47. LONG-EARED OWL'S YOUNG

(page 112)

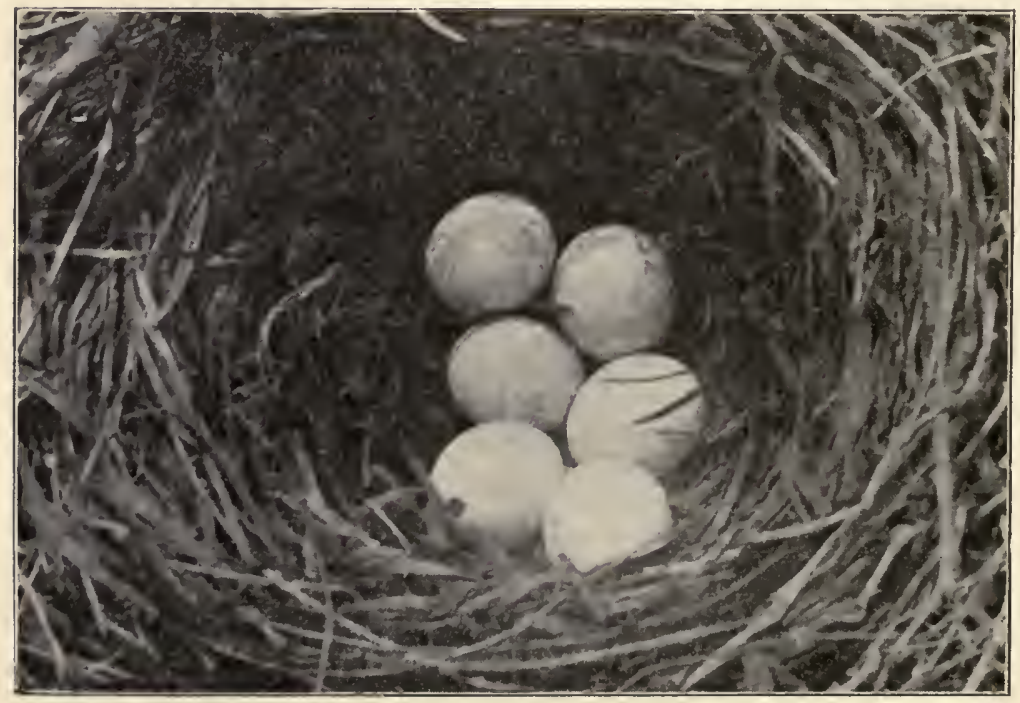

Fig. 48. LONG-EARED OWL'S NEST AND EGGS

(page 111) 


\section{XXII}

Litthe Green Heron; Fly-Up-the-Creek; Chalk-Line;

Poke

201. Butorides virescens (Linn.)

With the single exception of the Least Bittern, this is the smallest of the long-legged fish-eating Herons. Including the length of its long bill, neck, legs and little body the bird measures only from seventeen to eighteen inches. It is marked by a greenish crown and line below the eyes, a buffy-white throat, a general reddish chestnut back and an ashen belly.

Anywhere in temperate North America or even as far north as Manitoba this Heron may be found. Its favorite habitat is along the tree and brush-grown shores of shallow lakes and small streams, where it finds an abundance of minnows, snails, crawfish and other small denizens of the shallow water.

From choice the Little Green Heron prefers solitude and is seldom seen with others of its kind, though on rare occasions it builds its nest along with other Herons and with Cormorants. This nest is an unfinished affair of coarse sticks, usually located in trees from ten to fifteen feet from the ground.

All country boys are on familiar terms with this little Heron, as both are wont to frequent the same swimming hole or fishing stream. Many of us recall the solitary bird fisherman, dropping on noiseless wings on a dead snag or stump near where we were fishing. Do you, dear reader, remember how it used to register surprise when it discovered you, fairly springing into the air like a "jack in the box" and uttering agitated squawks, as with dangling legs and extended neck it flew to some nearby dead tree or limb, where it perched with its neck stretched to its fullest, watching you and giving an occasional squawk of protest? From its habits you recall 
one of its names, "Fly-up-the-creek"; the other is unprintable.

If the bird is not disturbed too much it becomes very tame and will continue its fishing within a few yards of you, as long as you remain perfectly quiet.

The Little Green Heron should be protected. 


\section{XXIII}

Limpkin; Crying Bird; Coulan; Clucking Hen 207. Aramus giganteus

Having seen this queer-looking bird as it slowly walks through the tough slough grass on its rickety legs, one can easily understand why it is called the Limpkin. Every stride is seemingly made with a labored effort and lack of confidence in its powers of balancing. As it worms its way through the swamp it frequently gives a clucking sound like that of the domestic hen. I have never heard its crying call or, if so, I have failed to recognize it. (Fig. 32.)

This bird is found in the swampy areas of Florida and Texas, also along grassy banks of sluggish streams. It is about thirty inches long and builds its nest of coarse twigs in low trees or on the ground.

The Limpkin lays from four to seven eggs, cream color, marked with spots of brown. Like the Bittern it hides easily and will remained "fixed," its long neck and bill extended, making its detection very difficult, especially if it is standing in dead brown grass.

I have walked or rowed to within ten feet of the bird before it took to flight. It is an awkward and ugly thing while on the wing, with its dangling legs and slow, measured wing-beats. It feeds on snails, frogs and other small aquatic denizens. 


\section{XXIV}

\section{Bob-White; Quall; Partridge \\ 289. Colinus virginianus}

The Quail is the best known and most highly esteemed of the American game birds. It is widely distributed and, like most of the family, does not migrate but prefers to remain near the place of its birth, where it collects in flocks or coveys. It is an intelligent bird and, like the coyote and fox, maintains its place in spite of the advance of civilization. In fact, the Quail prefers man's open fields as summer breeding places, and his hedgerows as its winter resorts, where, on the coldest days, it may be seen huddled in flocks to maintain warmth.

The Quail is fond of dust baths and there are very few dusty country roads that are not pitted by the body of the dust-bathing Quail.

The California and Gambel Quails in a measure supplant the Bob-White in Texas and other western and southern states. Bob-White proclaims his name from stump or fence post, as he perches there while his mate incubates. The young are hatched fully fledged and leave the ground nest as soon as the shell is broken. The Quail is a prolific layer, often laying as many as eighteen or twenty eggs. (Fig. 35.)

Of all birds I have tried to picture, I consider this the most difficult. I have tried the tent method, covering the camera and tripod with vines, leaves and grass, and all methods have failed. I have succeeded in picturing only the eggs in the nest, just as I found them. In most instances where I have parted the grass to expose the eggs for picturing, the nest has been abandoned.

A young Quail can hide under a leaf right before your eyes, and the only way you can see it is to cause it to change its position. The old bird feigns great distress and resorts to every subterfuge to lead you away from her brood. 


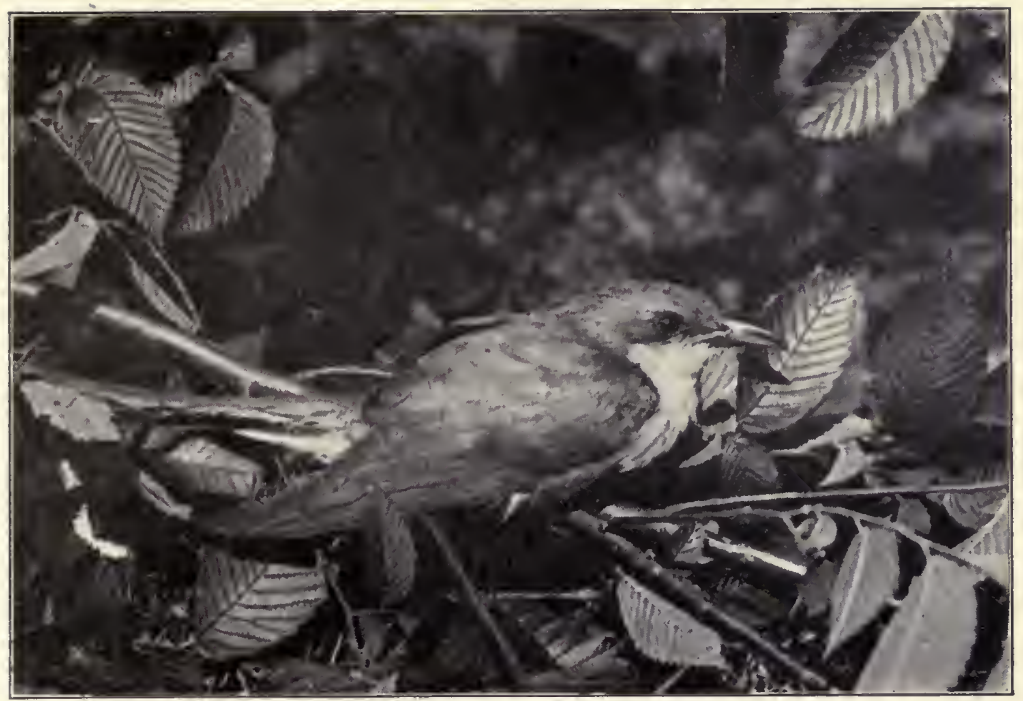

Fig. 49. YELLOW-BILLED CUCKOO

(page 116)

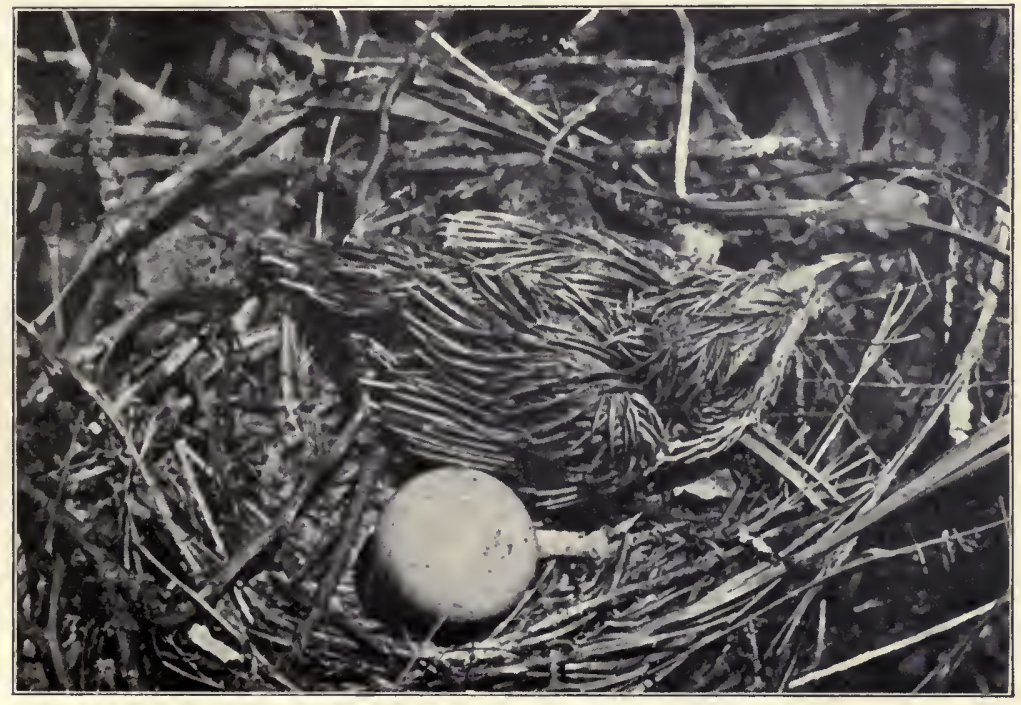

Fig. 50. YELLOW-BILLED CUCKOO YOUNG

(page 118) 


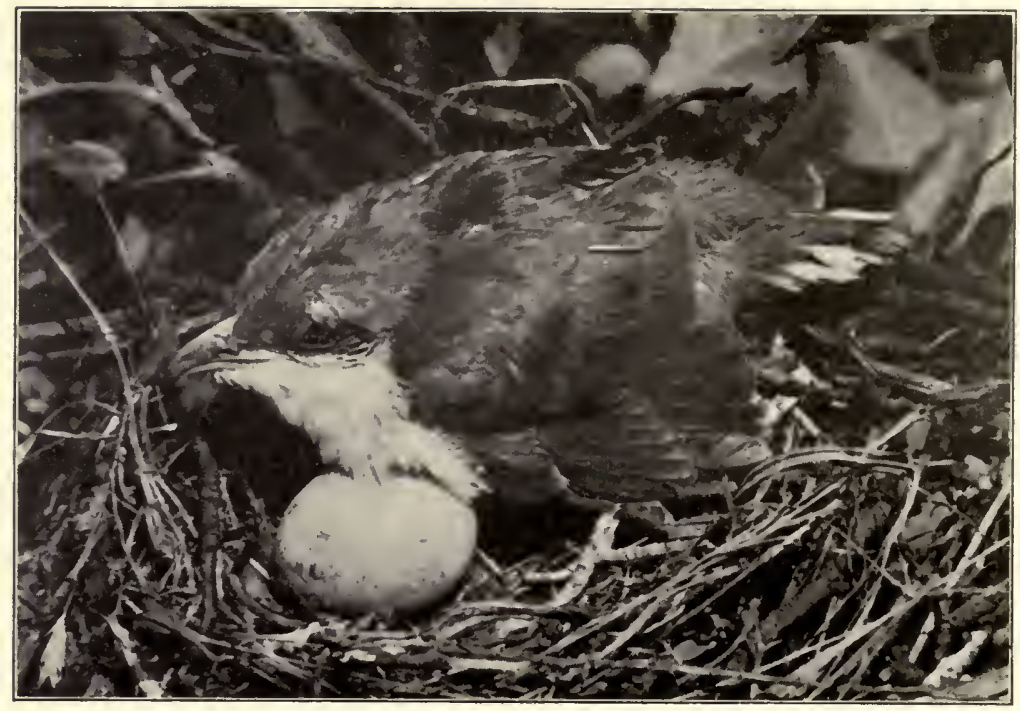

Fig. 51. YELLOW-BILLED CUCKOO YOUNG

(page 118)

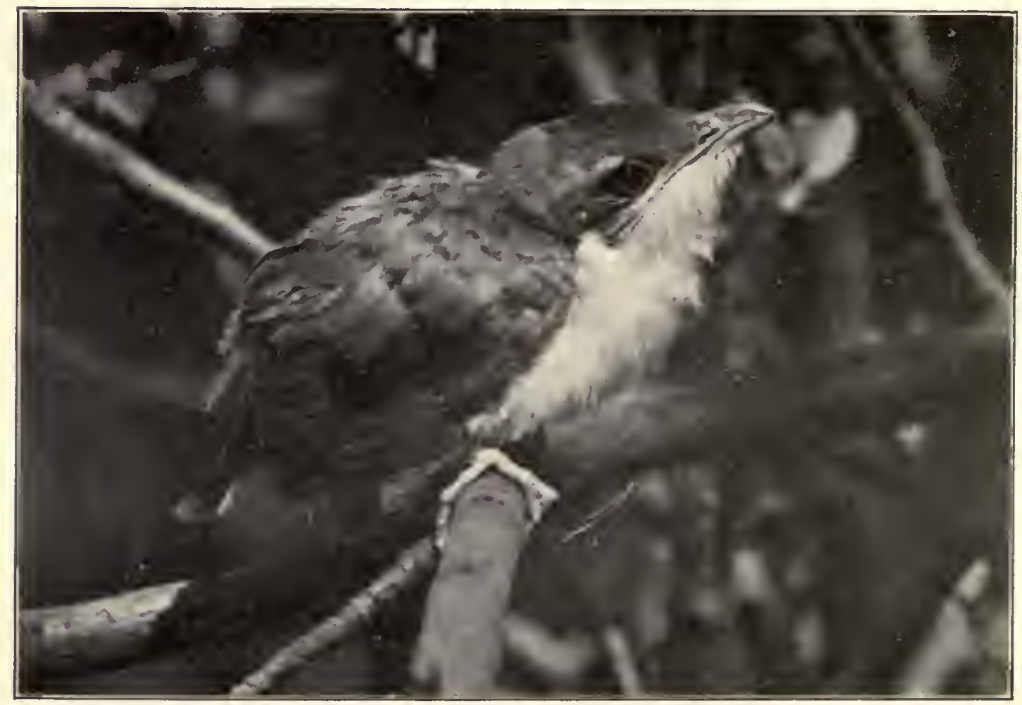

Fig. 52. YELLOW-BILLED CUCKOO YOUNG 
A timid hunter is much upset when a covey of Quail rise up from almost beneath his feet and with great buzzing of wings fairly shoot into the nearest thicket. His markmanship is here put to a severe test, and usually results in "Quail on toast," minus the Quail.

The flesh of the Bob-White is delicious and much sought by those who are fond of wild game birds. 


\section{$\mathrm{XXV}$ \\ Passenger Pigeon \\ 315. Ectopistes migratorius}

Dr. William C. Herman, of Cincinnati, has kindly presented me with an original negative of the last living Passenger Pigeon. (Fig. 36.) This bird, a female, died in the zoo at Cincinnati, in 1916. Thus closed the career of one of the most numerous bird hosts the world has ever known. Pathetic in the extreme was this Pigeon's prison death. All of its ancestors and companions had died from natural causes, or from man's ruthless slaughter. This last survivor was captured and placed behind prison bars, like a murderer or vicious criminal, where it spent its last days. The National Audubon and other bird-protecting organizations were too late to save the Great Auk and the Passenger Pigeon.

In my early life in Kentucky, near the great roosting places of Passenger Pigeons, I have seen the dome of the sky burnished with a continuous layer of beautiful glittering necks of gold and violet iridescence, by the passing of vast hordes of these birds.

Many factors entered into the extermination of the Passenger Pigeon, some of which will ever remain a secret. If some equalizing methods did not govern reproduction the whole earth would become one brier patch, a mass of tangled vines, a jam of buffaloes or of Passenger Pigeons. The distribution and sustenance of any given species are kept at a standard by food supply, duration of life and natural enemies. The larger the animal or tree, the fewer are the numbers produced or surviving; yet they live the longest, as the Elephant, the whale and the Sequoia Gigantia. The smelts, the moths and grass seeds illustrate numerically the small things furnishing food for the larger and less numerous.

E. H. Forbush says: "This action and reaction of natural forces constitutes what is known as the balance of nature." 


\section{XXVI}

\section{Mourning Dove; Turtle Dove}

\section{Zenaidura macroura carolinensis (Linn.)}

This bird is so universally distributed over the whole United States that its identification is easy and requires very little to be said about its plumage, as an aid to its recognition. Its head and neck are brown and the general coloring of the bird is grayish-blue; it has a golden iridescence at the side of the neck and black spots under the ear coverts. The tail is leaden blue and bordered with white.

Mourning Doves are about twelve inches long and are semi-gregarious, migrating in small flocks about the first of October. The eggs, two in number, are pure white.

The Dove's nest is one of the poorest samples of bird architecture; it is a mere flat layer of small twigs, resembling a piece of corduroy road, a willow mattress, or a $\log$ raft. Why the round eggs do not roll off this platform, I cannot understand.

Mourning Doves are ground feeders, eating only grain and weed seeds and showing partiality for wheat and oat stubble fields, where, in August and September, small flocks may be seen flying, when disturbed, from one farm to another. (Fig. 37.) Late in the day, as roosting time approaches, these birds fly to old abandoned weed fields and drop on the ground out of sight of Hawks and Owls.

When you are walking across the fields after dark the Doves, ever on the alert, fly up several feet ahead of you and disappear in the darkness. Unfortunately, for them, they are very palatable and much sought by hunters during the months of August and September. I have seen a hunter have in his possession two hundred of these most innocent of the harmless and beneficial birds. 
Their song is a low and plaintive "coo, cou, $u-u$ !" during the mating period. On hot and sultry days this cooing may be heard a long distance.

Doves are rapid flyers and make a metallic noise with their rapidly vibrating wings as they fly. These birds are very shy when near their nest and will abandon their eggs, if disturbed very much. If approached too closely while incubating, they will tumble from the nest to the ground and feigning the most helpless and crippled condition go fluttering away with the unsuspecting observer in fruitless pursuit. As soon as the would-be captor has been beguiled to a safe distance the poor crippled things suddenly recover flight power and disappear in the distance, much to the pursuer's surprise and chagrin. 


\section{XXVII}

\section{Black Vulture; Carrion Crow 326. Catharista atrata}

\section{Turkey Vulture; Turkey Buzzard 325. Cathartes aura (Linn.)}

These two big, black, repulsive carrion eaters are so much alike in their general make-up and habits that with a few additions the description of one will, for all practical purposes, answer for both.

The Turkey Vulture is thirty inches long, slightly longer than the Black Vulture, but is not so heavy. The Black Vulture is black all over, including the naked skin of the head, while the head of the Turkey Vulture is of a deep crimson, and this bird is thus much more repulsive in its appearance than the other. Its range is broader than that of the black species, the latter being pretty well confined to the southern Gulf and Atlantic states.

Both species breed over their entire range, nesting in hollow logs, stumps, and on the ground and in rocky caverns, each female laying two eggs, cream-colored with large brown blotches. The Turkey Vultures frequently breed in communities. (Fig. 38.)

The young are fed by the regurgitation of injested carrion of anything putrid that is found. Be it snake, rat, skunk or a cholera-infected hog, it all looks, smells, and tastes alike to them.

The beautiful, delicate Humming-birds also feed by regurgitation, but their food is the purest, freshest and sweetest of flower nectar.

The black species of Vulture at one time was a common visitant to Southern Kansas, but of late years it is rarely seen there. This species flaps its wings more while flying than does the Turkey Buzzard. The latter frequently soars gracefully, high in the air, for hours at a time, with scarcely a visible movement of its wings. 
In some of the southern cities the Black Vultures become very tame, and may be seen perched on the housetops and strolling along the public thoroughfares, where the dogs and the passing throng seem not to disturb them.

It has ever been a mystery how these birds discern a carcass, whether by sight, by smell or by some special sense not possessed by any other living thing. A hog or steer is hardly cold in death before Vultures are hovering over the body, and they seem to come from all directions, when, two hours before, not a Buzzard was to be seen.

When a boy, I used to try to deceive these big birds by feigning death, but I never succeeded; all they would do was to quicken their speed, as they sailed over me with their heads turned to one side to get a good view. But just drag a dead hog out into a pasture and every tree in that vicinity is quickly filled with these putrid flesh eaters. They do not attack any living thing; they are far from being "the purifiers of the air," as some writers have seen fit to call them, although they are looked upon in some localities as great and beneficient scavengers.

In Mexico, these repulsive things, in some of the cities, dispute with you the freedom of the streets and sidewalks. Any country or city that depends on these filth-eaters to cleanse the streets or to get rid of dead animals and other refuse is resorting to an out-of-date and dangerous so-called sanitary measure.

While on a bird-picturing trip along the gulf coast of Texas, I saw many Vultures and their nests. Both birds assisted in the incubation, which, I was told, lasts twenty-eight days. By a peculiar, awkward hopping on the ground, as they approach the nest, they make a little path easily followed.

Goss says: "Their rank odor is not alone from their food, but from natural causes." Nature here did the Buzzard a great favor by making its own odoriferous body out-rank that of its food supply.

Can you imagine any bird more repulsive than this one, with its nauseating feeding habits, its natural intolerable stench and its refusal to defend itself when attacked, except by hisses, only? The Vulture possesses 
no semblance of a song. Add to all this ugliness its habit of disseminating contagious diseases among hog herds, which is undoubtedly the case in hog cholera, where one epidemic is spread to distant droves by Vultures polluting water courses and hog drinking-troughs, and the evidence is sufficient to convict the Vulture and lead to its extermination.

While looking for the Black Vulture's nest in Old Mexico, near the Rio Grande River, I saw a Painted Bunting, passerina ciris, with its unrivalled plumage, excelling that of any other bird I have ever seen in the harmonious blending of ultra-marine blue on the head, vermillion red on the under parts, green and yellow on the edge of the chin and greater wing coverts and purplish blue on the tail. As I looked at this symphony in colors and saw near me the hissing, incubating Black Vulture, I considered that the maker of the latter had just about ruined it. 


\section{XXVIII}

Golden Eagle; Black Eagle 349. Aquila chrysotos (Linn.)

This rapacious and tyrannical great Sampson of the bird kingdom, with one exception, the Condor, is undoubtedly the strongest and most robust of all diurnal birds of prey; it is of a beautiful dark brown color, with feathers extending to its toes. It is slow in reaching breeding maturity but lives many years-some say one hundred years. Although from choice it lives in the mountains and far northern countries, it is often forced by food conditions to tarry or migrate and nest in densely wooded districts far from the place of its choice. (Fig. 39.)

The eyry of the Eagle is a huge affair of coarse sticks and twigs, lined with leaves, moss and feathers, and is used year after year, being repaired and added to each season.

The eggs, usually two, are drab colored, splashed with sienna or umber. What a shark is to the fishes of the sea, what a tiger is to the mammals of the jungle, this Eagle is to all birds of the air and small mammals of the earth. It is the king of the air, the monarch of its nesting zone. Small mammals or birds that invade the territory of the Golden Eagle do so at the risk of their lives. (Fig. 40.)

From a mere speck in the sky this bird, three feet long with seven or more feet of wing-spread, by its gift of powerful eyesight, can detect the smallest bird, mouse or rabbit and swoop upon it with a speed and accuracy almost unbelievable.

While on big game hunting trips on the upper reaches of the Frazier River in British Columbia, I repeatedly saw these great birds and heard them screaming as they circled high in the sky when I approached their eyries on some, to me, inaccessible mountain crag. Golden Eagles do not take kindly to captivity; they 


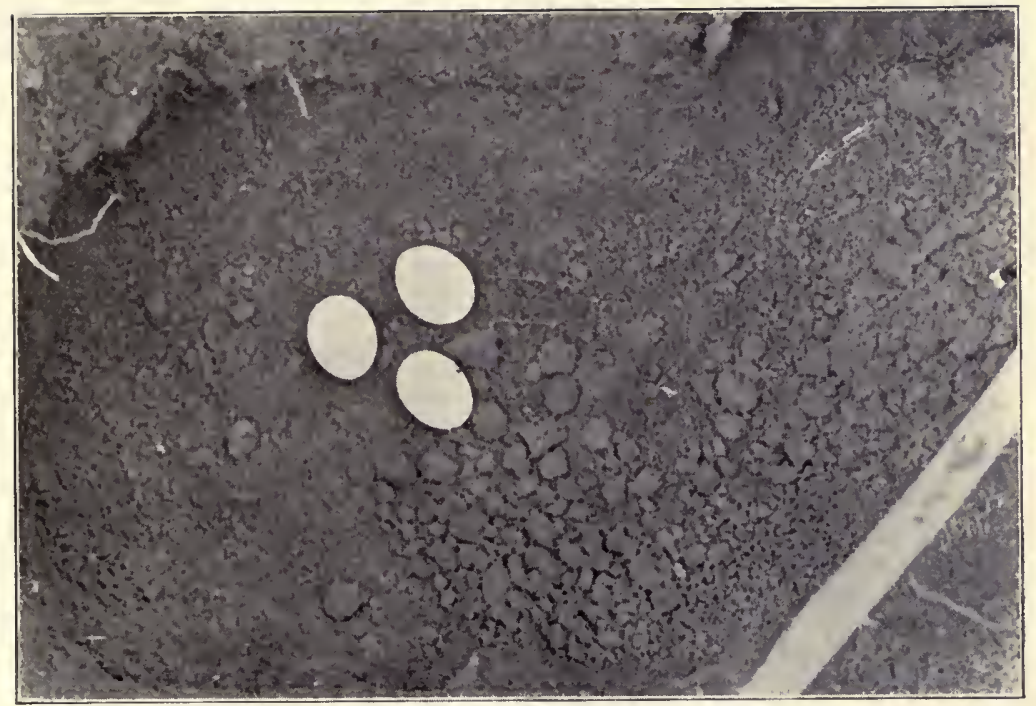

Fig. 53. BELTED KINGFISHER'S NEST AND

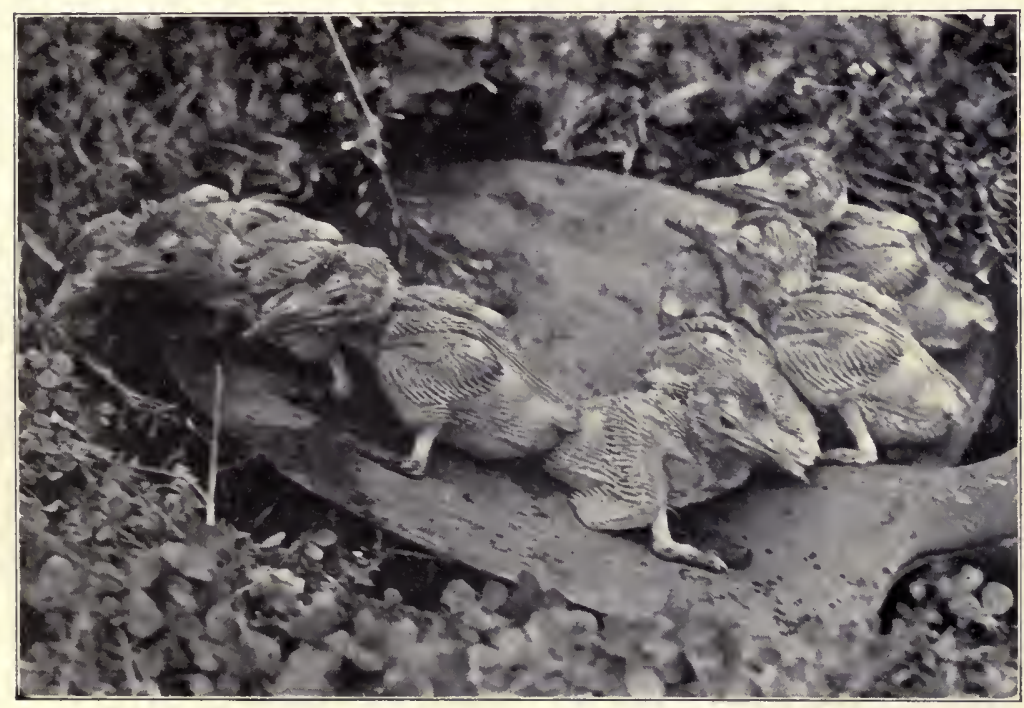

Fig. 54. BELTED KINGFISHER YOUNG

(page 121) 


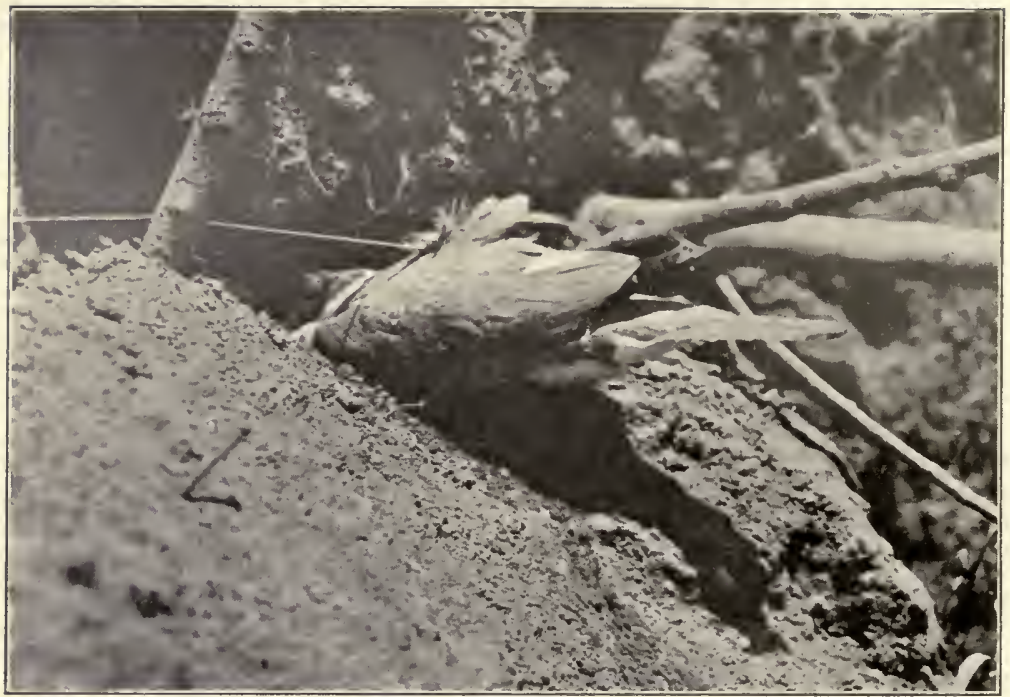

Fig. 55. BELTED KINGFISHER MAKES HIS PICTURE (page 121)

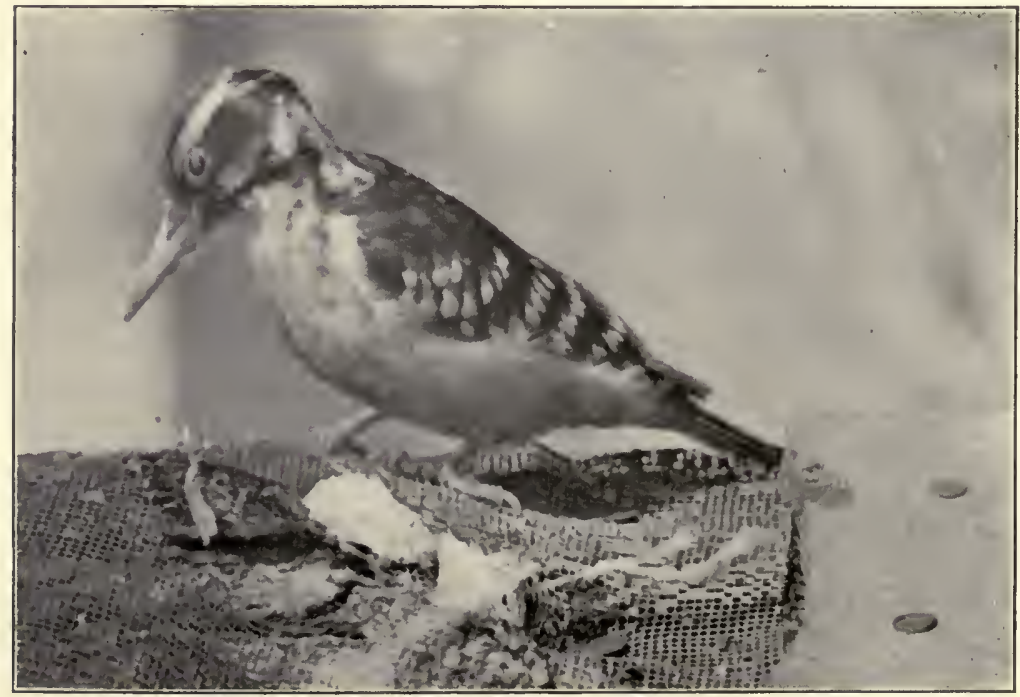

Fig. 56. DOWNY WOODPECKER 
may live for years in cages, yet they never show any disposition to meet their keepers on half-way friendly terms, but remain combative and defiant to the last.

These birds are fond of young pigs, lambs, rabbits and chickens, and instances where young children have been attacked are of frequent occurrence. Although they prefer to capture and kill their prey, Golden Eagles have been known, on rare occasions, from lack of an abundance of fresh food and force of hunger, to feast on putrid carcasses of cattle and horses. While this is the exception with the Golden Eagle, it is of common occurrence with the Bald Eagle. As I have repeatedly seen the latter perched on the cast-up carcasses of large fish of the Atlantic Ocean and the Gulf of Mexico, I cannot understand why the Golden Eagle, with all its power, dignity, courage and clean habits was not selected as our national emblem, instead of the Bald Eagle-a bird whose every trait shows cowardice in the protection of its home and its young, thieving indolence in procuring its food and perverted and depraved taste and filthy habits in selecting the character of that food. None of these traits typify the character of this, the greatest of the Great Nations. 


\section{XXIX}

\section{Bald Eagle; White-Headed Sea Eagle; Bird of WASHINGTON 332. Haliocetus leucocephalus (Linn.)}

The Bald Eagle, the emblem of our country, is a bird of wide distribution, extending from the Alaskan peninsula to Key West, Florida. The body of the Bald Eagle is dark brown in color and its head and tail are white; it is about three feet long, with a wing-spread of seven or more feet.

The first three years of its life this bird is of a blackish brown color; then the white on the head and tail makes its appearance and becomes the distinguishing mark of the Bald Eagle, as compared to the Golden species.

The nest is usually in a tall tree near the ocean, a large inland lake, or river course, and is primarily a huge affair, while the repairs added each year make it assume proportions almost beyond belief. (Fig. 41.) It must be recalled that these birds are said to mate for life and have been known to occupy the same eyry for forty or fifty years. Sticks as large around as a man's wrist and four feet long enter into the walls of these homes. Each nest usually has two eggs, with no special markings. In Florida, laying usually begins in November and December and by late February the young birds are ready to leave the nest. In Alaska, the nesting season is in May and June. The Alaskan species is larger than the southern bird.

Bald Eagles are more docile in captivity than the Golden and in some instances become attached to their keepers, but they are always timid or rabid with strangers. These birds are not so skilled as Ospreys at fishing from the water, but are expert when it comes to attacking the other fishermen in the air. An Osprey or Gull with a beak full of fish has very little show of reaching home with the catch if a Bald Eagle should make an attack 
on it. The only chance for the victim of the attack is to let go of the fish and flee, while the Eagle, with a speed and accuracy almost beyond belief, catches the prey before it reaches the water or the ground.

Bald Eagles are filthy in their habits; they may be seen along the Gulf shore with Vultures and Caracara, feasting on the carcasses of rotten fish, horses or cows, although the Eagles can and often do capture their prey of living mammal or fish. The bird, moreover, is an unscrupulous and persistent thief; it is capable of ignoring weather conditions of cold and rain and will remain in any locality where food is obtainable.

During certain seasons of the year Bald Eagles feed on the dead salmon lining the banks of the streams entering the Northern Pacific Ocean, gorging themselves until unable to fly, and thus are easily captured by the Indians, bears and lynxes.

While hunting the Kodiak brown bear along the shore of Kodiak Island, I saw hundreds of Bald Eagles. Many were perched in dead trees that, from a distance, looked like a giant snowball bush with blooming flowers all over it. Unfortunately, a bounty has been placed on the scalps of Bald Eagles and before long flocks of them will be a sight of the past. In Alaska, especially, this asset of the country should receive legal protection, as a part of every attractive landscape the visitor beholds as he travels along the shore.

Near St. Petersburg, Florida, there are a number of Eagles' nests, and many a winter sojourner who has never seen a real bird's nest in all its magnitude visits these nest-sites and returns with new experiences to relate to the people at home. Thus the Bald Eagle of Florida, also, is an asset worth preserving.

In company with Frank Hodges, of Olathe, Kansas, I visited an eyry in Florida. We secured the services of a painter, his automobile dray and ladders, and drove eight miles out to this nest. It was ninety feet from the ground, in a yellow pine tree. Old settlers in that vicinity told me that the nest had been occupied yearly for over forty seasons. After the ladders had been anchored to the tree the nest was reached and the accompanying picture of the young full-grown bird was 
made. (Fig. 44.) Although this young Eagle had never been away from the nest, when Mr. Hodges got within three feet of it, the bird hopped to a nearby limb, posed for its picture, spread its vast blackish wings and plunged into space. Thence, with the grace, ease and wing poise of an old bird, it sailed away over the waters of the bay and was soon lost to sight.

Among other articles of Bald Eagle diet in this nest was half of a putrid skunk and a half-eaten water moccasin. As far as concerned that nest and its owners, if scentiment were the issue in selecting the bird as our national emblem, the judges would have received strong support had they decided according to the exhalations in the top of this yellow pine tree that hot March afternoon. 

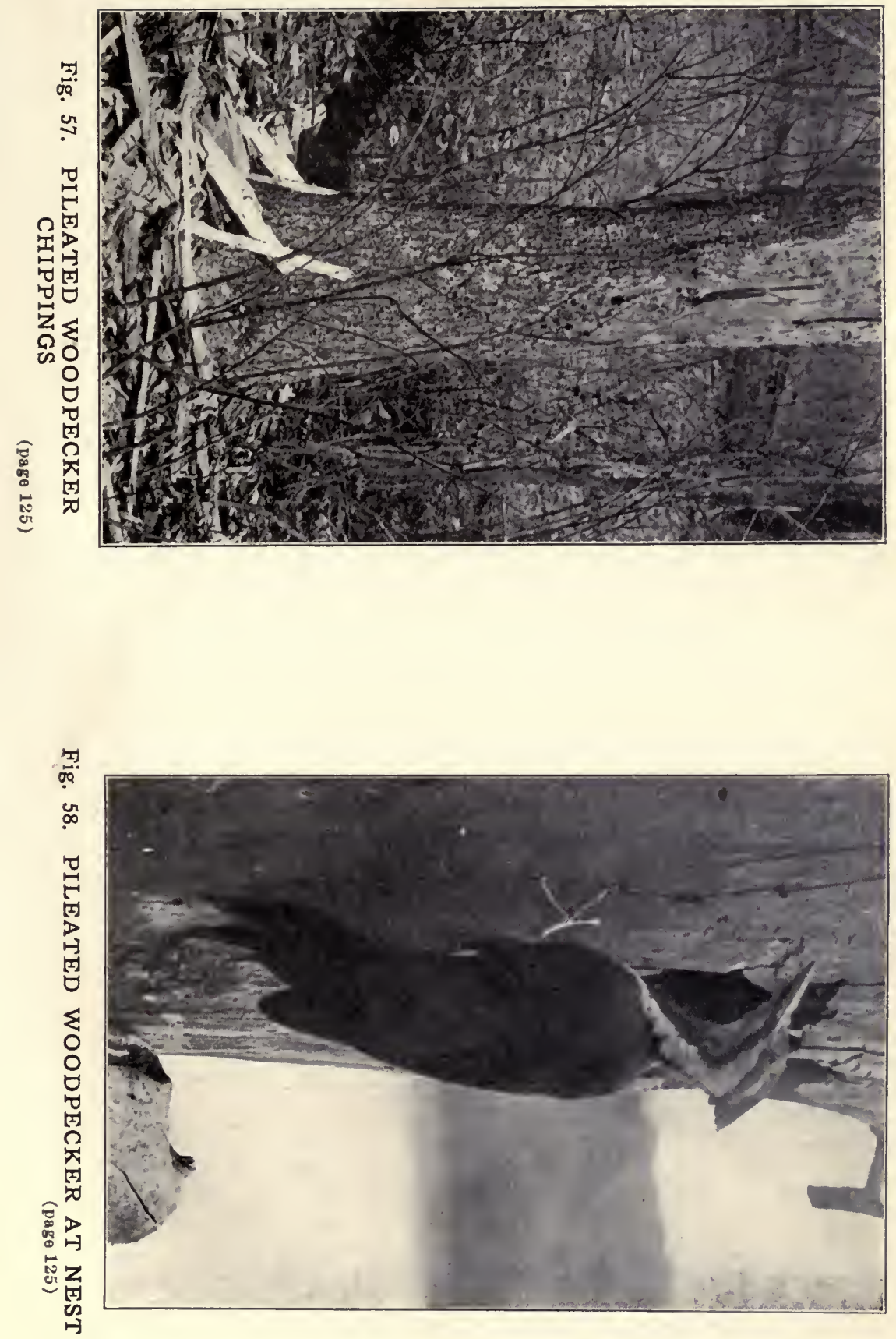


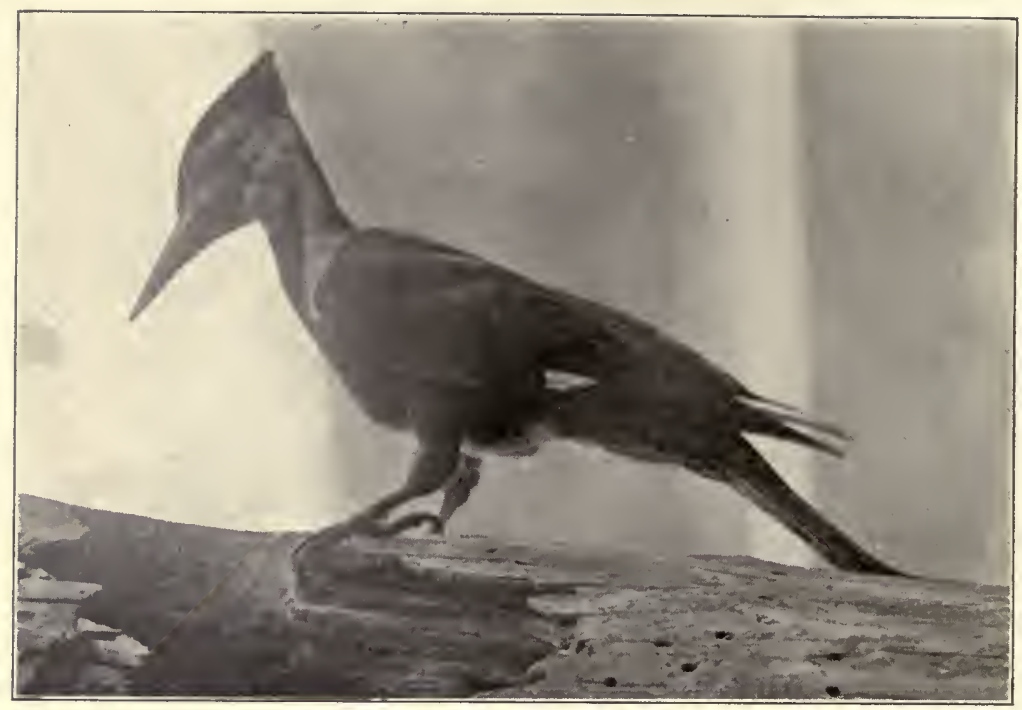

Fig. 59. PILEATED WOODPECKER AT NEST

(page 125)

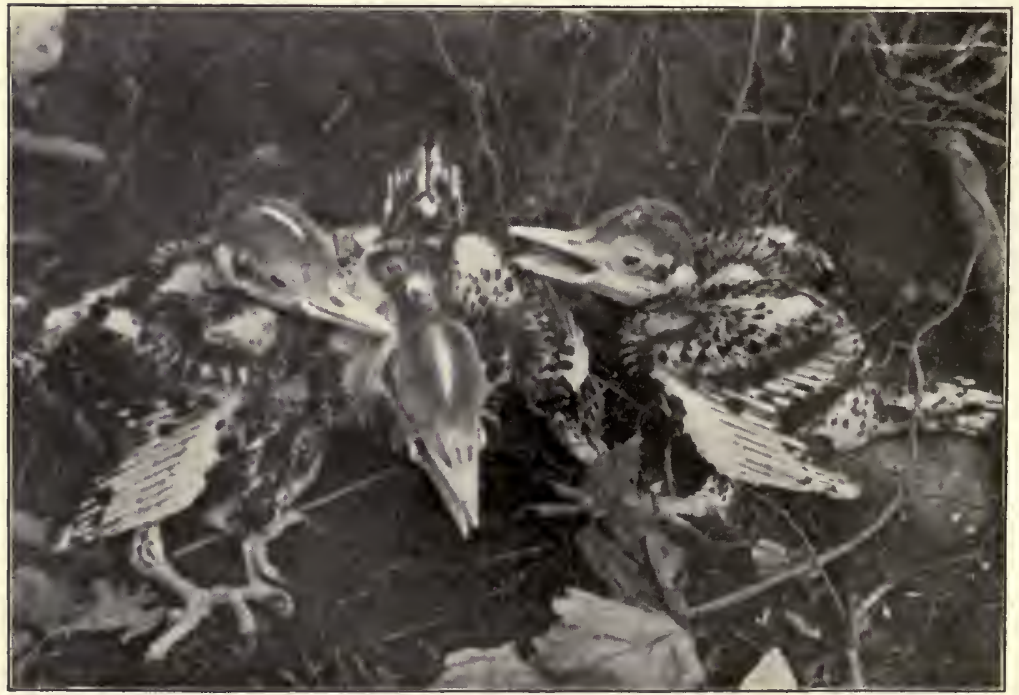

Fig. 60. PILEATED WOODPECKER YOUNG

(page 126) 


\section{$\mathrm{XXX}$}

\section{Sparrow Hawk \\ 360. Falco sparverius (Linn.)}

This is the smallest of the United States Hawks, measuring about ten inches, or about the length of the Robin. The Sparrow Hawk is a beautiful bird of a general chestnut, gray and black color, and is found all over temperate North America. The bird is easily identified, as no other Hawk resembles it. It nests in natural cavities in trees and in abandoned Woodpecker holes in telephone poles. It lays from three to four eggs, of a buff color marked with brown splotches. (Fig. 43.)

The Sparrow Hawk has the habit of hovering over a given spot, with wings all a-quiver and head turned to one side, inspecting a suspicious mouse-looking object on the ground. If a mouse is discovered the bird swoops down with the rapidity and accuracy of an arrow and grasping its prey in strong and sharp-pointed talons flies to a nearby perch and proceeds to execute the victim.

One day I saw a Sparrow Hawk capture a mouse, on the ground, and as the bird arose the mouse evidently bit the Hawk's foot, causing it quickly to release its hold. But the mouse was recaptured before it reached the ground and was borne to a nearby telephone pole, where it was quickly killed and eaten.

I once discovered a pair of Sparrow Hawks inspecting a Flicker's hole in a telephone pole by the side of a road. I watched the two birds on and off for several days, then I climbed the pole and peeped into the house; it contained one egg, of a dirty mottled brown color. Two weeks later I inspected the nest again. I found the mother bird incubating. I put my face within six inches of her head. She did not wink an eye and seemed perfectly composed, making no effort to escape. What a glorious sense of security motherhood brings, even to a bird of prey! Her attitude of confidence seemed to say: 
"Can you not see I am busy incubating? Please go away and let me alone."

One day I saw one of these birds fly to a hole about twenty feet from the ground, in a telephone pole. The bird hung to the side of the pole with its feet, as a Woodpecker does, and poked its head into the hole, withdrew its head and looked around, then took another peep. I presumed that its mate was incubating. As I came closer the Sparrow Hawk flew away and lighted on a wire fifty yards distant. I struck the pole with a stick, and to my surprise a Flicker stuck its head from the hole and surveyed the surroundings. Then seemingly satisfied that everything was all right it withdrew to the inside. The entrance hole was too small for the Hawk; therefore Mrs. Flicker was permitted to continue her household duties with no further interruption. 


\section{XXXI}

\section{Audubon's Caracara; Mexican Buzzard}

362. Sub-Family, polyborinae caracara

This big carrion eating bird possesses many of the traits of Hawks, but more of those of Vultures, with which the Buzzard associates; it is about twenty-two inches in length and is found along the southern maritime border of the United States from Florida to the mouth of the Rio Grande River. (Fig. 42.)

The bird feeds on or near the ground along with the Black and Turkey Vultures; it is of a general blackish color with throat, upper breast and neck of a dirty white, crossed by blackish bars. It has a well-defined ashen crest; the tail is white, barred with black. In many respects this Buzzard resembles the Osprey. It builds its nest in low trees, lays two or three cream-colored eggs, marked with rich reddish-brown splotches, and is gregarious while feeding.

While I was doing some field work near Lake Okeechobee, Florida, I first met with the Caracara and not having posted myself on the bird, I was much puzzled as to its identity. The natives of that locality called it the Mexican Buzzard and treated it with much contempt, on all occasions, by calling it many other unprintable names. It was associating with Black Vultures, as they fed on dead fish and putrid alligators. It would perch on a fence post or dead stump of a tree near a carcass, and at every opportunity, when the Vultures left an opening in their circle around the carrion, the Buzzard would dart in, pull off a billfull of flesh and return to the perch greedily to devour the filthy decayed mass.

The next time I met this bird was near the mouth of the Rio Grande, in Texas. It was there associated with a Harris Buzzard, Parabutes unicinctus, locally known as the Mexican Eagle. This latter bird possesses many of the traits of the Caracara. Truly, "birds of a feather flock together." 


\section{XXXII}

\section{American Osprey; Fish Hawk}

\section{Pandion halioetus carolinensis}

The extent of the living and breeding range of the Osprey is not surpassed by that of many birds. It is found practically all over the North American continent, and breeds wherever unfrozen rivers and lakes are found, during the nesting season wintering in abundance in the Gulf states.

It is of a general dark brown color, with head, neck and under parts white, and, by the inexperienced, is often mistaken for the Bald Eagle. The diet of the Osprey consists of fish caught in the water by grasping them with its long bill and powerful talons, as it swoops upon them from great heights. It refuses to collect and eat dead fish from the ground, as is the habit of the Bald Eagle. (Fig. 45.)

The Osprey is a sociable and friendly bird, often seen in small flocks of its kind, and does not shun or attack other birds. Many instances are on record where other birds have actually made their nests in the coarsely built nests of Ospreys, as if seeking protection. The nest is a bulky affair of rough sticks and is frequently seven feet across. Each year the old nest is repaired and used again; thus it increases in dimensions. It is placed in the highest branches of the tallest trees or on pinnacled rocks. As one travels through Yellowstone Park, the guide is very careful to point out to his passengers the Eagles' nests, high on a pinnacled rock in Golden Gate and the Grand Canyon, both of which are the nests of the Osprey.

The Osprey is a splendid flier. It dives like an airplane and suddenly shoots upward in its practice flights, or while fishing. 'If it is successful in its plunge for a fish it rises with a triumphant cry, shaking the water from its feathers like a water spaniel. It is met at its nest by its mate, to whom the food is transferred and in turn fed to the young. 


\section{XXXIII}

\section{LoNG-EAREd OWL 366. Asio wilsonianus}

This Owl is easily identified by its long ear tufts as compared to the ground-roosting, Short-eared Owl, and by its smaller size as compared to the Great Horned and Barred Owls. It is very shy and loves to seek seclusion and safety in the deep, dark woods.

It is rarely seen unless one actually frightens it from its hiding place. When on the alert, as you approach, it contracts its feathers snugly about its body and remains so erect and quiet that its dark gray feathers blend with the surroundings and make it hard to discover.

On dark and cloudy days it may leave its retreat for a short period. Its usual hunting time is in the night. When on its noiseless flight, the small night-prowling mammals may well be on the lookout lest they are picked up by this bird, as its dietetic list is made up principally of small rodents.

Long-eared Owls hoot during the breeding season only, the call being more like that of the Screech Owl than the hoot of the Barred or Great Horned Owls. The species should be legally protected, for it is one of the best friends of the farmer.

These Owls rarely nest in holes, preferring last year's Crows' nests and other abandoned nests. (Fig. 48.)

On April 22, 1922, while exploring some timbered tracts, forty miles west of Kansas City, I discovered what proved to be a Crow's nest fifteen feet from the ground in a red-haw tree. It was in a good state of preservation and showed recent repair work near its rim. As I neared the nest I discovered that it was occupied by an Owl. The bird contracted her feathers until she disappeared below the top of the nest, all save the ear tufts. I could see her big yellow eyes, as she peered from between the coarse sticks that capped the rim. 
I started to climb. I had hardly touched the tree before the Owl rose from the nest and with much ado, with voice and threatening manner, wheeled about my head for a short time. Then, with a great feigning of complete invalidism, useless wings and legs, she fell to the ground within fifty feet of me and, like a Mourning Dove, proceeded to demonstrate how utterly helpless an incubating Long-eared $\mathrm{Owl}$ can become in the face of threatened injury to her home and its contents.

I climbed to the nest and found six cream-colored eggs, seemingly far advanced in incubation. These I carefully lowered and placed in a Crow's nest that I had secured near by. Then I made several negatives and returned the eggs to their original position.

The male bird had soon joined the female, but made no move toward assisting her in the protection of their home and its contents. The female repeatedly alighted within a few yards of me, while I was making the pictures, each time giving a scolding-like squeal and hiss.

Three Blue Jays had also put in their appearance (they frequently pry into other birds' affairs). With much enthusiasm and rage they attacked the female and thus added to her troubles, all the while proclaiming the virtues of the Jay family!

There were a number of Crows' nests in this little body of timber and several Crows were flying about all the time, but they made no move toward an attack on the Owls.

These Owls lay early enough in the season for their young to be hatched and leave the nest before the Crows begin to lay; thus a last year's Crow's nest may be used as an incubating home for both an Owl and Crow in the same season. Crows frequently repair and use their last year's nests.

At the end of two weeks I returned and found that all six of the eggs had hatched. The bird's habit of beginning incubation as soon as one egg is laid was beautifully illustrated in this instance, as the young varied in size from the oldest, as large as one's fist, to a baby, just hatched, the size of the egg of the Long-eared Owl. I succeeded in getting a picture which shows this variation in size due to stages of incubating. (Fig. 47.) 
These little mice and lizard catchers, even in their infancy, have the characteristic, pectinated, sharp claws of their foot-grasping parents. I am convinced that these birds begin their incubating as soon as an egg is laid, to keep the eggs from freezing and to prevent the Crows from stealing them. 


\section{XXXIV}

\section{Soreech Owl; Little Horned OwL 373. Megascops asio (Linn.)}

This, the smallest of the eared Owls, is about the length of the Robin and, having long ear feathers, looks like the Great Horned Owl in miniature. The Screech Owl is the best known of the Owl family, as it frequently nests in hollow limbs near our homes, in abandoned Flicker holes, under the eaves of the barn or other out-houses or, perchance, in a box prepared for the Purple Martins.

The range of the Screech Owl is over the entire United States and southern Canada. It presents many color phases, from an ashen gray to a beautiful chestnut brown, the feathers marked with wavy bars. (Fig. 46.)

There is a wrong impression prevailing that Owls do not see during the day. Just try to sneak up on one as it perches in some darkened shadowy nook and observe how quietly it disappears to a safe distance.

The Screech Owl has the usual absurdly dignifiedlooking facial expression seen in most members of its family. Its melancholic, tremulo notes on moonlight nights are familiar sounds to many a city dweller, as most city parks harbor one or more pairs of these birds.

This sociable little night prowler often makes its home in the same place for several seasons. In a big leaning black walnut tree on a golf course over which I play, a Screech Owl once lived for many years. Every day, as I passed the tree, I could see the little fellow thirty feet from the ground, sitting in his front door, blinking away at the sunlight as he watched the day and the golfers go by. If I approached, he faded away like a dissolving motion picture scene.

The Screech Owl has the peculiar habit of cutting off the heads of mice and eating those choice morsels first. The bird's upper and lower mandibles have free motion 
like a snake's; thus the owl is enabled to swallow objects that are large in proportion to its own head. It is fond of small snakes, grasshoppers, small birds and, especially, mice. Any farmer owning Screech Owls will have fewer mice about his premises.

When the shadows grow long this silent bunch of feathers and blinking eyes grows animated, and its ghostsuggesting trills and screams may be heard all through the treetops as it moves on wings free from noise. Its facial resemblance to one of the worst bird-destroying mammals, the house cat, is remarkable.

Like the wise ant, the Screech Owls frequently lay by a food supply to be used in bad weather. They often hunt in pairs.

The night call of this Owl suggests the thought of one of the late so-called dances, the "shimmie." Add to this the bird's droll habit of slowly winking one eye and the picture is that of a "shimmie vamp." The negroes in the Southern States call the Screech Owl the "Shivering Owl." 


\section{$\mathrm{XXXV}$}

\section{Yellow-Billed Cuckoo; Rain-Crow; Ratn-Dove 387. Coccyzus americanus}

The Yellow-billed Cuckoo has an olive-gray back and is pure white below; its tail is long, white-tipped and edged with white; the lower mandible is yellow.

The Yellow-billed Cuckoo breeds throughout the central part of the United States, but it is a poor builder; it nests in apple and other low trees, on a horizontal branch from ten to twenty feet from the ground. The nest is a mere platform of sticks with no side walls, and why the eggs and the young birds do not fall off is a mystery. It looks as if every passing breeze would dash them to earth. The eggs are three or four in number, ash colored, and are laid rather late in the season. (Fig. 49.)

These Cuckoos are migratory, leaving their summer homes late in September. The male arrives a week in advance of the female. Both birds work together in building the nest, incubating and feeding the young, and both are loyal mates and devoted parents-sentiments not shown by the Cowbird and the European Cuckoo, both of which are polygamous and parasitic in habits.

The Cuckoo often feigns a broken leg or wing, as it tumbles from the nest at your approach and goes fluttering along the ground in an endeavor to lead you away.

Cuckoos are partial to caterpillars and cankerworms, pests usually shunned by other birds. They lay their eggs over a long time; hence fertile eggs and large young may be found in a nest at the same time. Yellowbilled Cuckoos have occasionally been known to drop an egg in another bird's nest.

I found a Cuckoo's nest containing one egg on the twentieth of July; on the first of August, another was laid; on September the seventeenth, the old bird was still setting; on the twentieth of September, she abandoned 
the nest, neither egg hatched. Two long hot months with no young birds! No parasitical traits there!

These birds are accused of being egg-suckers, but I doubt it; they are also accused of doing much harm by destroying the eggs of other birds, and are frequently called "Rain Crows" and unjustly denounced as false weather prophets, when, in the imagination of the layman, the birds' "couk! couk!" fails to bring a downpour. The Cuckoo call, like that of other birds, is given at any and all times and is frequently heard during the night.

It is so universally believed that the Cuckoo never builds a home, but lays its eggs in other birds' nests, that one of the big daily papers of Kansas City, Missouri, my home city, offered one thousand dollars reward to any man, woman or child who would show the editor a Cuckoo's nest. At the time I was making daily visits and picturing the family and the doings of a pair of Cuckoos, in their own home, within the city limits.

In an old abandoned plum and apple orchard I had found a regular land bird-nesting rookery, including many nests of the Mourning Doves, Catbirds, Mockingbirds, Flickers, Bronze Grackles and, along with them, one Yellow-billed Cukcoo's nest. It was on a horizontal limb of an apple tree, about fifteen feet from the ground. The nest, as usual, was a flimsy, shallow affair of small sticks, containing two bluish-green or whitish eggs. The birds were incubating and were easily approached, but the location of the nest made it difficult to get a good picture, for the limb kept swaying with every breeze. However, I anchored the camera within a few feet of it and with line to shutter proceeded to picture the old birds at their activities. I kept this up for several days; then one egg hatched. The female came and perched within five feet of the nest for half an hour, all the while holding in her black and yellow mandibles a big caterpillar. The male now put in his appearance, gave his assurance call, and the female flew to the nest to feed the young bird. This youngster, when only two days old, was four times as large as the unhatched egg in the nest by its side. It was very black-skinned and was an ugly thing, with 
unusually large mouth-spread. At the end of four days some straggling downy hairs put in an appearance on the bare spots, while the pin-feathers were developing rapidly.

In this bird the feathers remain sheathed up to the last days in the nest, as the picture beautifully illustrates. The unhatched egg so often found in the nest is accounted for by the habit the female has of laying an egg after her incubating period has begun.

At the end of seven days the young Cuckoo resembled a porcupine more than a bird. I now cut the limb holding the nest and brought it to the ground. Within three feet of it I then put up the umbrella tent that I might at close range observe minutely the rapid transition of a porcupine-looking object into a fully feathered, beautiful Rain Crow.

I entered the tent with my camera at nine $\mathbf{A}$. $\mathbf{M}$. Soon the parents renewed their feedings. What anxious, expectant and sizzling moments I spent in that tent that August day, for five or six hours, no one can imagine unless he has endured the same. Did I enjoy it? Every second was a thrill of pleasure, of new experience and added knowledge. The first picture was made at nine o'clock. (Fig. 50.) This shows the young by the unhatched egg; the horny, sheathed feathers were fully two inches long, making the bird look like a porcupine. About ten-thirty the sheaths began to burst, and with each split a fully formed feather was liberated. This process took place with such rapidity that it reminded me of the commotion in a corn popper or a rapidly blooming flower. All the while I was within three feet of the bird, and could see every new feather, as it blossomed, so to speak.

At three P. M., six hours after the first picture was taken, I made another photograph, showing this same bird in the full plumage of a Cuckoo, except the long tail. (Fig. 51.) This was one of the most remarkable transformations in so short a time that I have ever witnessed in any living, blooded being.

Thirty minutes after its transformation the young bird left the nest and posed three feet from it for a last picture. (Fig. 52.) I then emerged from the tent, 
looking like one who had been imprisoned in the hot room of a Turkish bath, but thoroughly satisfied and rather proud of having had such a rare opportunity of actually seeing at close range a Cuckoo's appearance change from that of a repulsive porcupine to that of a beautiful bird whose feathers presented lovely delicate bluegrays and varying browns. 


\section{XXXVI}

\section{Kingfisher; Belted Kingfisher 390. Ceryle alcyon}

This bird is such a regular summer resident along all small streams that merely to mention its name is to convey to the mind exactly what it looks like, its size and its general habits. It is about thirteen inches long, and is colored in a general way something like a Blue Jay, with crested head and white collar, and is of a general bluish color with white breast. I have met species of these birds from the Aleutian Islands to the City of Mexico.

For a nesting site the Kingfisher selects the bank of a creek or a soft earth bluff. Two or three feet from the surface it makes a burrow extending from six to eight feet underground. The entrance to this tunnel usually has two grooves marking the place where the bird dragged its feet in backing out. Frequently, an extra burrow a few inches deep and close to the main tunnel is made. At the end of the main tunnel a cavity fifteen inches across is excavated for the future nest. No nesting material is carried into this dark recess. Like their remote ancestors, the alligators, these birds are tunnel diggers and cave dwellers. They will work for days excavating their homes, but waste no time upholstering the interiors.

In each of these gloomy cavities are laid from five to seven pure white eggs and here are hatched an equal number of the ugliest looking young kings that ever ruled a kingdom. (Fig. 53.) In their dark and dingy restricted chamber they remain for several weeks before the glories of the out-of-doors, with its sunshine and fresh air, become their domain. Before this time the pale blue of the old birds is plainly visible on the porcupine-like quills of the young. Having once seen the interior of this dark, damp, dungeon-like nursery one naturally wonders why the featherless young birds do not have blindness, bron- 
chitis, pneumonia and rheumatism. With their porcupine-quill-looking feathers, their alligator-like heads and bills and their quarrelsome dispositions, the young are comical little clowns. One would suppose that a family of these birds would be congenial, cooped up as they are in a small chamber during their early lives, but such is not the case; they are constantly pecking at each other, refusing to be shoved about without vigorous protest.

The young have the peculiar habit of walking backward on the whole length of the tarsus, or shank bonea habit that some claim is due to backing in and out of the entrance tunnel on the approach of the parents with the usual food supply of frogs and minnows. (Fig. 54.)

Kingfishers fish from a perch or, like Brown Pelicans, while flying, or from a hovering position from ten to thirty feet above the water. A minnow rarely escapes the rapid and accurate plunge of one of these birds, the toes of which are constructed so they can hold a slimy fish against a limb while perching. Having captured a fish they kill it by whipping it against a post or the limb on which they perched before diving for the prey. When a given reach of a stream abounding in small fish has been once pre-empted by a pair of Kingfishers any intrusion upon the territory by another bird meets with assertive protest. The fishing hole of a Kingfisher must not be poached on by any of its king neighbors. Its only song seems to be a kind of chatter or rattle, usually given with much enthusiasm.

If you are canoeing or walking along the bank of a small stream, any time between March and December, on rounding a bend you may discover this king perched on his throne overhanging the water. The bird takes flight, with much grumbling protest and disappears around the next bend, only to have you rout him out again. This performance the bird, like the Little Green Heron, continues to repeat until it decides to return to its usual haunts, when it circumvents you by flying up over the treetops, all the while chattering Kingfisher objections.

My picture of this bird was made by passing a line across the tunnel entrance and fastening it to the shutter release. The Kingfisher threw the shutter by passing across the taut line. The seven little kings were the young birds belonging to this nest. (Fig. 55.) 


\section{XXXVII}

Downy Woodpecker; Checkerboard

394. Dryobates pubescens medianus (Swaims.)

There are six sub-species of these birds, but the Downy Woodpecker is the one found in the central part of the United States and in northern Canada.

Downy and Hairy Woodpeckers are often incorrectly called "Sapsuckers." The latter bird is much larger, and its range is farther north than that of the former. The Hairy Woodpecker is larger than the Downy, but resembles it very closely. The Sapsucker selects trees that are sound in which to excavate a nest, often drilling through several inches of hard pine to reach the dead heart of the tree, in which the nest is built. (Fig. 56.)

The Downy is the smallest of the family and is a sociable little fellow, accepting your proffered bit of suet with grace and freedom. However, he insists on helping himself before surrendering any of his rights to his winter associates, the Titmouse and Chickadee. The Downy eats very deliberately and rarely shows any restlessness or suspicion, as is the case with the Titmouse.

This Woodpecker has very acute hearing and may frequently be seen pausing in its pursuit of insects to turn its head to one side, as if listening for concealed wood-borers. It is a persistent food-hunter. When the ground is frozen solid and the trees are popping like a great forest cannonade, this strong-necked and hardbilled little carpenter may be seen cheerfully pursuing its labors, as it chisels away at the bark in search of dinner. Whether on the upper or lower side of a limb or vertical branch, the bird is equally and easily poised, as it sends its awl-like bill into the tree. I have stood so close that the bark chips fell all over my clothing.

The Downy Woodpecker is a confiding bunch of down and feathers, and will let you almost touch it, as it pokes its bill into the bark crevices, looking for worms and eggs. It may with modesty, lest it offend you, work 


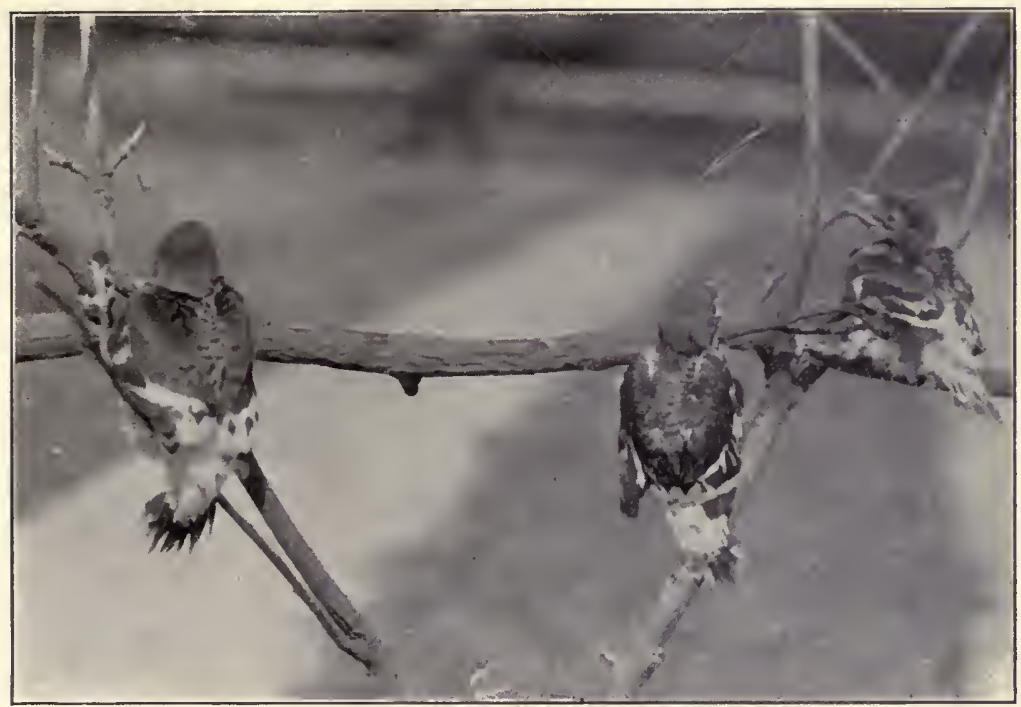

Fig. 61. RED-HEADED WOODPECKER YOUNG

(page 127)

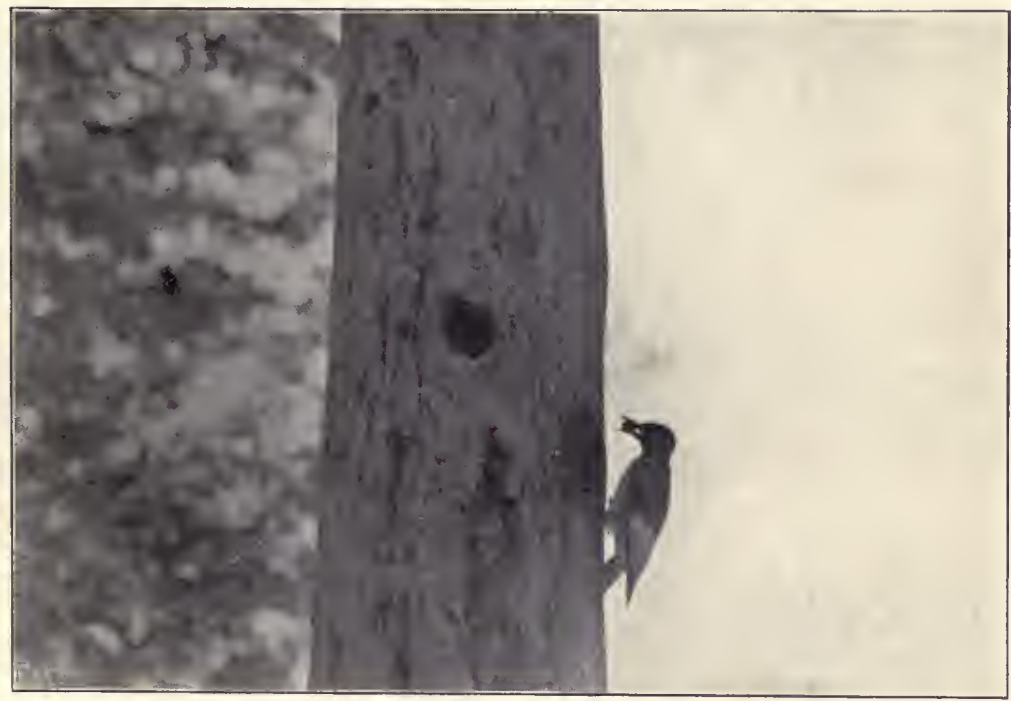

Fig. 62. RED-HEADED WOODPECKER AT NEST

(page 128) 


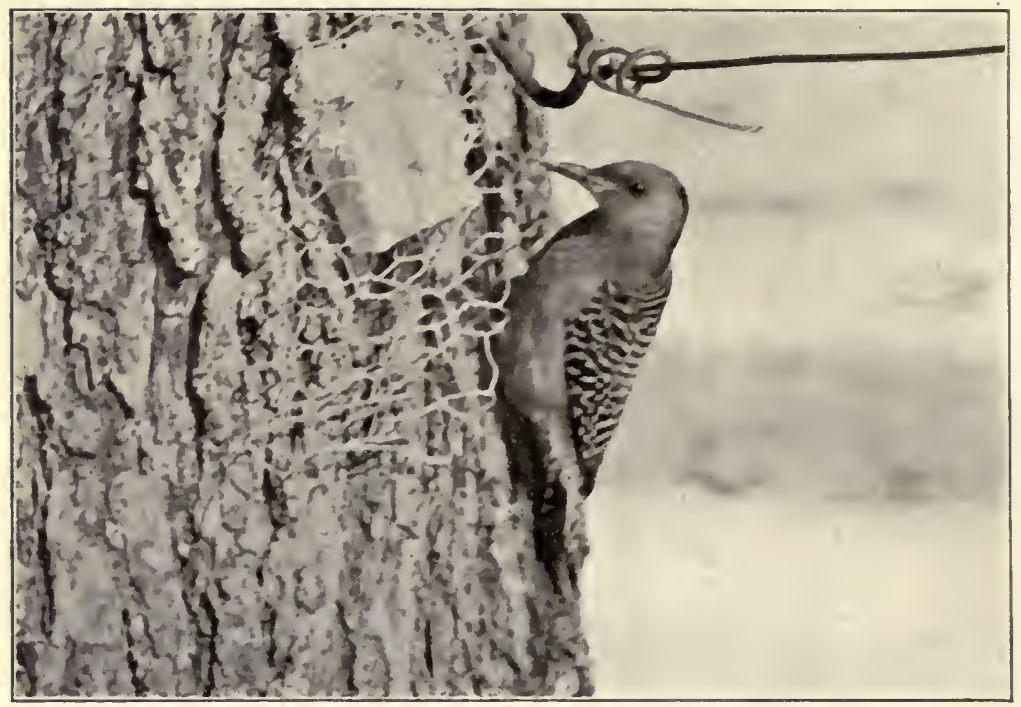

Fig. 63. RED-BELLIED WOODPECKER

(page 129)

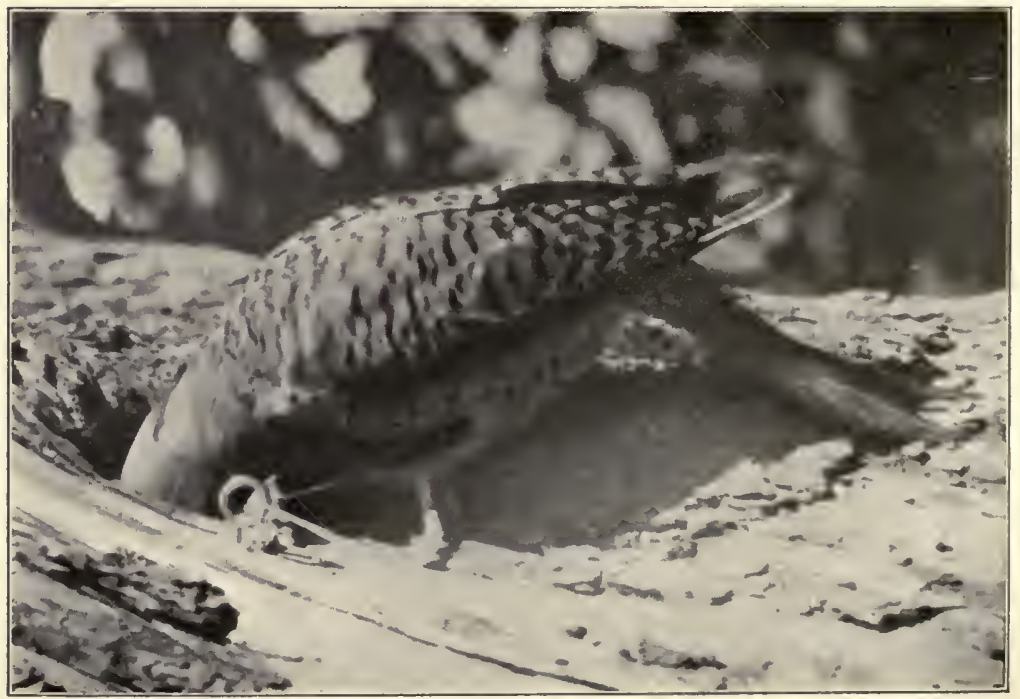

Fig. 64. FLICKER

(page 132) 
slowly around the tree trunk to the opposite side, but don't think for an instant that your presence has been forgotten, for the bird will repeatedly take a careless glance at you from around the corner.

Our highest paid forester, in proportion to his size, does not render a greater service to our trees than does the little Downy. He is busy winter and summer destroying injurious insects and their larvæ.

Like most hole-nesting birds Downy lays unmarked white eggs. Its association with Chickadees and Tufted Titmice is not a mere coincidence of winter residents, but is for mutual interest in food-hunting and safety from enemies. 


\section{XXXVIII}

Pileated Woodpecker; Cock of the Woods; Northern PILeated Woodpecker

405. Phoetomus pileatus albieticola (Bangs.)

When I was a boy in Kentucky, these big Woodpeckers were to be found along the creek bottoms where there were large bodies of heavy timber. The birds were extremely shy and required about as much skill in stalking to within gunshot range as a Wild Turkey. Their departure was so silent that you did not discover their flight until you heard them a half-mile away, seemingly daring you to follow.

The Pileated Woodpecker is a powerful bird, about as long as a Crow-eighteen inches-with a bluish-black general marking and a white stripe from the angle of the mouth, beneath the eyes and down the side of the body. The head is capped with a large crest of the deepest scarlet; the bill is black, this feature being one of the principal distinguishing marks as compared to the Ivory-billed bird, now almost extinct, found chiefly in the Everglades of Florida, where I saw three in 1921.

The United States pileated, black-billed bird also is becoming very rare, yet a few are to be found along the larger watercourses, bordered by primeval forests. It has a loud and rasping voice that is monotonous in its repetition during the mating season.

In the same game preserve in Missouri in which I pictured the Snowy Heron and the Prothonotary Warbler in 1921, I saw and heard several Pileated Woodpeckers. They are extremely shy and only two or three are to be seen in one locality. They are so much afraid of man that they will not remain when he invades their territory but retreat before civilization into the remote fastnesses of big tracts of heavy timber.

The Pileated Woodpecker is the best wood-carver of the Woodpecker family, and great piles of chips are always to be found on the ground at the root of a nest 
tree, or where the bird has been feeding. (Fig. 57.) It is mostly insectivorous, and with its great strength of neck and powerful bill is enabled to search out and live on the hibernating larvæ and worms so abundant in the vast forest in which it lives during the rigors of winter. These powerful birds pull great splinters of dead wood from the trees while seeking their food of wood-borers and other tree-destroying worms.

This Woodpecker does not migrate, even from the cold climate of Canada. I have seen it along the streams flowing north into Hudson's Bay. The Indians call the bird, "Cock of the Woods," or "Log Cock." When you approach a tree in which one of them is feeding, it is very careful to keep on the farther side from you and all you will see will be an occasional poke of the bird's head from behind the trunk, to see what you are doing. (Fig. 58.) I used to have another boy "circle" the tree at a hundred yards distance, while I remained hidden until the bird showed up on my side of the tree. By this ruse, I am sorry to say, I succeeded in killing a few of these big birds. Whenever I have wounded one of them the tenacity with which it clung to the tree before falling was something remarkable. The Pileated Woodpecker will fight to the death, if you wound and capture it.

In 1922, while bird-hunting with my camera in southern Missouri, I discovered a nest of this big Woodpecker. It was located in a dead tree, standing a hundred feet from the shore in an artifically made lake. The nest hole was sixty feet from the water. The problem of getting a "close-up" of the old birds at the nest was therefore a perplexing one. However, there was a dead limb near by. I climbed up, anchored my camera on this limb within four feet of the body of the tree and, covering it with paw-paw leaves, dropped a fishing line which I trailed to the bank where I had built a blind of green boughs. Entering the blind, I had my assistant get into the canoe and row across the lake.

Within ten minutes I had secured the first picture as this great bird, with characteristic poise, posed for me just before she entered the nest to feed the young. (Fig. 59.)

I changed plates and retired to my blind to await the return of the feeding birds. I remained in the blind 
for one hour and a half, but the birds had seen me enter and refused to come to the nest.

Leaving my position I motioned for my assistant to come back. He walked with me to the blind; I entered and he took his departure. The birds, thinking all was well, returned within twelve minutes and I secured the second picture-birds count only one! I then removed the three young birds, photographed them, and returned them to the nest. (Fig. 60.)

These young birds were about the size of a frying chicken, and were covered with pin-feathers. Their grizzly pileum was a deep, poppy red. Even in these youngsters the female was distinguishable by the forehead and part of the crown of grayish-brown.

\section{"A woodpecker pecks}

A great many specks

Of sawdust, while building a hut.

$\mathrm{He}$ works like a nigger

To make the hole bigger;

He's sore if his cutter don't cut.

He has no use for plans

Of cheap artisans,

But there's one thing can rightly be said:

The whole excavation

Has this explanation,

He builds it by using his head."

-F. L. RICE. 


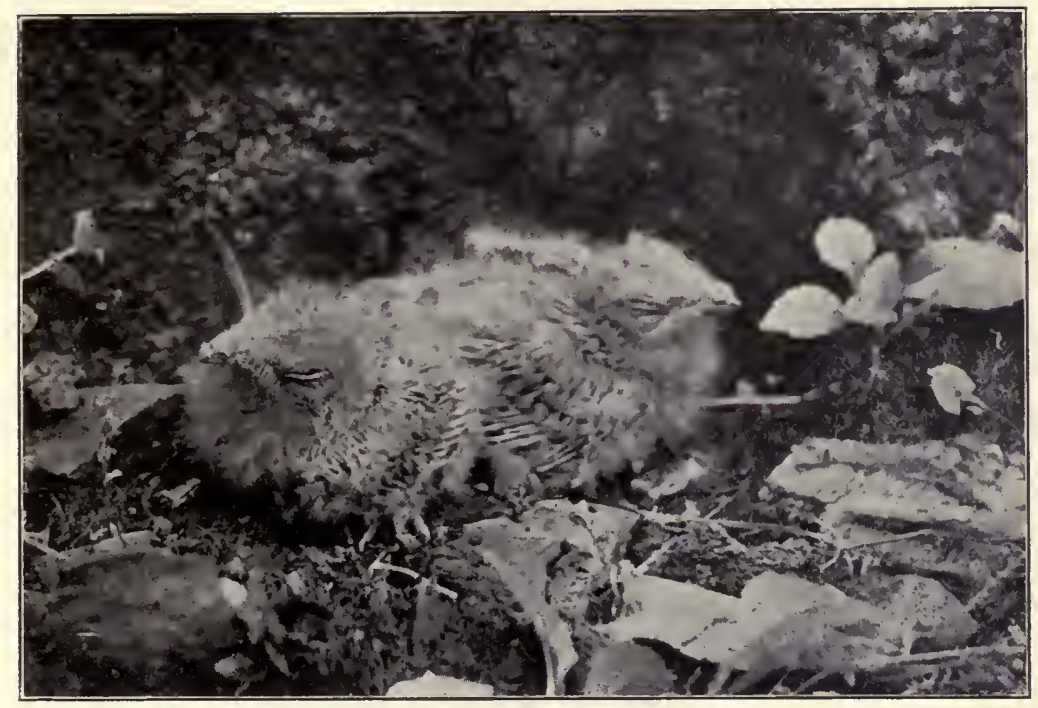

Fig. 65. WHIP-POOR-WILL

(page 134)

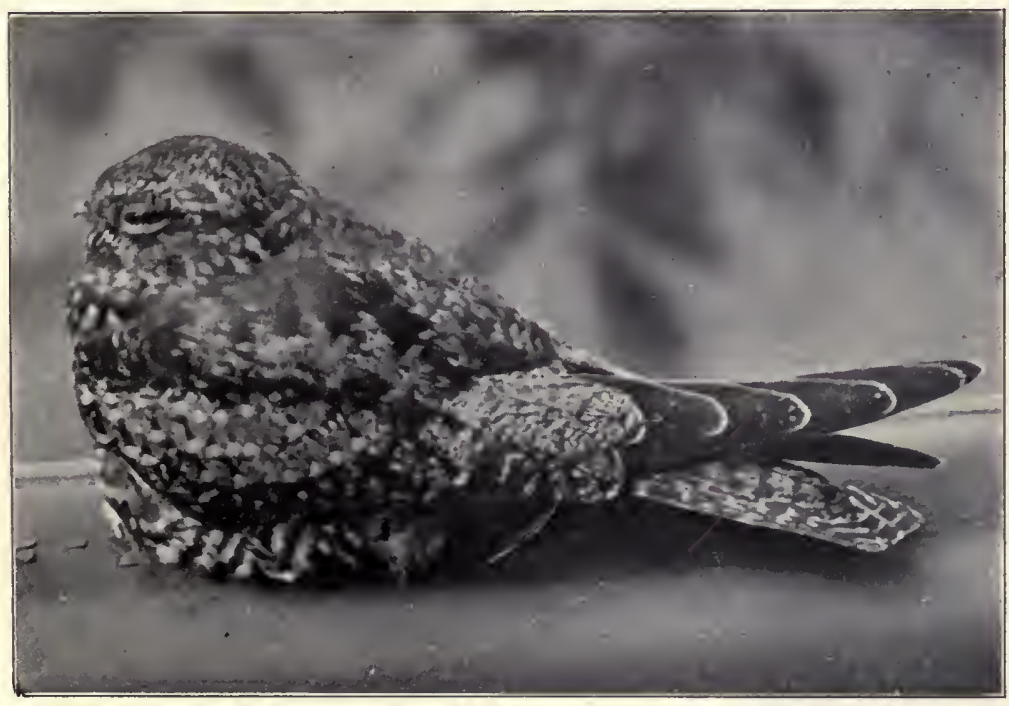

Fig. 66. NIGHTHAWK 


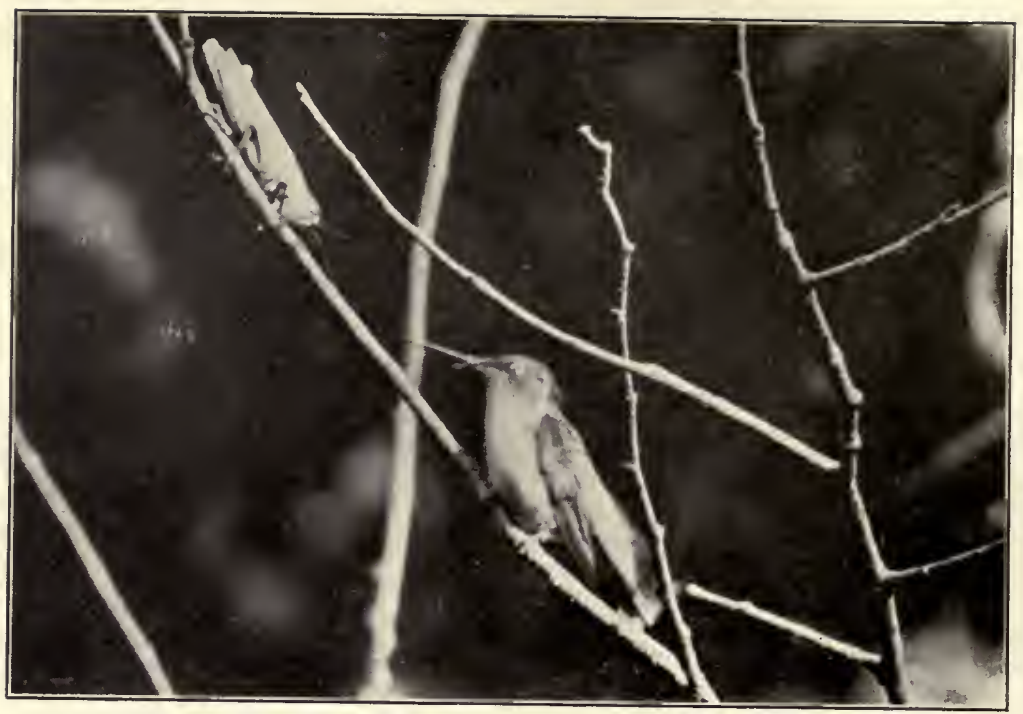

Fig. 67. RUBY-THROATED HUMMINGBIRD

(page 138)

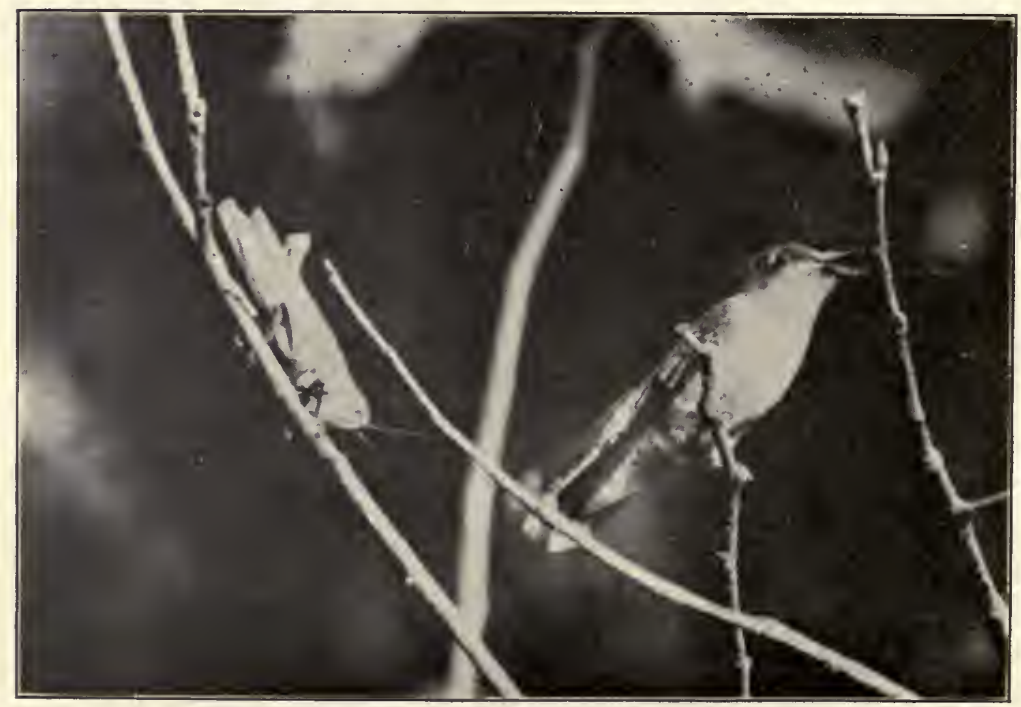

Fig. 68. RUBY-THROATED HUMMINGBIRD

(page 140) 


\section{XXXIX}

RED-HEAded WoOdPECKER; Tricolor 406. Melanerpes erythrocephalus

The red, white and bluish-black markings of the Redheaded Woodpecker are so well defined and so uniformly present that having once recognized the bird is to remember it. It is ten inches long and more migratory in its habits than are its cousins, Downy and Hairy. While most of these birds have taken their departure by October a few may remain in the central states all winter and may be seen with the Downy seeking food stored in the crevices and holes by the last summer's neighbors. (Fig. 61.)

The Red-headed Woodpecker has the habit of laying up a winter's supply of acorns and nuts, which it often never returns to eat. It is a great destroyer of injurious wood-borers and foliage-eaters. I have, on two or three occasions, caught this bird in the act of destroying the eggs and devouring the young of other birds. It builds its nest in a cavity excavated by its own labors in a dead tree trunk or a dead limb of a live tree. Here it lays from four to six eggs which, like those of most birds that nest in dark recesses, are pure white, unmarked.

This bird is especially fond of clearings where many large dead trees have been left standing, from the tallest limbs of which it seeks its winged prey. No flying insect coming within visual range is safe. I have seen a Woodpecker fly from its perch, vertically, two hundred feet, and catch some kind of flying moth or beetle.

Woodpeckers often quarrel among themselves and with their bird neighbors, regardless of any justification, but, though quarrelsome and inclined to fight one another, there are times when they show much friendship and sense of humor while playing a game of "You Are It" or "Hide-and-Seek." It is of absorbing interest to watch a half-dozen of these birds engaged in this amusing pastime. 
While the Red-headed Woodpecker is fond of insects and animal food it has an appetite for acorns, beechnuts and fruits and is in a measure governed in its migration south more by the harvest promises of the latter than the scarcity of the former.

Every child of school age knows this bird on sight and by hearing, for it is as conspicuous on every telephone pole near our cities as the advertisements setting forth the superior qualities of a particular brand of chewing gum, liver pills or smoking tobacco. In fact, the owners of some of the trolley lines entering Kansas City have found it necessary to wage war on these kitchenette builders in the cedar trolley poles. (Fig. 62.)

$\mathrm{My}$ residence is on one of the most traveled boulevards in the city, yet within a half-block of my house several Red-heads live each year and become tame, having pre-empted several phone poles in an alley just back of me. Daily during the mating season a male bird may be heard riveting away on the top coping of the slate roof of my house. Why he does not break or dull his awl-like bill I do not understand. It may be music to the patient and devoted ears of his mate but, to my way of thinking, there is a lack of that harmony one expects in music. 


\section{$\mathrm{XL}$}

Red-BeLlied Woodpecker; Zebra WoodPecker 409. Centurus carolinus (Linn.)

The Red-bellied is one of the handsomest of the Woodpecker family. The male, with crown and nape of deep scarlet and a faint redness on the belly, with whitebarred outer tail feathers, white rump and general grayish color, is easily identified. In the female the red of the throat is replaced by white.

The Red-bellied Woodpecker may be readily differentiated from the Sapsucker, or Yellow-bellied Woodpecker, since the latter has a crimson crown bordered with black, and a crimson patch on its chin, similarly bordered; the remainder of its under parts are yellowishwhite.

Red-belly is about ten inches long. The young quickly assume the plumage markings of the old birds. The species is distributed over the central part of the United States, where it may often be found at all seasons.

These Woodpeckers excavate nest cavities in dead limbs of live trees and in trunks of dead deciduous trees: The nesting hole is usually a deep, roomy affair in which are laid from four to six eggs. No nesting material is carried into this dark recess. The bird shows a remarkable sagacity in selecting the under side of a limb or leaning tree trunk, where the front door will be protected from the rain and glaring rays of the sun.

Like its big pileated cousin the Red-bellied Woodpecker resides from choice in large and heavily timbered flats near watercourses; it is not so alert or so shy as the former, but occasionally builds its home and rears its young in the large trees in suburban residential districts, and is a much more peaceable bird than the Red-headed Woodpecker. (Fig. 63.)

Like the Hairy Woodpecker the Red-bellied bird is often wrongly called a Sapsucker. The latter's breed- 
ing range is much farther north and it prefers live coniferous trees in which to excavate a nesting chamber.

Like the rest of the family the Red-bellied Woodpecker secures much of its food from beneath the bark of trees; it may be seen at all seasons spirally girdling the tree trunks in search of insects and their larvæ, often interrupting this routine by darting after some winged insects of its choice, as they fly near.

These Woodpeckers do not visit fruit and berry patches as often as the Red-head, and thus are far more beneficial to the farmer than harmful to the orchardist. 


\section{XLI}

Flicker; Northern Flicker; Golden-Winged WoodPECKer; High HoLe; YeLlow-Hammer 412. Colaptes auratus luteus (Bangs.)

The Flicker and its sub-species are found over most of the United States; it is migratory and, like most insect eating birds, is governed by climate and food supply.

This Woodpecker is about twelve inches long. Its wings have black bars on a brownish background; white, on its rump, is especially noticeable while the bird is in flight; the tail and wings have a beautiful lining of freshly-burnished, old golden-yellow. There is a black crescent across the breast of the male and a black stripe from the upper mandible, likened to a moustache. On the nape is a scarlet spot. As these birds fly they open and close their wings, making undulating sweeps.

Flickers nest in holes of their own making or in natural cavities in trees, selecting dead trees or decayed wood to excavate for nest-sites. The eggs-from four to six in number-are pure white. The birds carry no nesting material into the excavated cavities. Although Flickers are wild birds, nesting in seclusion, they often invade large cities and carve their nest holes in large trees along the sidewalks and in the parks.

As it likes the open fields and grassy pastures for feeding grounds, the Flicker prefers to live near the habitation of man. It is fond of man's Flicker houses, when they are constructed along its own architectural lines, although it is a good carpenter and chisels the deepest nest of any of its family. There, however, its wood-carvings cease, as it does not, like the rest of its kind, dig into trees in search of food but is a ground feeder. Nothing suits the Flickerish taste more than a meal of big, black ground ants.

These birds are a common sight on golf courses and cattle pastures, digging away at ant hills. A Flicker soon starts a commotion in an ant colony, and, of course, 
as usual, the ants rush to the surface. All Mr. Flicker has to do then is to lick them up with his long, sticky tongue. While on the ground their bodies lie very flat and they have the habit of frequently raising their heads to assure themselves that no danger is near, and then slowly resume their food-seeking labors.

Progress, on the ground, is made by a series of jumps; in the air, by a wave-like bounding. It is an amusing and interesting sight to witness a social gathering of several of these birds on a big oak limb. Of all the polite bowing, scraping of feet and sidestepping you ever saw this is the greatest. While these gyrations are going on the most voluble gossip is under way, first one, then another taking turns, as if indulging in backyard scandal.

The Flicker is a bold, fearless bird when nesting and will return to the nest while you are within a few feet of its location. The picture here shown was made as the bird passed over a fish line running from below the nest entrance to the shutter release. (Fig. 64.)

Like other members of their family, Flickers love to peck away on a tin roof or chimney. They are the drummer boys of the bird regiments in every woodland and pasture. 


\title{
XLII
}

\author{
WHIP-POOR-WILL; NIGHT-JAR \\ 417. Antrostomus vociferus
}

As the twilight fades and the shades of approaching darkness are slowly drawn over the woodland landscape, after the Wood Thrushes have ceased their songs, then the Whip-poor-will from its far-off leafy dell begins its evening concert, which is soon taken up by others in nearby glens, until the night resounds with the music of these nocturnal songsters.

If you approach the source of the song cautiously, you may get within a few feet of the bird and hear its ventriloquist-like subdued tones before it takes flight on noiseless wings, only to renew its serenade from the next ravine.

The Whip-poor-will is an abundant summer resident in the Mississippi valley. It prefers scrub-oak, dry hillsides for its home. Swope Park in Kansas City, for instance, is a favorite nesting place for the bird. It does not frequent pastures since, if it did so, its eggs would be destroyed, as are those of all ground-nesting birds, by grazing herds or devoured by hogs.

The nest is a mere depression in the ground, no building material or lining being used in its construction. The nesting bird is rarely found unless you flush it from beneath your footsteps; then it goes away in the feigned condition of a bird terribly crippled in both wings and legs. In my early life I was led away from the eggs many times by this ruse, the bird flying to safety when I had followed it for quite a distance from the nest.

The Whip-poor-will resembles the Night-hawk very closely, and the latter bird is often called the Whip-poorwill. But if one will only recall that the habits of the two are entirely different the mistake will not often occur. While many Night-hawks may be seen flying in great circles on cloudy days and at approaching nightfall, these birds that so much resemble the Night-hawk 
are never seen in flocks and do not feed during daylight. The Whip-poor-will is a solitary bird, feeding after dark near the ground. With noiseless wings it glides across the fields at dusk in pursuit of insects. It is about ten and one-half inches long, of a general ashy-gray color,-finely mottled, with a black medium stripe on the head and a collar of white marking the under side of the neck; the belly is of a dirty white with faint brown transverse bars, and a part of the outer tail feathers are dirty white.

The picture of the Whip-poor-will in this collection was kindly furnished me by Professor A. E. Shirling. (Fig. 65.) 


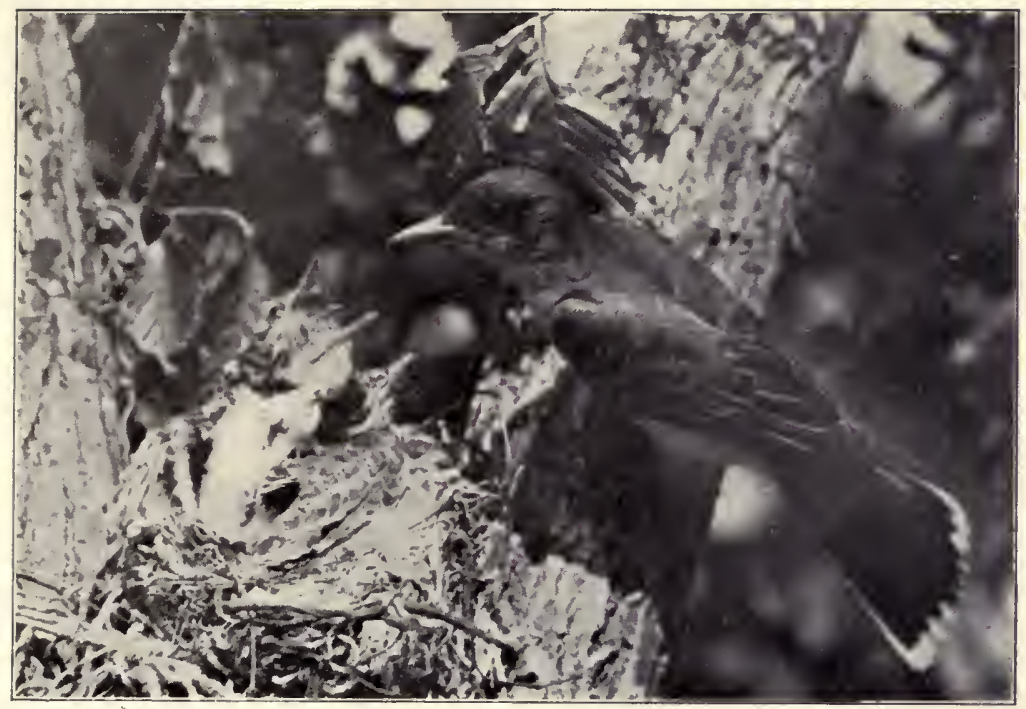

Fig. 69. KINGBIRD

(page 142)

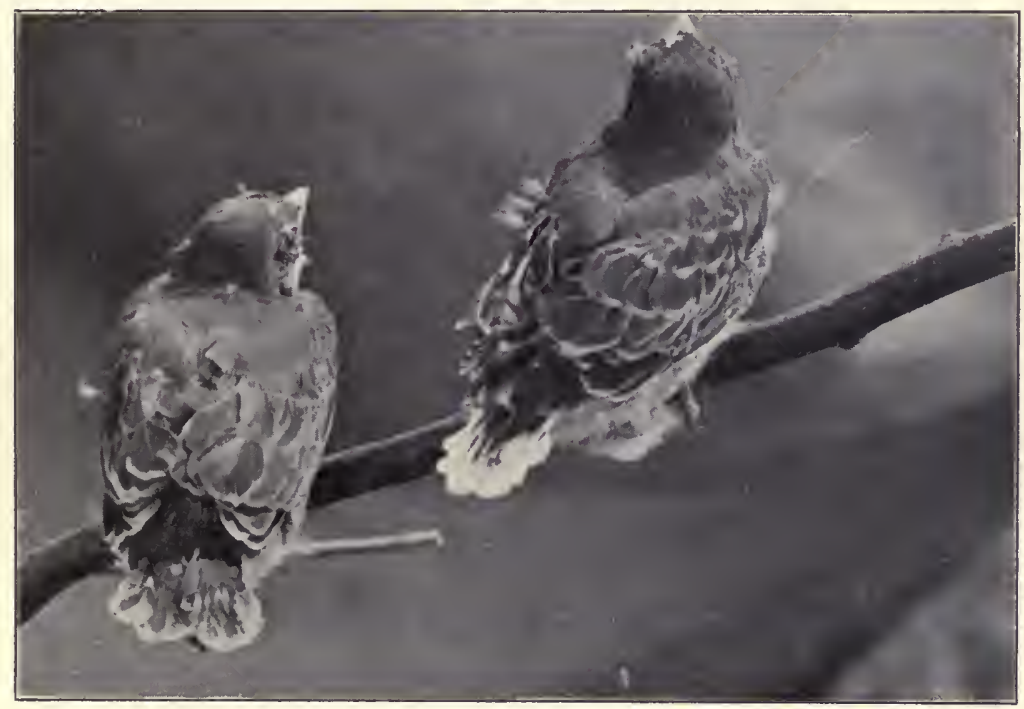

Fig. 70. KINGBIRD YOUNG 


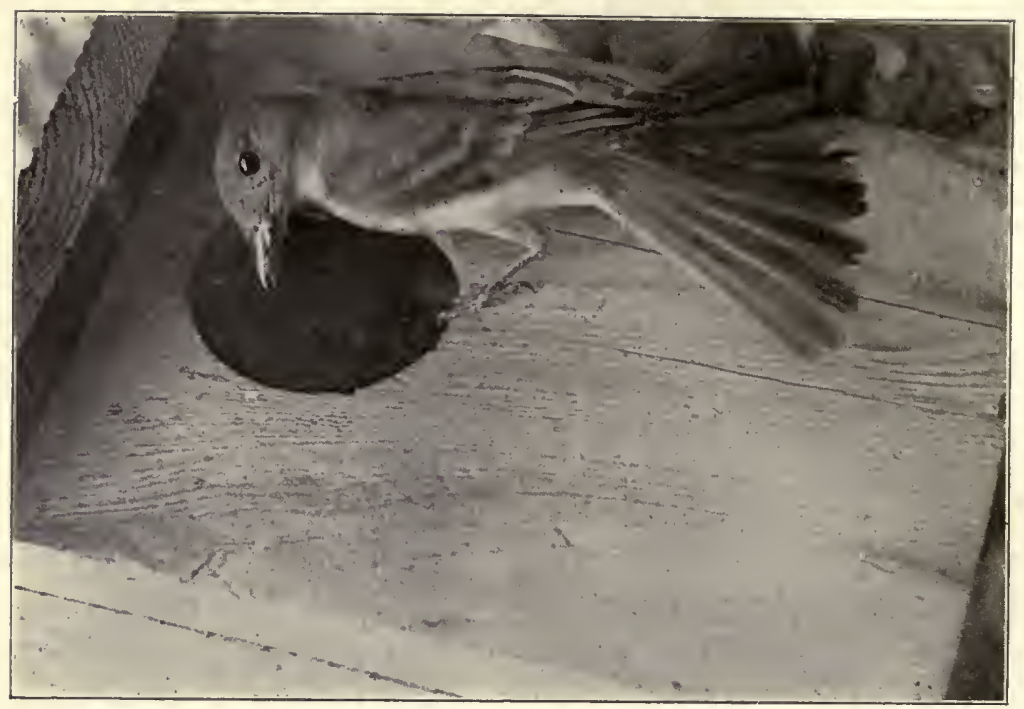

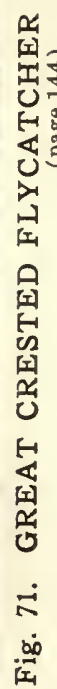
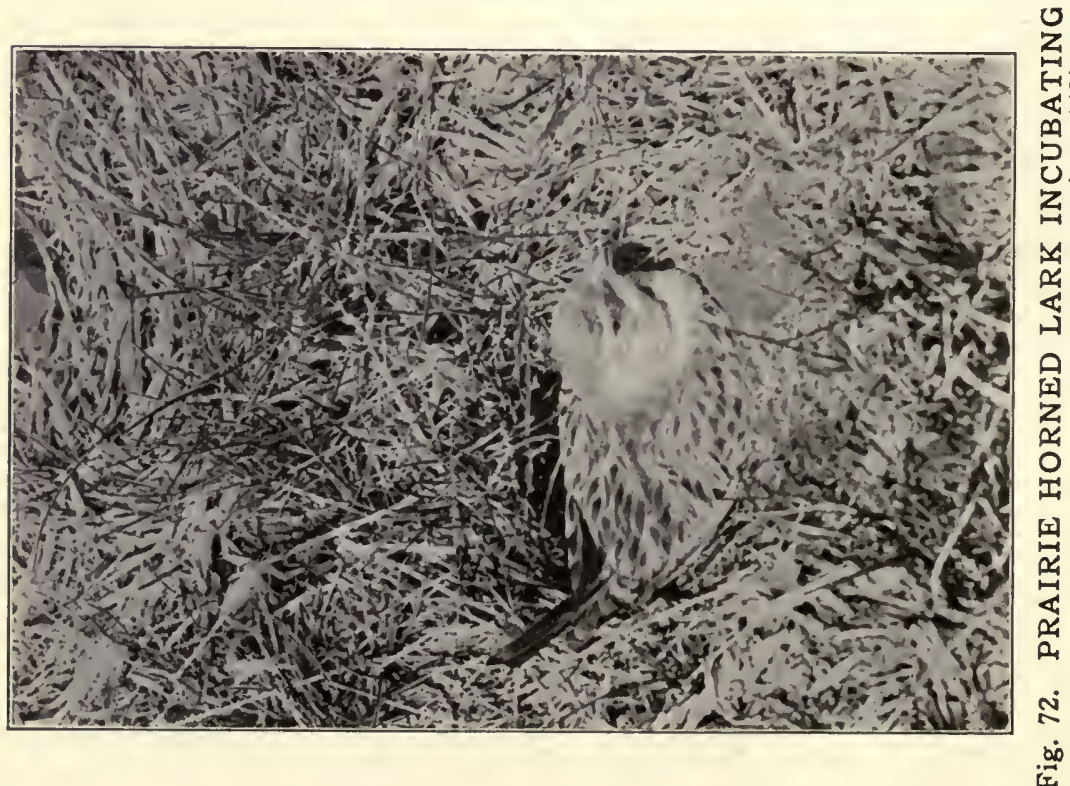


\section{XLIII}

\section{Night-Hawk; Bull Bat \\ 420. Chordeiles virginianus sennetti}

The Night-hawk is ten inches long and has beautiful gray and white-marked feathers, well adapted to blend with its setting when nesting, as it does, on the bare ground or on a rock. The eggs are stone gray. No preparation is made by the bird for the comfort of the two prospective young; the nest is just a bare spot on the cold damp earth, where the surroundings are so nearly the color of the setting bird that it is hard to see or picture, so completely does the plumage mimic the background.

This bird in no way resembles a Hawk either in actions or appearance: it has neither the grasping talons nor the hooked bill of the raptores; neither is it a bird of prey. It is often mistaken for the Whip-poor-will which it resembles in appearance, but not in habits. It is a graceful, swift and sure flycatcher. Not even the quick dragonfly can escape the accurate and vigorous movements of the Night-hawk.

From the bellowing-like noise produced by the air rushing through its wings as it makes a lightning headdive from great heights, the bird is known as the Bull Bat. With a frog-like mouth bordered by bristles and a diminutive beak, it is a peculiar looking bird. It has not a single bad trait and many useful ones. It should be protected from ruthless slaughter.

When the young first escape from the egg they resemble a miniature powder puff, or a bunch of rabbit's fur, and are colored so much like their surroundings that they are hard to find, even after one has marked their location.

They are birds of wide distribution in the United States, with similar traits, regardless of locality. They have white identification marks on wings and tail, by which they may be distinguished from the Whip-poor-will. 
The daylight-feeding habits of the Bull Bats and their habit of collecting in flocks late in the evening also are traits not observed in the Whip-poor-will.

The Night-hawk, or Bull Bat, is a poor percher, owing to the shape of its feet. As with closed eyes and feather-hidden beak it sits lengthwise of the perch, it presents a sphynx-like appearance.

In almost any locality, at certain seasons, on a cloudy evening, flocks of these birds can be found darting after their flying food; they are the original animated head-divers. During the mating season many may be observed circling high in the air; and occasionally from no discernible motive one may be seen to take a headlong dive toward the earth at such a rapid and reckless speed that you fear for the safety of the bird, but it glides gracefully in a beautiful curve upward and takes its place among its companions whirling high above it.

As a boy, I remember many a fruitless chase after this bird, as it fluttered from its eggs in a most helpless and pathetic endeavor to escape being trampled upon. The race usually resulted in leading me away from the eggs or young and always in the bird's suddenly recovering from the feigned helpless condition and taking refuge in a flight to safety, much to my surprise and disappointment.

The photograph in this collection is of that pale subspecies known as the Sennett's Night-hawk, found in the open prairie sections of the central United States. (Fig. 66.)

I had been longing for a chance to make a good picture of this bird and had about abandoned all hope, when early one morning Mrs. Cordier, looking from her bedroom window, discovered a bird sitting the long way of a metal down-spout on the porch roof, within ten feet of the pane. She called my attention to it and within ten minutes I was busily engaged in taking the Nighthawk's picture. It was the most artistic piece of birdrepose posing $I$ have ever seen. It rested in this position from seven A. M. until half after five, and during that time I made one dozen good negatives. As twilight approached and the glare of the sun diminished, the sleeping bird slowly opened its eyes, gently ruffled its feathers, spread its fluffy wings and noiselessly took its departure to join 
its feeding companions, as they circled and dived in the insect-laden upper air currents. Should the bird ever pass this way again on tired wings, a hearty invitation to visit me awaits it and the down-spout will be found in the same old place. 


\section{XLIV}

\section{Ruby-Throated HummingBiRd 428. Archilochus colubris}

The back of the Ruby-throated Hummingbird is of a metallic green color; the chin is black, the throat is ruby and the belly is whitish. The females and the young are without the ruby throat. The tail feathers are barred black and white-tipped. The length of the bird is four inches.

The "Hummers" are confined to this continent where about five hundred species have been classified, extending over a range from the Arctic Circle to Patagonia. About sixteen species are found in the United States. The Ruby-throat is the only one found in the vicinity of Kansas City, Missouri. (Fig. 67.)

They are late nesters, as the warm season must be thoroughly established lest the delicate young be chilled to death by an unexpected cold spell. The nest is located a few feet from the ground on a horizontal limb, frequently over the water. There are two eggs, pure white, or slightly rose-tinted. The nest is the very climax of bird architecture, finished in wonderful perfection and lined with the most delicate, silken, plant down.

The male is very attentive during the mating season; he is frequently seen feeding the female and bestowing other sweet and loving tributes, but as soon as the eggs are laid he refuses to accept as any part of his duty the drudgery of household affairs. Incubation lasts about twelve days, and the young remain in the nest twenty. eight days after hatching.

Hummingbirds are pugnacious tó a marked degree and do not hesitate to attack birds many times their size, or even human beings if the sanctity of the bird homes is invaded.

These birds feed on honey from the flowers and eat the small aphis so abundant on flowering plants. The delicate feet of these beautiful little creatures are rarely 


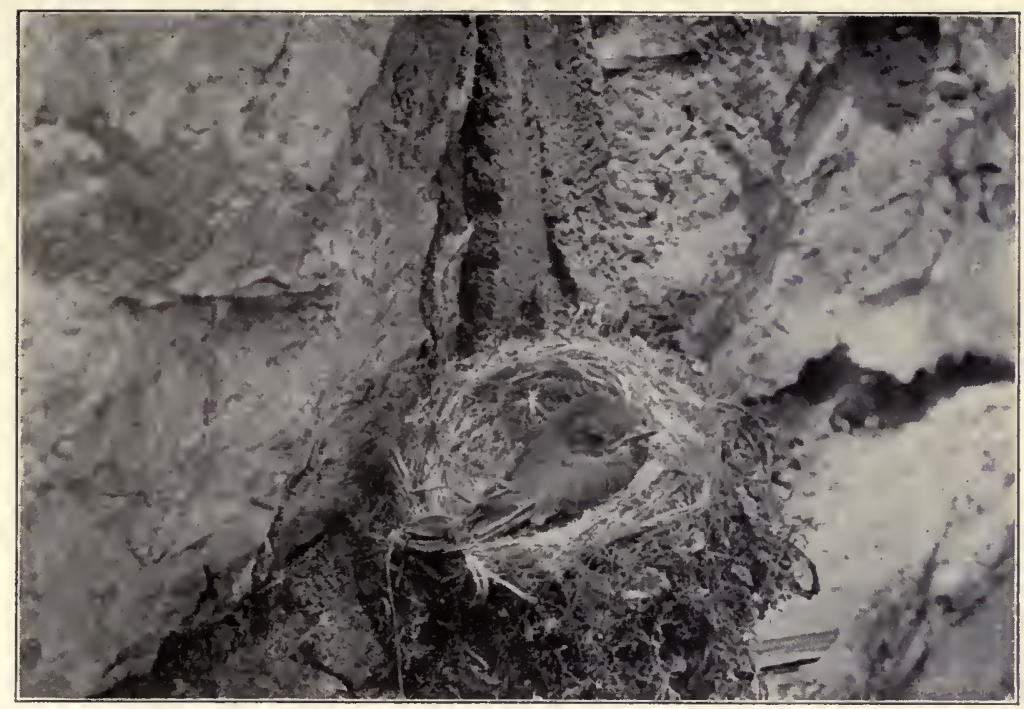

Fig. 73. PHOEBE YOUNG

(page 147)

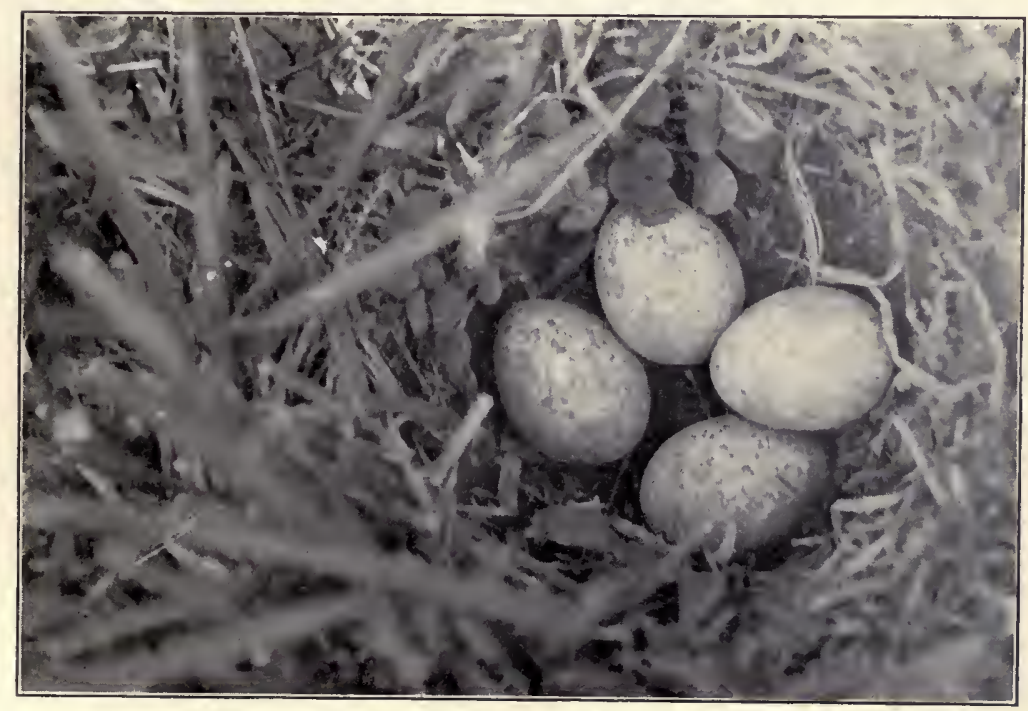

Fig. 74. PRAIRIE HORNED LARK'S NEST AND EGGS

(page 148) 


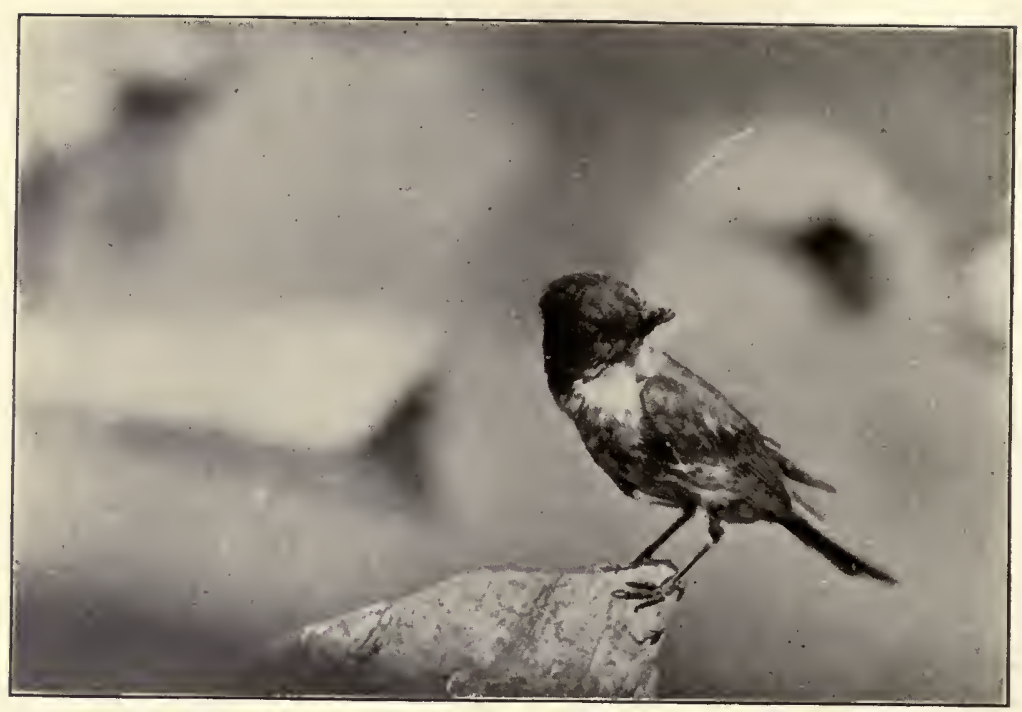

Fig. 75. PHOEBE

(page 146)

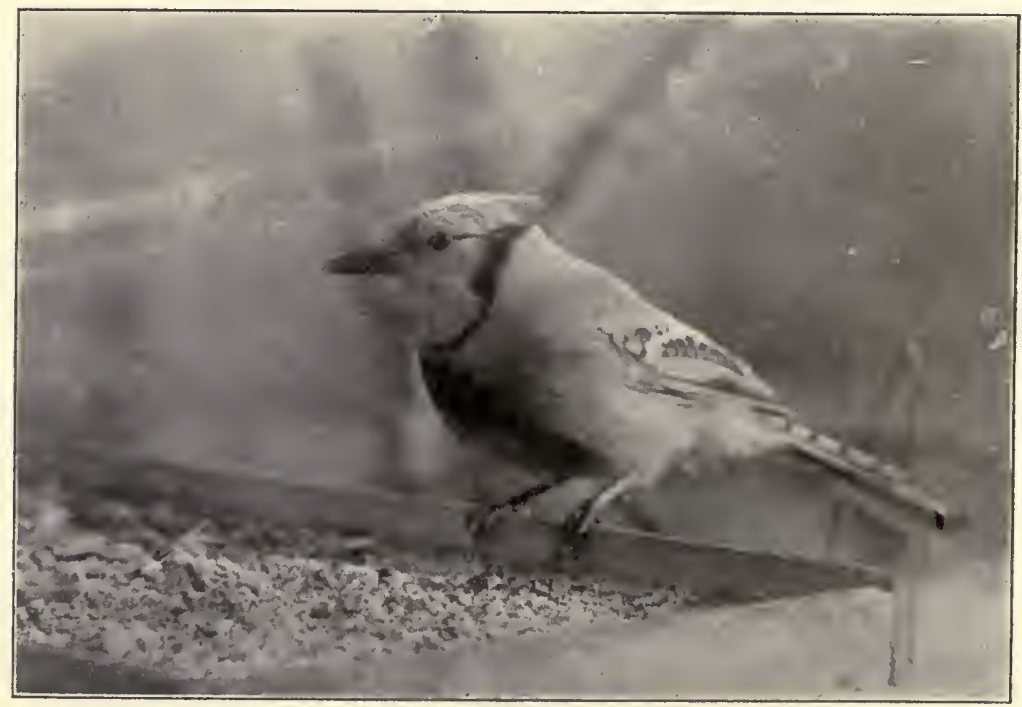

Fig. 76. BLUEJAY

(page 150) 
seen by the average observer, as they are seldom still when within close range. From the bird tent, for the first time, I got a good look at the feet of a living Hummingbird, and such diminutive naked ankles and bare feet as they have! The foot is a perfect anatomical foot of a perching bird.

When one beholds these four-inch mites of the bird kingdom and compares them with the great Condor, the Ostrich, the Eagle or the Man-o-war bird with its eight feet of wing-spread, one can only marvel at the disparity in size, and the kind and quantity of food consumed by each. Just imagine the graceful poise of the Eagle as, without effort, it soars high in the heavens, and compare it with the halo of invisible vibrations of the wings of the tiniest of our birds. Then view the exquisite shimmer of the Hummingbirds in their floral settings and you will not dispute their right to the title, "Jewels of the Bird Creation."

The first day I arrived off the coast of Laguna de la Madre, in Texas, I was much surprised at the vast number of Ruby-throats. They were whizzing in all directions, as they flew from flower to flower. Many of the birds had the black gorgets of the Black-chinned, or Alexander's Hummingbird. I hunted faithfully for a nest, but failed to find one in the locality.

My first nest was found in Missouri, on an apple limb six feet from the ground. Daily I visited this nest, being careful to avoid disturbing the mother bird. One day when I peeped into the nursery I beheld two naked, helpless atoms, looking as little like their beautiful feathered parents as possible. Without form, with big heads, and with dimmed darkened areas the location of their eyes, they resembled a young drone bee, or anything else, rather than a bird.

What a change in the appearance of these babies a few days made! At the end of ten days the young birds were partly feathered and had increased several times in bodily weight. At the end of four weeks they were snugly packed into the little cup-shaped nest, fully feathered, and were making preparations for breaking home ties. With vibrating wings and much ado these pygmies perched on the rim of the cup and made their first effort to fly a few feet and perch a short time before 
taking their departure into the big world beyond. (Fig. 68.)

One afternoon, while prowling through an unfrequented part of Kansas City's great Swope Park, I found a large bed of jewel flowers in full bloom. I paused on the edge of this matchless spread of pink and yellow blossoms to admire its beauty. A flash of color shot by my head, accompanied by the hum of a pair of wings, then another and another, until I stood in the midst of a flock of Ruby-throated Hummingbirds, eight of them, busily endeavoring to drive the unwelcome guest from the vicinity of their cups of nectar. First one and then another darted above my head like feathered bullets. Finally, seeming to realize that I meant them no harm, they accepted my presence as of no significance and returned to their unfinished repast. I soon discovered that there were three or four families. No full-grown males were present. After a few flowers had been robbed of their sweets one or more of the birds alighted on a certain small dead twig near the ground in the edge of the flower bed. I soon had my umbrella tent erected and my lens focused on the spot where the birds had been resting, and in the course of two hours succeeded in getting eight good negatives of this hard-to-photograph bird.

On one occasion, just as I was on the eve of making the exposure of the plate, a large green-grasshopper alighted on the twig within two inches of the bird. I quickly pressed the bulb. The Hummer, not much larger than the grasshopper, looked inquiringly at the intruder and in a dignified manner jumped three inches to another twig, and I pictured the pair a second time.

I examined many of the flowers in this bed for small insects, but failed to find a single bug. Whether the bugs had all been removed by the birds, I cannot say, but anyway the birds were feeding persistently; it must have been on flower juices alone.

These smallest of all birds are truly little comedians; their antics were very amusing as they tried to feed two at a time from the same flower, or as they chased one another from flower to perch, and around the sides of the tent. The birds repeatedly fed so close to the slits 
in the walls of the tent that I could have touched them with a finger through the openings.

The mother bird was constantly uttering words of assurance or advice, all the while flying about the young. The whole time they were feeding they kept up a continuous chattering that sounded more like that of a basket of young kittens, or the squeaking of a small piece of unoiled machinery, than a young bird's song. When they fed within two inches of a tent-slit near my face the buzzing of the air was like that of an electric fan. 


\section{XLV}

Kingbird; Bete-Martin ; BeE-BIRD 444. Tyrannus tyrannus (Linn.)

After watching this bird, which is only eight inches long, in its persistent and vicious attacks on birds many times its size, one can appreciate why it is called the Kingbird, or the Tyrant. It has a broad territorial range and breeds where found during its summer sojourn. There are few open pastures, parks or golf courses whose wide spaces, scattering shade and ornamental trees do not harbor a pair of these birds.

The Kingbird is of a blackish ash color over the back; it has a white breast, dusky wings with white edgings; a beautiful fan-shaped tail of twelve dark feathers tipped with white, and a crested crown with a flaming spot on the center. (Fig. 69.)

The nest is placed from ten to fifteen feet from the ground and is composed of twigs, grasses, rags, twine and paper. The eggs, usually four, are white, thinly speckled with lilac or brown.

The Kingbird is the best of our flycatchers. For hours, patiently, this bird will perch on a dead mullen stalk or isolated twig, ever on the alert for passing insects; it is a great moth killer, thus destroying the egg layers of the small insect pest.

The Kingbird has no song and its only utterance is "keet, keet, keet!" while perched on some dead twig, waiting and watching for food. These same notes are rapidly repeated when the bird is fighting other birds, or anything that invades the sanctity of its home surroundings. Its every utterance, its every attitude, is one of alertness.

With white-rimmed eyes and erect orown the bird looks the tyrant its name implies. A Cowbird would be risking her very safety should she try to deposit one of her eggs in the nest of a Kingbird. It is the bravest of birds and will attack an Eagle, a Hawk or Crow. In 
fact, it has a special aversion to the egg-stealing Crow and the black rascal has rough sailing when it ventures across the border of the Kingbird's domain. I have repeatedly seen the fighter, in its vicious attack on a Crow, actually light on the latter's back, throw the plucked feather into the air, and keep it up for fully a mile. All the while the Crow was flying for dear life, acting quite as though it felt it had made a great mistake in traveling along that route that day. I am willing to wager it went the other way next time. Yet, with all its reputation for bravery and for fighting I have seen the tyrant put to flight by the smallest of our birds, the audacious Rubythroated Hummingbird, with seemingly little effort.

The pictures of the young birds were made after they had left the nest and were able to fly a hundred yards. (Fig. 70.) I captured them by throwing my focusing cloth over them, then by gentle handling persuaded them to pose for their photographs. Rest assured many assaults were made on me by the old birds. Repeatedly, my straw hat was knocked off as with bullet-like speed they darted past my head, all the while screaming their protest in the few words at their command. 


\section{XLVI}

\section{Great Crested Flycatcher 452. Myiarchus crinitus (Linn.)}

This bird is olivaceous in color, with brown head and a prominent crest; the throat and breast are ashen-colored, meeting abruptly the bright yellow of the belly. The length of the Crested Flycatcher is eight inches and its body is of a rather slim build. Like all worm and insect eating birds it is migratory, and is a woodland bird by choice, nesting in natural cavities in trees and in abandoned Woodpecker holes.

The nest is of an enormous size for so small a bird, and is composed of miscellaneous material into which, frequently, the cast-off skins of snakes enter. The eggs number from five to eight, buff-colored, with heavy, wavy, purplish longitudinal markings which are characteristic of the eggs of these birds.

The Crested Flycatcher is very quarrelsome and illtempered, and is also exclusive, claiming as its own the territory in the vicinity of the nest.

Owing to its habit of selecting a nest-site in heavily timbered areas this bird is not observed as frequently as its relative of the open glade-the Kingbird. However, that the Flycatcher sometimes invades the haunts of man is shown by the picture illustrating this chapter. Its screaming note, "what!" is often made just before it flies to another limb or tree, and you must not expect to see it at the point from which the call came. The loud shrill notes during the mating period and early nestbuilding cease with the advent of the young.

My friend, Professor A. E. Shirling, a lover of birds and the out-of-doors, was fortunate enough to draw in his bird box lottery a nesting pair of Great Crested Flycatchers, and through his courtesy I was privileged to picture and study the pair at close range. (Fig. 71.)

After I had once anchored my camera close to the nest the birds made no attempt at attacking me or the 
camera, although they are brave and are given to the habit of pulling out the tail feathers of their rivals and tearing them to pieces.

In the nest referred to were enormous numbers of chicken feathers, as though the birds had visited the barnyards in that vicinity. There were, also, large patches of chicken skin with feathers attached, as if the birds had utilized them as substitutes for snake skin.

It is claimed by some naturalists that a snake never goes near a piece of its own hide. The Crested Flycatcher, of all birds, most frequently utilizes a piece of snake skin in building, yet the nest is placed high in holes in trees too large for any snake to climb. The fact seemingly would negative the theory of the skins' being used as protection against snakes, but its use may be due to a preconceived idea on the part of the birds, or to inherited tradition. It would be just as well to reason that a Wood Thrush universally adds a piece of newspaper to her nest to keep away the editors and newsboys.

Each time the parents came with food, they perched on a nearby limb and silently viewed the camera, then flew to the nest entrance and quickly entered the box to feed the young. The box was full of loose feathers; a carpet-sweeper or a firm breeze across the entrance would surely have aspirated many of them. I could see the long necks, the big ugly heads and large eyes of the young birds as they were waved to and fro among the feathers. In this nest one of the very young birds became ensnared in the coils of a hair from a horse's tail and was found dead, hanging from the entrance to the nest, evidently thrown there by the old birds as it was too young to have escaped unassisted.

I considered myself very lucky in having the opportunity so easily to get a good picture of this living bird. The picture shows the temper of the bird, as it brooks no interference with its home affairs. 


\section{XLVII}

\section{Phoebe; Bridge Bird; Water Pewee 456. Sayornis phoebe}

After the arrival of the Prairie Horned Lark, Bluebird and Robin, our earliest spring birds, comes the little seven-inch-long Phœbe, adobe or mud nest-building, Bridge or Culvert Bird. The male arrives two weeks in advance of the female. The little plasterer-the male does not assist in the building-with moss and mud frescoes her future home on the sides of the bridge stonework, and if a deep pool of water is underneath the bridge all the better for Phœbe's choice. In it she lays four white eggs. The male, while shirking the plaster work, is faithful in feeding the female during incubation and in caring for the young. (Fig. 75.)

In unsettled localities Phœebes build under overhanging rocks near streams and other damp places. However, these birds prefer man-built bridges, not because man has built them, but because about them man has made open pastures and broad lanes, where the Phoebe loves to perch on a dead twig while watching for its flying food supply. As it patiently awaits the flying moth its tail is ever twitching and over and over it repeats its plaintive call, "Phœbe, Phœbe!"

These birds are skilful flyers and artful flycatchers. A moth wandering into a Phoebe's range rarely escapes the quick snap of the bird's mandibles. Once, on the twenty-eighth of May, I watched the parents of three young Phobes that had left the nest, gathering moths and other insects and feeding them to the young birds. The rapidity and accuracy with which they accomplished this task was a surprise. The old birds did not pause a second after catching a miller before delivering it to the young; this was managed exactly as a Hummingbird probes a honeysuckle- - that is without alighting during the act of feeding.

The Phoebe, a confiding little creature, appeals to all bird-lovers. It is so demure in manner that it at 
once elicits our sympathy and excites our admiration. Its very selection of a nesting site is one that takes us in memory back to the happy days of bare feet and muddy knees, when, as boys, we sought the location of a nest securely mortared against the bark on a log supporting the old-fashioned wooden bridge that spanned our favorite fishing branch or creek. $\mathrm{Oh}$, how we all loved to leave the tracks of our bare feet, knees and other parts of our anatomy imprinted on the slick banks underneath the old bridge - the home of the Phøebs! I am thrilled, in memory, as I write, remembering with what joy wethere are always two or three boys in every country neighborhood-proclaimed the discovery of a Phøebe's nest; and how surprised we were by the flight of the bird from beneath the bridge.

Like the early prairie settlers who built their homes from the material at hand, the prairie sod or sun-dried bricks or adobe, the Phobe does not go far for its nestbuilding material. The nest is beautifully built and securely anchored, and often covered with growing moss and lined with feathers and rabbit fur.

Under a bridge spanning a creek of the Blue Hills golf course a Phœbe built its nest. Hundreds of golfers crossed the bridge with only the thickness of an inch board separating their spiked soles from the head of the incubating bird. The male, perched on a nearby snag, watched tirelessly for insects, singing his song of "Phœbe, Phœbe!" and wagging his tail in a salute to the passing throng. And, incidentally, he had his photograph taken. Later, by the aid of a mirror, I secured some splendid negatives of the nest and young under the bridge. (Fig. 73.) 


\section{XLVIII}

\section{Prairie Horned Lark \\ 474. Otocoris alpestris praticola}

The scientific description-for identification of this bird is entirely too long for a short treatise on birds, such as this book is intended to be.

In a general way the Prairie Horned Lark resembles a Field Sparrow. It is about seven and one-half inches long and is marked by a grayish back, and a pale yellow on the throat; the under parts are white and there is a black streak across the forehead, ending on each side in a feathery horn; a black bar extends from the upper bill through the eye.

The nesting habits of the Prairie Horned Lark are very different from those of the Sparrow. The Lark is one of the very earliest birds to build its nest and rear its young; it has a broad stretch of territory for its range, breeding from Indiana to the Rocky Mountains and from Texas to Canada. (Fig. 74.) The nest is a depression in the ground, lined with fine grass. The eggs are four in number and are of a dark drab color, marked with splotches of brown.

Early in March, if you should be playing golf or strolling across a pasture on a gentle sloping hillside toward the east or south, where the early spring sunshine has melted the snowbanks and thawed the frozen soil, and should behold two little birds running along on the ground, pausing every few feet to look at you, then taking wing, flying in a circle and dropping near the spot from which you flushed them, busying themselves in a most indifferent manner gathering grass seed, you would be quite safe in the guess that these same birds were Prairie Horned Larks. Then, if you should look about and find a little grass-lined cup in the ground, you could be sure of the identity of the owners of the nest.

I have set my camera directly over the incubating bird and made her picture without disturbing her. (Fig. 
72.) It was a picture ever to be remembered. Four inches of snow fell when the young were a week old. I had visited the nest the day before, so when I looked from my bedroom window and saw the earth clothed in a mantle of pure white, my first thoughts were of the little, featherless, young birds. I made haste to visit them. When I reached the vicinity of the nest I could locate it only by the stake I had driven into the ground to keep the golf players from stepping on it. Much to my pleasure and surprise the little mother, with her gray back and beady eyes, was snugly hovering over her babies, while the drifting snow in the face of a stiff March wind had nearly hidden her patient and warm little body. That afternoon the snow on that southern exposed hillside melted, and the devoted little mother reaped her full reward by rearing all four of her precious, tender offspring. The little fellows increased forty per cent in weight the first four days.

After watching the fidelity of the old birds to parental duty, and noting the frequency with which these little ground birds were fed, one can easily understand the rapid increase in their weight. The parents invariably alighted on the ground a few feet from the nest and, running quickly to its site, fed the young, cleaned the nest and flew away. One of the birds kept close to the nest most of the time, but occasionally both birds joined in the chase of a particularly hard-to-catch moth. From early morn till late at night these parents fed on an average of every four minutes. No wonder the young birds fairly burst into full-grown birdhood. 


\section{XLIX}

\section{BLUE JAY; JAY-BIRD 477. Cyanocitta cristata cristata}

A minute description of this well-known bird is unnecessary. With its blue tail, tipped with white, bright blue wings with black bars, and its purplish-blue back, the Bluejay is most easily identified. If you do not see the bird, it will proclaim to you its name from a nearby tree, "Jay! Jay! D'Jay! D'Jay!"

It has a coarse, but substantial, nest, building when possible in an evergreen tree. There are from three to five eggs, buff with brown markings.

Blue Jays have a limited migratory habit, but are considered permanent residents of most of the central part of the United States. These birds have the habit of storing acorns and grain, to which they rarely return.

Because it has many disagreeable traits, the Blue Jay is justly placed on the black list of the birds we do not enjoy or encourage to be with us. (Fig. 76.)

"D'Jay! D'Jay!" the usual noisy exclamation, is frequently interrupted by an attempt to put consternation into the hearts of all hawk-fearing birds, by giving a good imitation of the cry of the Red-tailed or other Hawk-a kind of scream, followed by "Smart Alec, Smart Alec!"

Blue Jays are fond of bathing. During the nesting period the female acts as if she were the owner of an illicit "moonshine distillery," ever on the outlook for detectives on her trail. Observe her, as she noiselessly and slyly approaches the nest, dropping from limb to limb, until she reaches the threshold, when with no ado she settles into its depths, almost out of sight. As she sits in the nest a good picture can be made only when the camera is pointed downward on her back. This is not always possible, as the nest-site is frequently close to the body of the tree, thus making it difficult to place the camera in a good position. The Jay will let you picture 
the nest, or disturb the young, seemingly satisfied to remain quietly perched near by, as an onlooker.

The Blue Jay-the usually unsuspected demon of the bird world-is so demure and gentle in its meanderings of investigation that it will mislead you until you actually catch it in the act of stealing the eggs or devouring the young of other birds. Most birds are allies when it comes to making war on the Blue Jay, their common enemy. A Brown Thrasher whose nest was in my backyard, had daily fights with a Blue Jay, until a certain friend of the former put an end to the Jay's invasion of the Thrasher's domain.

Jays are great conversationists and seem to delight in their assembly meetings, or in gossip of a most earnest and confiding fashion, first one and then another, in turn, expressing views on the subject under discussion. This is true, especially, in family gatherings, after the young have left the nest. Jays have no tender spot in my bird affections. To me, the Blue Jay has a disagreeable personality, in that I look upon it as a villain, first, last and all the time. It belongs to no league of bird nations, recognizes no laws of bird-home boundaries, and invades the privacy of other bird homes, destroying the eggs and devouring the young. It is a sneak in its personality, yet proclaims its virtues in the loudest tones when it sees an Owl or Hawk, even joining the bird throng attacking the birds of prey. 


\section{Canadian Jay; Whiskey Jack; Camp Robber; Moose-Bird}

484. Perisoerus canadensis

This Jay is much paler in all of its colorings than the Blue Jay. The head and nape of the Canadian Jay are blackish and its back is ashy gray; the wings and tail are ashy blue and faintly tipped with white. The length of the bird is twelve inches.

These Jays build their nests in coniferous trees in remote and secluded places in the bottom land in Canada and the northern states, and on the foothills and sides of the Rockies. There is no bird that boasts a warmer or more serviceable nest than the Canadian Jay, as it is the very earliest to build, frequently building and laying its eggs in zero weather. In our northern states fullgrown young birds are often seen in early April. The eggs, four in number, are grayish with dark brown spots.

This Jay has a variety of pleasing notes and, like the Blue Jay, may fool you by its mimicry of other birds. It is an omnivorous eater and has the audacity of a pet Crow. Repeatedly, while on big game hunting trips in the remote regions of Canada, Alaska and the Rockies of the United States, I was visited at my camps by some of these birds, who made themselves at home by helping themselves to anything that met their fancy. I found them to be inveterate thieves; they would perch on a pine tree ten or fifteen feet from where I was eating and fuss, quarrel and complain about my want of hospitality, or charity. The instant my back was turned, or I took my eye off them, or the food was left for a minute, one of the Jays flew to my plate, grabbed a piece of venison or moose meat and departed in triumphant haste. One day I nailed a piece of tough mountain goat meat to a stump near my tent and gave "Jack" an invitation to help himself. He was not slow in accepting my hospitality, at the same time having his picture made. (Fig. 77.) 
When he is about your camp-site just watch his sly expression, which seems to say: "You just give me a chance and see how quickly I will help myself to anything edible or transportable." Despite his audacity and thieving proclivities I was always glad to see him and I gave him a hearty welcome. If you have two Indian guides, a cook, a congenial hunting companion, a few chipmunks and camp thieves about your tent, making free with your supplies, and you are not happy, your case is utterly hopeless.

One must admire the Canadian Jay for its endurance and stability, as it winters near a zero home-site, while nearly all its summer neighbors migrate to sunny climes. These Jays will eat anything they can find, and they will steal everything they can carry. At one of my hunting camps in British Columbia, one of these birds actually devoured half a bar of laundry soap and did not appear to regret its unusual diet, for it continued to be a daily caller as long as I remained in that vicinity. 


\section{LI}

\section{Crow; Common American Crow}

488. Corvus americanus

The head and back of the Crow are dull black, with wings and tail burnished. It is about twenty inches long and is found all over North America, nesting in tall trees or hedges. The nest is a large, compact structure of sticks and in localities where much binding twine is used in wheat fields, that material is freely used. I have seen nests where half of the structure was composed of twine. The eggs number from four to six and are of a greenishwhite with lilac or brown blotches.

Crows are very intelligent and have held their own despite the farmers' dislike of them. They use an alarm sentinel while the flock is feeding; they are omnivorous feeders. It is claimed that they are mated for life.

Both birds equally assume the nursery duties. (Fig. 78.) In winter Crows congregate in large flocks at night at one spot to roost. These birds are great lovers of their kind and of their homes. In its evening flight the Crow suggests, in its every movement, eagerness to reach the roosting rookery before dark. Ever on the alert, the bird is able to detect the presence of a gun in your hand or on your shoulder from a great distance.

In crossing a field where Crows are peacefully feeding on the ground, you may walk quite near them if you are unarmed, but just let their sentry, perched on a nearby elevation, see you with a pitchfork or hoe handle over your shoulder, and instantly his warning " $\mathrm{caw}$, caw, caw!' puts consternation into the whole bunch and they hurriedly make their getaway. As the plowman plods along behind his team and the furrows are turned, these same Crows seem to say, as they strut down the freshlyturned soil behind the farmer and his plow, "All I find is mine."

From a sentimental point of view the Crow has some traits to be admired, but from its general character as 


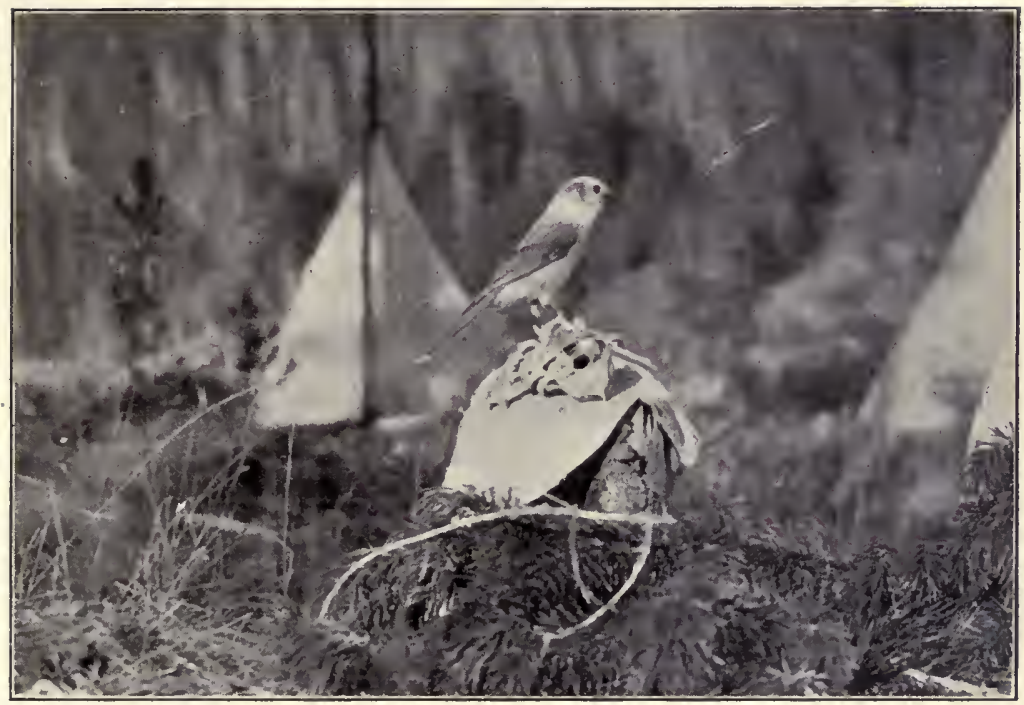

Fig. 77. CANADA JAY

(page 152)

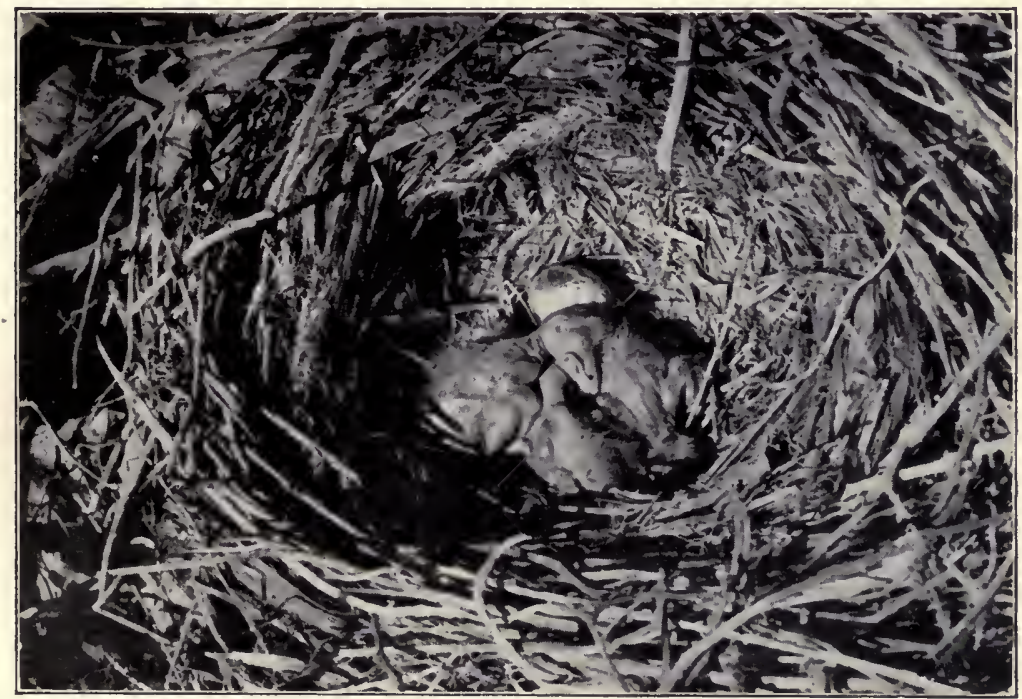

Fig. 78. AMERICAN CROW'S NEST AND YOUNG

(page 154) 


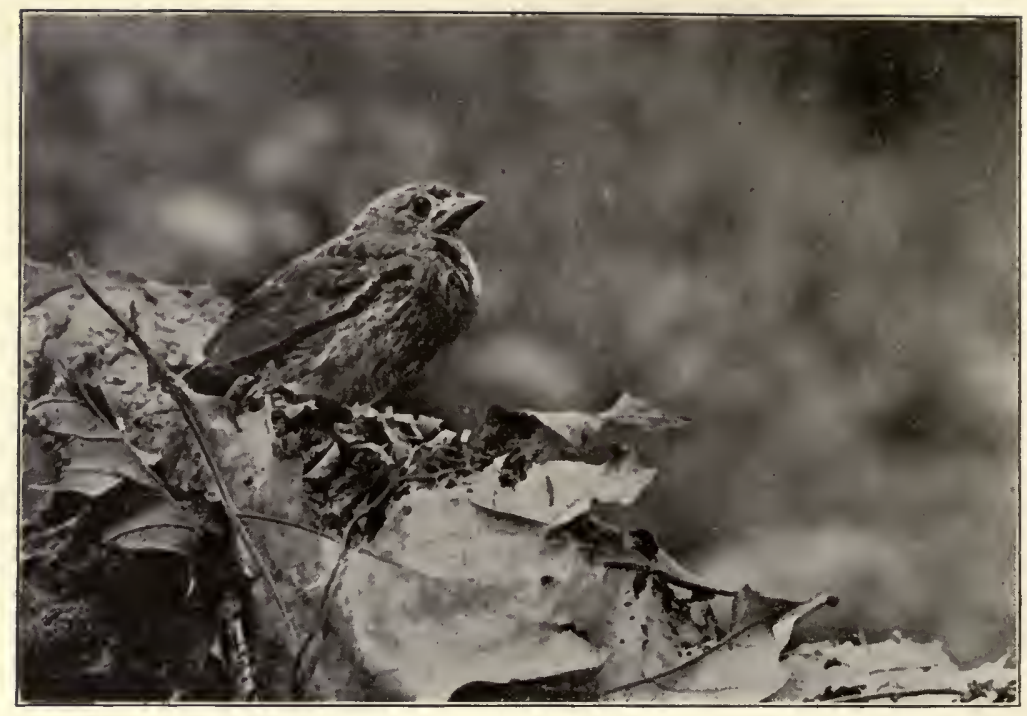

Fig. 79. COWBIRD YOUNG

(page 157)

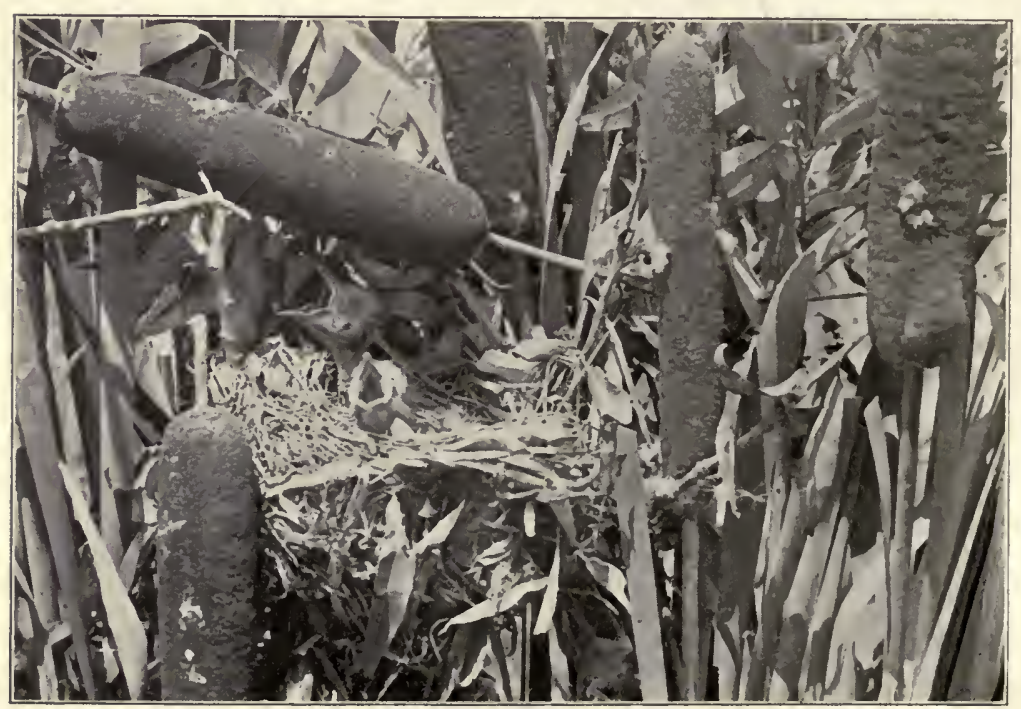

Fig. 80. RED-WINGED BLACKBIRD'S NEST AND YOUNG (page 160) 
a robber of other birds' eggs and young, and from its custom of pulling up freshly sprouted corn, it loses much of the sympathy of the farmers, who believe that their neighborhoods would be improved by the extermination of Crows. In persons we exact a standard of honor and usefulness. If we used the same measure in estimating the standing of the Crow in its community it would fall below the one hundred per cent mark. However, lest we do the bird an injustice, let us not use our own virtues for the basis of a Crow's standard. We must not let our young corn, young chickens, birds' eggs and economy make us narrow and exacting.

No farming community would be complete without its Crows. What farmer's inventory at the end of the season would be full without listing a few of these big black rascals among his livestock. We may not have much friendly feeling for the Crow, but we cannot refrain from admiring its audacity and persistence in its endeavors to be our neighbor and our guest. On the coldest winter day the Crow remains with us to give good cheer by its presence, as it wends its way through the cold air to nowhere in particular and every place in general.

The incomparable tribute of Bishop Quayle to the Crow will ever remain a classic:

"The Crow-nothing would induce me to part from him. Frankly, I love him, though to the best of my belief he does not return my affection. I love him and am glad I have woods where he nests in summer and where he spends his nights in winter, with his dusky wings closed against his dusky sides and his sagacious eyes asleep. He may do harm, but I doubt it; he does more good than harm .... for wherever he may have been by daylight, home he comes by twilight. . . . . If everybody knew enough to come home at night, wherever they may have been by day, the world would have more laughter and sweeter mirth and more heaven before heaven were journeyed to." 


\section{LII}

Cowbird; Cow Blackbird; Lazy-Bird; Vagabond; Tramp 495. Molothrus; ater ater

Most birds possess some trait that appeals to our admiration, love or sympathy; they are either beautiful, sweet singers, or useful adjuncts to our pest-destroyers, or they are edible. In the Cowbird we have a freak, in so far as its personality is concerned. Unfortunately, it does not possess a single quality that appeals to any of our better emotions. With its mongrel coloring of dull black and rusty brown, its unmusical, noisy attempt at singing, it's lazy method of obtaining food, its polygamous ideas and its utter abandonment of all parental responsibility, it is placed beyond the pale of human sentiment, and in the list of the outcasts of the bird kingdom.

The company of the Cowbird is avoided by all birds save the English Sparrows and Red-winged Blackbirds, which, in the fall of the year, are often seen mingling with the outcasts in small flocks.

Because of the fact that Cowbirds lay their eggs in the nests of other birds there is no way of estimating the number laid in any season. The eggs are dull white, sprinkled with small amber blotches.

The Cowbird is an omnivorous eater and is equally fond of seeds, berries and insects; it is just as broad in its social habits as it is firm in the belief of Mormonism and the practice of polygamy, and, void of parental instinct, it refuses to build a nest for its own use, or to assume any responsibility in the incubation of eggs and providing for the young, leaving all family pleasures, cares and responsibilities to some small bird in whose nest the Cowbird's egg is deposited and abandoned to the protection of the foster-parents.

The intruder's egg, being larger than those of the small bird, receives more warmth from the body of the incubating bird than the other eggs receive, and is hatched first. Then, being rapid in development, it 
crowds either the unhatched eggs or the little birds out of the nest and appropriates all the food the busy little foster-parents can provide. (Fig. 79.)

When the female Cowbird slyly steals through the underbrush and stealthily deposits her egg in the nest of the little Vireo, or the Yellow Warbler, and abandons it, she knows by some mysterious instinct that her egg and its future young will be amply provided for by the foster-parents. When the time comes for the Cowbird to lay her egg she does not feel the home-building impulse, or at least does not respond to it. Why bother about anticipated maternal duties by building a nest, or changing plumage, or pressing the male into the carpentry or plasterer's trade, when all these duties may be performed by others?

The Cowbird, to me, always has a peculiar sheepdog, sneaking demeanor, with nothing dignified, assertive or pugnacious to be seen in its actions. Watch the female as she sneaks to the branches near the ground in her quest of some nest to despoil with her egg. Her every action is that of a thief, or eavesdropper. She does not protest your presence in that locality. In fact, she seems to say, by her actions, that you have more rights near a bird's nest than a Cowbird has, and I fully agree with her on that point.

Unless I desire to observe the rearing of the young Cowbird by its foster-parents, I always remove the egg from the nest with a little stick, as the Vireo and other birds often abandon the nest if you touch their eggs with your fingers.

Cowbirds are good nest-finders. But on some occasions the small bird refuses to assume additional forced parental duty and builds a false floor in the nest to cover the Cowbird's egg. She then lays her own eggs on the new nest-bottom and thus thwarts the endeavors of the slacker.

The Yellow Warbler often resorts to this procedure. One day in July, while looking for nests and birds to photograph, I saw a slacker come up from the weeds and underbrush to a low limb. Her every expression was that of a sneak; her every movement was that of a traitor and a coward. I was satisfied that there was, in that vicinity, some bird's nest which she had been despoiling 
with one of her eggs. Sure enough, there, within two feet of the ground, in a small paw-paw bush, was a nest of the exquisite Indigo Bunting, containing three young Indigo birds, about half-grown, and right on top of them was a freshly laid egg of the Cowbird. This is the only instance in which I have actually driven the bird from the nest. It is the only instance where I have found a Cowbird's egg in a nest containing half-grown young birds.

The parental feeling in the foster-parents is much stronger than their power of identifying their own young, so the intruder continues to be cared for to the exclusion of the smaller weaklings, until, in many instances, the foster-parents' own young die from overcrowding and neglect, while the young Cowbird thrives on an undivided food supply. I have seen a blue-gray Gnatcatcher, not much larger than a Hummingbird, feeding a young Cowbird larger than the whole nest and its contents.

The Cowbird is the one so often seen on the backs of cattle grazing in the roadside pastures.

The Cowbird was justly named, when the older ornithologists dubbed it, "Mol'othrus"- the Vagabond, Tramp, Parasite. 


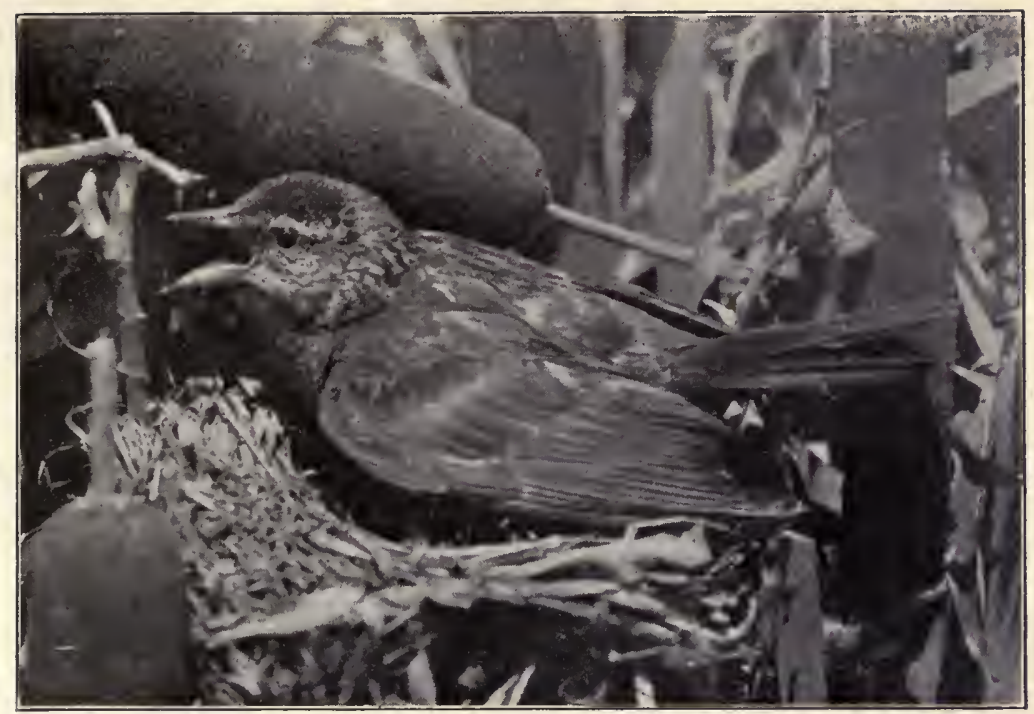

Fig. 81. RED-WINGED BLACKBIRD BROODING

(page 161)

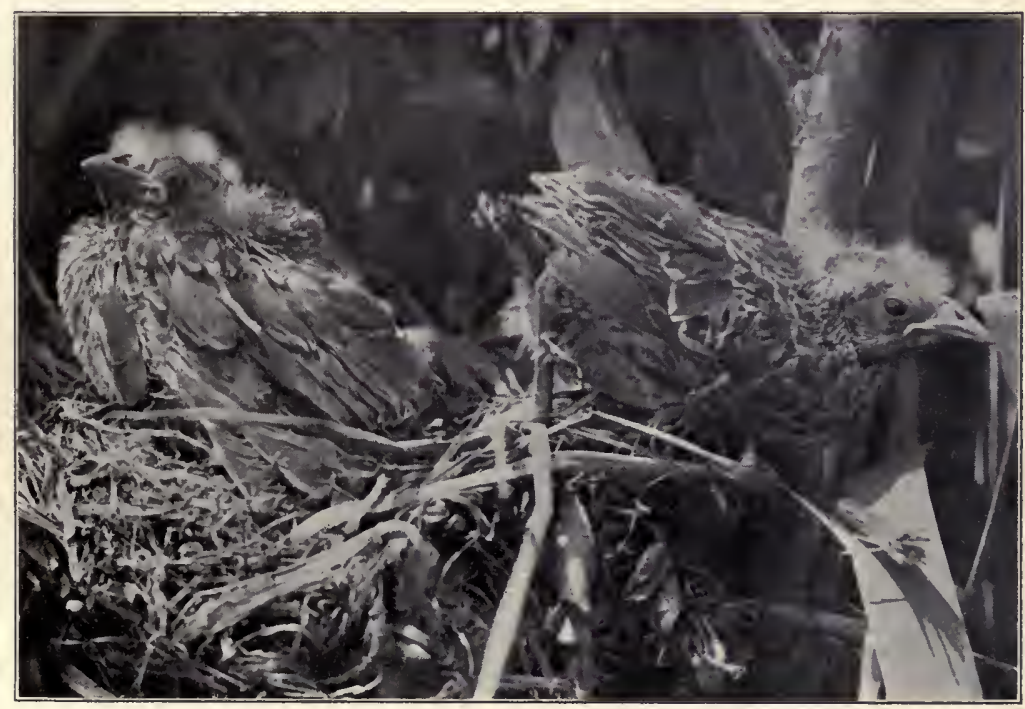

Fig. 82. RED-WINGED BLACKBIRD YOUNG

(page 162) 


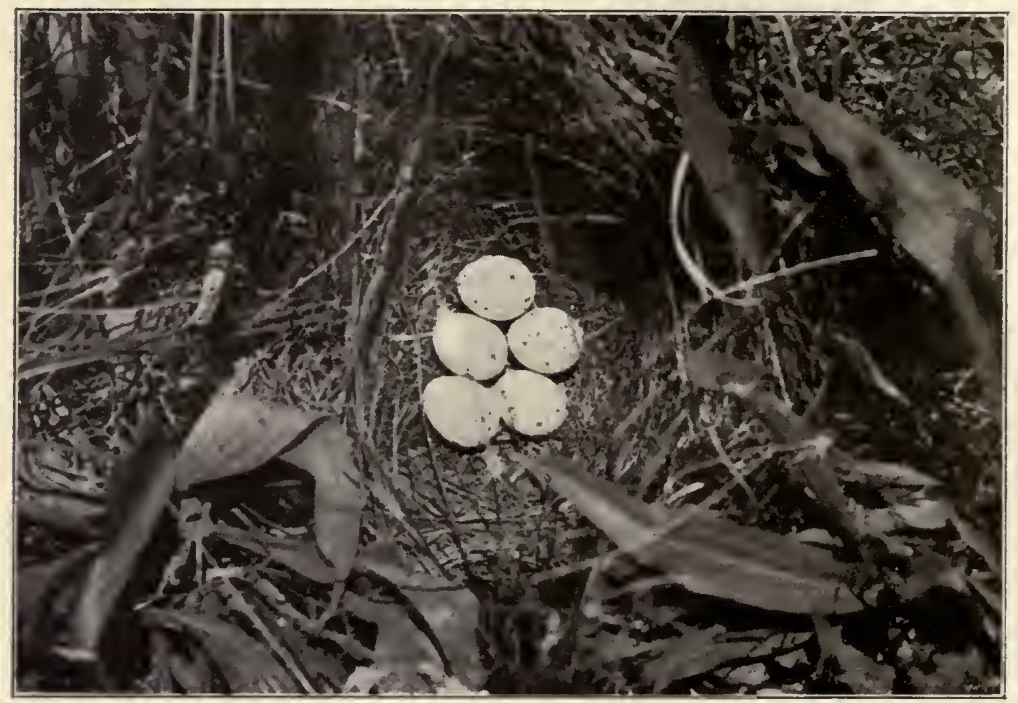

Fig. 83. MEADOW-LARK'S NEST AND EGGS

(page 163)

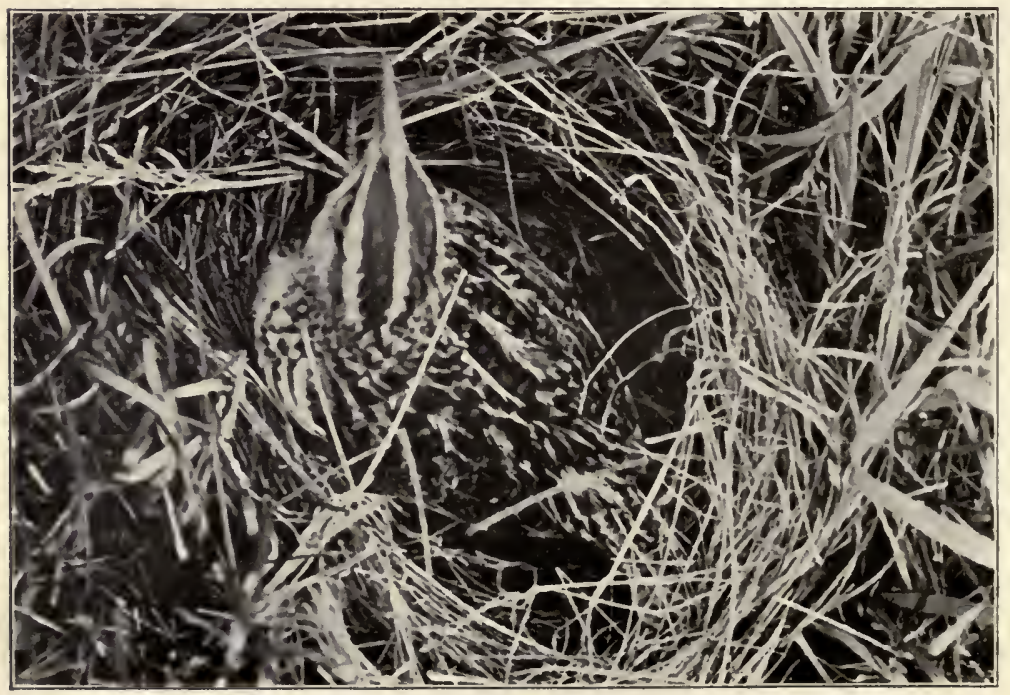

Fig. 84. MEADOW-LARK INCUBATING

(page 164) 


\section{LIII}

\section{Red-Winged Blackbird; Marsh Blackbird; Maize ThIEF}

498. Agelaius phoeniceus

This bird breeds all over temperate America. The male is easily identified by his general crow-black color, his scarlet epaulets and his poor efforts at singing. He is about from eight to nine inches long and is usually to be found in swampy localities, especially where cattails abound.

Red-winged Blackbirds nest in colonies. The female does not in the least resemble the male; her general color is brown and she is much smaller than the male. In fact, she looks much like a big Sparrow. Two or more broods are reared each season. From two to six pale bluish-green eggs, dotted or scrawled with brown, are laid.

These birds collect in immense flocks in September and October and often do much damage to grain crops. I have seen large numbers in company with Crows in their evening flights toward their roosting rookery. As these big flocks of Red-wings pursue their sinuous course they remind me of a great serpent, alternately rising and falling as they cross hills and hollows and dodge obstructions. I have seen these feathered processions miles long and several hundred yards wide. Stragglers from fatigue, or from a determination not to be led farther, drop out and light in nearby trees, but soon rejoin the horde and arrive at the roosting place with the "tail-enders."

Cowbirds, Grackles and Red-wings are all known as "Blackbirds." There is nothing in nature's doings of more absorbing interest than the evolution of a few bunches of water-soaked grass into the home of a Redwinged Blackbird. The nests are placed about three feet from the surface of the water and are carefully woven about the stems of the coarse grass and cattails. The 
nest-building material is used while wet. As it contracts in drying, the structure is firmly anchored to the uprights. This insures safety for the young birds.

To illustrate the use of the umbrella tent in photographing and observing birds at close range, I shall detail at some length the experience $I$ had in picturing the Red-winged Blackbirds. (Fig. 80.)

When I discovered this colony of nesting Red-wings, in a swamp near a fresh-water bathing-beach, the birds were in the height of nest-building. It was on the tenth of August. I made frequent visits to the settlement, for several weeks, and during that time I observed them from the date of corner-stone laying to that of the breaking of the home ties of the young. I made no effort at a close approach to the birds while they were at their work, until the incubating period was established; then I set up my tent within a few feet of a typical nest, and from day to day made close observations and many notes on the habits of the old birds. I have never spent a more interesting time at any nest-site than in that little swamp, up to my knees in water, cooped up in August, with perspiration streaming from every pore, yet with concentrated enthusiasm thrilling every nerve fibre. The unpleasant features were soon forgotten after entering the tent.

When I first erected the tent within two feet of the nest and returned to the edge of the swamp only a few yards away for my photographic outfit, the male bird that had been persistently flying about my head while I was putting up the tent started to follow me, but instead returned to the tent and began attacking it with all of the rage of a demon in feathers. Alighting on top, he would run about all over it, pecking at every crease and edge, then fly away ten feet and return to renew the assault with increasing rage, screaming with all his might. When I returned and entered the tent his temper was furious and the canvass was bombarded with feet and beak.

During this time the female did not approach the nest. But ten minutes afterward the male, from a nearby perch, began assuring the female that all was well, but that she must approach cautiously. With his "kankquer-ree" assurance she flew to the nest and renewed her 
incubating. I then made her first photograph with the lens within thirty inches of the nest. (Fig. 81.)

A few days later three young Redwings made their appearance in this nursery. Of all the commotion made by a bird this female's excelled. With a cricket in her bill she would come screaming toward the nest and light within two feet of it. The noise always excited the male and urged him on to a vicious assault on the tent. His attacking the top and sides with all of his vigor and rage seemed to dispel the fears of the female, for she would come to the edge of the nest, feed the young in a deliberate manner, and clean the nest before peacefully departing. All of this time her spouse, with his beautiful scarlet epaulets, his dark brown bill, and black feet and legs, was cavorting over the top of the umbrella tent, while from within I frequently tickled the bottom of his feet with a finger. This surprised and greatly bewildered him, as he vainly searched for the source of his mate's excitement, but he soon became reconciled and, perched on the center rod of the umbrella, uttering his peculiar "kank-quer-ree! kank-quer-ree!" while the female sought more food for the begging nestlings, and the bird photographer sweated, smiled and changed plateholders, getting ready for the next picture.

Each juicy cricket brought to the young was placed in a gaping mouth, observed by the parent bird-and the photographer-until it disappeared. If the favored youngster was unable to swallow the morsel it was removed by the parent, masticated and replaced. Then, if not swallowed, it was removed and given to another and observed until it disappeared.

The parental instinct was stronger in the female than in the male, but he showed more combative traits than she did. He alone attacked the tent, and the female did all of the feeding, while the young remained in the nest; but the male frequently fed them after they had left it.

While the young were in the nest the female, after taking a bath at the side of the tent, would return with her feathers wet and cool and hover over the young like an animated sunshade to protect them from the August sun.

At the end of ten days the home ties were broken by both of the young birds departing at the same time. 
However, they paused just long enough on the threshold to have their pictures taken. (Fig. 82.)

The time was now ripe for their first flight, as the nestlings were fully fledged. After much scolding and persuasion from the female, the young birds pitched headlong into the cattails, toward the boggy earth, but caught with each foot an upright stem and with straddled legs held on for dear life, climbing from stem to stem, until they reached a dead willow twig, a safe perch; there they posed for their last picture.

When I bade this family adieu I wished them a happy return to the place of their birth. 


\section{LIV}

\section{Meadowlark; Field Lark}

501. Sturnella magna magna (Linn.)

The Meadowlark is ten inches long; its crown is streaked with black and blackish-brown lines run behind the eyes; the lateral tail feathers are white. In general, brown and black colors prevail over the back, and yellow over the belly, with a black crescent on the breast. The two sexes are much alike in plumage. Owing to this bird's habit of constantly climbing over and through the tough grass, near the ground, its tail feathers become much worn and ragged by late fall of the year. In recent years a number of instances have been reported where the bird presented well-marked albinoism.

Meadowlarks are abundant summer residents in the vicinity of Kansas City, Missouri, breeding over their broad range. Their color is of a dead grass character, well adapted to protective mimicry during the ground-nesting period. They are insect feeders from choice, and seed eaters by necessity, and are fond of man's protecting surroundings. These birds are given to hiding in the grass, depending on their coloring to elude discovery. They alternately flap their wings and sail, when flying.

They nest on the ground, frequently arching over the nest entrance with living and dead grasses. The eggs, from two to five, are white with reddish-brown specks. (Fig. 83.) In one nest I found ten eggs. I believe that two mother birds claimed the ownership of that home, as there were two females much interested in the tripod and camera while it was near the site. Meadowlarks are shy and return slowly after having been frightened from the nest.

Frank Chapman, the great ornithologist, says: "I do not recall ever having seen a photograph of a Meadowlark at its nest, and the bird's avoiding the trip of the camera hunter is no small tribute to the keenness of its observation and discrimination. 
"The trap has been set," continues Chapman, "I know from my own experience as well as that of others, but the birds are so suspicious that the most carefully concealed camera near their nest is sufficient to scare them away."

I have succeeded in getting some very good pictures of the bird on the nest. I set my camera on its tripod directly over the nest, concealing the legs with living weeds, and using a line two hundred feet long. This was before I began using the tent. After the camera was in position I patiently awaited the bird's return; she alighted on the ground within twenty feet of the nest; then, with all of the stealth possible, she approached, with drooping wings, lowered head and tail dragging on the ground. As she passed the border of the nest I pulled the string that released the shutter and a Meadowlark's picture at the nest was secured. The following season I made a picture of another bird quietly incubating. (Fig. 84.)

Barbed wire fence posts are favorite song-perchingplaces for this sweet, though not voluble, songster. Part of its song has been interpreted by someone as "Laziness will kill you!" and to me that is about as nearly correct an interpretation of the sounds as any I have seen in print. Again its call comes, "I see you-you can't see me-ee-e!" Once to see and hear this bird is always to remember it and its song.

Meadowlarks remain in pairs during the breeding season, but congregate in large flocks during the winter in Florida and other southern states. These birds are ever cheerful and are a valuable asset to any farm, golf course or city park. Their glorious song has brought good cheer to many a downcast, as to Riley's Discontented Farmer:

"Does the medderlark complain, as he swings high and dry

Through the waves of the wind and the blue of the sky?

Ort a mortal be complainin' when dumb animals rejoice?" 


\section{LV}

Baltimore Oriole; Fire Bird; Hang Nest; Hammock 50\%. Icterus calbula

The male Baltimore Oriole is beautifully marked, with his head, throat, back and wings black, and his breast and belly of a rich orange color. The female is smaller than the male and in her the brilliant markings are replaced by olive brown. The length of these birds is from seven to eight inches. The eggs, from four to six in number, are white splotched with dark brown.

The Baltimore Oriole has an extensive nesting range, and migrates to South America, departing for the South during the early fall months. With the full development of the elm and cottonwood in May, we may expect this bird with its suit of black sleeves, yellow vest and black hat. When the Oriole arrives the certainty of winter's departure becomes a fixed fact and we may plant garden seed and put out the tender house-plants with no fear of frost.

The Oriole is a bird of neighborly and friendly traits, rarely disturbing other birds and submitting meekly to any intrusion on its premises. The presence of Orioles should be encouraged, as they are great destroyers of insect pests.

The nest is so securely fastened with twine, grass and plant fibres to a high-swinging limb, that of an elm by preference, that no ordinary storm can tear it from its moorings; no marauding cat or other enemy can get to it. Rocked by every passing breeze the babies are secure and free from the usual dangers to young birds. The deep sack-like nest is so constructed, with the entrance near the top, that it is rare indeed that a young bird falls to the ground, even though the supporting bough may be storm-tossed.

Both male and female are wise, diligent and skilled weavers, and work together at the loom while forming 
the exquisite nursery at the tip of some swaying elm bough. (Fig. 85.)

The nests are difficult to find and many a last summer's Oriole home, hanging within a few feet of the sidewalk, is revealed only when the frost king has visited the leaves and the autumn breezes have stripped the protecting foliage from the trees. You are much amazed and chagrined because of your failure to find one of these nests in all your painstaking efforts during the summer months.

It is a charming sight to see these birds, with their flashes of brilliant orange and jet black, darting through the green of the nest tree while constructing their nests or feeding their young. (Fig. 86.)

Orioles are fruit and insect eating, and are strictly tree birds; they are among our best singers. During the moulting period, in early August, they cease their singing and live in seclusion and are rarely heard or seen until just a few weeks before they start southward in October. 


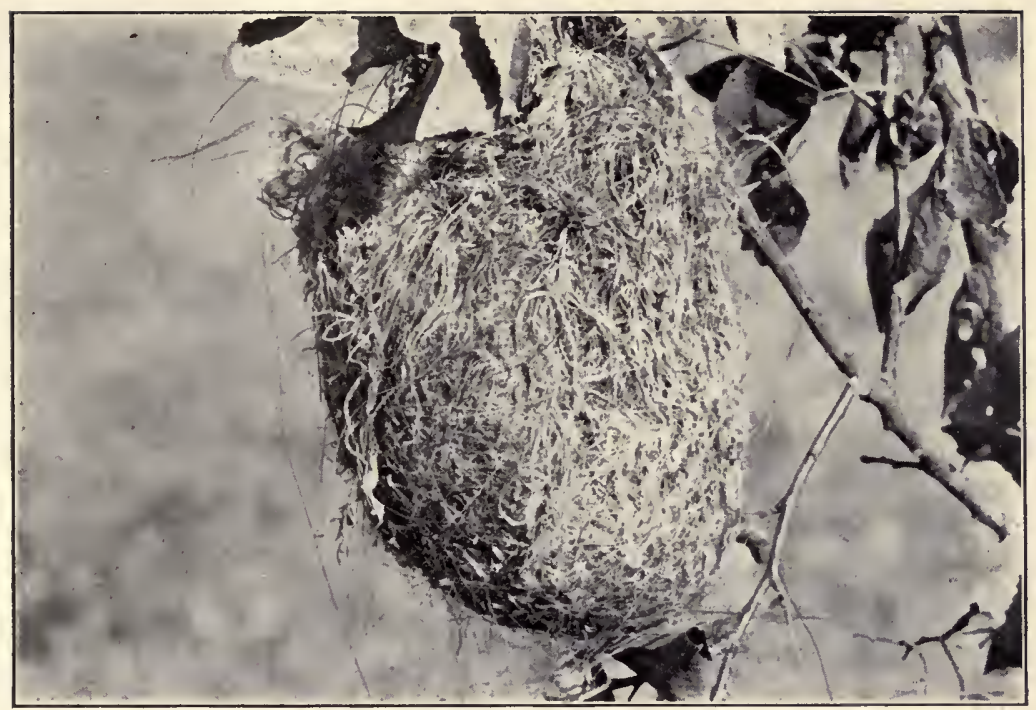

Fig. 85. BALTIMORE ORIOLE'S NEST

(page 166)

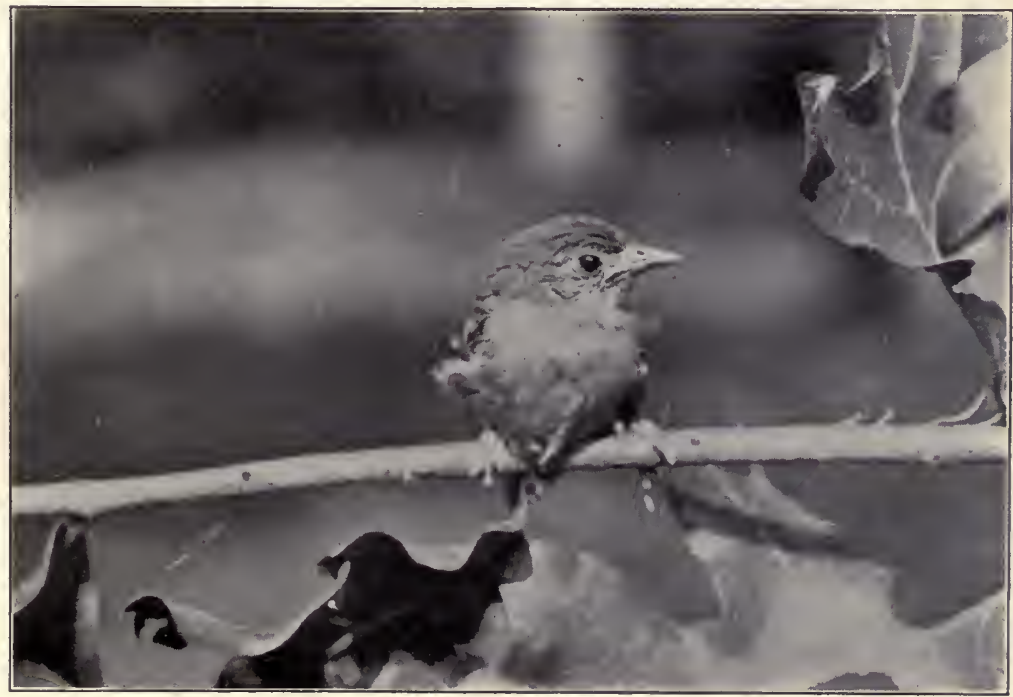

Fig. 86. BALTIMORE ORIOLE YOUNG

(page 166) 


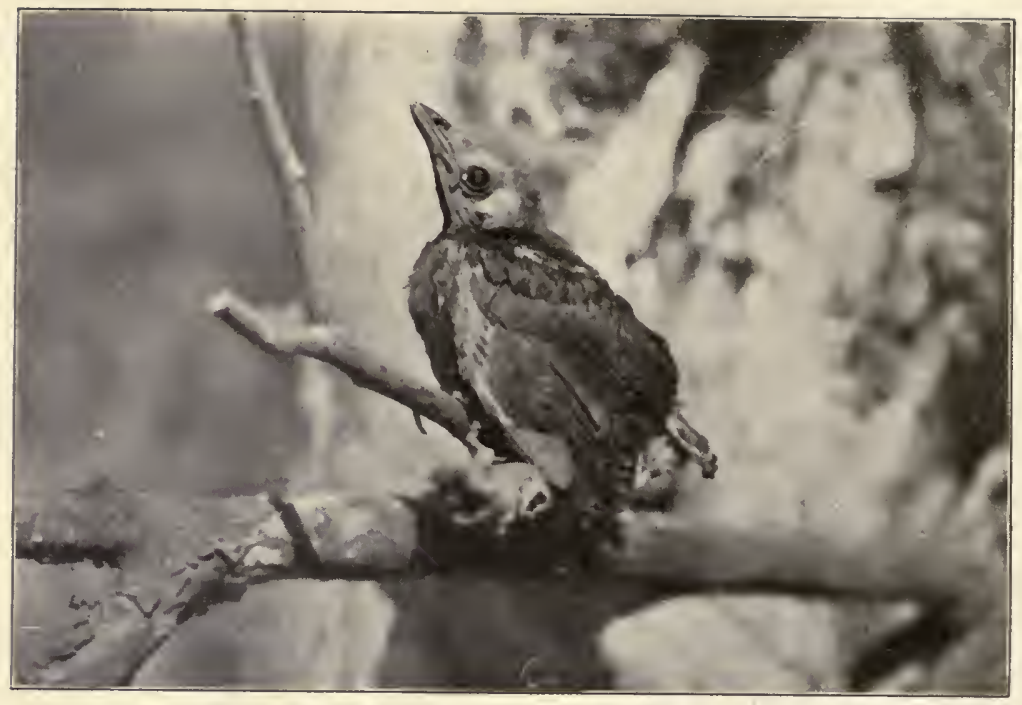

Fig. 87. BRONZE GRACKLE YOUNG

(page 167)

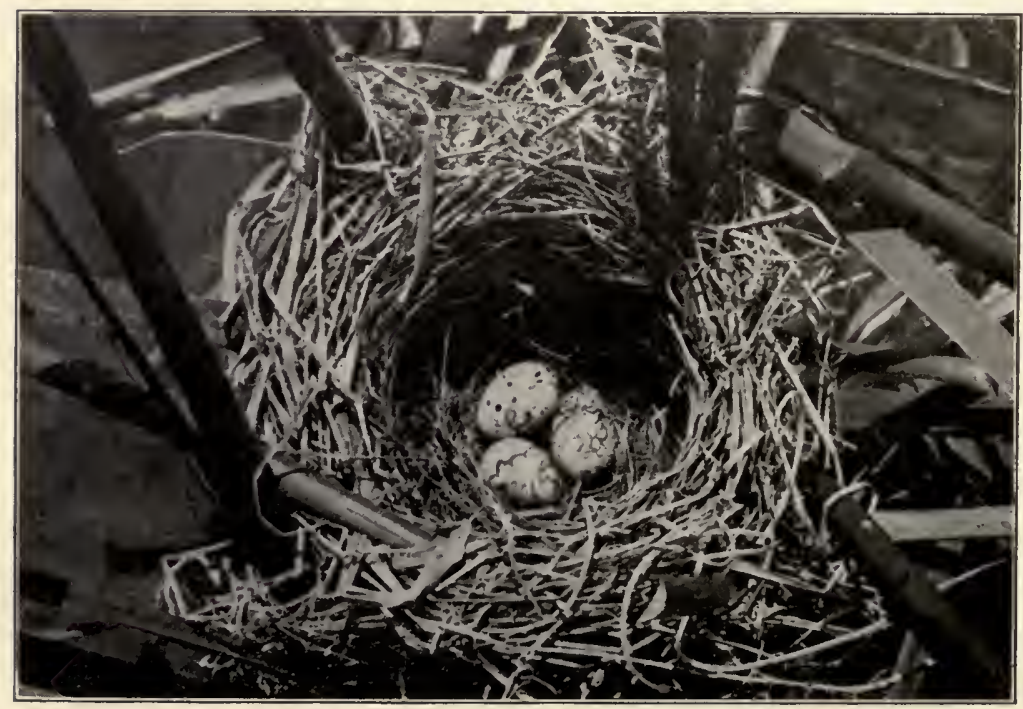

Fig. 88. BOAT-TAILED GRACKLE'S NEST AND EGGS 


\section{LVI}

\section{Bronzed Grackle; Crow Blackbird; Western Crow Blackbird; Boat-Tatled Blackbird \\ 511b. Quiscalus quiscala aeneus}

This tri-colored "Blackbird" is the species of Grackle found in the central part of the United States, and is about twelve inches long, with body of a brassy color, wings and tail purplish-violet, and head and neck steel-blue.

The Bronze Grackle is migratory, arriving in the vicinity of Kansas City in March and departing in October, and breeding as far north as Hudson Bay.

The nest is a rough bulky affair made of coarse sticks and rubbish plastered together with much mud. There are from three to six eggs of a bluish-green color, with brown worm-like scrawls. The birds prefer cedars and other evergreen trees as nesting sites. (Fig. 87.)

Like domestic chickens, Grackles will feed on all kinds of seeds, worms, grasshopers and garbage refuse. These birds live in small flocks the year around, but in late fall congregate in great hordes and in some localities do much injury to ripening crops. City parks are frequently selected as breeding places and trees along sidewalks are used as roosting spots by these Blackbirds, which thus make themselves a great nuisance, hard to get rid of. Although gregarious, they mate for the season.

We are all familiar with this trim, yellow-eyed bird, for it is a regular visitor and may be seen strutting, like a small Crow, along the furrows behind the plowman, or at the picnic grounds in our public parks picking up crumbs.

"You can hear the blackbirds jawin', as they foller up the plow-

$\mathrm{Oh}$, they're bound to git their breakfast, and they're not a-carin' how; 
So they quarrel in the furrows, and they quarrel on the wing,

But they're peaceabler in pot-pies than any other thing."

The flight of the Grackle is marked by a lateral or side wobbling of its body, as it guides its course through space with its trough or keeled tail.

These birds are very sociable and may often be seen, even in the breeding season, in small flocks in the top of some coniferous tree, carrying on a neighborhood talkfest, or in a dignified manner strolling across some recently mowed meadow or golf course, all the while talking in an undertone as if discussing some local bird scandal. If disturbed they fly only a few paces, guiding their flight with their rudder-like tails. 


\section{LVII}

\section{Great Boat-Tailed Grackle; Jackdaw 513. Quiscalus major}

This bird is black, with steel-blue metallic and purple general marking, and measures from fifteen to nineteen inches in length. The female is paler and much smallerfrom thirteen to fifteen inches long. The nest is near the ground, bordering low and marshy localities. The eggs, from three to five, are drab with tints of blue, marked with extensive brown blotches, or wavy lines. The long, wedge-like tail of the great Boat-tailed Grackle is a marked feature of the bird, which is Crow-like in length and is frequently called the Jackdaw. It is found in the extreme southern states near the Gulf or Atlantic Ocean. (Fig. 88.)

These birds congregate in large flocks and migrate, probably to South America, in the late fall and winter; they are omnivorous, but especially fond of small fish, snails and small, soft-shelled sea food.

The male deserts the female soon after the eggs are laid. Although these Grackles are presumed to be strictly maritime I have seen them a hundred miles inland, breeding in the rushes of a fresh water lake and in swamps. While I was on the Gulf shore in Texas it was a common sight to see these big Blackbirds wading about the shore, collecting and eating minnows and small crustaceans. They love to associate along the water's edge with Willets, Least Sandpipers and Turnstones, and secure most of their food in such localities.

On Big and Little Bird Islands in the Laguna de la Madre I found many nests of the Grackles in which the young were large enough in May to leave the nests. (Fig. 89.) Their flight reminded me of that of the ungainly Bittern, as, with dangling legs and measured wing-beats, they awkwardly arose from the weeds.

The pictures in this collection were made near Corpus Christi, Texas. A big breeding colony had taken possession of a magnolia grove in a farmer's front yard. 
In spite of all his efforts at driving them away by shooting and by destroying their homes, they persisted in returning in increasing numbers. At the time of my visit there were fully five hundred nests located in easily accessible positions, for good picturing. Birds and eggs were in all stages of incubation and growth, for the old birds had rebuilt many nests destroyed by the farmer. The female remained on the eggs while I set my tripod up within three feet of her. (Fig. 90.)

The noise of the birds, when a gun was fired into their midst, was of deafening intensity as they flew in confusion about the magnolia grove and returned to their nests. 


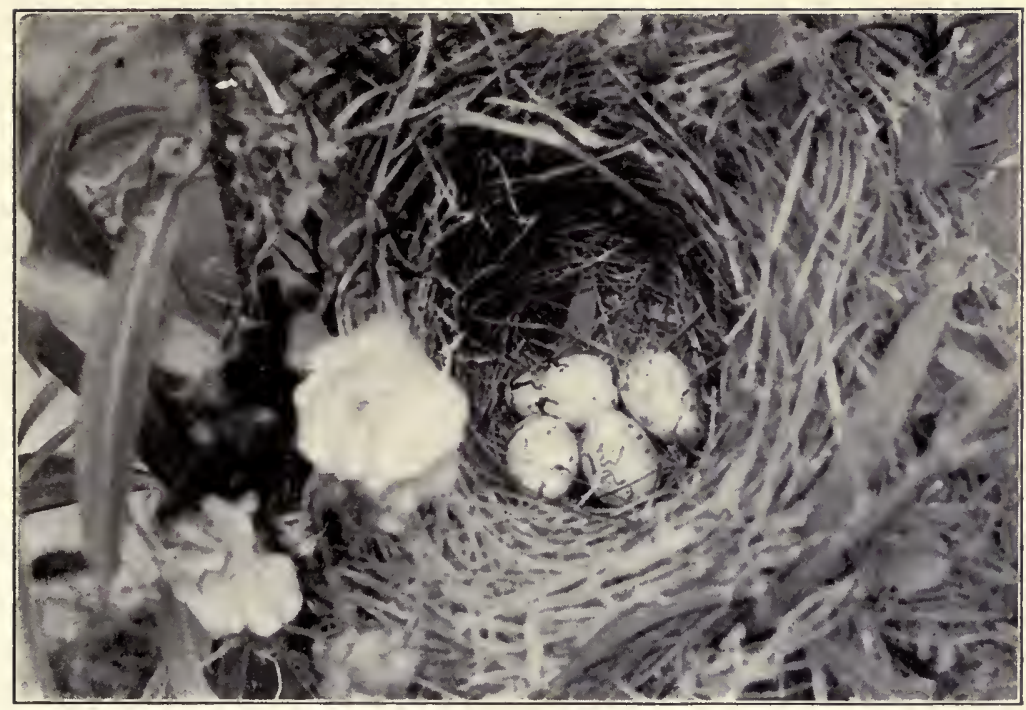

Fig. 89. GREAT BOAT-TAILED GRACKLE'S NEST AND EGGS (page 169)

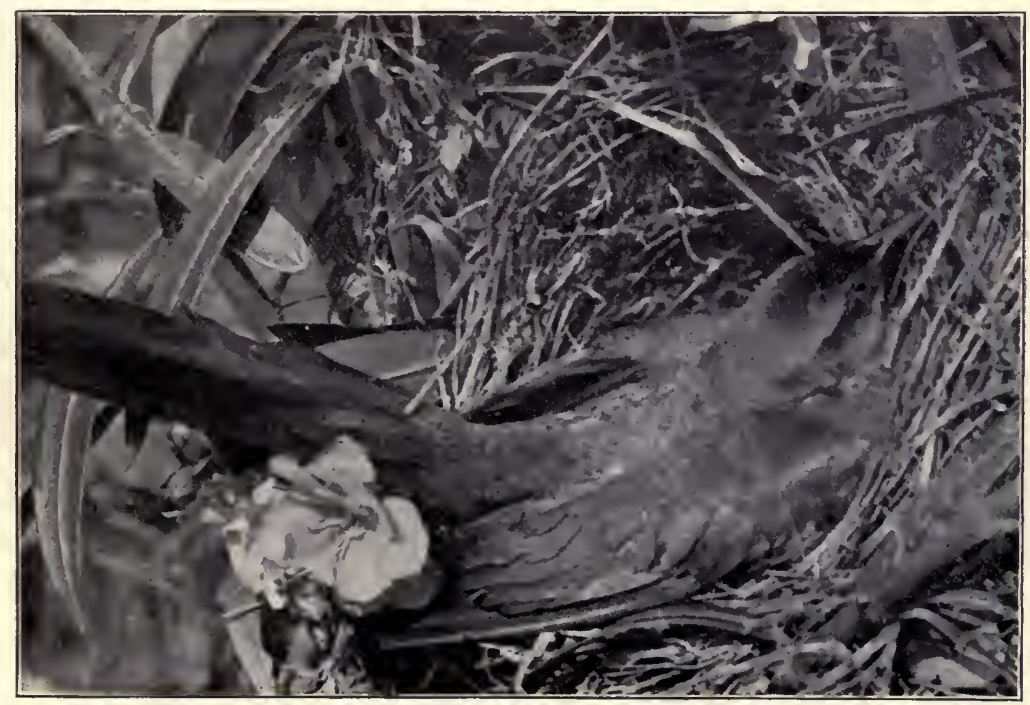

Fig. 90. GREAT BOAT-TAILED GRACKLE INCUBATING

(page 170) 


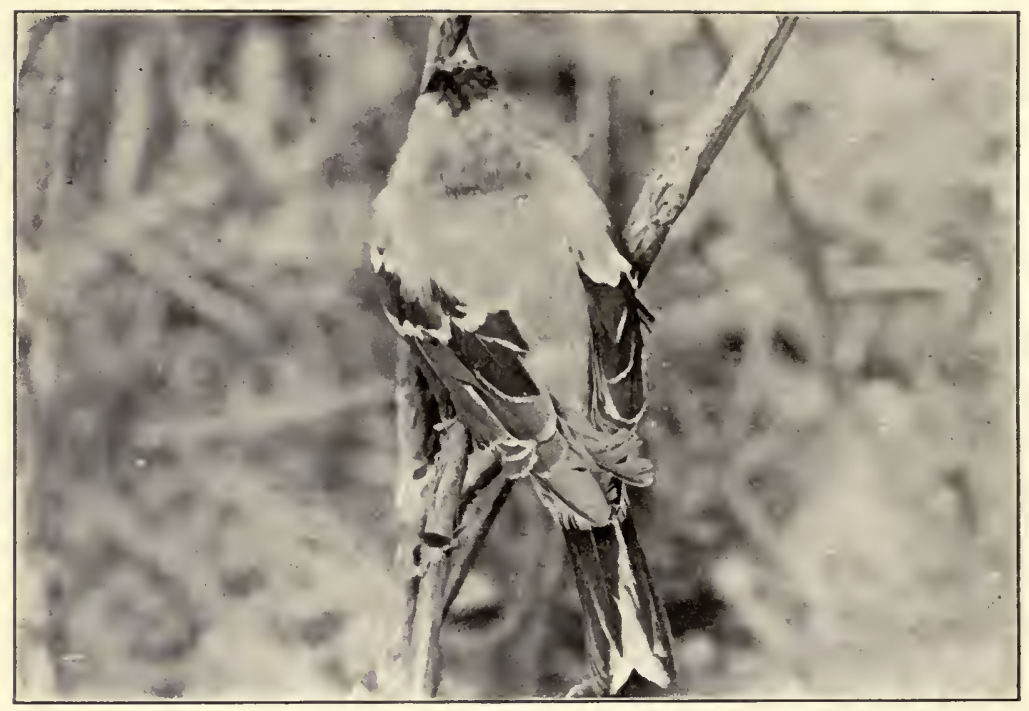

Fig. 91. AMERICAN GOLDFINCH

(page 171)

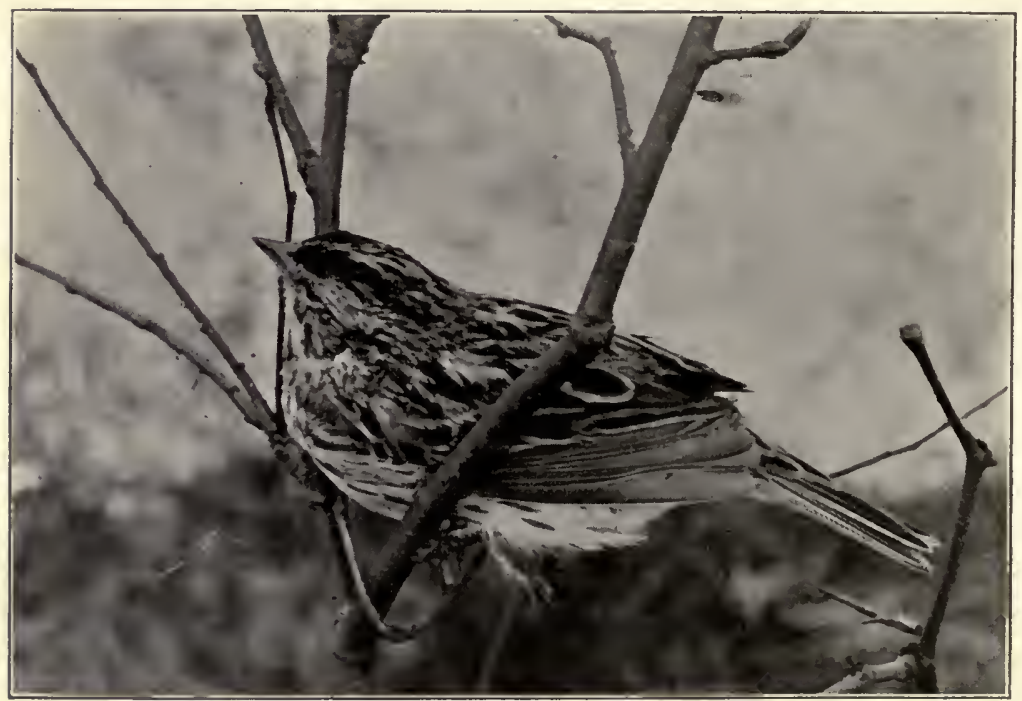

Fig. 92. SAVANNA SPARROW 


\section{LVIII}

\section{American Goldfinch; Thistle-bird; "Wild Canary"; YELLOW-BIRD}

529. Astragalinus tristis tristis (Linn.)

The length of the American Goldfinch is about five inches; its general coloring is a rich lemon-yellow, slightly whitish on the tail, with black patch on the crown; the wings and tail are black with more or less white marking. In winter the male and the female are much alike, as the male's yellow turns to brown and the black on his head fades, while the black on the wings and tail remains.

Goldfinches nest in thickets bordering open spaces, where thistles and other weeds thrive. The nest is ten feet from the ground and is composed of plant fibre, down and hairs. The eggs, from three to five in number, are whitish-green, sometimes marked with small brown specks.

The American Goldfinch is a bird ranging and breeding from Mexico to the interior of Canada; its nesting period is in a measure governed by the ripening of the seeds upon which it lives. It must not be confused with the Summer Yellowbird-Yellow Warbler-which is also sometimes called the Wild Canary. The latter has a yellow crown, while the crown of the Goldfinch is black.

In late fall and even in mild winters the American Goldfinch may be seen in gardens and weed fields; it is partial to lettuce and wild thistle seeds and its going south is, in a great measure, due to pursuit of food supply, and not to a strictly migratory trait.

Goldfinches are gregarious, except during the mating period; they delay mating until late in the season, frequently not nesting near Kansas City, Missouri, until September. (Fig. 91.) When these lovely semi-migrants return to us late in the winter or early in the spring, and feed in flocks on the fallen thistle pods on the ground, the male, at a distance, is hard to distinguish, with his 
yellow belly and back, from the numerous yellow blossoms of the dandelion.

One need have no difficulty in recognizing these birds by the sense of hearing alone, as their feeding notes are exactly like those of the tame caged Canary. They are very friendly and, if you remain quiet, will circle around you in their undulating flight and feed on the ground within a few feet of you, all the while singing as though they were giving you a free concert: "Dearie, dearie, hear me! hear me!" seemingly happy even when hanging to a frozen thistle or a seedless sunflower protruding from the snow. Their little lay of thanks and good cheer is heard under food and climatic conditions that ordinarily hush the voice of many sturdier creatures. 


\section{LIX}

Savanna Sparrow; Ground Sparrow 542b. Passerculus sandwichensis savanna

This migrant comes to visit with us for a few days during late March and early April, then resumes its long northward journey toward Hudson's Bay, where it finds conditions suited to its choice for rearing its young, returning south in September. It has not been known to build its nest in Kansas or Missouri. It has the appearance, in a general way, of the Sparrow family, with the added feature of wing margins marked with yellow and and a well-defined yellow streak over the eyes. (Fig. 92.)

The Savanna Sparrow is fond of marshy ground and hedge rows bordering the highways. In company with the Harris Sparrows the Savannas are rather numerous in the vicinity of Kansas City in April. They keep close to the ground while resting, and even in flight they rarely fly over a few feet from the earth; they are the most terrestrial in their habits of any of the Sparrows. Small insects and fallen weed seeds enter into their diet list. Their vocal ability is limited to a little twitter. They are rather tame and permit a close approach.

These Sparrows nest on the ground. The eggs number from four to five, and are of a grayish-green. 


\section{LX}

\section{Lark Sparrow; Lark Finch \\ 552. Chondestes grammacus grammacus}

The Lark Sparrow is a summer resident and breeds in the central part of the United States, as far east as the Atlantic Coast, and nests usually on the ground, laying from four to six white eggs with worm-like dark brown lines. (Fig. 93.)

In Missouri and Kansas the Lark Sparrow is one of the most abundant of the birds found scattered over the abandoned fields and pastures, where the grazing herds are always tramping about its nest. Why every nest so situated is not destroyed is almost a miracle. The Lark Sparrow is fond of man's prepared nesting-site surroundings and often invades gardens or dooryards. Its head is beautifully marked with chestnut and white lines; the general color of the bird is grayish-brown, while the tail feathers are dark brown, the outermost edged with white and others more or less tipped with white.

Lark Sparrows are said to make good cage singers, but I am pleased to state that I have never seen or heard these birds behind prison bars, and I sincerely trust that I may always witness their freedom limited only by the big out-of-doors. Goss, in his Birds of Kansas, says: "Their harmless ways and rich clear, varied song, unsurpassed in continuity and melody by any of the family, make their presence welcome."

One day while I was walking across a pasture a little six-inch bird flew from beneath my footsteps. I paused, and directly under my feet was a Lark Sparrow's nest containing four white eggs with dark markings. I set my camera on the tripod over the nest, made a picture of it and attached a string to the shutter release and retired twenty feet to await the incubating bird's return. I did not have to wait long, as the female was evidently so far advanced in her hatching task that a delay in returning would mean the spoiling of her labors. She posed for me nicely, and actually remained on the nest while I changed plates and made several exposures. (Fig. 94.) 


\section{LXI \\ HaRRIS's SPARROW \\ 553. Zonotrichia querula}

This bird is seven and one-half inches long; it is the largest of our Sparrows and may be easily identified by remembering that it is the only Sparrow marked by a jet black crown, face and throat, with its other markings similar to those of Sparrows in general. The female has less black on the head than the male and the throat is whitish. The different seasons bring variations in the typical markings.

In late March these Sparrows begin to make their appearance about Kansas City, Missouri, in the brushy parts of Swope Park, bordering the Blue River, and along the hedges in the adjoining country. They seem to prefer thickets near swampy land where they congregate in small flocks, busily engaged in scratching among the dead leaves on the ground while looking for food. A few are said to remain all winter.

Harris's Sparrows seldom fly far from their brushy retreats, even when frightened. They have a sweet, but limited, song that seems to carry with its delivery a message of sadness. It is not a song delivered with enthusiasm and emphasis. It must be a warm spring day to inspire this songster; he is not the cold weather vocalist that we have in the Song Sparrow.

The nesting habits of this bird are unknown at the present time, as there is no authentic report of anyone's having found an occupied nest. In a personal conversation with Valhjálmur Steffánsson, the great Arctic explorer, he told me that he saw flocks of these Sparrows, males and females, on May fourteenth, at Great Slave Lake. Evidently, they had not mated, or begun to nest. I have seen them in Missouri, as late as May tenth, still in flocks. (Fig. 95.)

It is a difficult task to tabulate the coming and departure of Harris's Sparrows. Unlike many migrants that are here today and gone tomorrow, a few of them 
remain with us long after the main body of their kind has departed. The migration route appears to be centered on a north and south line running through Kansas City, Omalua and the Dakotas. The bird is really Kansas City's own bird, as it was first discovered in what is now the confines of the present city limits.

Nuttall, the renowned ornithologist, discovered this bird in May, 1833, near the Blue River, just where the Belt Line Railroad now crosses it. In 1840, Audubon saw the bird near what is now Fort Leavenworth and named it in honor of one of his associates, Harris's Sparrow. (Fig. 96.)

Since the discovery of oil along the Mackenzie River, the tide of human migration is along the same lines as that of Harris's Sparrows. Let us hope, therefore, that some observing prospector may find the breeding home of the bird and thus lift the veil of mystery surrounding it. 


\section{LXII}

\section{Tree Sparrow; Winter Chippy; Canada Sparrow}

559. Spizella monticola (Linn.)

The breast and belly of the Tree Sparrow are whitish; there is a chestnut spot in the center of the breast and the side of the breast is rufous; the crown is of a beautiful chestnut with no center stripe; there is a small grayish border between the crown and the eye; the back is of a beautiful dark chestnut and the wings are generally dark brown with two defined white bars. (Fig. 97.)

This beautiful migrant Sparrow, with its undivided, chestnut-colored broad crown, is a frequent winter visitor in the vicinity of Kansas City, and very few are the hedgerows or abandoned old fields whose bunches of weeds and briars do not harbor a flock of these birds. The Tree Sparrow is especially fond of open places abounding in weeds and thickets, as it is a ground-feeder and likes to be near a safe retreat when frightened.

I have found the Tree Sparrow much shyer than the Song or other northern nesting Sparrows; but, by baiting it in snowy cold weather it may be approached and photographed by a set camera or from a tent. It is fond of being near low, open, marshy feeding grounds and is terrestrial in its habits, the name "Tree Sparrow" being a misnomer, as the bird is usually found feeding on the ground. When disturbed, however, it quickly seeks safety in trees or hedges. Although it is very sociable with others of its kind, and pairs may frequently be seen eating from the same weed stalk, it is shy on the approach of man. When one bird flies from an alarm the whole bunch will follow, darting into the nearest thicket to hide.

Like that of many migrants the limit of the southern journey is in a measure governed by the severity of the winter and the abundance of food supply. This bird breeds as far north as the Arctic Circle, and lays from four to six light green eggs marked with brown spots. 
With its nightless days within the Arctic Circle, and its journey to the Far South where the winter days and nights are almost of the same duration, the Tree Sparrow, like all Arctic breeding and migrant birds, lives in more sunshine than do our locail breeding birds. 


\section{LXIII}

\section{White-Throated Sparrow; Peabody Bird 558. Zonotrichia albicollis}

To my mind this is the most beautiful of the Sparrow family. There is something so harmonious in the beautiful white and black head and throat markings that to see the bird is to admire it and to bestow upon it the title of the beauty-prize winner among the Sparrows.

The White-throated Sparrow is a friendly, sociable bird and is usually found in company with Juncos and other Sparrows; its crown is black, divided by a median white line over the eyes; a yellow spot extends from the eyes to nostrils and there is a black line through the eyes. The throat is pure white, the breast and edges of the wings are a dark ash and the body is yellowish-chestnut. (Fig. 98.)

This species of Sparrow nests on the ground, or in low bushes, and lays from four to six eggs: It feeds mostly on the ground while scratching in the leaves and fallen weeds. It is fond of hedges and thickets and is shy and hard to drive from its thicket hiding-places. If driven out, it quickly returns or flies to the nearest brushy ground.

In early spring and late fall the song of the Whitethroated Sparrow is as musical and voluble in our clime as in its Canadian summer home. During the mating season, from morn till night, may be heard its "pea, pea, peabody, peabody!" repeated in a monotone until the charm of an otherwise sweet song becomes tiresome by its monotony. 


\section{LXIV}

\section{Chipping Sparrow; Chippy; Hatr-bird 560. Spizella passerina passerina}

This, the smallest of the Sparrows, only five inches long, is one of the best known and most easily recognized birds. Its bright chestnut headdress, whitish, unmarked breast and belly coat, black bill and pale feet are the identification marks.

The Chipping Sparrows are migratory, nesting all over their range; they are abundant in the central part of the United States, arriving in April and departing for their southern home in October. They are partial to pastures and cultivated farms bordered by dusty roads; also to the vine-clad fences and porches of our homes, where they may be seen picking up bread crumbs and seeds near the kitchen doors and in the yards. (Fig. 99.)

The nest of the Chipping Sparrow is usually built in shrubbery and vines near the ground. These birds do not build very substantially but the nests are well held together by the abundance of horse hair used in the lining. The eggs in a nest number from three to five, and are of a bluish-green with purplish spots.

Chippies are friendly little fellows and their proffered sociability should be met on half-way ground. Their song is a mere little "chip, chip!" and is repeated in a monotonous tone during the livelong day.

Because of the frequency with which these Sparrows build near man's habitation, they become the victims of the prowling eats of their neighborhoods. I know of many families that would rather give a cat a lysol bath for its mangy and flea-infested hide than offer protection to some of man's greatest and most useful friends - the birds of the neighborhood. When I see a worminfested shade tree in a front yard and half a dozen cats sunning themselves on the front porch, I feel that the owners of the premises are, in a great measure, responsible for the loss of their shade trees, because of harboring the destroyers of birds. 


\section{LXV}

\section{Firld Sparrow ; Bush Sparrow}

563. Spizella pussila arenacea

The Field Sparrow has no decided black or white about its crown or head. It is of a general brownishash, streaked with black. Its length is about six inches, and it ranges from North Dakota to Texas. (Fig. 101.)

These birds are often found nesting on old abandoned farms and on dry and hot hillsides. The question of burning sun's rays does not trouble the Field Sparrows; indeed, they appear to be better satisfied, and sing most persistently their "swee-see-see-se-e-e," on the hottest and dryest days.

Chapman says: "His song is one of the most pleasing I know. It is very simple, but very expressive, a sweet, plaintive cher-wee, cher-wee, cher-wee, chees-deee-e-e-e, which goes straight to the heart. It is sung most freely after sunset and is in keeping with the peacefulness of the evening hour."

The nest of the Field Sparrow is a frail structure of dead grass and weeds, frequently lined with horse's hair and located in a small bush or clump of briers near the ground. The eggs are usually four in number, whitish, marked with reddish-brown.

The picture in this collection was made on May sixteenth, near Kansas City, Missouri. The birds returned quickly to the nest, even when the camera was within two feet of it and not in any way hidden.

The Field Sparrow is a great destroyer of injurious insects and noxious weed and grass seeds; it is thus of great service to the horticulturist. 


\section{LXVI}

\section{SNOWBIRd; Junco \\ 56\%. Junco hyemalis hyemalis}

When Jack Frost with his frosty scythe has trimmed the brown foliage from the trees and the ground is strewn with his harvest, the birds of the Far North make their appearance. The Warblers, the Tree Sparrows, and many other of the migrants pause to feed and rest with us for a few days; then along come the more hardy birds-those that by their feeding habits are able to withstand the scarcity of food and the rigors of our winters. Among the last is the slate-colored Junco, or Snowbird; it is a sociable bird, often mingling with the other late departures, and usually is seen in flocks of its kind. It is fond of feeding in open weed fields bordered by thickets, into which it darts on becoming frightened, but it soon returns to its feeding place when assured that no dangers are near. (Fig. 100.)

While Snowbirds prefer seeds of their own finding, they are frequently driven by hunger, because of the snow covering their supplies, to seek sustenance in our dooryards. I remember, as a mere child, seeing this little Sparrow-size, slate-colored, white-bellied, whitebilled Snowbird on the soft, freshly fallen snow in our backyard near the kitchen door. The birds made tiny footprints as they hopped about looking for bread crumbs thrown to them, and flew into the lilac bushes when the door opened or closed.

The white margin on the tails of Snowbirds, seen in flight, and the white bill and slaty grayish color, make them easily identified. During the winter when their food is snowed under, many of these little birds die of starvation. They nest in Canada and Alaska. The nest is built on the ground and from four to five bluish eggs are laid.

Snowbirds are not very good songsters. They are at home in ordinary snowstorms and can stand much privation, but a prolonged cold snap is frequently very 
trying on them. They should be protected as they destroy many noxious weeds.

In Saskatchewan I found our little winter visitors nesting along the crumbling banks by the side of the trails and rushing mountain streams. The nests were usually fully protected from the heavy rains, by the unbroken and over-hanging beds of moss roots. The little parents were very busy with frequent feedings of their young, and permitted me to set up my camera within a few feet of their nursery and make photographic records of their family affairs.

It was indeed interesting to see these southern winter birds in their northern summer homes. 


\section{LXVII}

Song Sparrow; Silver-tongue 581. Melospiza melodia melodia

To many casual observers, any small bird of a grayish color streaked with chestnut is a Sparrow, and all Sparrows are the same. Of all species of Sparrows only a very few nest in the central part of the United States, while many breed within the Arctic Circle, and we see them only as migrants and winter sojourners. (Fig. 102.)

The Song Sparrow is one of the most beautiful of Sparrows and its songs are delightful. With its yellowish-white bill and six-inch coat of gray and chestnut blotches, the male is one of the handsomest of all its kind. It is a rather sociable and confiding bird, with a fondness for brushy hillsides. Even when disturbed it rarely flies far but, alighting in the underbrush, re-makes its appearance, through curiosity, on the top of some shrub. These birds are frequent winter residents near Kansas City, Missouri. They are often seen in small flocks in brush heaps in newly cleared ground. Their flight is an undulating one.

The Song Sparrow nests on the ground near water, and lays from four to five greenish-white sparsely speckled eggs.

On a cold winter's day, when all of nature's woodland forces are grasped by the firm hand of the frost king, if you should wander near a little patch of underbrush when the sun bursts forth, you may be surprised and delighted to hear near you the pleasing notes of this winter visitor. Such thrills are carried by the song of no summer resident. This little fluffy ball of feathers is an artist and sings surrounded by conditions that ordinarily silence other songsters. With its medley the Song Sparrow becomes enthused and enters into the concerts as though it enjoyed them. Nothing seems to come amiss to it. Who knows but that its songs are inspired by the memories of its moss-covered trunda, its summer home of the Far North. 


\section{LXVIII}

\section{Fox Sparrow; Fox-tail Sparrow 585. Passerella iliaca iliaca}

This is one of the best singers and is the largest of the Sparrows, measuring seven and one-half inches. As compared to the English Sparrow it is a much longer bird; it does not present so much rusty red markings on its head as most Sparrows, but its white breast with wellmarked reddish oblong spots will aid in its identification. The Hermit Thrush or female Red-winged Blackbird might mislead an untrained observer in identification. (Fig. 103.)

The Fox Sparrow has no wing bars; both sexes are similarly marked. The long tail, with the upper surface fox-red, and the ground-scratching habits of the bird are characteristic. It does not breed in the United States. It nests on the ground, or in low bushes, and lays from three to five greenish-white, rusty-spotted eggs. It spends most of the time on the ground, scratching among the leaves in pursuit of its food supply. The bird is very timid, seeking cover at the least alarm, but soon returns to its feeding on the ground in the thicket.

Fox Sparrows are frequently seen in company with Juncos, feeding within a few inches of them.

The winter of 1921 was one of unusually high temperatures and many of the migrants that usually spend the hard, cold winters farther south paused near Kansas City, where they were to be seen in every locality that suited their fancy. There was very little snow and no zero weather; in March the frogs were singing as though it were a May day and many birds of late April migration were to be seen in the hedge rows, brushy thickets and wood fields.

While doing some field work along a small stream bordered with sumach, elms and briars, I was attracted by several Fox Sparrows busily engaged, like so many domestic hens, scratching in the dead leaves, fallen grasses and weeds. Their actions were truly like those 
of chickens as, with their little feet, they threw the leaves and grass in all directions, examining the ground, all the while keeping a close watch for possible dangers from the air.

I was in no hurry to flush them so I remained beneath the edge of the creek bank, patiently observing the actions of the birds. One of their number flew to a limb of a nearby tree and such sweet singing one rarely hears in the early days of March in that locality. I was entranced by the vocal artist and its solo. Long may its kind return and pause with us each spring on its northward journey! A hearty welcome awaits its return. 


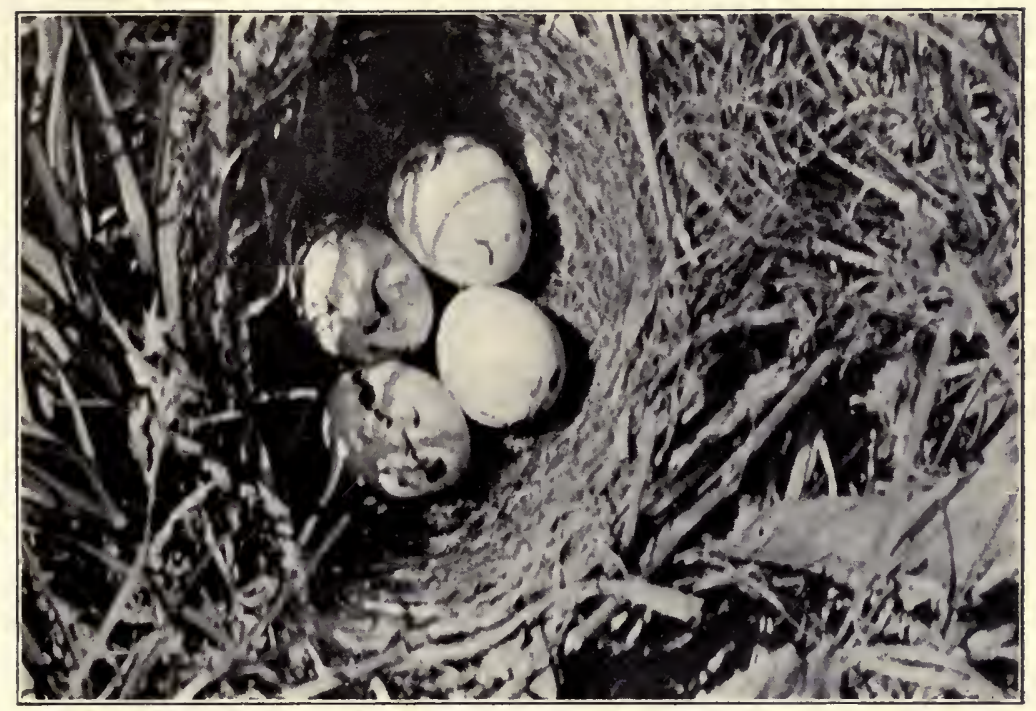

Fig. 93. LARK SPARROW'S NEST AND EGGS

(page 173)

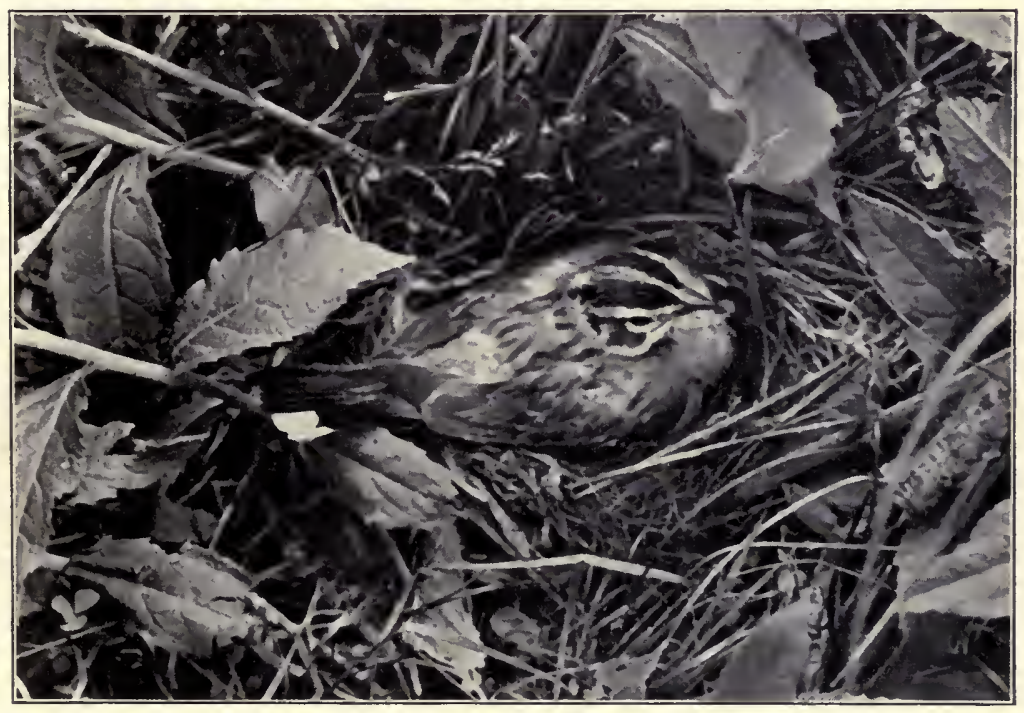

Fig. 94. LARK SPARROW INCUBATING 


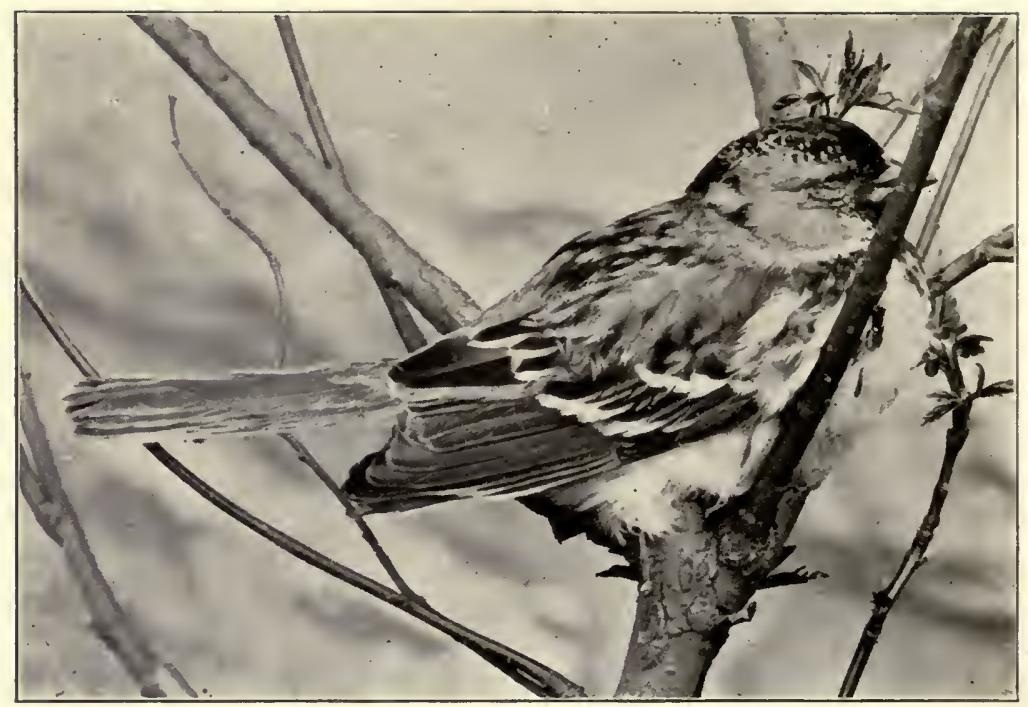

Fig. 95. HARRIS'S SPARROW

(page 175)

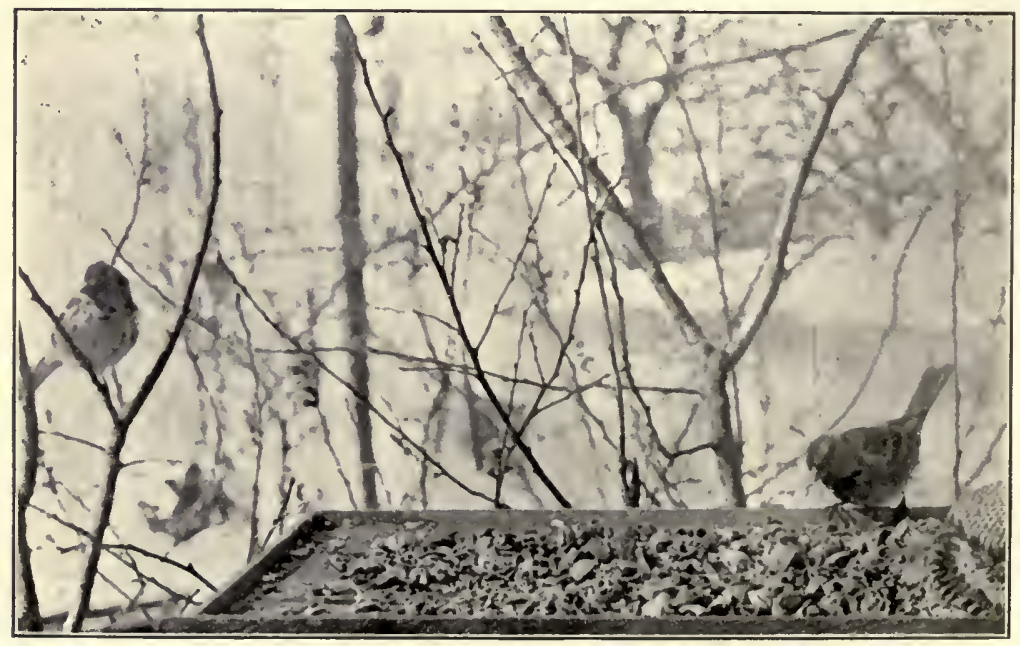

Fig. 96. HARRIS'S SPARROWS AT FEEDING STATION

(page 176) 


\section{LXIX}

Towhee; Chewink; Joree; Ground Robin 58\%. Pipilo erythrophthalmus (Linn.)

The upper part of the head and breast of the Towhee is of a glossy black, meeting with pure white on the lower breast, bordered by a beautiful chestnut brown; the tail feathers are black, the outer web on the first being a pure white that shows plainly when in flight. The iris is deep red. (Flig. 104.)

These birds nest on the ground near dead logs and roots of trees, and beneath heaps of brush. The eggs number from three to five and are of a grayish-white with brown spots. The male is much more elegantly dressed than the female. As a boy I knew this bird as the Joree 'bird. There are very few wooded hillsides covered with underbrush and briars that do not harbor one or more pairs of these confiding birds.

In the vicinity of Kansas City, in mild or open winters, they often remain with us all the season, especially along streams bordered by a heavy growth of timber. They range from Canada to Texas and breed generally over their entire range. The Towhee is about eight inches long. It will let you approach it but is really shy and hard to keep in sight; it rarely flies far or high, when you go near it, but sneaks through the underbrush, hopping from one limb to another or to a briar, flying only when crowded, and then only from the edge of one thicket to another. Like a Texas Road Runner, it covers distance quickly by a half-running and half-lying gait and is not a graceful flyer, as its flight appears to be made with much effort. The legs of this bird are strong and its claws are sharp, well adapted to vigorous ground scratching while seeking food among the dead leaves.

Early in the love-making and breeding season the Towhee has a pleasing song of limited range; this is uttered for long periods at a time, from a low limb, and the singer seemingly enjoys the song as much as his mate does. The latter apparently pays no attention to the 
vocal efforts of the male but continues her labors as though he were not near her.

Both birds vigorously protest your invasion of their domain during the brooding period. Their "chewink! joree! joree!" is an ever-welcome sound to those who wander into the dark lonesome thickets where these birds abide. 


\section{LXX}

\section{Redbird; Crested Redbird; Cardinal Redbird; CardinaL}

593. Cardinalis cardinalis

The male Redbird has rich vermillion red on his head, crest and belly but is slightly darker on the back. There is a black mask on his face and around the base of his bill; the latter is of a beautiful coral red; the feet are brown. The female is dressed in much more subdued tones.

These birds are about nine inches long; they are unusually beautiful and attractive. If captured while young they make sweet-singing cage birds, but lose much of their bright coloring by being imprisoned. They are more lovely and sing better in their primeval surroundings.

Redbirds are seed and grain eaters, by choice. They are common winter residents throughout the central part of the United States and select grapevines and other thickets for homes, but will nest in the backyards near our residences if no cats or other enemies are in that vicinity.

The nest is usually placed a few feet from the ground and is a rather frail affair, made almost wholly of twigs, roots and grape-vine bark. There are from three to five eggs, cream yellow, marked by many small specks of dark brown.

The courtship of the Redbird is one of much jealous intensity and when mated these birds are very devoted. The male objects vigorously to the presence of another male near his home site. The Redbird is a fighter of the bravest and most persistent kind.

Both birds assist in caring for the young. A young Cardinal, just old enough to leave the nest, is just about as comical looking as any young bird you will ever see. Its little body and big crest make it look ludicrous. (Fig. 105.) 
A nest discovered in the summer of 1921 was built on a horizontal limb not seven feet from the footpath on Cliff Drive, in Kansas City, where hundreds of people walked daily beneath it with heads almost touching the branch. Yet here the birds reared their young as contentedly as though they were hidden away in some grapevine-covered bush far from the traveled trail.

I set up my camera within two feet of this nest. The female was shy but the male came without any hesitation, fed the young and cleaned the nursery. On one occasion the sensitized plate caught the female in the act of brooding. (Fig. 106.)

While I was observing this family three Tufted Titmice, in the absence of the Cardinals, alighted on the edge of the nest and inspected the young birds, all the while carrying on quite a Titmouse conversation. They then took their departure, leaving the nest with its contents just as they found it. During this time the old birds were within ten feet of the young and offered no protest by voice or action. These little blue-gray birds have the habit of prying into other birds' affairs in their neighborhood, but $I$ have never seen one of them do any damage to eggs or nestlings.

On one occasion, when the young were about ready to leave the nest, I placed my camera close to it, and the mother bird succeeded in enticing the babies, bird after bird, until she had her entire brood out of the nest and scattered through the thicket. She would come up near the nest with a worm in her mouth and, with a peculiar call, or order, oft repeated, retire a few feet, as if to say, "Come on, come on! I will not feed you until you do come!"

After the last bird had broken home ties she retired to the depths of the thicket, triumphant, and joined the male, while the bird photographer folded his tripod and bade them goodby with best wishes for their future safety.

The Cardinal's disregard for zero weather, snow or rain, makes the bird of all seasons our friend. When we go forth clothed in furs and all other living things are snugly housed, we find the Cardinal with its flaming coat darting from thicket to thicket, as though flaunting joy 


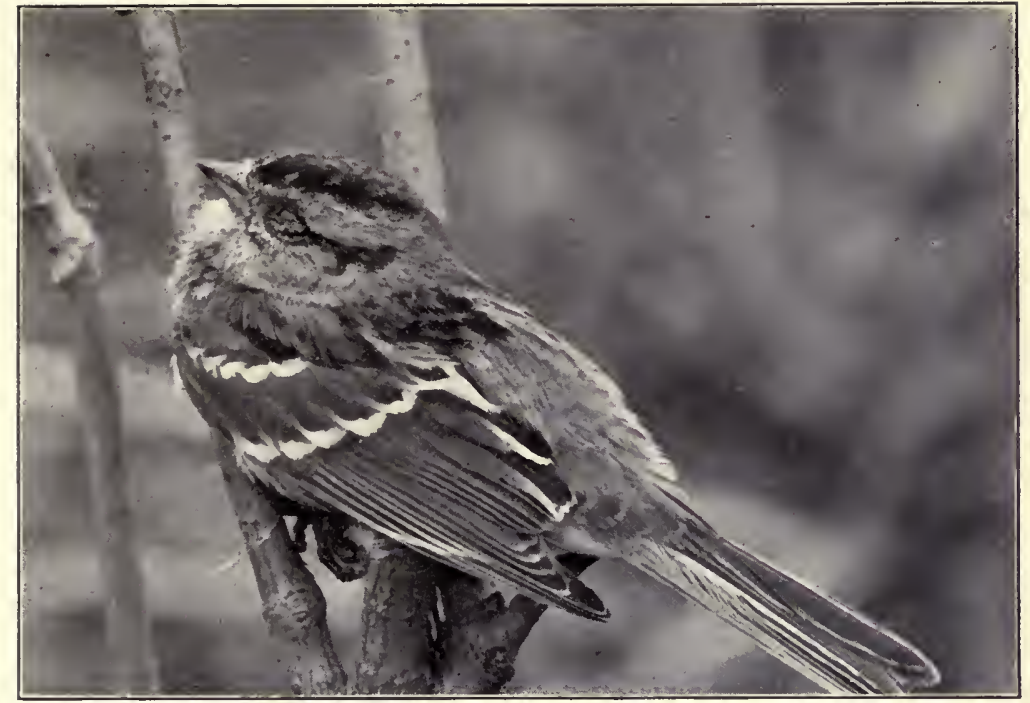

Fig. 97. TREE SPARROW

(page 177)

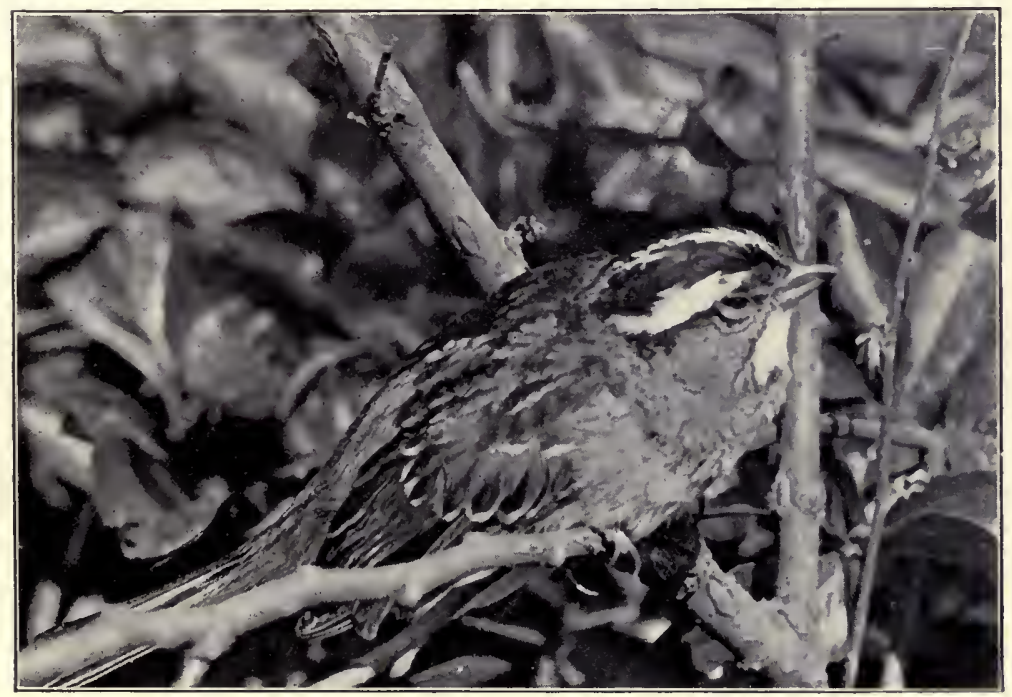

Fig. 98. WHITE-THROATED SPARROW

(page 179) 


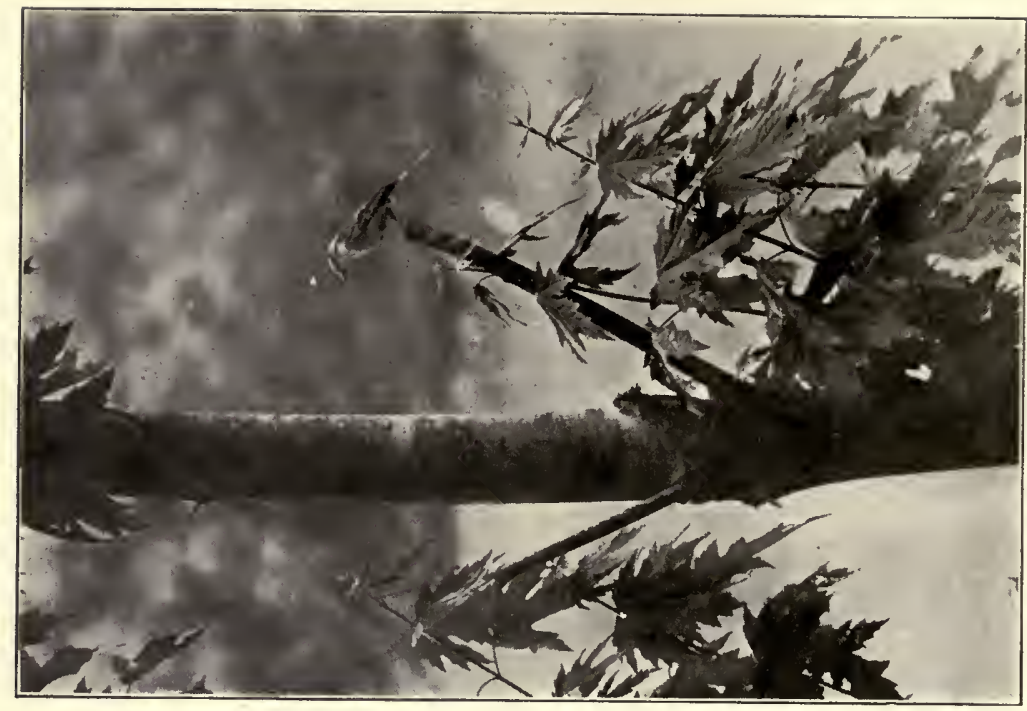

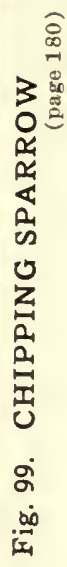

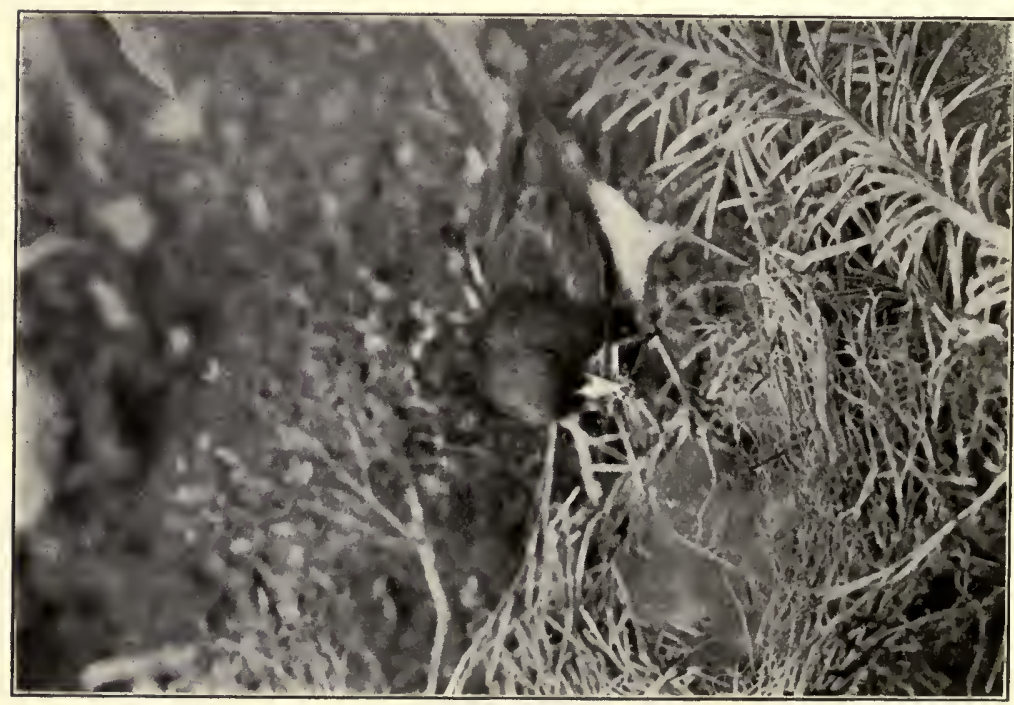

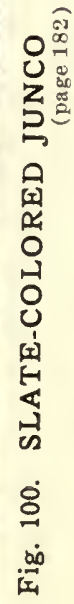


and security in the teeth of the frost king. Its clear, ringing tones are sounds of good cheer and well-wishes; its brilliant uniform and crown suggest dignity and defiance. Its home is its summer and winter resort and is enjoyed regardless of seasons. 


\section{LXXI}

\section{Rose-Breasted Grosbeak \\ 595. Zamelodia ludoviciana (Linn.)}

The male Rose-breasted Grosbeak is black above; his wings and tail are black with some white markings; his breast and tail coverts are rose-red, or carmine. The female is lighter in color, brown predominating. There is no red in the breast of the female.

The Grosbeak is from eight to nine inches in length. It nests ten or more feet from the ground in tangles of grape-vines and thick foliage. There are from three to five eggs of a dull greenish color with lilac and brown spots.

The range and breeding territory of these birds extends from Central America to Canada, and throughout the Missouri Valley. Several pairs of Rose-breasted Grosbeaks nest each year in the city parks of Kansas City, Missouri.

With his rose-red short vest, his beautiful contrasting color and his brilliant song, the bird is one of our most attractive summer residents. (Fig. 107.) As a singer he ranks with the very best bird artists. The song is varied, from vaulting climaxes to low, tender pathos. He is liberal with his art, singing persistently on the hottest summer noons, when other birds are in the shaded nooks, with wings spread and mouths open, trying to keep cool.

No bird has a happier combination of sweet songs and beautiful plumage than the Grosbeak but his lovely plumage has cost him dearly. So-called fashion decreed that he looked more beautiful on a lady's hat than on his own vine-clad bower; hence a price was placed on his scalp. Many states, however, have wisely legislated against his destruction. These birds journey from the distant South to make their summer homes with us and deserve all the protection and kind treatment possible.

The Grosbeak is one of the few birds that is partial to the Colorado potato beetle, also eating the caterpillar. 
If Mrs. Grosbeak would only impart some of her domestic secrets to our wives, I fear more of the household duties would be performed by the male members of the firm. For instance, the male Grosbeak's happiest and most musical moments are spent as he incubates and performs other household duties imposed on him while the female visits her clubs and otherwise enjoys herself. 


\section{LXXII}

\section{Indigo Bunting \\ 598. Passerina cyanae}

The Indigo Bunting is one of our migratory birds, arriving about May first and returning south in October. It is about five and one-half inches long and of an indigo color on head and neck, with a greenish tinge on the back and belly.

Buntings are rather abundant in thickets bordering roadsides and open glades, where they may be seen and heard on hot June and July days. Their song is very much like that of the American Goldfinch. The nest is a substantial one, built in thickets and vines near the ground. Four to five bluish-white eggs are laid in June and July. (Fig. 108.)

Late one afternoon in July, while bird-nest hunting for photographic purposes, I saw Slacker, the Cowbird, come up on a low limb from the weeds near a path in a ravine. Her every expression was one of the sneak that she is; her very movements were those of a traitor and a coward. I was satisfied that she had been in mischief, and that there was in that vicinity some small bird's nest which she had been despoiling with one of her eggs.

Within two feet of the ground, in a bush, was the nest of an Indigo Bunting, containing three young Buntings, and right in their midst was the egg of a Cowbird. She was too late this time. It was plain that the egg had just been laid and it is the only instance where I have personally known a Cowbird to lay her egg in a nest containing young birds almost ready to leave the nest. I removed the egg and examined it carefully and found it perfectly fresh.

I made a photograph of the nest, the young birds and the egg, just as I found them. (Fig. 109.) I kept tab on the nest thereafter and photographed one of the young birds after it was able to fly. 
The female Indigo Bunting looks more like a small Sparrow than like her beautiful bright-colored mate. She is very fond of her young but the male appears to be somewhat indifferent to them. At this nest he rarely made his appearance and then only looked about and quickly retired to the depths of the wooded ravine. 


\section{LXXIII}

\section{Dickcissel; Black-throated Bunting 604. Spiza americana (Gmel.)}

This seven-inch long, common-sparrow-looking bird, with its dark gray back, chestnut-colored wings, faint yellow streak over the eyes, black blotch on the throat, and yellow-splashed breast with black dot in the center, is easily distinguished by a close observer. It is fond of dry upland pastures bordering roadsides, especially if they are overgrown with thistles and other heavy weeds. It lays four bluish eggs in July. The nest is a deep structure into which enter much bramble and clean straws, and is built on or near the ground. (Fig. 112.)

The Dickcissel ranges from the Gulf to Canada, and from the Alleghenies to the Rockies. About the first week in May the male puts in his appearance, to be followed by the female a week later. Then in the last week in August, after large flocks of these birds have collected, they depart for the South, where they spend the winter months.

The male takes no part in the nest-building or in feeding the young. His principal occupation during this period, apparently, is to perch on the nearest wire, twig or post and incessantly repeat his attempt at song: "See, see, see! dick, dick, dick!" This monotonous, unmusical refrain he keeps up for hours, during the heat of the day, when all other birds have sought the seclusion of the deep shadows.

Because of their back markings and yellow breasts with central spots, Dickcissels in some localities are erroneously called "Little Meadowlarks."

They are weed, seed and insect eaters and are of much benefit to the farmer. They are very shy around the nest, and will abandon it if disturbed very much. Every one of their homes in which I have found a Cowbird's egg along with those of the rightful owners was abandoned. It is extremely hard to photograph the 


\section{DICKCISSEL; BLACK-THROATED}

female near the nest, as she refuses to return as long as a tent or other blind is in sight.

To what extent scientific ornithology can be carried, one investigator recently reported in painful detail: he had killed and examined eighty-seven Dickcissels that he might be able to examine their juvenile plumage. A shame! 


\section{LXXIV}

\section{Bank Swallow; Sand Martin 616. Riparia riparia}

These little Swallows, only five inches long and of a lustreless brown color on the breast and back, with a white belly, are birds of wide distribution and are among the few birds not known as "water birds" that colonize during the breeding season. They are fond of banks bordering streams or in close proximity to marshes, and nest in holes which they excavate in the ground, laying from two to four spotless white eggs.

Bordering the flats of the Missouri River, near Kansas City, there is an immense loess deposit, one hundred feet thick. In constructing a railroad, a deep cut was made through this firmly packed, but granular mass. It is an ideal place for Bank Swallows to build their nests. A colony of several hundred annually congregates there. The tunnels of the Swallows are from two to three feet deep, and only a few inches apart, making the face of this dirt wall look like a well shot-up target on a rifle range. (Fig. 111.)

These birds are certainly accurate marksmen. In their headlong dives at a terrific pace they hit the "bull'seye," so to speak, with every shot, so that the face of the target looks as if a machine gun were assaulting it.

Bank Swallows are great moth and mosquito catchers, and while feeding do not, as true perching birds do, approach the nest cautiously, alighting on a limb here and a post there before delivering the food morsel to the young. Like an express train entering a tunnel they plunge into the dark passages and are out of sight.

In company with Professor A. E. Shirling, I visited this colony of Bank Swallows. Elsewhere, during the feeding time of the young, a visitor rarely hears such a chattering as we heard; every hour of the day there were many heavily loaded trains with all their rattle and with engines belching smoke and live cinders, passing within 


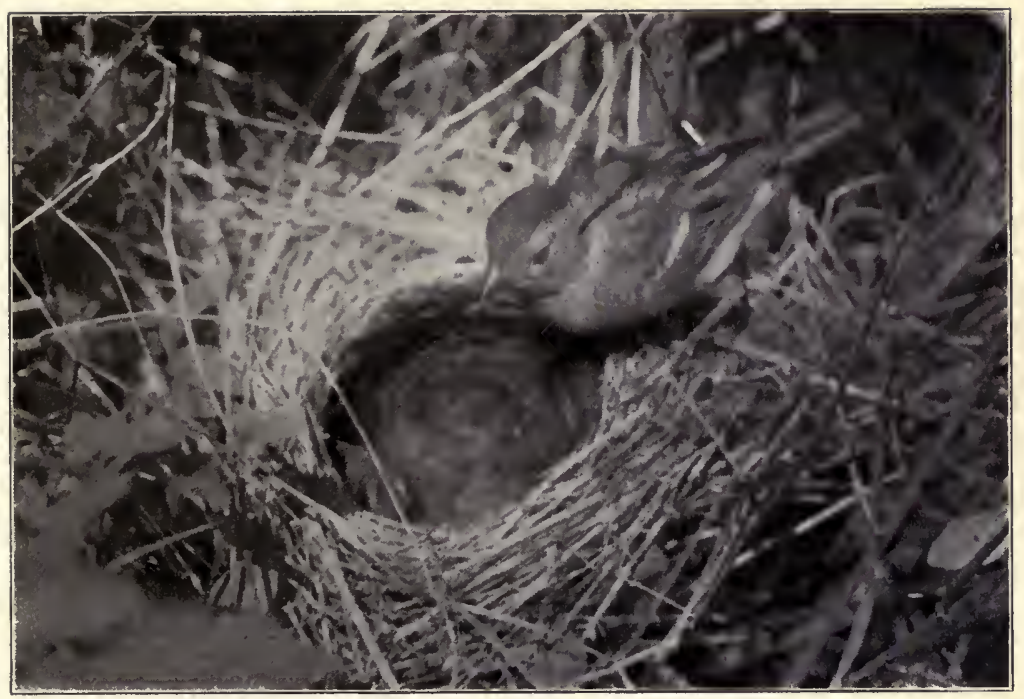

Fig. 101. FIELD SPARROW

(page 181)

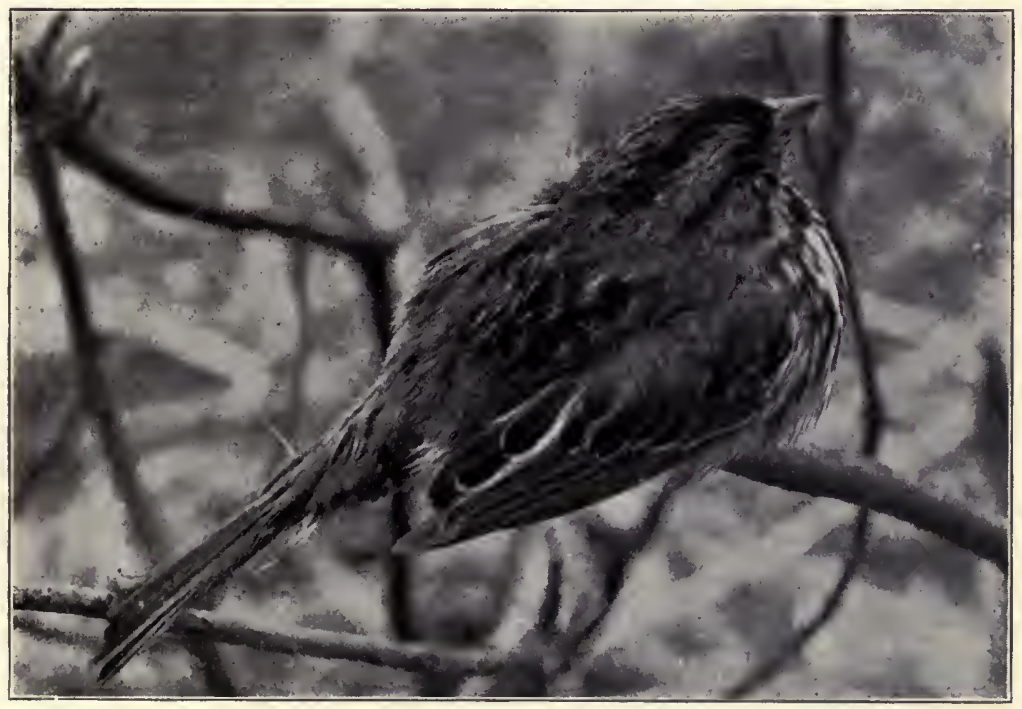

Fig. 102. SONG SPARROW

(page 184) 


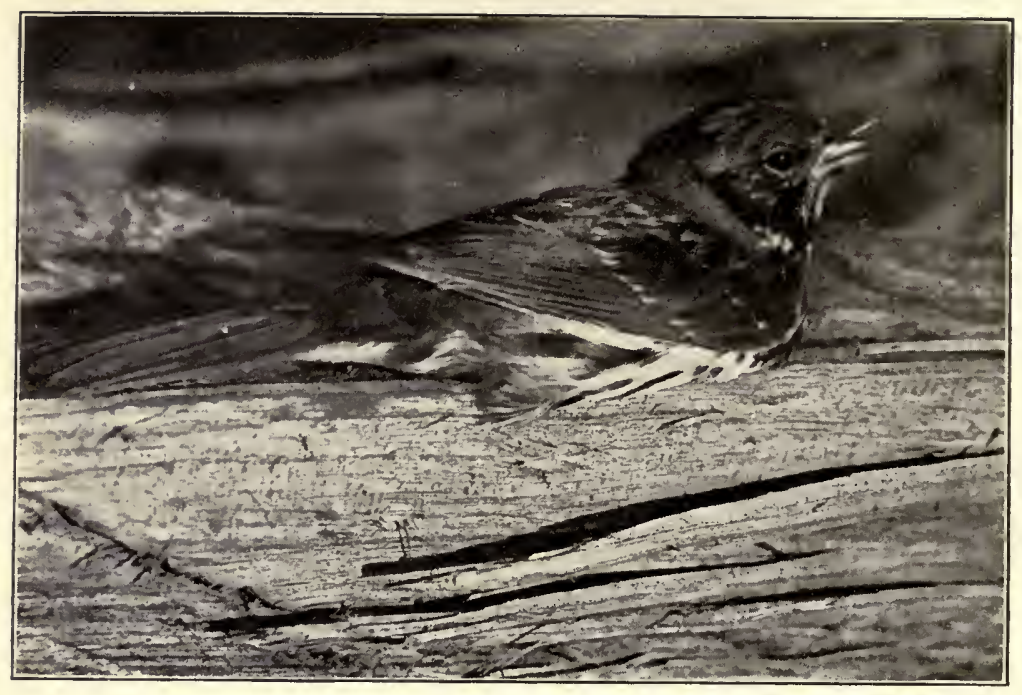

Fig. 103. FOX SPARROW

(page 185)

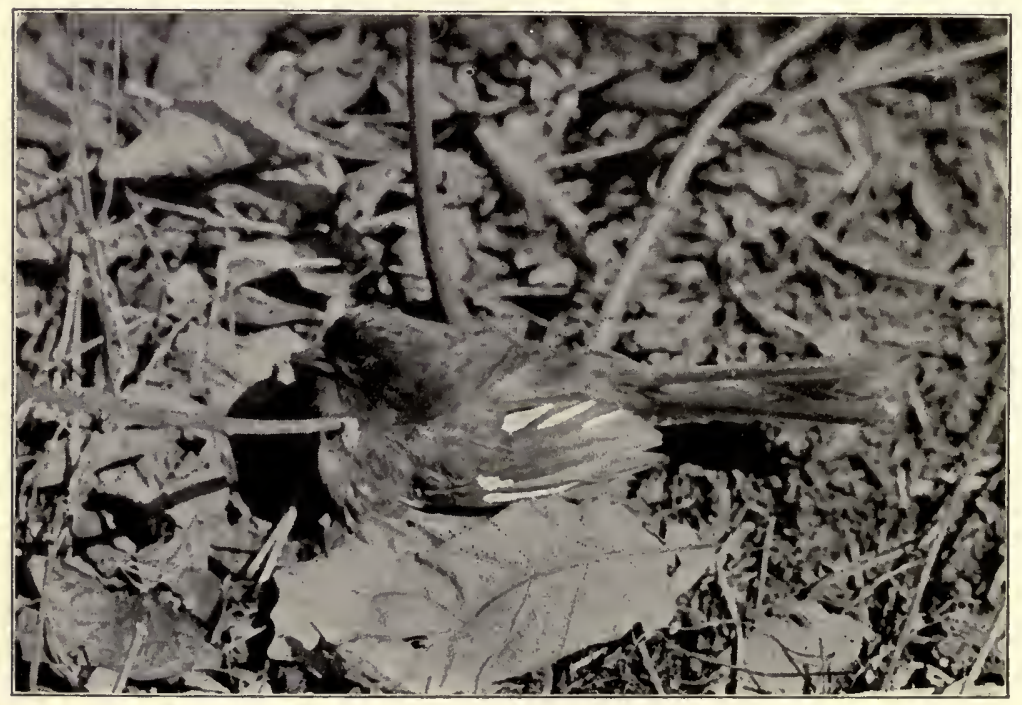

Fig. 104. TOWHEE

(page 187) 
fifty feet of these nests. Established confidence in security is a wonderful bird sentiment.

As we stood there late in the afternoon the birds, by the hundreds, came wheeling into the vicinity of the nests in gradually diminishing circles, like a vast inverted cone, with apex at the face of the bank, and were fed into the sieve-like hopper until the last Swallow had disappeared.

We dug into a number of these kitchenettes, photographed the young and the nests, and restored them unharmed to their original positions. 


\section{LXXV}

\section{Migrant Shrike; Loggerhead Shrike 622a. Lanius ludovicianus excubitovides}

The Shrike is of a general slate color on the back, and whitish below, with patches of white on tail and wings, in this respect resembling the Mockingbird, but having a black bridle extending over the eyes and across the forehead.

This Shrike is about nine inches long and is an abundant summer resident in the central part of the United States. It builds a big, rough, unfinished nest of weeds, rubbish, strings, feathers and cloth and prefers thorn or scrub oak trees for a nest site. The nest is from ten to fifteen feet from the ground. The bird lays in June and July from four to six eggs, grayish-blue, spotted with brown or umber. (Fig. 110.)

The very makeup of the Shrike suggests ferocity and carnivorous traits. See it, as it perches! Its attitude and demeanor are of a threatening character. See how small birds avoid its company and how they dart into the thick brush at the Shrike's approach! It possesses all of the temperamental rapacious traits of the true birds of prey: it is quarrelsome and overbearing to its kind and other small birds, killing and devouring those weaker than itself; it is a Hawk in looks and habits, possessing a hooked bill, but weak, Sparrow-like feet. It cannot catch or hold its prey with its feet; hence the Shrike has a habit of impaling its catch on thorns and barbed wire fences, where it may perch near its food and with its strong neck and powerful hooked bill tear the victims into shreds to be devoured.

When you let this bird and its young alone I know of no other that seemingly ignores your presence more than the Shrike. I have repeatedly stood beneath a thorn tree within five feet of one of these birds and watched it impale a grasshopper or a small bird with entire indifference to my presence-not even on speaking terms with me. (Fig. 113.) 
The male is much devoted to the female during incubation and the rearing of the young. Both birds are brave and attack with vigor anyone disturbing their young, while with the most eloquent pleading they seemingly beg him to desist. On approaching a nest too closely I have been struck on the hand by one of these birds; and on one occasion, the male actually lashed my hat when I captured a young bird that had left the nest. All the time both birds hovered over my head, uttering their peculiar, "quit, quit, qua-a-a!" protest. (Fig. 114.)

Shrikes may be seen, like the birds of prey, perched in some conspicuous place while waiting for victims. Unlike strictly insectivorous birds, they do not have to migrate so early or so far south to keep within food range, for they can capture the many seed-eating birds that remain in the North. I have seen Shrikes in the vicinity of Kansas City every month of the year.

No slacker Cowbird dares to invade the premises of these birds, as they are vigilant and fight an unwelcome visitor to a finish. With its big head and hawk-like beak the Shrike suggests power and destruction to all smaller birds. There is nothing about its appearance to elicit any of our bird sympathies or admiration.

The Loggerhead Shrike rightly belongs to the southeastern states. However, many specimens have been secured in the central part of the United States. The lighter colored, or so-called "Migrant" Shrike, is the one most frequently found near Kansas City. It is a solitary bird, rarely seen in pairs except during the nesting season.

One day, while standing under a thorn tree, I heard a noise as though birds were discussing some family matter. On looking up, I saw two Shrikes sitting within two inches of each other on a limb about five feet above me. Then, looking still closer, I discovered that one was a full-grown young bird and that the parent was doing something that was of absorbing interest to the youngster, which repeatedly assumed an expectant and pleading attitude. The parent bird, it seemed, was busily engaged in the task of dislodging and re-impaling a fullgrown English Sparrow on a thorn. Ruthlessly it would pull the dead bird on the thorn and in so doing tear a 
streak of flesh from the victim's breast; then it would disengage its prey, each time pulling the Sparrow farther on the thorn and tearing another long slit in the flesh by a tugging movement. All the while the young Shrike was impatiently begging for more. Not once did the old bird use its talons to grasp or hold the carcass, but depended entirely on the thorn-like skewer to hold the bird, while the tugging with the bill tore ribbons of flesh from the Sparrow's breast.

After watching the two for twenty minutes I made my presence known and under threatening protest by voice and action I took possession of the remains and photographed them just as the birds had left them on the thorn.

The full-grown Bluebird herein illustrated was a victim of these impaling birds. (Fig. 115.) 


\section{LXXVI}

Red-eyed Vireo; The Preacher 624. Vireosylva olivaceus (Gmel.)

This bird is a common summer resident in the vicinity of Kansas City, Missouri, and is known as the Preacher Bird, owing to its habit, in early spring, of repeating all day long a song that seems to say, "Preacher, Preacher!" The Vireo is olive green above and its crown is ashy. Above the eyes is a black line bordered with white, while a dusky line runs through the eyes. The under parts of the body are white with a tinge of yellow on the side. The length of the bird is six inches. It is an insect eater and, of course, is migratory. The eggs are four in number, white with small brown specks. (Fig. 116.)

Vireos prefer orchards and clumps of small elms and maples as nesting sites. The range extends from the Gulf of Mexico to Arctic regions. The bird selects a fork of a horizontal or drooping small elm or maple, near the ground. To this is snugly fastened the basket pensile nest of grasses and plant fibres. The birds appear to be very happy while at this work, as they keep singing all the time, even in the heat of the day, "Preacher, Preacher!"' The male incubates, and sings contentedly while doing so. (Fig. 117.)

The Cowbird slacker delights to sneak up to a Vireo's nest and, after depositing one of her eggs, return to her polygamous associates in a cow pasture near by. The impostor usually succeeds in thus forcing the Vireo to incubate and rear the parasite at the expense of the death of her own progeny from overcrowding and starvation, while the vagabond thrives on monopolized Vireo diet.

I once found this little restless bush-bird's nest in the usual location, anchored to two small branches of an elm sapling, about three feet from the ground. It was a beautiful sample of exquisite bird architecture, a per- 
fect cup about two inches deep, so nicely woven that one would think it had just been turned out from a hemp basket factory. It was so shut in from the daylight that I had to separate the surrounding brush in order to make a picture.

This small bird is so strangely suspicious of human invasion of its domain that it would invariably leave its home before I could discover it, though my visits were frequent, as the happenings in this particular nest were of much importance to me. The old song of many years ago was here surely exemplified:

"Many a man rocks another man's son, When he thinks he is rocking his own."

Snugly nesting among the five beautifully formed white eggs with brown spots was an egg of the vagabond slacker, Cowbird, about three times as large as the Vireo's own, and having a dusky background with brown blotches.

I was delighted with my find, as I had long looked for just the state of domestic affairs found in this bird home. I made several pictures of the nest and contents, then replaced the shading branches and left the bird to continue the task of playing enforced foster-mother to the Cowbird's egg.

Within a few days I visited the nest again and found the shy and much-abused mother sitting on the mixed brood of eggs. Two days later, the nest contained a big hulk of a Cowbird. (Fig. 118.) The Vireo eggs were not hatched, and the Vireo was busy feeding the impostor. Four days later, the Cowbird was thriving and was already larger than all four of the unhatched Vireo eggs. The Vireo was trying to incubate her own eggs and at the same time feed the tramp; thus they were neglected and failed to hatch. At the end of six days after the culprit had hatched, all of the Vireo eggs had disappeared but the impostor was covered with pin feathers and was as large as the Vireo. It was one continuous cry for more food so the Vireos were kept busy and, in a "better-be-happy-than-wise" mood, continued to sing in their blissful ignorance. 


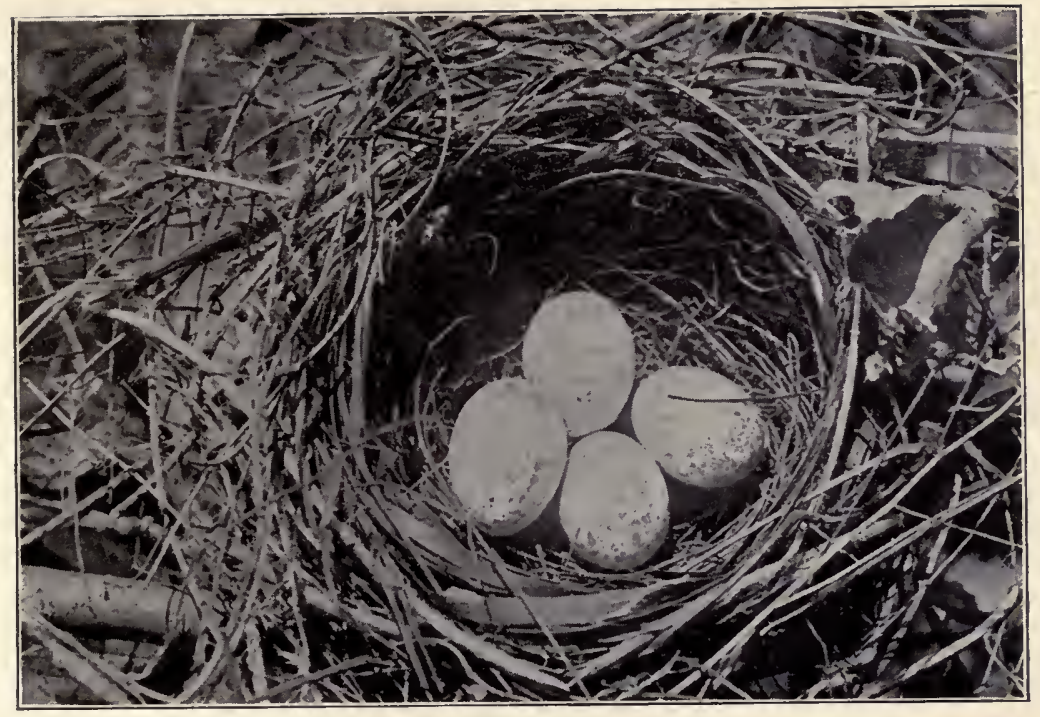

Fig. 105. CARDINAL'S NEST AND EGGS

(page 189)

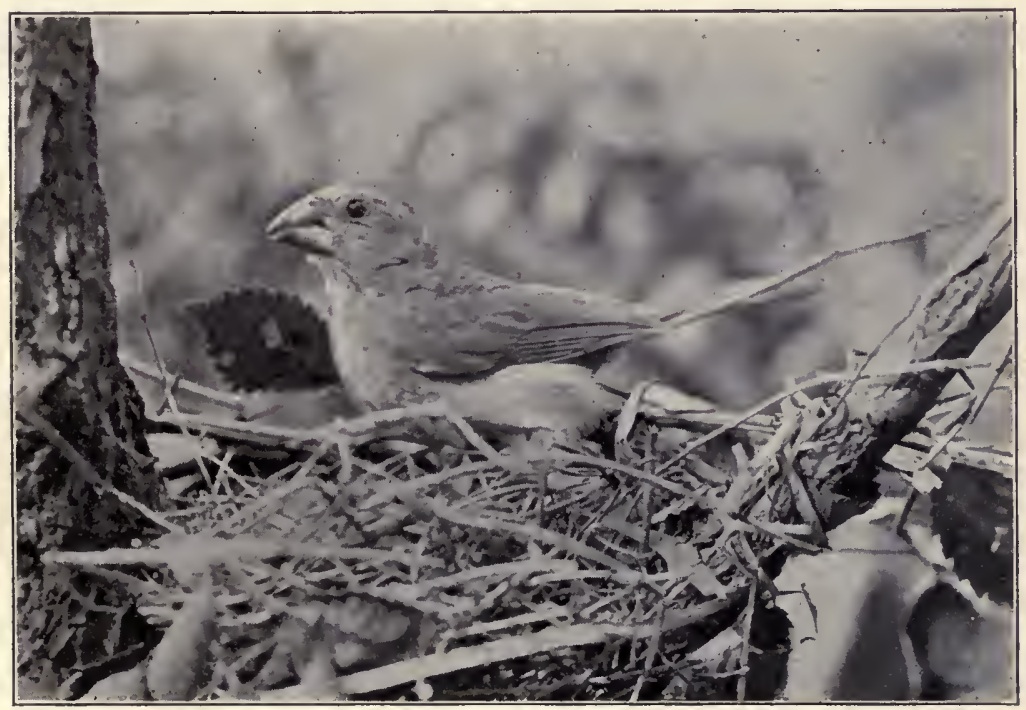

Fig. 106. CARDINAL BROODING 


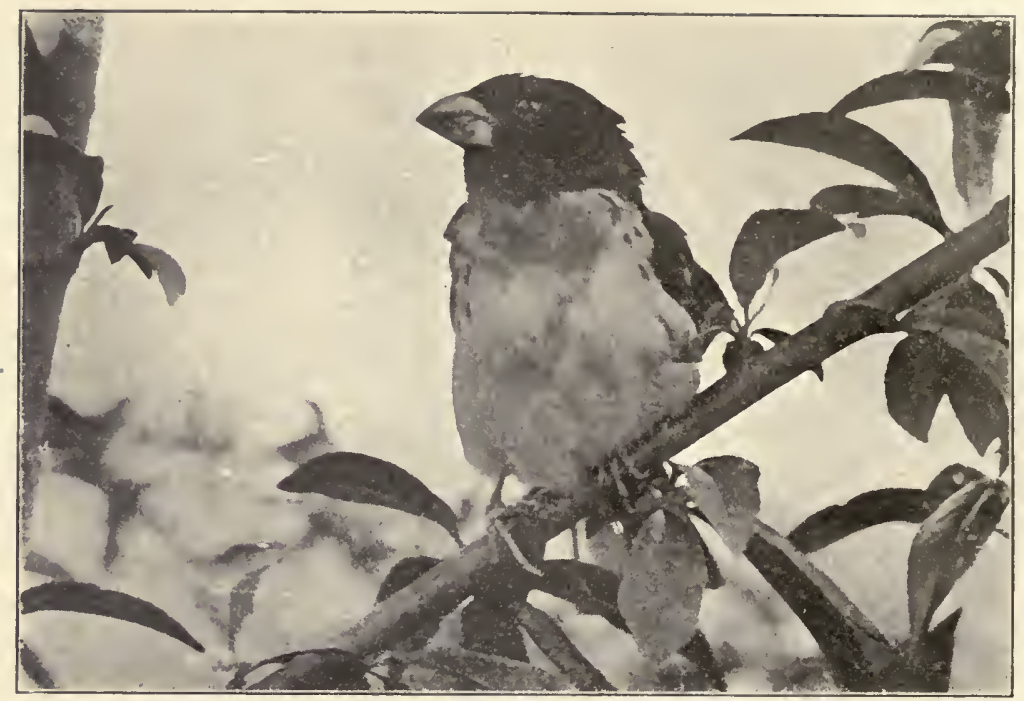

Fig. 107. ROSE-BREASTED GROSBEAK

(1)age 192)

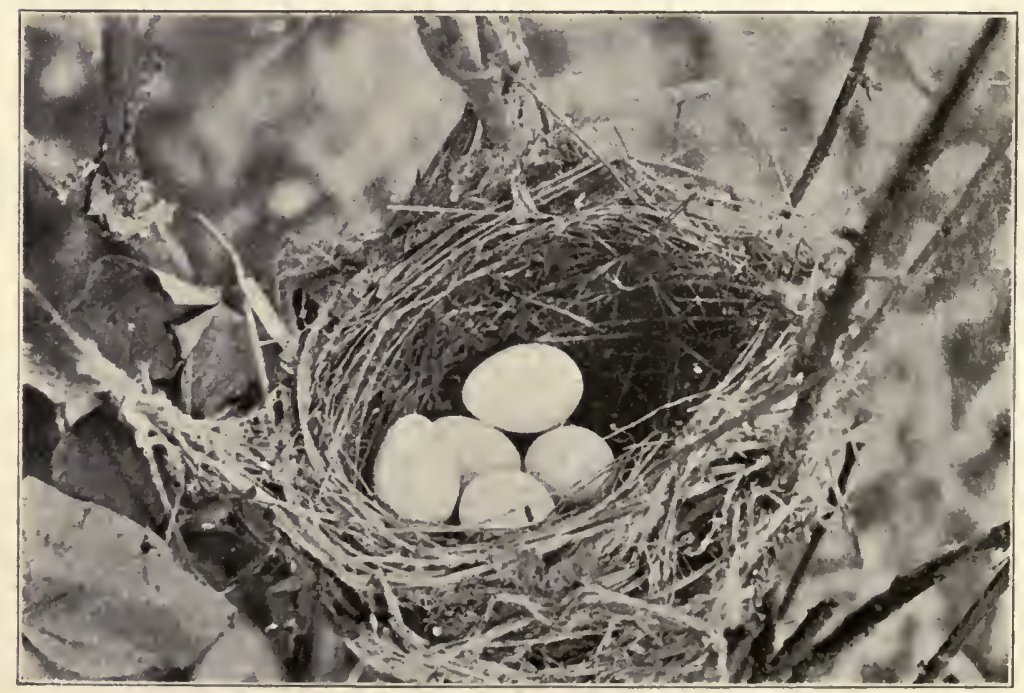

Fig. 108. INDIGO BUNTING'S NEST AND EGGS

(1)itge 194) 


\section{LXXVII}

\section{Bell's Vireo; Bell's Greenlet 633. Vireo belli belli}

Of the true Vireos this is the species most frequently seen and heard in the vicinity of Kansas City, Missouri, but the White-eyed, the Red-eyed and the Warbling Vireos are also quite common summer residents. The Warbling Vireo is a bird of high-tree branches, while the others mentioned are shrubbery birds.

Many of the bunches of small elms, blackberry briars and other shrubbery in our city parks harbor one or more pairs of these little five-inch olivaceous and whitish songsters. They nest, usually, within two feet of the ground and lay four white eggs marked with minute brown specks. (Fig. 119.)

Bell's Vireo is olive green on the back, sulphury yellowish on the belly and has two whitish wing bars. In this species there are no eye-bars or white circles around the eyes. The male and female are alike. The bird is insectivorous.

Unless you weave your way into the tangle of underbrush and keep close to the ground and look upward through the leaves, you will rarely get more than a flitting glimpse of this bird, although its curiosity will keep it within a few feet of you all the time. Its subdued ventriloquist-like song keeps you guessing as to its location but rest assured its little keen eyes are peeping from behind a leaf at you all the while. It is restless and remains in one position but a moment.

The nest illustrated in this collection was suspended from a blackberry briar and was a deep cup-like structure, in the make-up of which much lint and cottony plant fibres had been used. There were four white eggs and the bird was incubating when I found it.

I visited the place every few days. Then, one day, I peeped into the little nursery and beheld four uglylooking young Vireos. When I had first seen the nest it had in addition to the eggs of the Vireo, one egg of the 
slacker Cowbird. This I had promptly removed. Thus the mother had one less mouth to feed.

It was a hot day and I knew that the little mother would not remain long away from her new babies. I set my camera within three feet of the nest, focused carefully, fastened the shutter release line and retired to a bunch of briars to await her return. I had already separated the briars so I would have good sunlight on the nest. When the mother returned I made an exposure and changed plate-holders. To my surprise the bird did not leave the nest, but continued with her feathery sunshade to protect the delicate young. I made two more exposures; then I decided to place my hand as near her as she would permit and make a close-up. To my surprise she remained perfectly quiet, letting me gently stroke her graceful little back and tail without protest. I quickly made an exposure showing my hand in this position. (Fig. 120.)

Before I left I pulled the briars together and thus built a shady bower for this little mother and her tender brood. Then with heartfelt best wishes for their safety I departed, conscious of having done them no harm and fully realizing that with maternal love nature throws aside all fear and stands willing to sacrifice life in the protection of the defenseless young. With this lesson fresh upon me I resolved to honor, respect and assist these humble little creatures whenever an opportunity presented itself.

Never have I so fully realized the utter helplessness of small birds as I did on that occasion, with my huge hand within grasping distance of the tiny bunch of feathers. Some human beings could, with credit to themselves, follow the precepts of birds in providing for and protecting their young. 


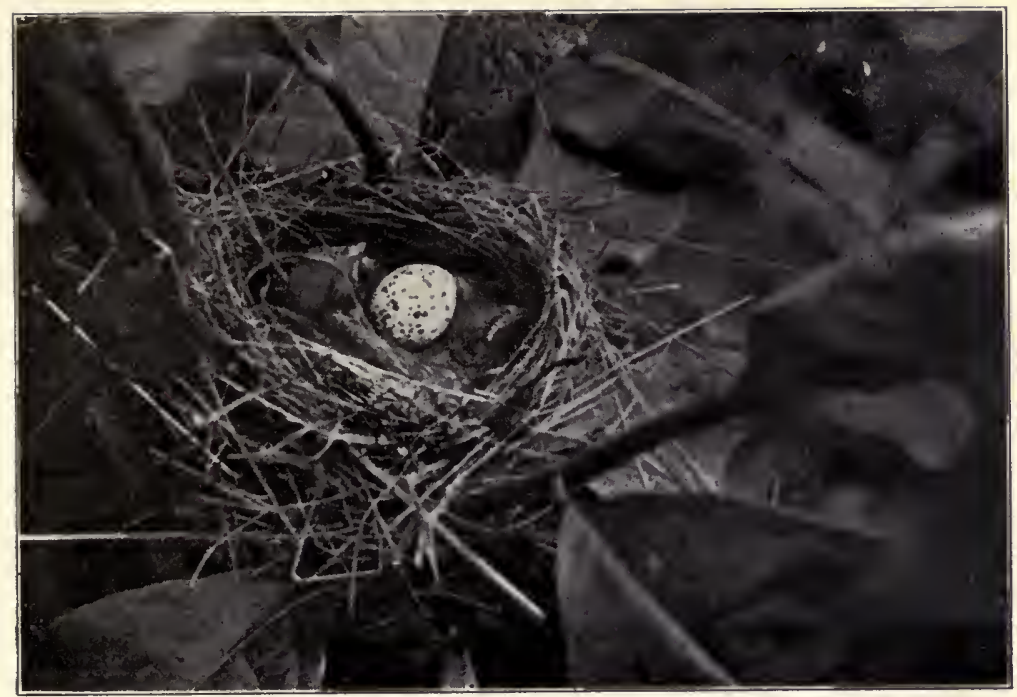

Fig. 109. INDIGO BUNTING YOUNG. NOTE COWBIRD EGG (page 194)

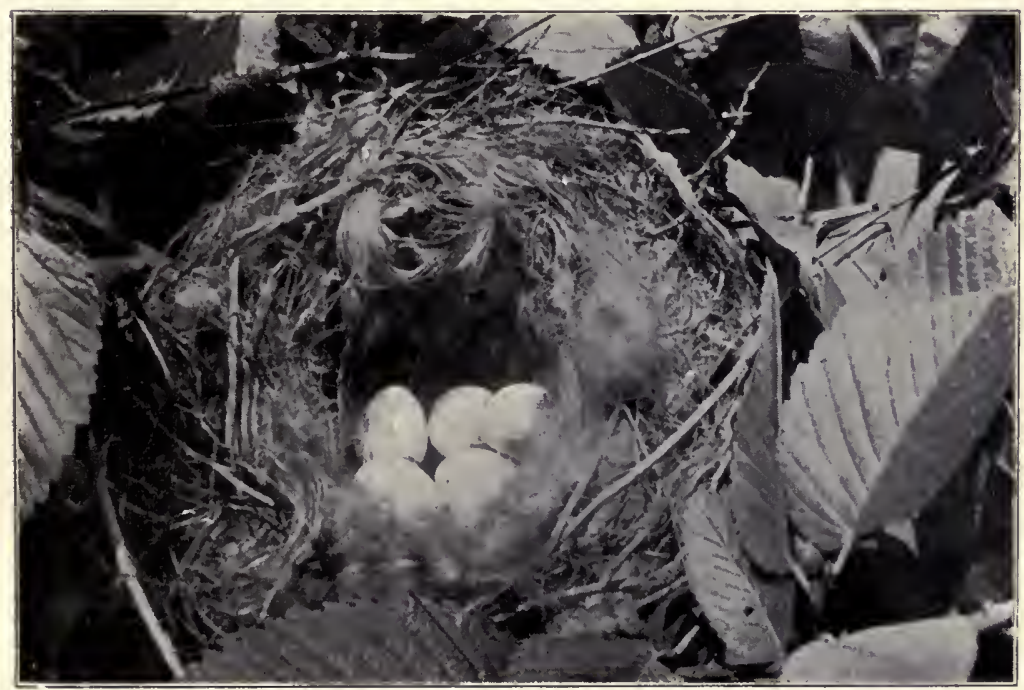

Fig. 110. WHITE-RUMPED SHRIKE'S NEST AND EGGS 


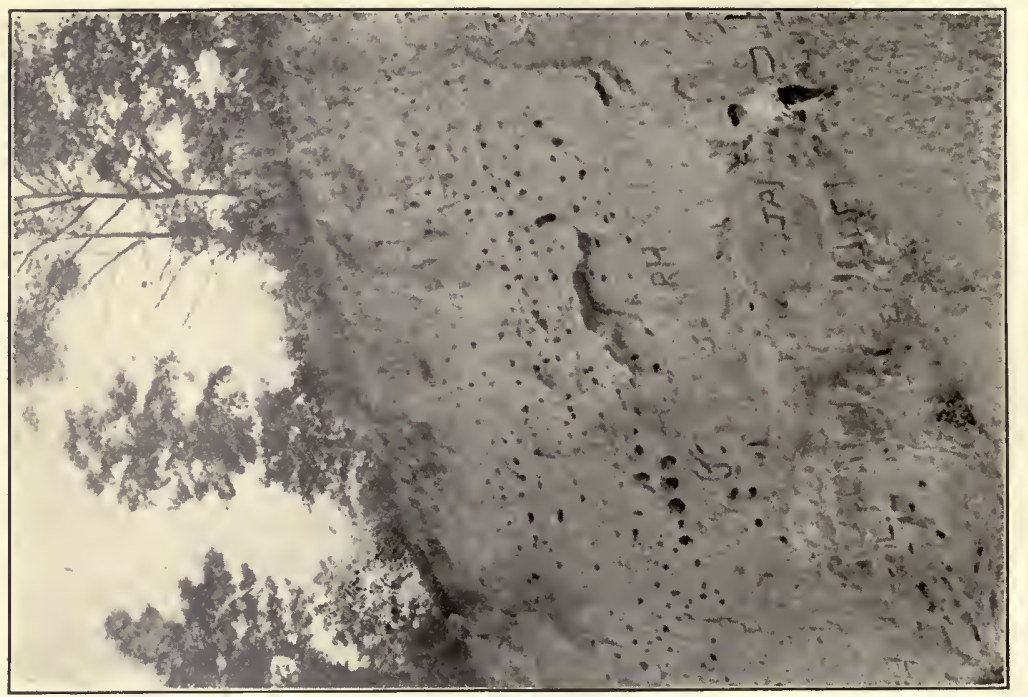

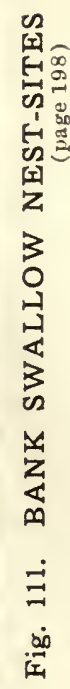

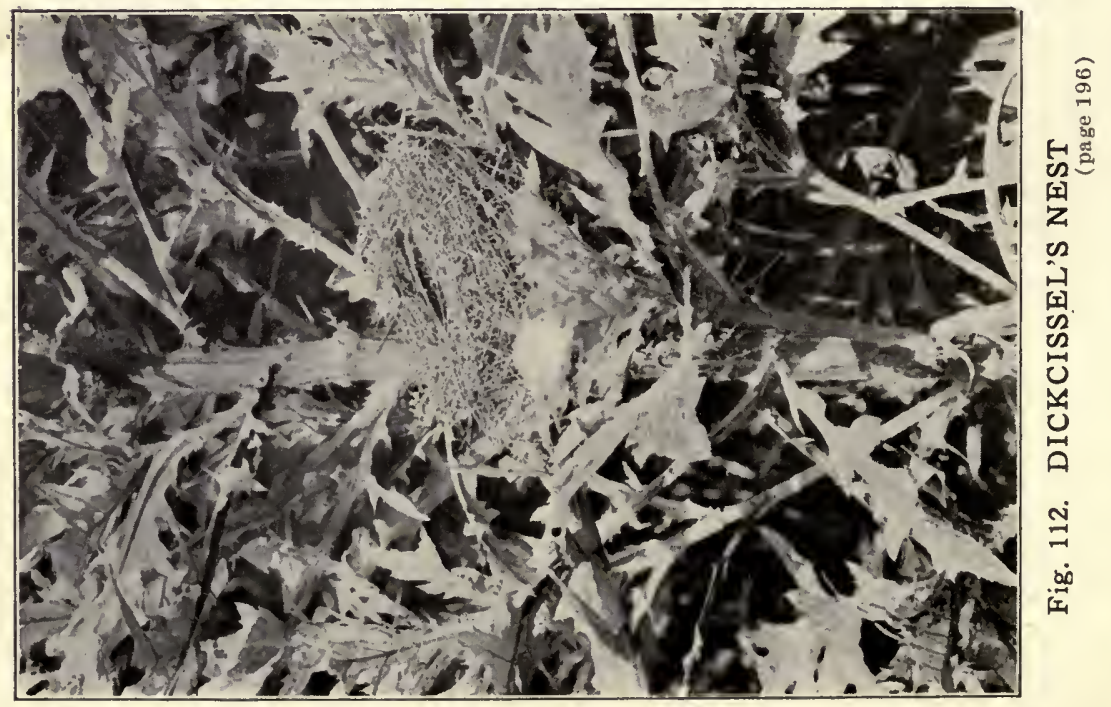




\section{LXXVIII}

Prothonotary Warbler; Golden Swamp Warbler 637. Protonotaria citrea

The Prothonotary Warbler is a rather common summer resident in the vicinity of Kansas City, Missouri, but it is rarely seen and recognized by the average bird enthusiast; as its habits and nesting sites are usually away from the easily followed paths. It arrives a few days ahead of most of the Warblers on their northern journey, departing for the South several weeks in advance of the same throng.

Prothonotary Warblers breed throughout their summer range. Few birds are more universally covered with cadmium yellow plumage than are these six-inch Warblers. They select for their nests abandoned Woodpeckers' holes in dead willows in swampy places. This habit, in itself, aids in identification of these birds. Should you see a little yellow bird collecting food on driftwood and half-sunken rocks in a swamp and carrying it into a hole in a dead willow leaning or standing in the water, south of latitude 43 degrees, it would be a safe guess to call it the bird under discussion. They also nest in other localities, such as old cans, auger-holes and trestleworks, usually near the water.

The love-making of these Warblers is vigorous and hasty and when mated the two are a devoted pair. Their song is sweet, but limited in range.

Sixty miles south of Kansas City there is a vast tract of bottom land subject to annual overflow. Two hundred acres of this land was made into a permanent swamp when a gun club built a retaining bank to keep the overflow water from draining into the nearby stream. This water has killed all of the trees, many of which are still standing. Probably one-half are willows, the soft wood of which is easily excavated by the Downy, Hairy and other Woodpeckers. The last year's nests are invariably appropriated by the Swamp Warblers, since 
they are not endowed with excavating tools with which to build their own nest holes. (Fig. 121.)

Last summer, while I was stopping at the clubhouse, the keeper asked me if I would like to photograph some Wild Canaries, and informed me that every June a large number nested in the holes in the willow stumps down in the swamp.

On investigating I found, as I had already surmised, that the "Wild Canaries" were really the beautiful and rarely seen Prothonotary Warblers. There were many of them, the nest holes in most instances being within a few feet of the water. The nest material consisted of the chips from the natural excavating, but the finished nests were of fine dead grass and contained, in most cases, five white eggs, marked with many small brown spots.

This is one of the few Warblers remaining in the vicinity of Kansas City during the breeding season. Most of them continue their northward journey after pausing a few days during their migration. This Warbler has been found nesting as far north as Minnesota.

In striking contrast the Black-poll Warbler continues its journey northward to the shores of the Arctic Ocean, where, with the Eskimo, the musk-ox and the polar bear as its neighbors, it builds its nest and rears its young, and in the fall returns to its winter home in South America. Twice each year this frail but brave bird makes this ten-thousand-mile journey. 


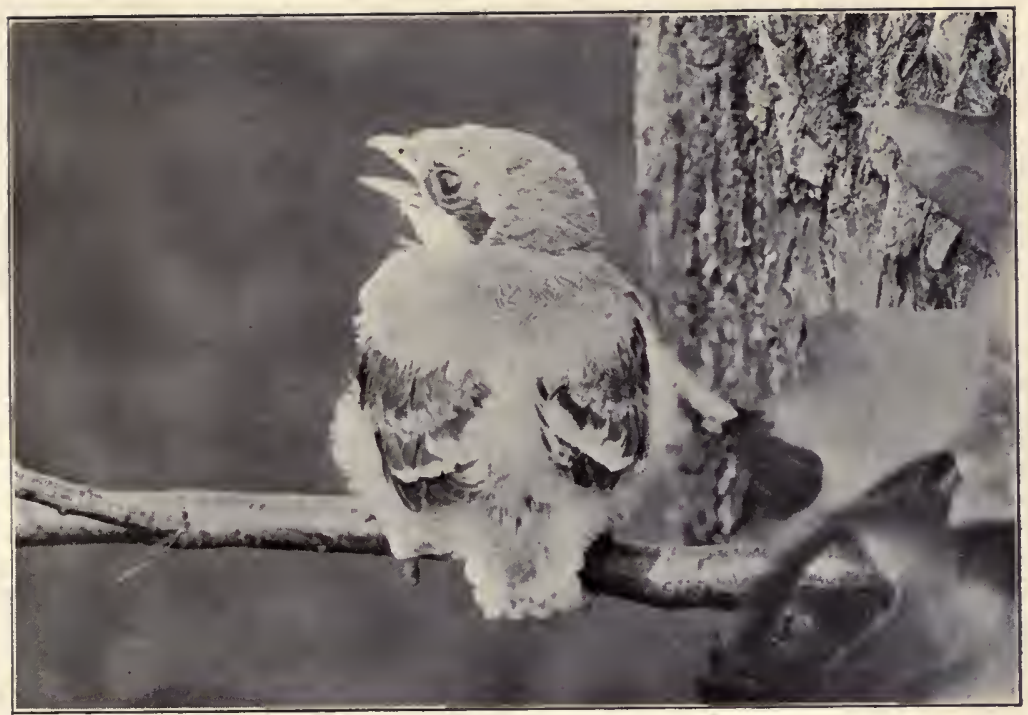

Fig. 113. YOUNG SHRIKE

(page 200)

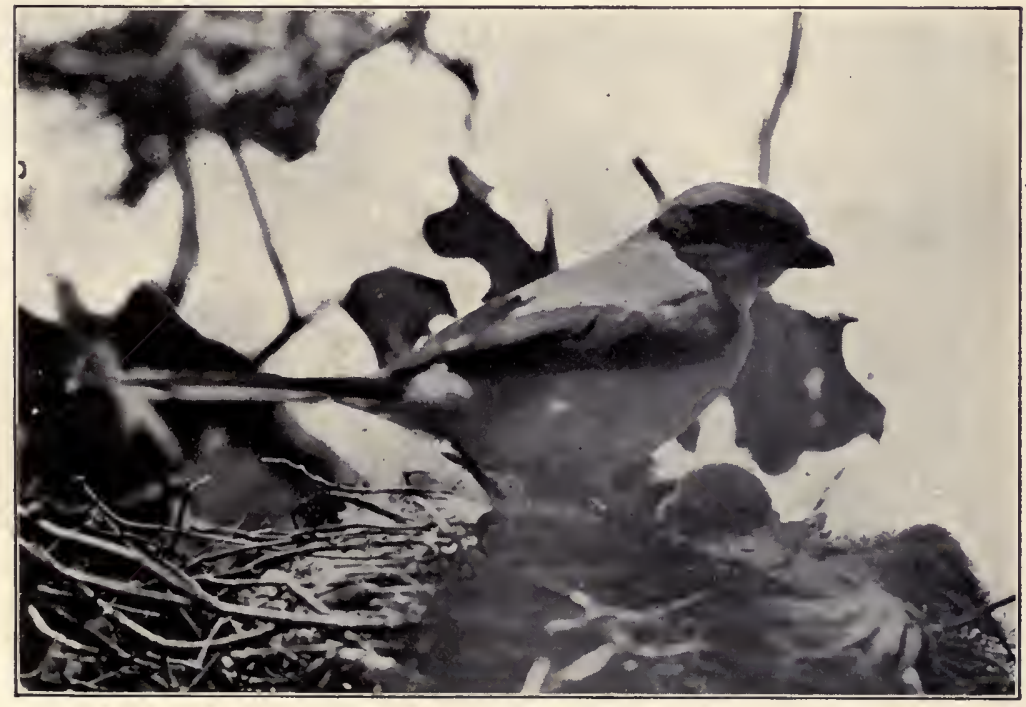

Fig. 114. SHRIKE AT NEST

(page 201) 


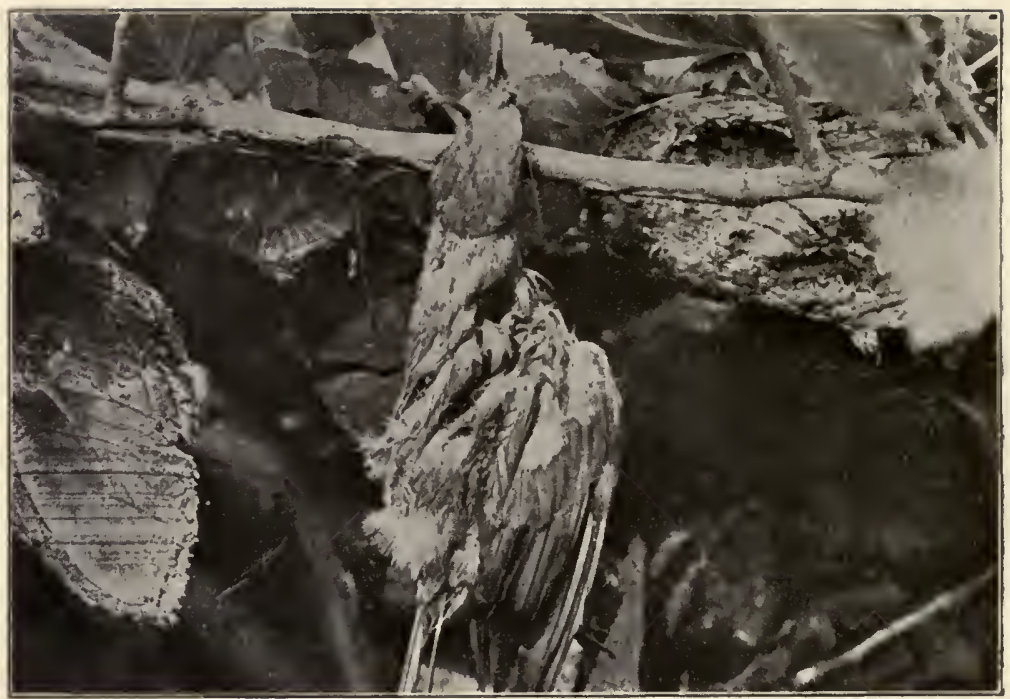

Fig. 115. SHRIKE-IMPALED BLUEBIRD

(page 202)

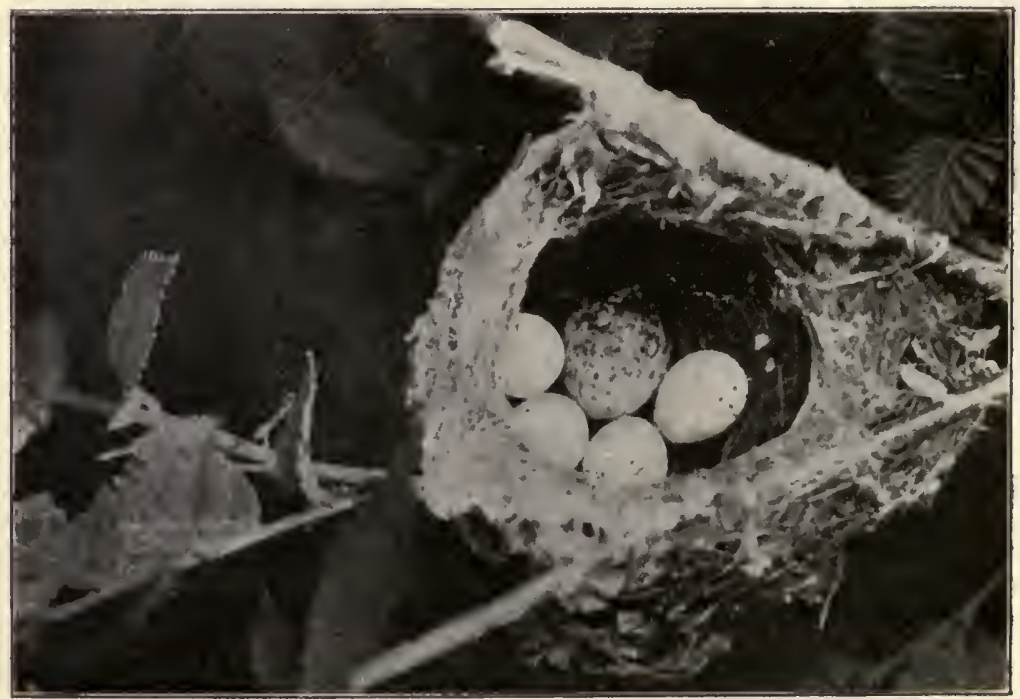

Fig. 116. RED-EYED VIREO'S NEST. NOTE COWBIRD EGG (page 203) 


\section{LXXIX}

Yellow Warbler; Summer Yellowbird; Yellow Poll; Golden Warbler; Wild Canary 652. Dendroica aestiva (Gmel.)

The term, "Wild Canary" must not be confused with the same name as applied to the American Goldfinch, as the latter looks much more like a Canary than does the former, and its song is similar to that of our well-known domestic caged bird.

The Yellow.Warbler is of a rich yellow color, with chestnut or brown streaks over the under parts and a yellow-olive back. The bird is about five inches long and ranges over the entire United States and Canada, even within the Arctic Circle, breeding over all that territory. It is therefore one of the commonest of Warblers. It is a bird of orchards, briar and brushy overgrown fence rows, of elm shade trees and park shrubbery. Although common enough in most localities, the nest is tucked away so snugly in the fork of some small tree and is so completely hidden by the foliage, that it is an accident when one is discovered. I had looked for three seasons before I found one. (Fig. 123.)

The Yellow Warbler is the most easily recognized of our Warblers; its nest is a compact, heavy, well-built structure of vegetable fibre and cottony material, securely anchored in the small fork of an elm or fruit tree. The eggs number from four to five and are of a greenishwhite dotted with lilac-shaded spots.

The song of the Warbler is pleasing, gentle and soft, and is a zealous performance. This bird is especially fond of willow covered lowland bordering large streams.

One day in early June, on the beautiful Cliff Drive, in the heart of Kansas City, I saw a glint of yellow flash through the branches of an elm. After watching for an hour I saw the bird go to the nest, which was located about twenty-five feet above the park driveway in the triple fork of a small elm. Both birds were at the nest when I discovered it. The young were of such size that 209 
I could see their heads when they were raised above the basket to be fed. I remained near by for hours, watching the little worm-catchers feed their babies, all the while wishing the nest were nearer the ground and trying to devise some plan to make a picture of it without disturbing its surroundings.

Extensive repairs were being made on the driveway, necessitating the use of much explosive, and heavy blasting was going on day after day. Vast particles of dirt and rock were constantly falling all about the nest tree, yet the birds kept at their daily toil of feeding, regardless of danger. No doubt remains in my mind but that their labors were of equal import to the park with those of a score or more workmen blasting out the new driveway.

The first night after I discovered the little nursery, a four-inch rain fell within an hour's time. My thoughts in the night frequently reverted to the goldencolored midgets and I wished for their safety. The next morning early I visited the locality of the nest and was much pleased to see the parents feeding the young, as usual. All through that four-inch downpour the faithful little mother had hovered, with cuddling wings, over her precious babies, assuring them of their safety.

I was anxious to make a close-up picture, and the only way to do this was to cut off the limb, carefully lower it to the ground and return it to a safe place where the old bird could easily locate it. I made the pictures and re-anchored the nest ten feet from the ground in the midst of a bunch of elm leaves. I returned three hours later and found the parents feeding the four youngsters quite as though it had not been disturbed. The young were so far advanced that the yellow was appearing in many places in their plumage.

Two days later two of these little mites had blossomed into almost full plumage and were perched on the edge of the nest, about ready to break home ties. They were comical-looking bird pygmies, not much larger than a good sized chintz-bug.

These birds, when feeding the nestlings, simply peck the food into the young birds' throats and are gone in a second, thus making it very difficult to photograph them while at the nest. 


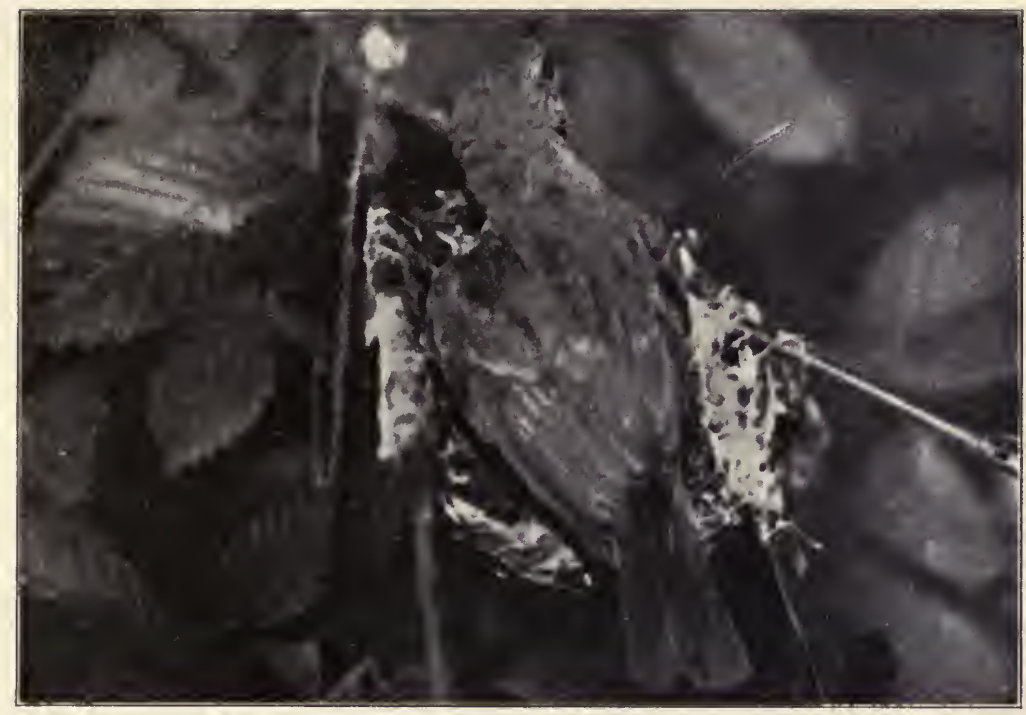

Fig. 117. RED-EYED VIREO INCUBATING

(page 203)

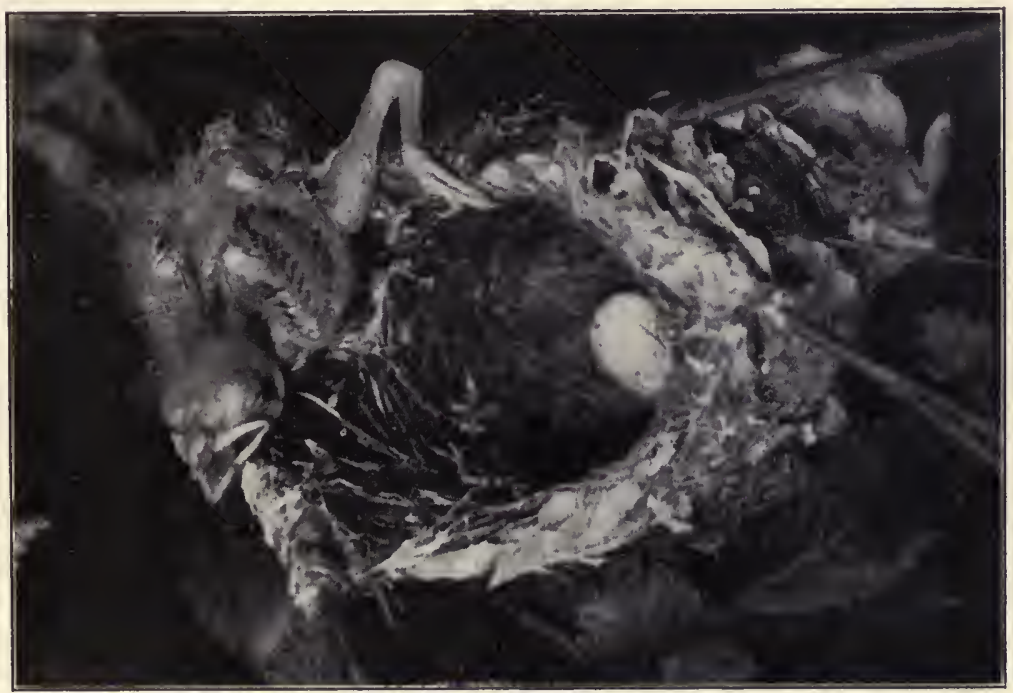

Fig. 118. YOUNG COWBIRD 


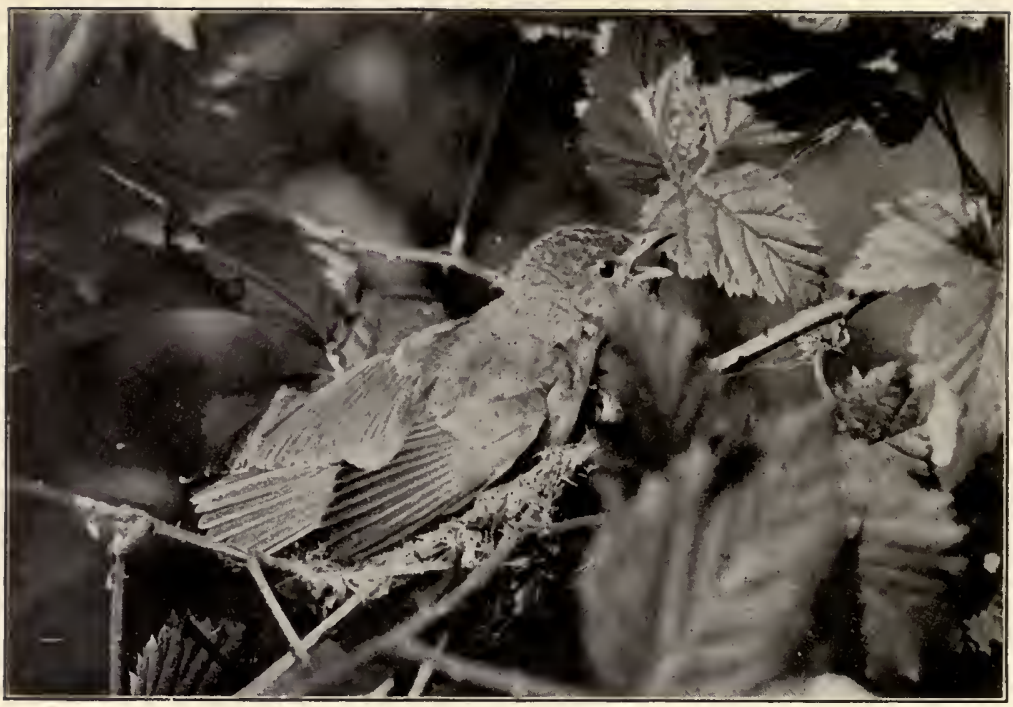

Fig. 119. BELL'S VIREO BROODING

(page 205)

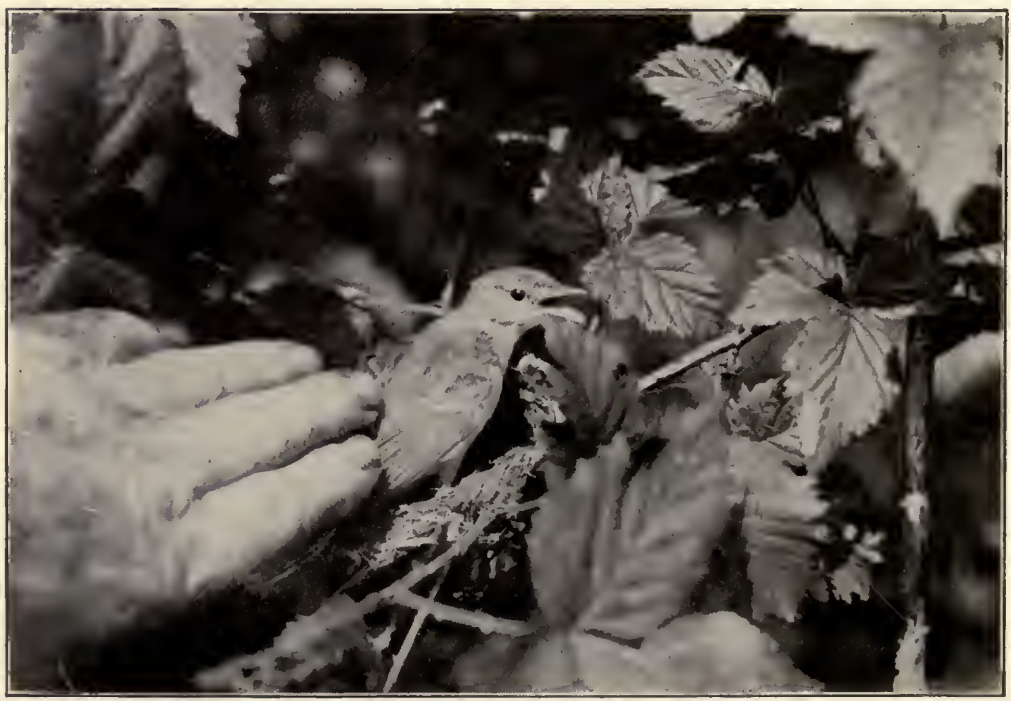

Fig. 120. BELL'S VIREO BROODING

(page 206) 
The Warbler is often victimized by the Cowbird. On examining this nest, after the birds had left it, I found that the rightful owners had evaded the responsibilities of foster-parents to a slacker's young by building an extra floor in the nest, snugly walling off the intruded egg. Thanks to the wisdom of this pair of Yellow Warblers, there is one less Cowbird. (Fig. 122.)

What changes in the appearance of Yellow Warbler babies, a few days brings! At the end of a week, they are partly feathered and have multiplied several times in bodily weight. In two weeks, they are feathered and some of the golden yellow tints are to be seen; the colors that aid us in distinguishing the species take their places on breast and back. Much ado and excitement mark the time for home-tie breaking. With vibrating wings and encouraging words the devoted parents seem to say:

"Do you see us? Don't be afraid, but please be careful."

One's bird affections are made stronger by sights like these, and his enmity is increased toward all things that destroy these innocent and beneficial friends of man. 


\section{$\operatorname{LXXX}$}

Myrtle Warbler; Yellow-rumped Warbler; YellowCrowned Warbler; MYrtle Bird 655. Dendroica aestiva aestiva

You may identify this migrant Warbler by its four spots of yellow; the central crown patch, the rump patch and two on either side of the breast. The general coloring of the Myrtle Warbler is slaty-blue; the belly is white and the throat also is white. It has a white line over the eye and a white bar directly beneath it that accentuates the eye and gives it a prominence not seen in many birds. The length of the bird is about five and one-half inches. The Audubon Warbler is marked the same with additional yellow on the throat. (Fig. 124.)

The Myrtle Warbler breeds in Canada and Minnesota. It winters from the southern half of the United States to Panama. It is the only Warbler found near Kansas City during the entire winter. It is a trim-made bird and is very graceful in its movements. While feeding it has the combined traits of a Flyeatcher, Wren and Nuthatch, and is fond of insects, bayberries and the seed of the poison oak.

Like all birds whose diet consists of a mixture of insects and berries this bird is a less typical migrant than most of the Warbler family. The Myrtle Warbler is one of the most abundant migrating Warblers, and may be seen in April and October in almost any place where patches of trees and climbing vines are plentiful. It is usually mixed in with Sparrows and other small birds.

The nest is usually built in low bushes, rarely on the ground. The eggs, four in number, are cream-colored or buff. This Warbler is rather friendly during migration; the picture in this collection was secured with the bird within six feet of the camera.

The Warbler family is found only in North and South America, and is one of the largest, comprising about one hundred and fifty-five species, half of this num- 

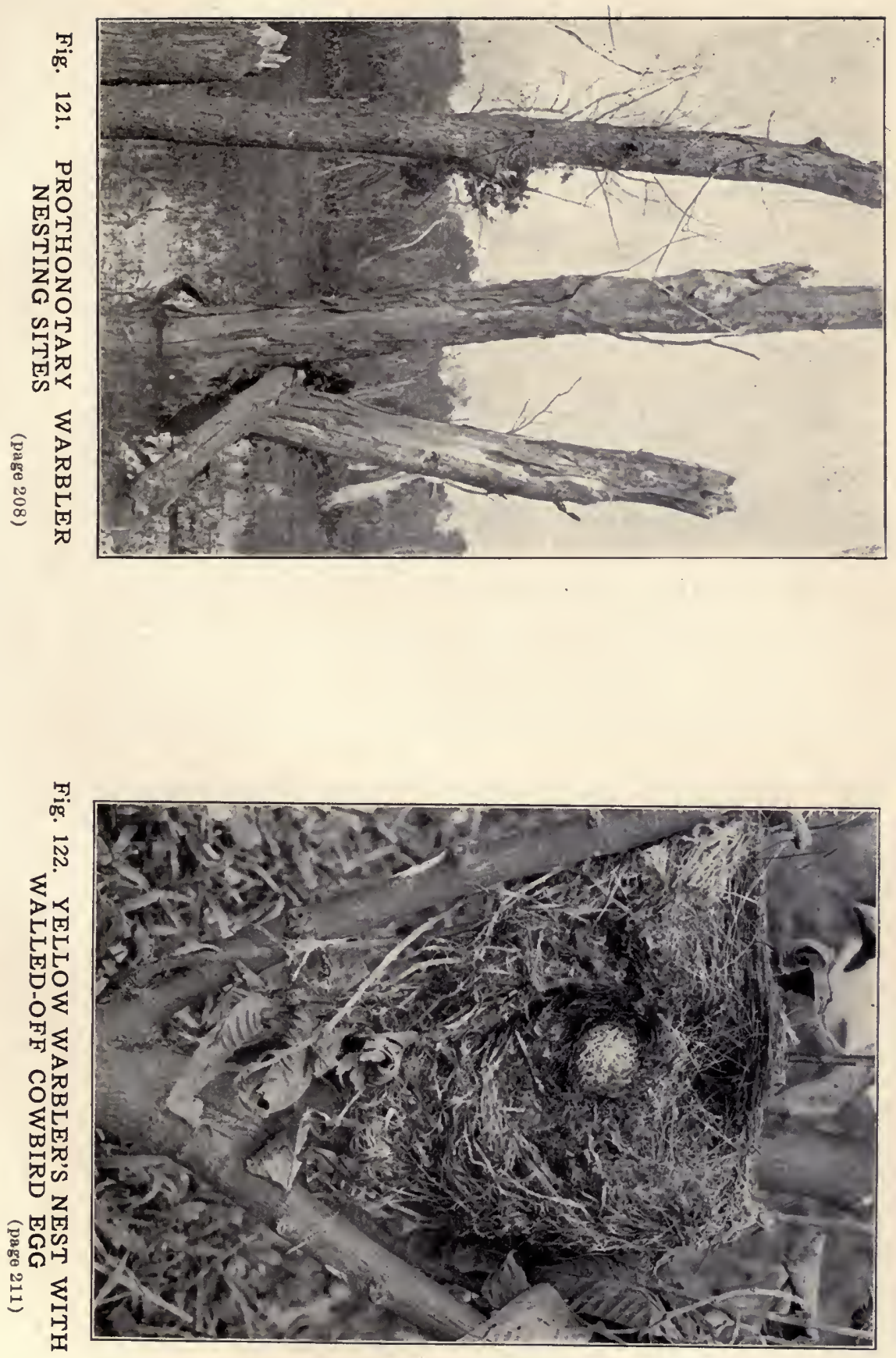


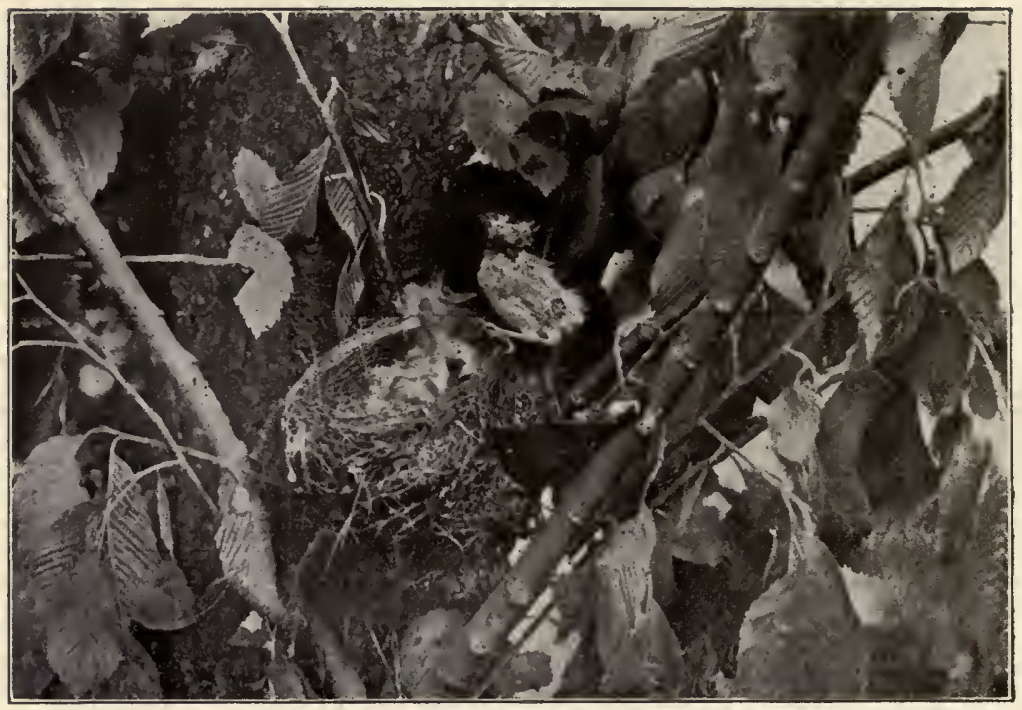

Fig. 123. YELLOW WARBLER'S NEST AND YOUNG

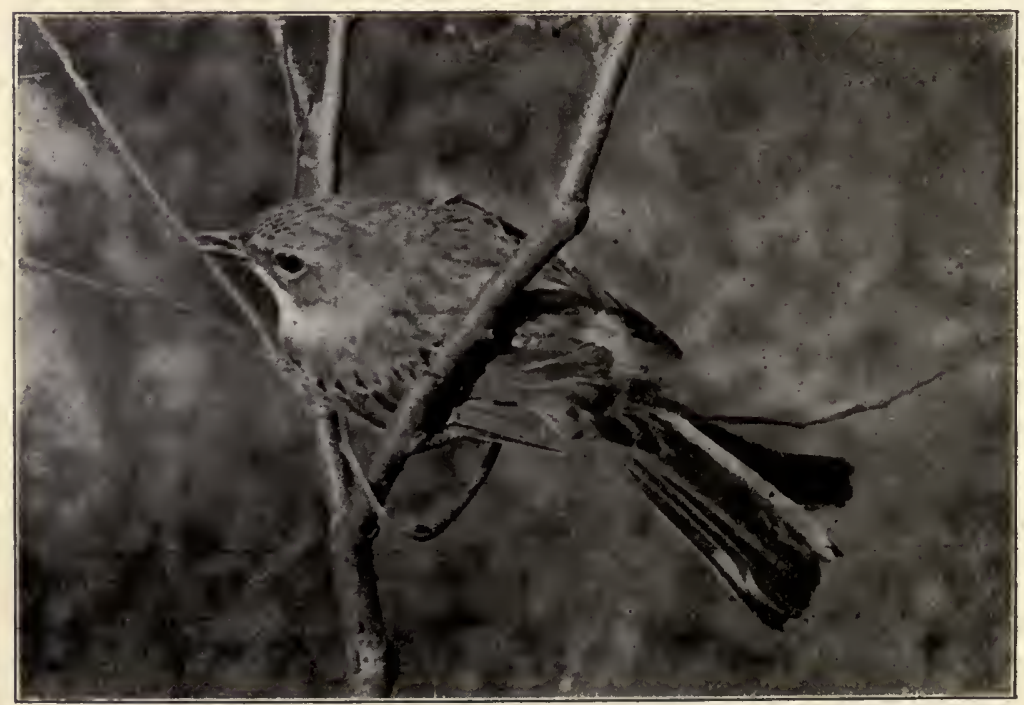

Fig. 124. MYRTLE WARBLER 
ber being found in the United States. In color, Warblers vary from the plainest garb to the most beautiful varigated plumage of any of our birds, and are all small in size, measuring on an average about five inches. They are all migratory in their habits, some species nesting on the shores of the Arctic Ocean, others in the northern tier of states bordering Canada, even to the middle central states, and going, on the southern journey, into Mexico and South America.

In general, Warblers are insect eaters but some like a mixed diet of seeds and berries. A typical example of this family is the Myrtle Warbler. With its graceful, trim figure, its bright, dark brown eyes, and its slatishblue plumage trimmed with golden yellow on rump, head and sides of breast, this bird possesses, in a marked degree, the beauty characteristic of its family. 


\section{LXXXI}

Maryland Yellow-throat; Yellow-throated Ground WARBLER; BLACK-MASKED WARBLER 681a. Geothlypis trichas (Swaims.)

The sub-species, Northern Yellow-throat, is the Warbler found in the central part of the United States, and is slightly larger and more clearly defined in color than is the Atlantic Coast bird.

The upper parts of this Yellow-throat are olive, the wings and tail are brown, practically all the under parts are rich yellow, the face and forehead are covered by a mask of black and the bird is small, measuring about five inches. Nests are on or close to the ground, in low damp places, usually near a stream or swamp. There are from four to six eggs to a nest, white with a few lilac spots.

These birds are migratory, appearing in Missouri about April tenth. They have a broad migratory and breeding range. The female does the incubating, while the male busies himself eluding and misguiding all who come near the nest. As he darts among the branches it is hard to follow his movements though he continually proclaims his new location by calling what sounds like, "Here it is! here it is!" But when you move toward the source of the song the nest is not there. He is ever masquerading, with his yellow suit and black mask across his face.

The female, too, will go sneaking away from the nest, inviting you to accompany her with her, "Here I am! here I am! Follow me!" but not waiting a second for you to catch up with her. The "whichitee, whichitee!" of the two may be heard at all hours of the day in midsummer; they are among the easiest birds to identify, as their markings are constant and clearly defined.

For years I had hunted for a nest of these birds. I had often seen both the male and the female in the vicinity of their home and had watched them carrying worms into thickets and briar patches, but every effort of mine to 214 


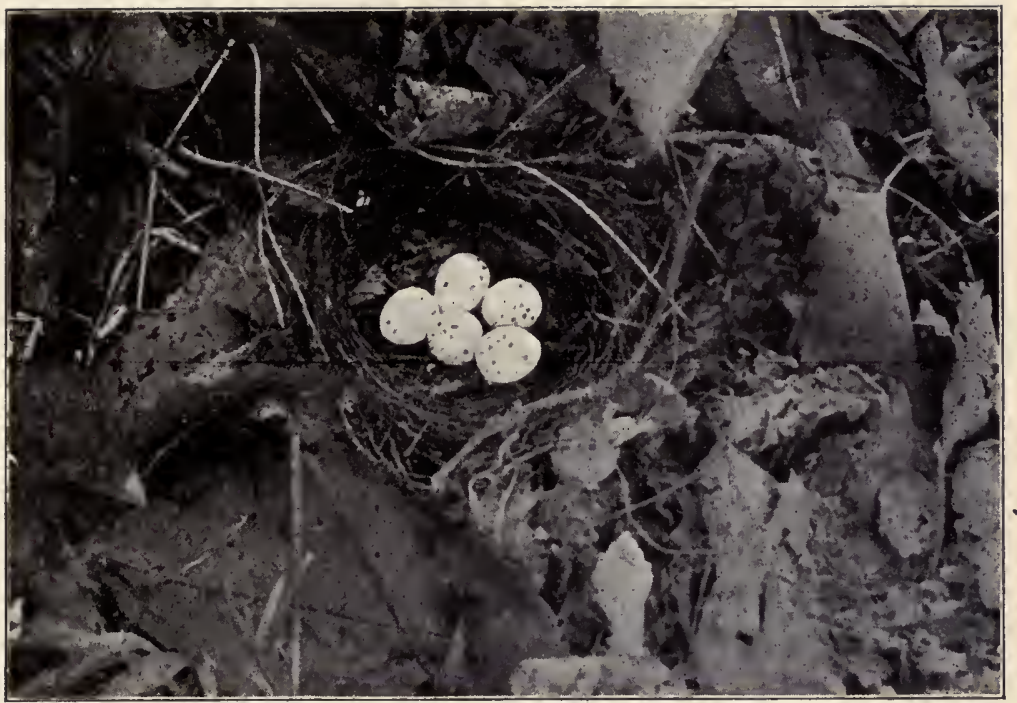

Fig. 125. MARYLAND YELLOW-THROAT'S NEST AND EGGS (page 215)

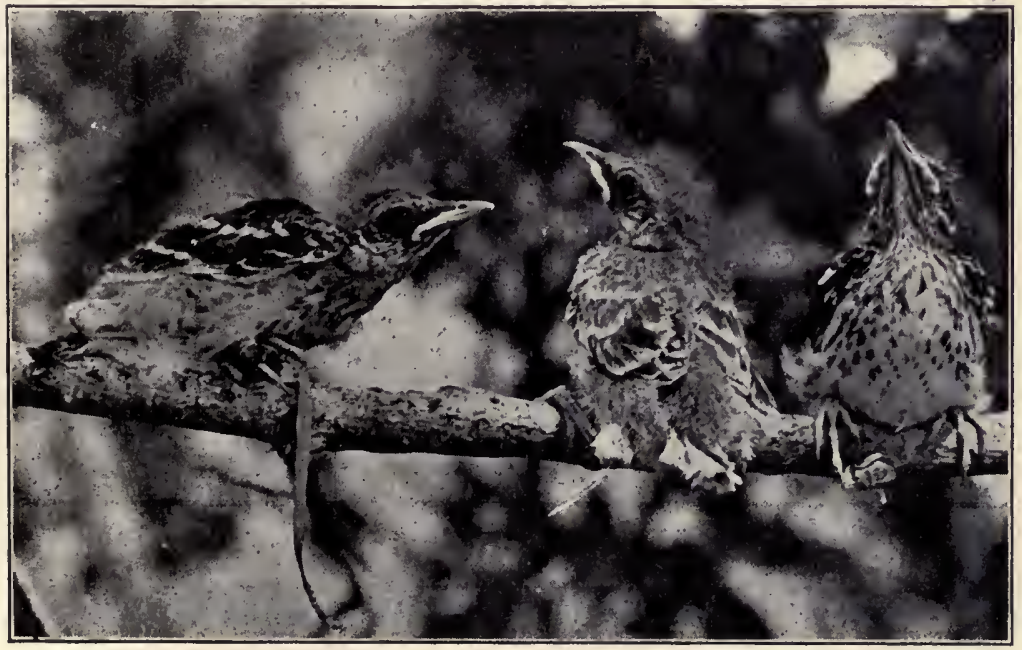

Fig. 126. MOCKING BIRD'S YOUNG 


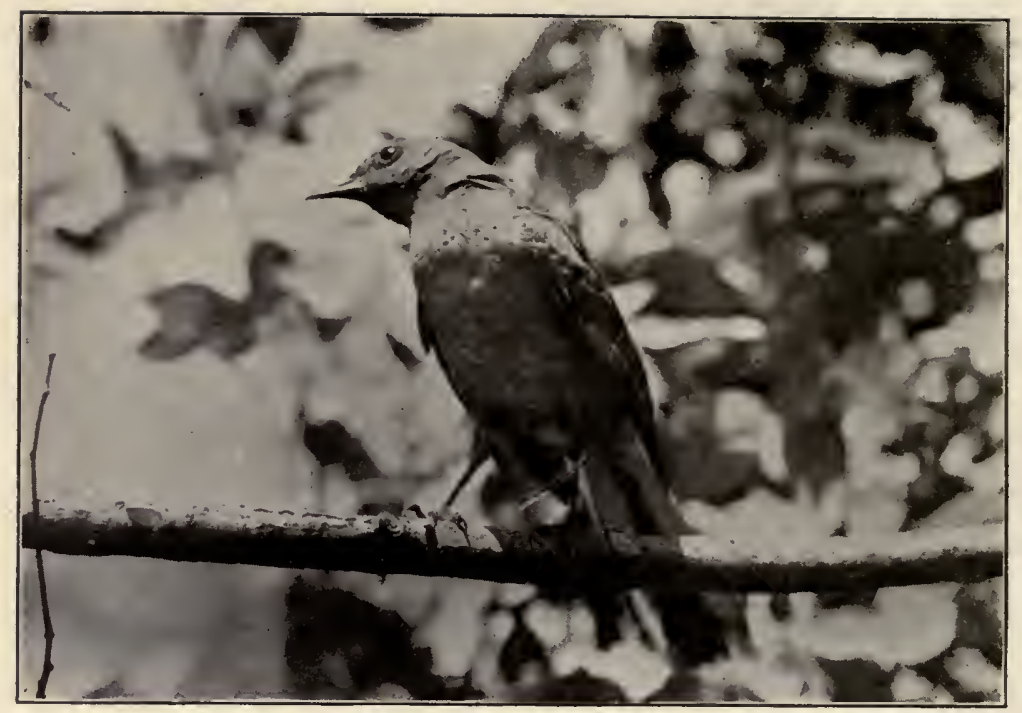

Fig. 127. MOCKING BIRD AT NEST

(page 216)

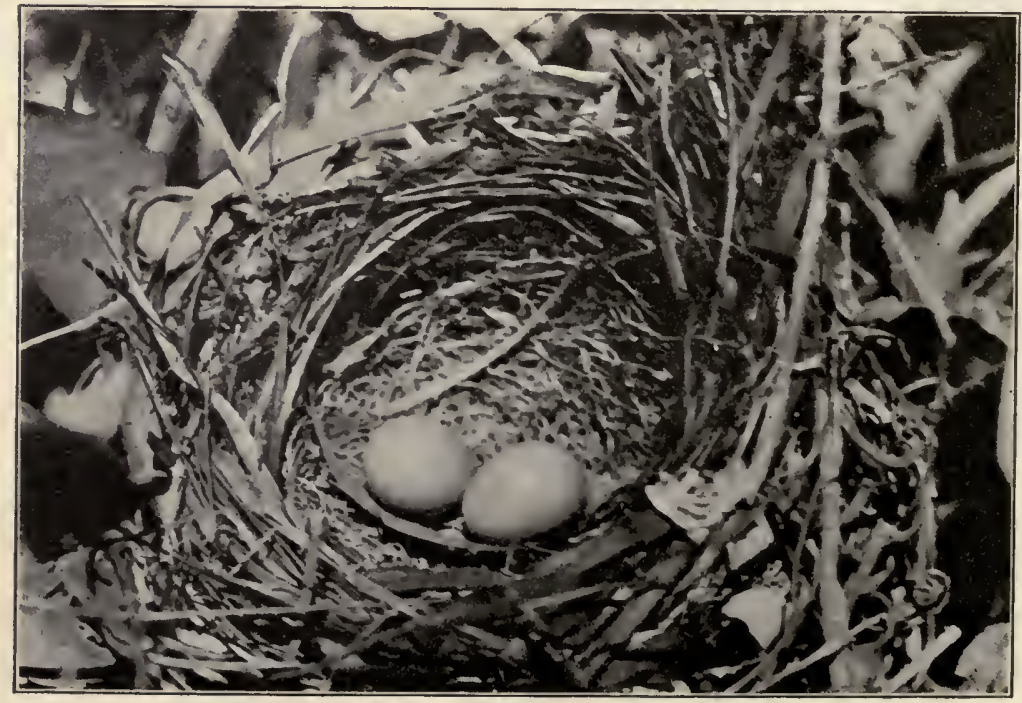

- Fig. 128. CATBIRD'S NEST AND EGGS 
locate the nest was without success until one damp morning, as I was plowing my way through the water-laden tall grass and jewel flowers in a ravine near a small stream, known to be a good locality for these birds, I saw a small dark streak dart right from under my damp and soggy shoes. Quickly I set my camera down to mark the location, knelt to part the grass, and, exactly beneath my camera, was my first discovered Yellow-throat's nest! It contained five white eggs, with many minute lilac-colored spots. I parted the grass more carefully and photographed the nest with the eggs; it was placed directly on the ground with its outer walls covered with dead leaves and the whole inner lining made up of closelywoven grape-vine twigs. I felt as if I had really accomplished a feat worth recording when I discovered this nest of the Yellow-throat and photographed it. (Fig. 125.)

The two birds were restless, moving about all the time, but not what one would call shy; they scolded me viciously each time I entered their thicket domain and continued to fly about me. As long as I remained near their home they occasionally lit on limbs near my head. They were curious and kept prying into my affairs by following me about and peeping at me from behind a leaf, all the while uttering a faint "pit, chit!" protest or query as to my business in that locality.

Yellow-throats are of much value to our park and woodland foliage, destroying the cucumber beetle and black olive scale. 


\section{LXXXII}

\section{MOCKINGBIRD \\ 703. Mimus polyglottos polyglottos (Linn.)}

The Mockingbird is about the size of a Robin, ten inches long. It has a pure gray back and grayish-white on the under parts, with well-marked white patches on the wings showing when in flight, very much like those of the Shrike; the outer tail feathers are white. It resembles a Shrike in looks, but has no black streak across the eyes and forehead. The sexes are similar in coloring.

The Mockingbird has a broad living and breeding range, extending from the Atlantic to the Pacific on our southern border and coming as far north as the central states.

The Mockingbird nests in bushes and small trees. (Fig. 126.) The eggs are from four to six in number and are of a bluish green with brown spots. Although Mockingbirds are poor nest-builders they rear two or more broods in a season and are very affectionate mates and devoted parents, resenting with vigorous protest the invasion of their home surroundings, and attacking Crows, Hawks or other known enemies of small birds. While I was picturing the Mockingbirds at the nest they would fly near me in a most piteous appeal or perch close by and repeatedly beg me to "quit, quit, quit!" (Fig. 127.)

They are fond of fruit and berries but are of more benefit to the farmer than harmful to the orchardist. They are especially fond of the favorable nesting surroundings near our homes.

Much of the so-called mimicry of the Mockingbird is in reality part of its own song brought out by hearing the sound from other sources during the singing. It is a favorite bird for the cage for it accepts confinement rather philosophically and retains its wonderful singing ability. The sight of the prison bars, however, acts as a damper on my appreciation of the song, as I realize that this bird of the big outdoors is robbed of the freedom nature intended it should enjoy. 


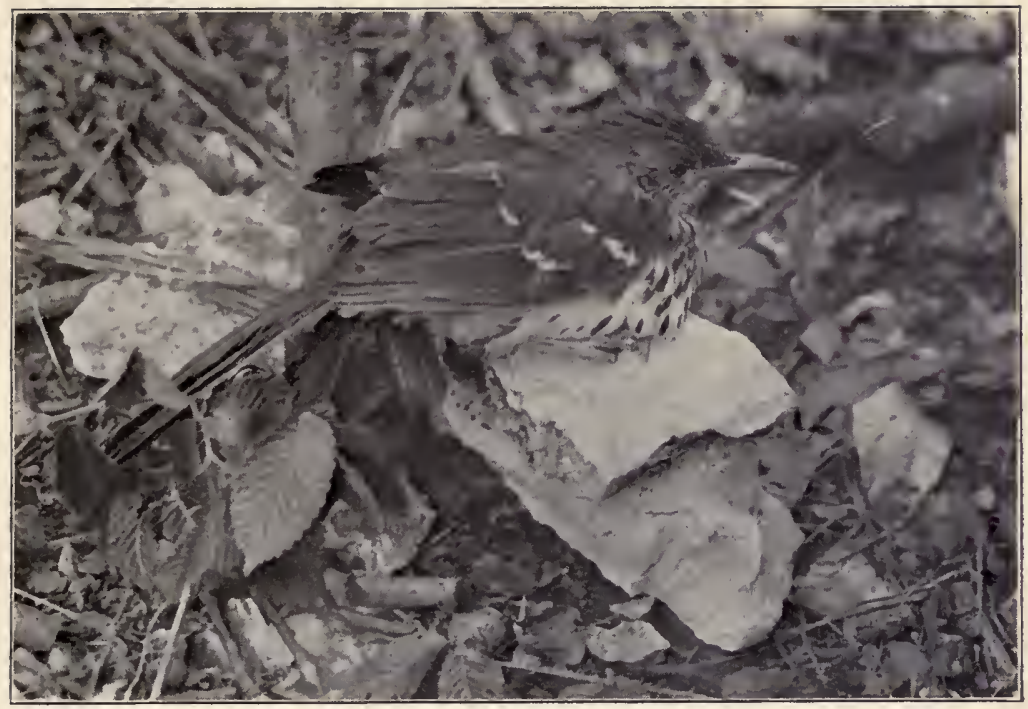

Fig. 129. BROWN THRASHER

(rage $\mathbf{2 2 0}$ )

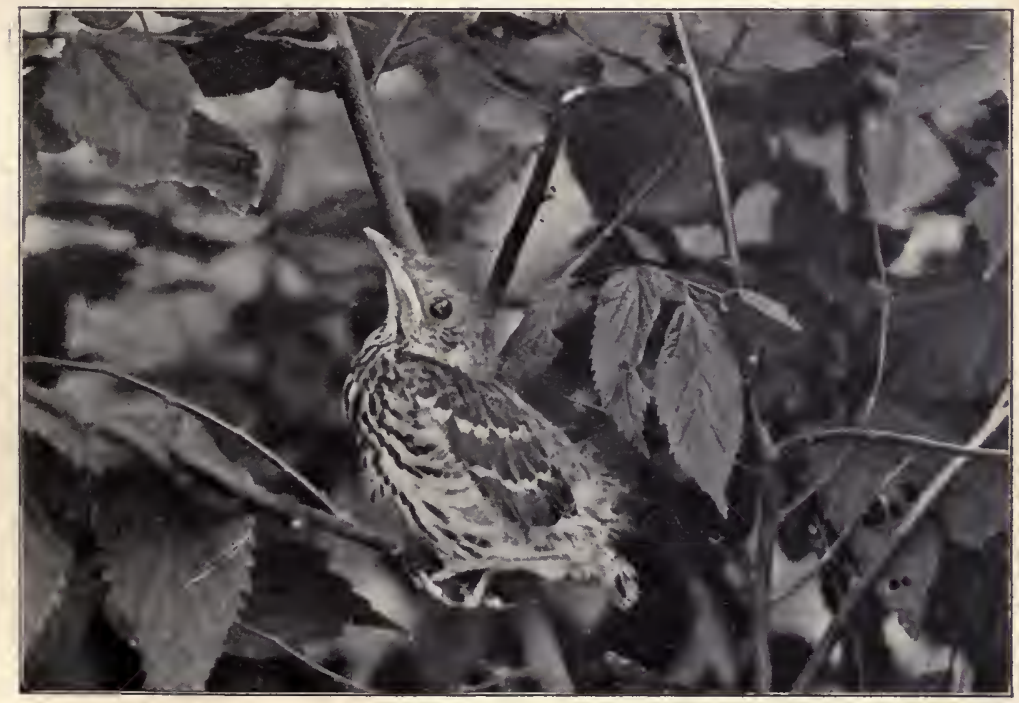

Fig. 130. BROWN THRASHER YOUNG

(page 221) 


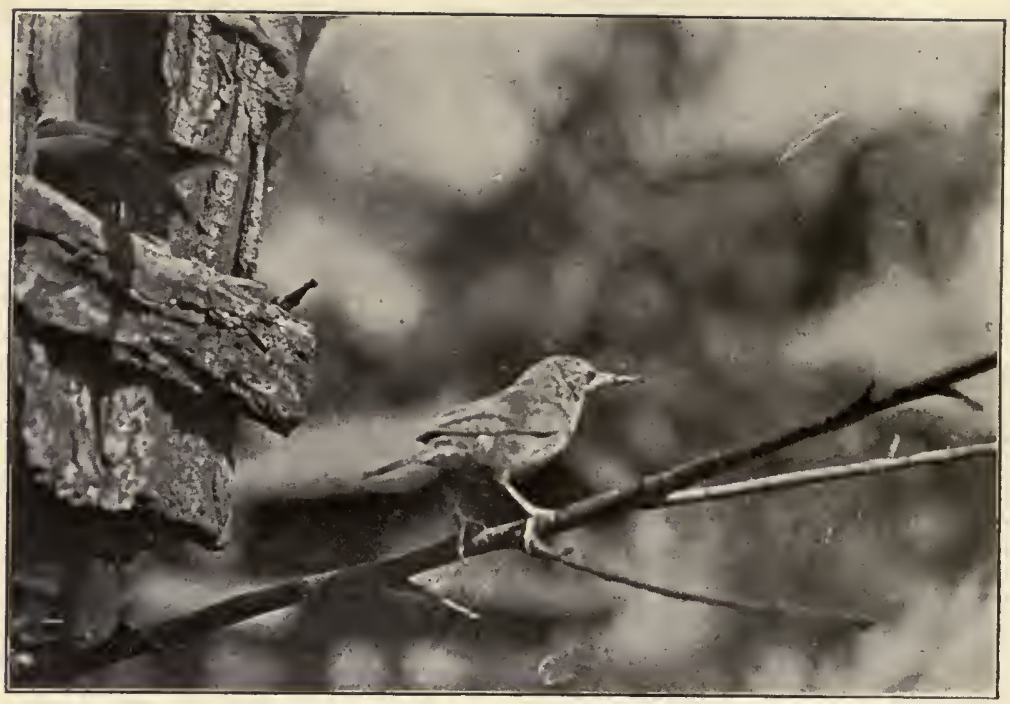

Fig. 131. HOUSE WREN

(page 223)

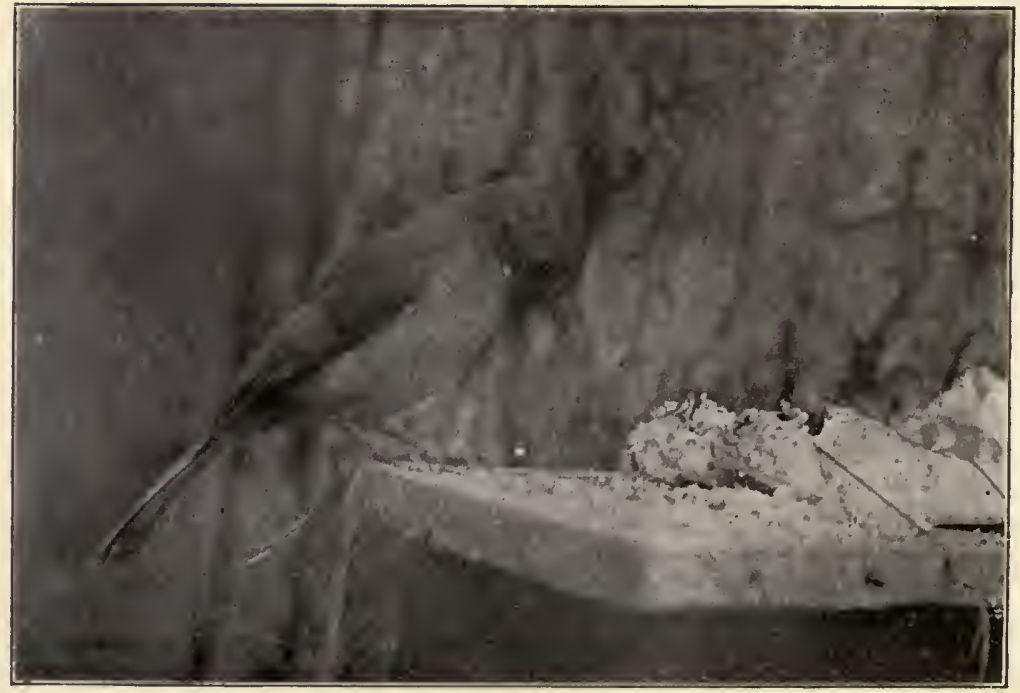

Fig. 132. TUFTED TITMOUSE 
Whenever I behold one of these birds perching upon an isolated dead twig in the top of some tall tree and am enthralled by its varied song, I congratulate the singer on its escape from the limiting bars of a cage and a diet of hard-boiled eggs and mush. See how this musician adds zest to a lyric concert by bodily gestures and poses! In fact, the bird is rarely still during one of these impromptu musicales. These entertainments are not confined to daylight performances; during the breeding season the exquisite melody of the male bird is heard at all hours of the night as he perches in some conspicuous place near his mate and young. 


\section{LXXXIII}

\section{Catbird \\ 704. Dumetella carolinensis}

In general, the Catbird is of a dark slate color with the top of its head and tail much darker; it is about the size of a Robin. Having once seen a Catbird and heard its voice, you need never be in doubt about recognizing it again, even though you should see it under very different circumstances. A Catbird is the same, be it male or female, young or old. In the spring, summer, fall and winter its plumage does not change and its catlike mew is easily identified.

This bird selects, by preference, a home site near man's habitation, not because of any liking for man's companionship, but because man plants and grows shrubbery that makes choice nesting sites. Catbirds like deep shadows and dark recesses beneath tangles of vines and lilac bushes, such as are found in man's dooryard and in public parks. (Fig. 128.)

These birds have thus endeared themselves to us by nesting near our homes. The disposition of the bird to remain on friendly terms with us as long as we do not invade its brushy sanctum, makes us admire it all the more, when it protests with all the vim of an insulted and enraged demon in feathers our too-near approach to the nest site. When you disturb the shrubbery near its home you may expect to get a good scolding from the owner, in which all its bird neighbors join through sympathy.

During the cold, bleak winter months the Catbird loves to bask in the semi-tropical climate of the extreme southern border of the United States and Mexico, returning in early spring to build its nest and rear its young in localities where fruits and worms abound.

The nest is built from three to eight feet from the ground and is a compact structure into which much coarse material enters, such as sticks, plant roots, leaves and the outer rough surface of grapevines. As a lining 
in one nest the label of a well-known brand of chewing gum was woven firmly into the walls. The eggs, four or five in number, are laid in late June and are of a deep bluish-green color.

The household cat is this bird's worst enemy. One pair of Catbirds are, to my way of thinking, worth more than many cats.

The song of this bird compares favorably in range and sweetness with that of the Mockingbird and the Brown Thrasher, whose notes, along with those of many others, the Catbird imitates. Like that of the Wood Thrush, its song is one of late twilight and early dawn and blends with the harmonies of the night-singing birds. There is a pleasing sadness in the gentle and appealing songs of the night's shadows.

The mimicry of the cat is the bird's masterpiece and is uttered vehemently when you approach the nest or the young. My hand has been assaulted vigorously and fearlessly when I made such an attempt.

Catbirds are easily tamed and make excellent caged song birds. However, some of them become morose in captivity and refuse to sing - a good reason why no wild bird should be imprisoned and expected to amuse its captor by its delightful wild harmony. 


\section{LXXXIV}

Brown Thrasher; Ground Thrush; Red Thrush 705. Toxostoma rufum

The general coloring of the Brown Thrasher is rustred with a slight tendency to a bronze lustre; the wings are white-tipped and the under parts are whitish with cinnamon brown markings. The sides and breast are streaked with dark brown and the throat is white. The length of the bird is about eleven inches; it has an unusually long tail, but short wings, hence is not a graceful flyer.

The Brown Thrasher breeds throughout its extensive migratory range and nests by choice in thick shrubbery and tangles of vines within eity limits. It lays from four to five whitish brown speckled eggs, and arrives April first and departs October first.

Of the highly developed Oscines the Thrasher is given first rank. It is a worm and insect eater, although it doesn't eschew a good juicy cherry. Watch it carefully and see how neatly it strips the legs and wings from the bug or grasshopper! See how thoroughly it mauls with its beak the big worm, on a limb, until the morsel is deadened and pulpified, before feeding it to the young! This habit gave the bird the name, "Thrasher." (Fig. 129.)

It is a beautiful and exquisite songster and endears itself to us by its disposition to nest in our shrubbery and hold its harmonious rehearsals in the highest branches of our shade trees. It is excelled, as a songster, by the Mockingbird only. The Brown Thrasher gives out its superb melody from the tallest trees and with a freedom rarely excelled. Not caring to copy the songs of other birds, its solos are of its own composition and are rendered unstintedly and without price.

The male is an artful wooer, a diligent nest-builder and a believer in equal suffrage, which he practices by sitting on the eggs and assisting in the feeding of the young. 

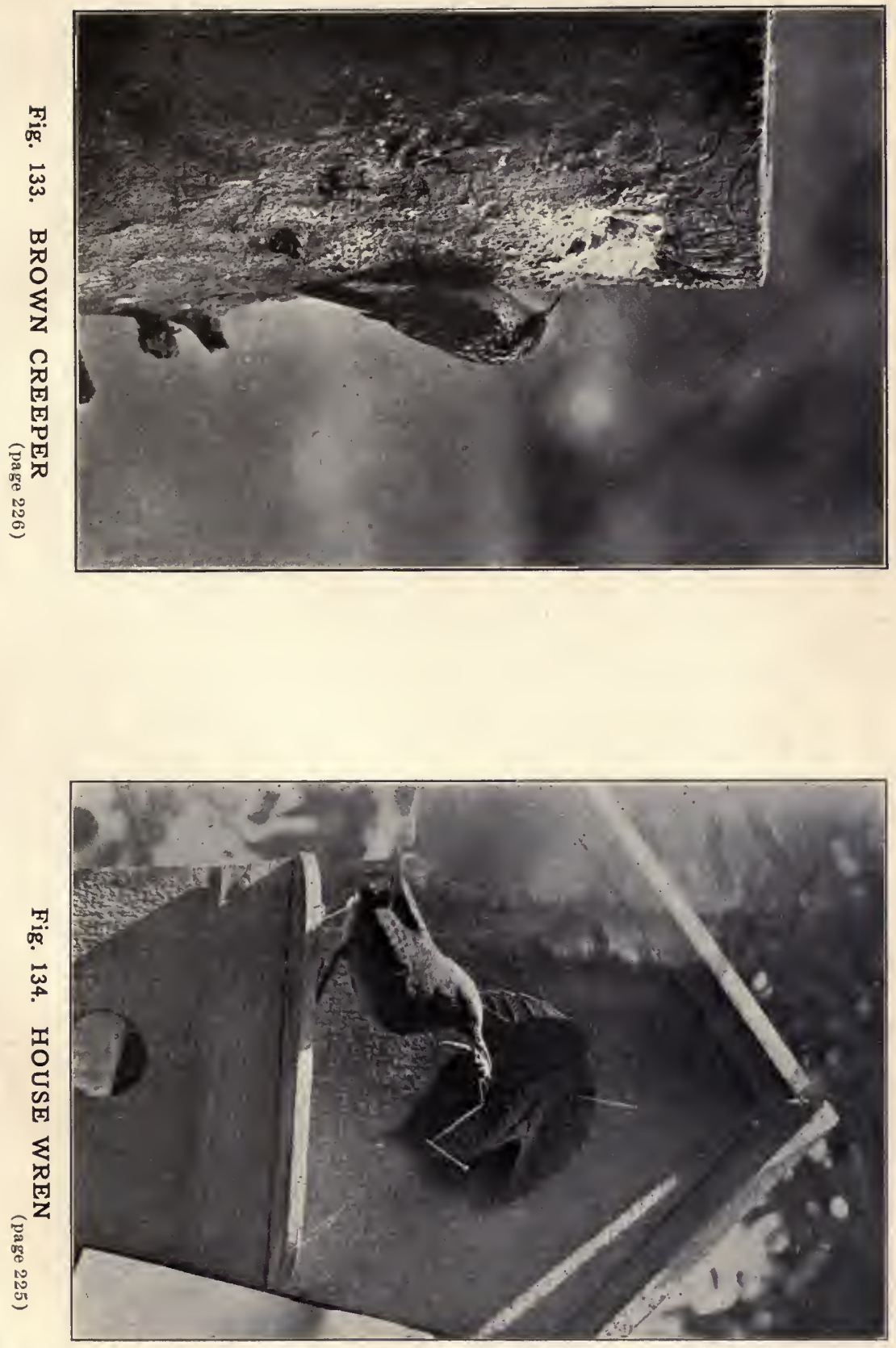


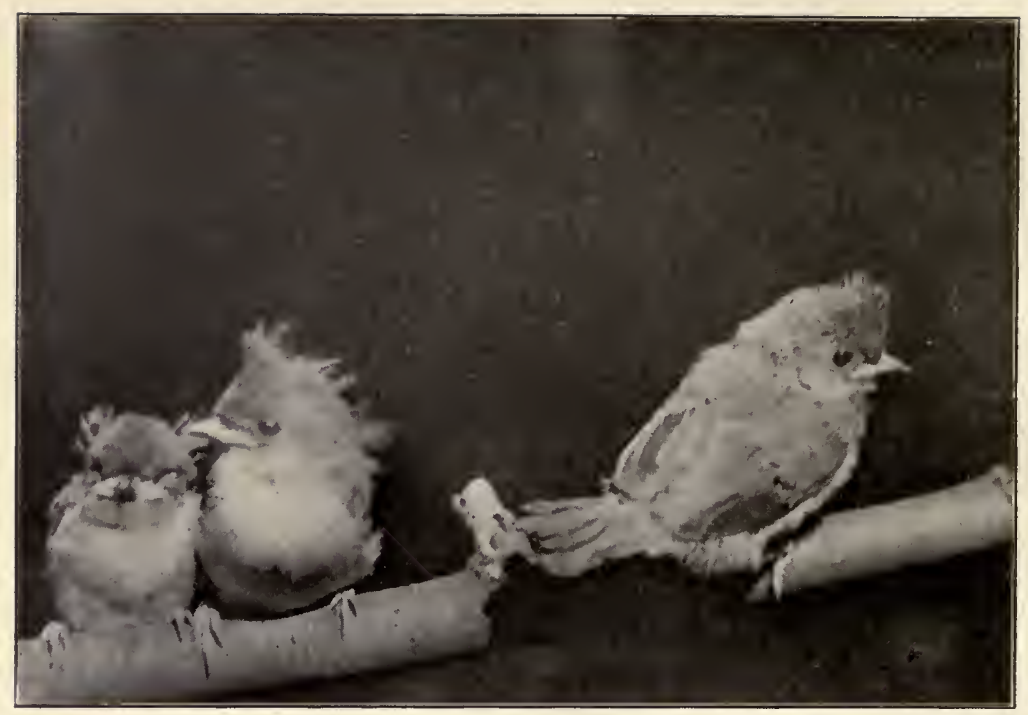

Fig. 135. TUFTED TITMOUSE YOUNG

(page 229)

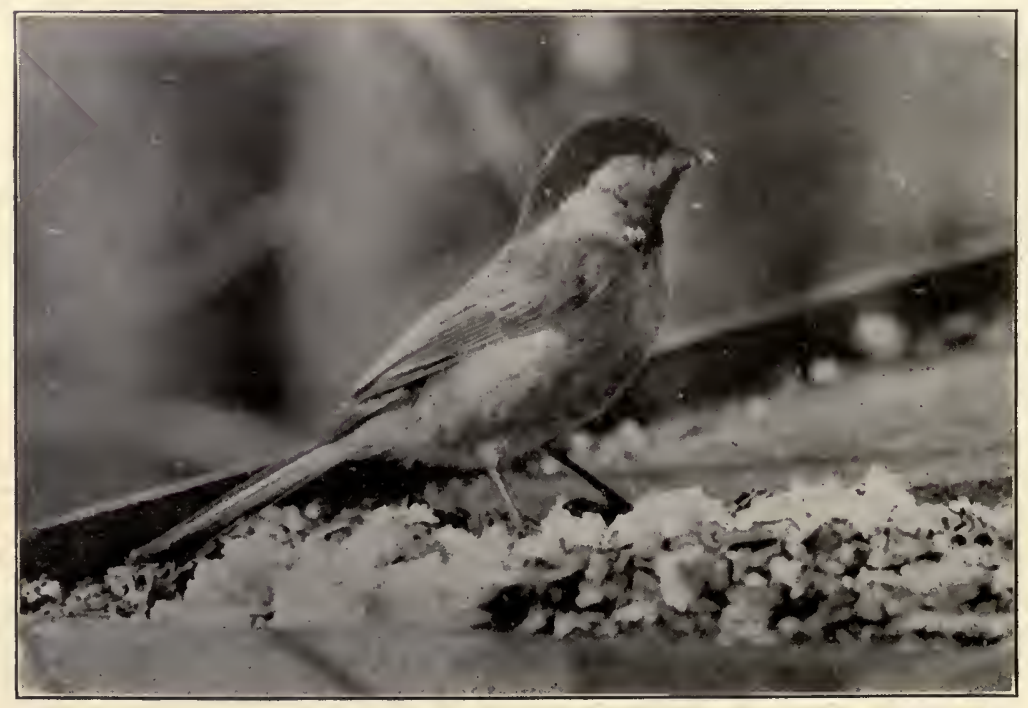

Fig. 136. CHICKADEE 
The protective coloring of the Brown Thrasher is perfect; it remains on the nest until you almost touch it. One actually sat on the eggs and took bread crumbs from my hand, and often left the nest and fed from a shingle covered with crumbs, held near by. But if, for any reason, the bird is afraid of you it quickly manifests another disposition. When you approach the nest you may not see either bird, yet rest assured that one of the pair, usually the male, is within easy reach and will make its presence known by its positive assertions that you had better depart. If he fails in thus driving you away, he is quickly joined by the female and the pair, with piteous appeals, quickly elicit the sympathy and support of all the birds in their vicinity, all joining in defending the young Thrashers. (Fig. 130.)

Brown Thrashers make excellent cage songsters, becoming very gentle and appreciative of good care. But if you do not cage them more people will hear them sing, and their songs will be pæans of glorious freedom.

We have often heard discussed the question of whether or not a bird is ever charmed by a snake. The following incident actually took place, from which you can form your own conclusions.

On August 7, 1921, while I was hidden in a wooded ravine, my attention was called to the peculiar actions of a Brown Thrasher. The bird lit on a dead twig, within six inches of the ground. As soon as it lit, it spread its wings as Turkey Vultures or Anhingas do when sunning themselves, its head, neck and body feathers closely pressed or flattened to the body. The bird seemed to be perfectly composed and free from fright or anger; its attitude seemed rather that of indifferent and deliberate curiosity. Then it hopped to another limb, within six inches of the first, and assumed the same attitude as before. All this time not a sound was uttered by the plucky and ordinarily assertive Thrasher. This performance was kept up for fully ten minutes before I focused my field glasses on the scene. The bird was only twenty feet away from my hiding place and I now discovered the object of its apparent mesmeric attraction: a blacksnake, fully five feet long, was slowly crawling away from beneath, within six inches of the Thrasher. The snake paused several times in traveling its length, 
turned its glossy black head with the beady rat-like eyes toward the bird, protruded its forked tongue, then resumed its leisurely serpentine journey and was soon lost to view. At once the Thrasher seemed to regain its mental equilibrium, flew to a nearby tree, ruffied its feathers, shook its wings and disappeared into the nearby thicket.

The snake could have easily captured the bird and was of sufficient size to have swallowed it without an effort. If there is such a thing as a snake-charmed bird, this Brown Thrasher was certainly that. 


\section{LXXXV}

Western House Wren 721. Troglodytes ædon

According to some of our best authorities on birds of the three sub-species, the Western House Wren is the one found in the central part of the United States. It is about five inches long, is brown above and brownishwhite below, with bars of brown on its wings and tail. It holds its tail erect and is quick in its actions. It builds not only near the habitations of man, but also in the deep wood, in Woodpeckers' holes and in natural cavities in trees. It lays from five to eight eggs. In preparing a Wren box the hole of entrance should be exactly the size of a silver twenty-five cent piece. A large door would admit the English Sparrow, the worst bird enemy of the Wren. (Fig. 131.)

The Wren feeds near the ground, where it may be seen crawling through the weeds and flowers, peeping into every cranny for small insects and plant lice. The young grow very rapidly and are able to fly away from the nest at the end of two weeks.

The Wren is a harmless, egotistical, busy little body, ever prying into the private affairs of the birds of its neighborhood. No bird commotion can take place in the vicinity of a Wren without its making an investigation, slyly creeping about tree trunks or peeping from behind some leaf or vine. If you are near her home when "Jenny" returns, you must act quickly if you wish to secure a still picture of the little lady, for she seldom tarries long while carrying the meals to her nursery full of hungry babies. With six or seven gaping mouths and as many seemingly ever-empty stomachs to fill every three to five minutes, she must be continually on the go, lest a feeding period be missed.

Of all birds the little House Wren is the most nervous; not that it exhibits a nervous fear but it just cannot keep still a moment, either in body or tongue. Especially is this true when nesting. During the incubating 223 
period either the male or the female is singing every minute. All this time the male becomes almost a nuisance, as he begins his song near your bedroom window at four A. M., and keeps it up every few minutes for the next sixteen hours. There is nothing private about the premises of these birds. In fact, they seem to delight in telling you where they live and they extend to you an audible invitation to come to visit with them.

What an inquisitive little bundle of nerve the female is! She must cease her household duties every little while and run to her front door to see who is passing her way, or, perchance, to cast a glance at her better-half, perched on a nearby limb, calling to her every few minutes that he is close at hand and that all is well.

As usual last spring my male Wren made his appearance in my backyard ten days or two weeks before the female. As soon as he landed, he got very busy building a nest. Not satisfied with the old last year's home site, he proceeded, as the male frequently does, to construct a nest in every available likely spot on the premises. A hole under the porch eave, the last year's box and a new box were all looked over in turn and pre-empted as nest-building places.

It is surprising, the size and length of sticks, wire and other coarse building material that these little birds carry into the boxes through a hole the size of a twentyfive cent piece! On arriving at the entrance with a long stick grasped at the middle and finding it impossible to carry it into the box in that position, the bird keeps moving its bill-grasp along the twig until, turned sidewise, the end of the stick enters the hole, to be followed by the builder. During the nest-building labors of the male I never saw him carry a single feather, string or other downy material, such as is later used by the female in completing the nest.

With three home sites pre-empted, Mr. Wren was very busy during the days of his bachelorhood. Then, one bright warm morning, the graceful little female arrived. He was all bubbling over with love songs and ardent wooing as, with great pride and much enthusiasm he escorted Jenny from nest to nest, always remaining on the threshold while she entered and inspected his proffered homes. I was sure it was a case of love at 


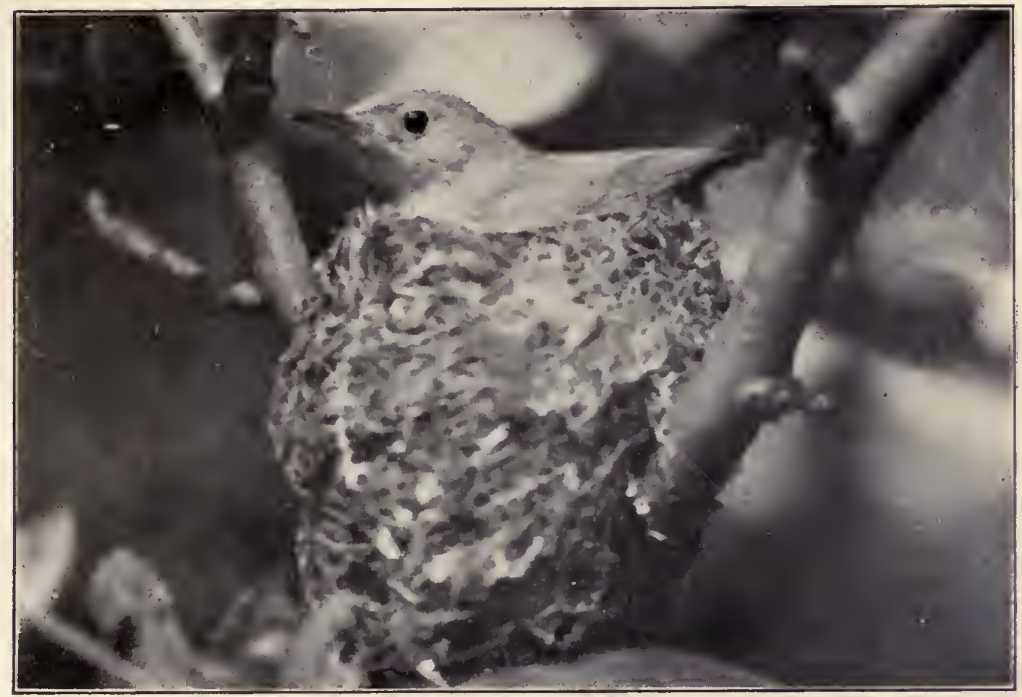

Fig. 137. BLUE-GRAY GNATCATCHER

(page 232)

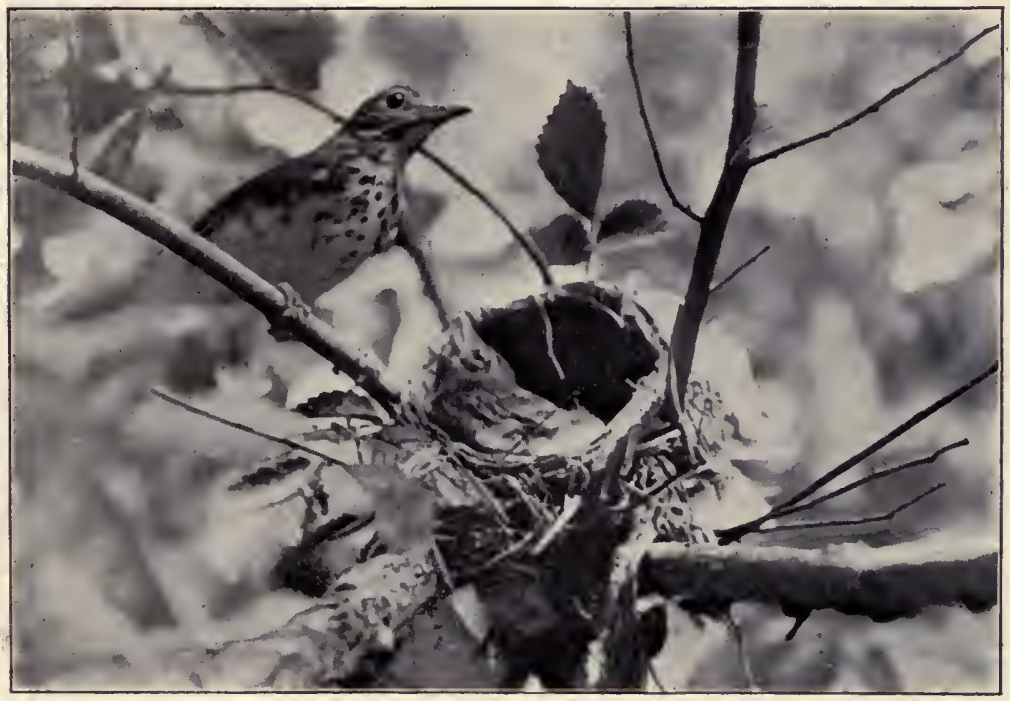

Fig. 138. WOOD THRUSH AT NEST 


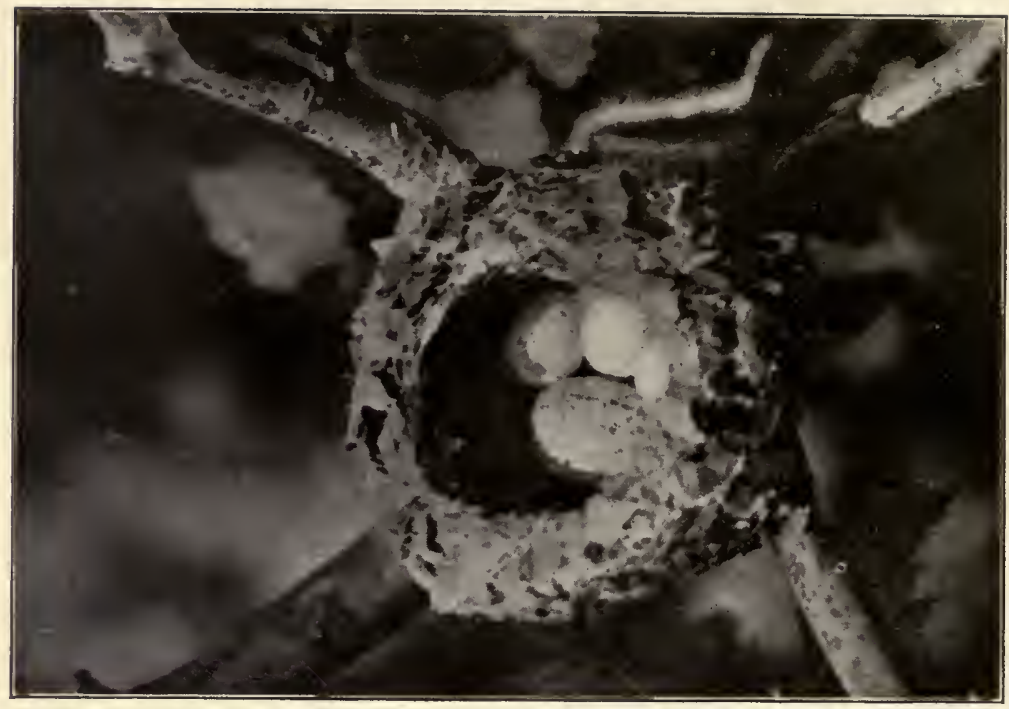



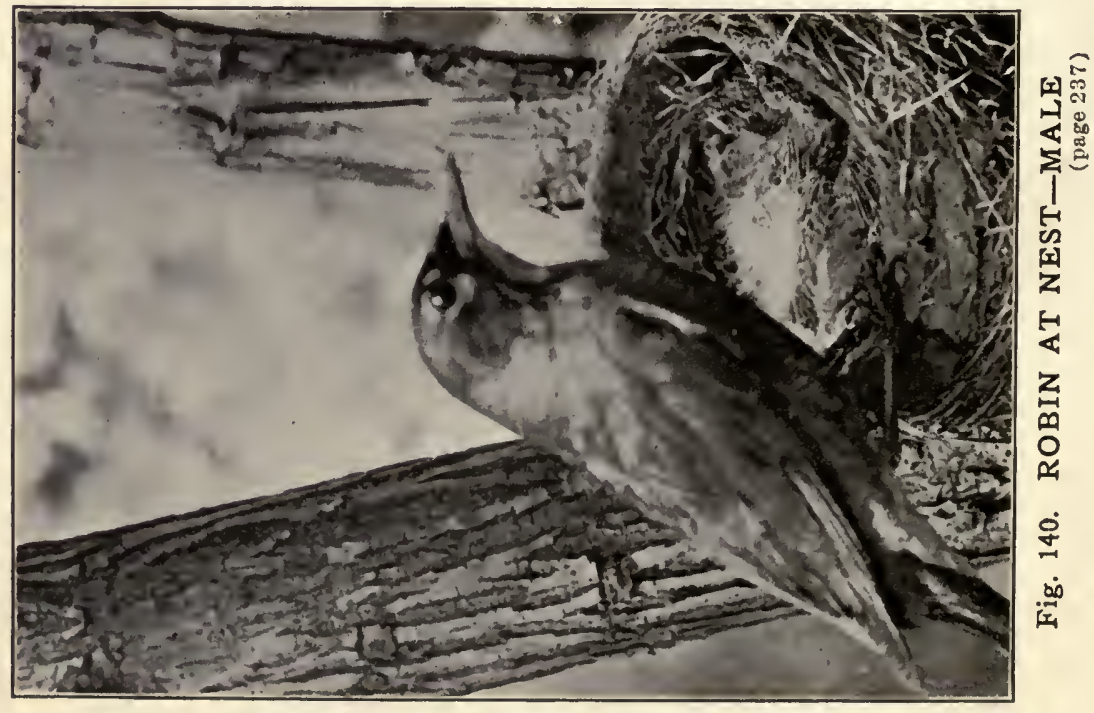


first sight but I was disappointed for days by the disappearance of the female, and I assure you the male's loneliness was truly pathetic to behold as he sat perched first near one nest, and then another, anxiously watching and persistently singing for hours each day. Then one fine day the female returned and when I saw her carrying soft cottony pieces of nest-building material into the new box, I knew that the little lover had won his mate.

English Sparrows now gave this threshold a wide berth. The premises were posted, "No trespassers allowed."

Why the male builds more than one nest before the arrival of the female is, in my opinion, explained by his desire to monopolize the building-places and by the absence of the female in the early stages of the nest building, since her decision, apparently, is final. Then it may be that his nest-building instinct is not satisfied until one of his efforts is approved by the female. I noticed that he repeatedly visited and protected the duplicate nests for weeks after the female made her selection. (Fig. 134.)

In the artistically constructed Wren box of one of my friends there were seven nearly full-grown young birds. This box was about five feet from the ground in an arbor of blooming Dorothy Perkins roses, through which a black snake four feet long climbed and entered the box and devoured the young Wrens. Its greed was its downfall, however, since it could, with all its efforts, get only about twelve inches of its gluttonous body out of the box. In that position it was discovered and quickly dispatched. 


\section{LXXXVI}

\section{BRown CReEPER \\ 726. Certhia familiaris americana}

The Brown Creeper is a grayish-brown bird about five inches in length, characterized by a rather slender, curved bill and whitish belly. The nest is usually placed beneath a piece of dead detached bark on trees standing in or near swampy places. The eggs are rather numerous, four to eight, and of a creamy color with reddishbrown spots. (Fig. 133.)

The breeding range of the Brown Creeper in the northern part of the United States has been extended to southern Minnesota and Iowa. The bird is of a retiring disposition and rarely is seen unless, because of scanty food supply during prolonged snows, it visits the haunts of man or his Downy Woodpecker and Chickadee feeding stations.

The tender fragile bill of the Brown Creeper does not permit it to dig for a living; hence it may be seen creeping about and up trees gently picking from the surface and crevices of trees the eggs and larvæ of insects. The birds are very confiding and will permit of a close approach while they are girdling the trees in radial, upward spirals in pursuit of food.

In February, 1920, on -Scarritt Point, Kansas City, Missouri, I established a bird-feeding station. The billof-fare consisted of corn bread, corn grits and beef fat or suet. The food was confined by nailing a piece of wire screen to a large oak tree. In this screen was cut a small hole which would permit the birds to reach the food and, at the same time, limit the feeding range of the birds, thus keeping them in sharp lens focus for picturing.

The second day after the food was placed, I found feeding, the Downy and Hairy Woodpeckers, Tufted Titmice and Chickadees. Then, to my surprise and delight, a long-billed, slim-bodied, brown-colored bird, the Brown Creeper, made its appearance. It looked so small and 
its actions were so characteristic of the species that one could not help noticing the bird.

With its habit of always climbing upward-in this respect differing from the Nuthatch-it presented an amusing spectacle in its efforts to get to the suet. The Brown Creeper first flew from a nearby branch and alighted on the food tree, as usual near the ground. Then began an upward climb but each time, on approaching the suet, the journey was stopped by the four-inch broad floor of the little feeding and perching box just beneath the suet. Next came a series of careful, curious experiments as to the best course to pursue: first a side or angular climb of a few inches to the edge of the box and back; then an upward climb by the side of an upright board, nailed to the tree as a photographic background. This last maneuver brought the Creeper a foot above the suet and the problem of getting down to it was of equal perplexity as the bird refused to back down, like the Downy Woodpecker. Finally the Creeper flew to a nearby tree and from there, at an angle of forty-five degrees, skidded through the air like a flying squirrel to the root of the food tree again. This time the upward climb brought the bird to the side next to the camera and to one side of the base-board. From here with a series of delicate steps, so to speak, the suet was reached. The frail, decurved bill pulled off such minute particles as one could hardly imagine.

All this time I was within a few feet of the bird, but out of reach of the line leading to the camera. I therefore failed to get a picture, though I had a rare experience watching this peculiar bird following its usual food-hunting habits. 


\section{LXXXVII}

\section{Tufted Titmouse \\ 731. Baeolophus bicolor (Linn.)}

The Tufted Titmouse, with its coat of dull whitish color or ashy brown and its elongated crown feathers, presents a picture familiar to everyone who makes a trip into the timbered areas during the winter or early spring. The bird is about the size of an English Sparrow and is a permanent resident, but is seen most frequently during the winter months. These birds form into small flocks while going from one feeding ground to another; they are fond of the heavily wooded regions, nesting in natural cavities or abandoned Woodpecker holes, and laying from six to eight eggs, in early May.

While the male takes no part in the construction of the nursery, he is the very emblem of love and fidelity to the female during her labors, and may be seen following her to and from the prospective home site, ever with a cheerful word and much encouragement by his actions.

The Tufted Titmouse is a restless bird, always on the move, constantly singing its "peto, peto, peto!" It is impudent and inquisitive and responds to your call, if you make a fair effort at imitating its voice. As the bird approaches it jumps from limb to limb, looking all the while for the source of the call, then disappears for a few minutes, only to return and probably bring a new recruit to assist in locating the vexatious and unwelcome intruder on the Titmouse domain. (Fig. 132.)

These birds have the habit of hammering a captured insect that is too large to be swallowed whole. The bug is grasped firmly in the bird's bill and pounded against a limb until pulpified. The bird holds its food with its strong little foot, while it pulls off a piece and swallows it.

The Titmouse is of much benefit to the farmer as it not only eats the living insects during the summer but seeks the eggs and larvæ all winter. After watching the actions of the trio, the Tufted Titmouse, the Chickadee 228 
and the Downy Woodpecker, I am convinced that there is a food-seeking alliance between them. Repeatedly, when I visited a feeding station, all three of these birds came at once and each time the Downy Woodpecker fed first, then the Titmouse, and at last the Chickadee. On one occasion, when the Titmouse was helping himself, a Downy lighted on the body of the tree, ten feet above the suet, and by a gradual spiral descended by four-inch bounces until he reached the suet. The Titmouse, in the meantime, had departed.

The Titmouse has a call-note of alarm that, I have heard, causes all of the winter birds, Juncos, Chickadees, Song Sparrows, Downy Woodpeckers and Cardinals, to flock around the caller in an inquiring attitude, as if to ask the source of worries. If Tit flies to another tree they all follow and perch near until assured that all is well; then they return to their usual haunts. (Fig. 135.) 


\section{LXXXVIII}

\section{Chickadee; Black-Capped Titmouse 735. Penthestes atricapillus (Linn.)}

The Chickadee is grayish on the back and whitish on the belly and the crown and throat are black. The bird is about five and one-half inches long. It nests in natural cavities in trees and stumps and in abandoned Woodpecker holes. The nest is made of moss, hairs, feathers and rabbits' fur. There are from two to five eggs with reddish-brown specks on a white background. There is no race suicide in the Chickadee's family, which is broadly distributed, living the year around over its range. The bird is an eater of seeds and insects and is fond of fresh meat.

Both birds assume all family duties. The male is very attentive to the female and seems to consent to her every wish.

On a cold winter's day, as you stroll through the woods, clothed in your heaviest furs, with the mercury hovering near or below the zero mark, when the tree trunks are crackling with loud reports from the grip of the frost king and almost all living things have sought a warmer clime or are "holed up" for the season, you are surprised and gratified to hear the faint, but wellknown cheerful voice of the little Chickadee, as it busies itself on the side of a nearby tree, seeking its dinner of larvæ and insect eggs. (Fig. 136.)

In amazement and admiration you pause to utter silent prayer in behalf of the bird. Now watch closely, for it is not alone, as you will probably discover. Little Downy Woodpecker, Tufted Titmouse and Nuthatch are almost sure to be in that same locality. That they harvest together what others have planted is easily demonstrated by their constant association and concerted action.

The Downy, with its powerful and awl-like bill, removes the bark behind which the eggs and larvæ are hidden; then, "Dee, dee, dee" and "Tit" gather up the 

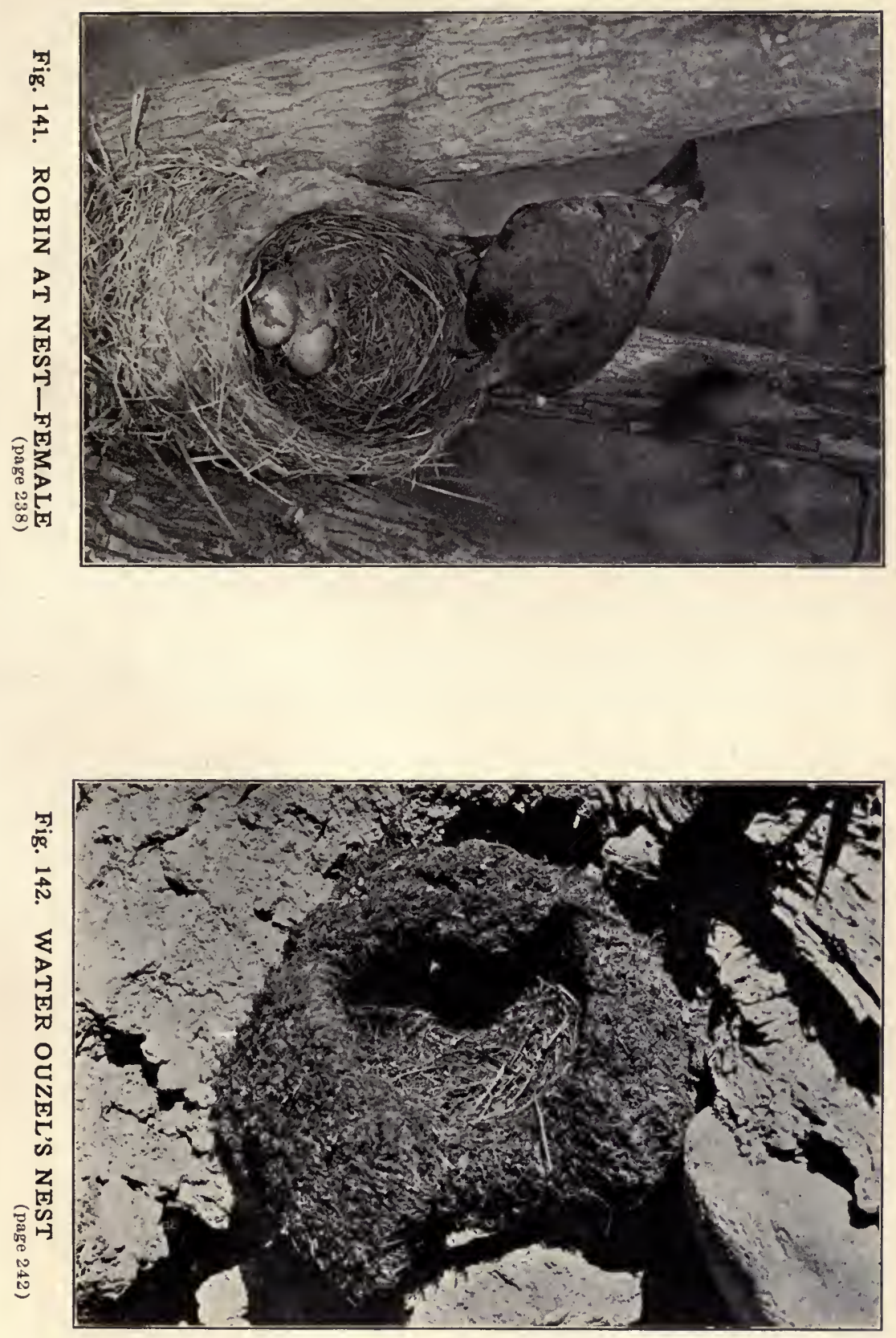


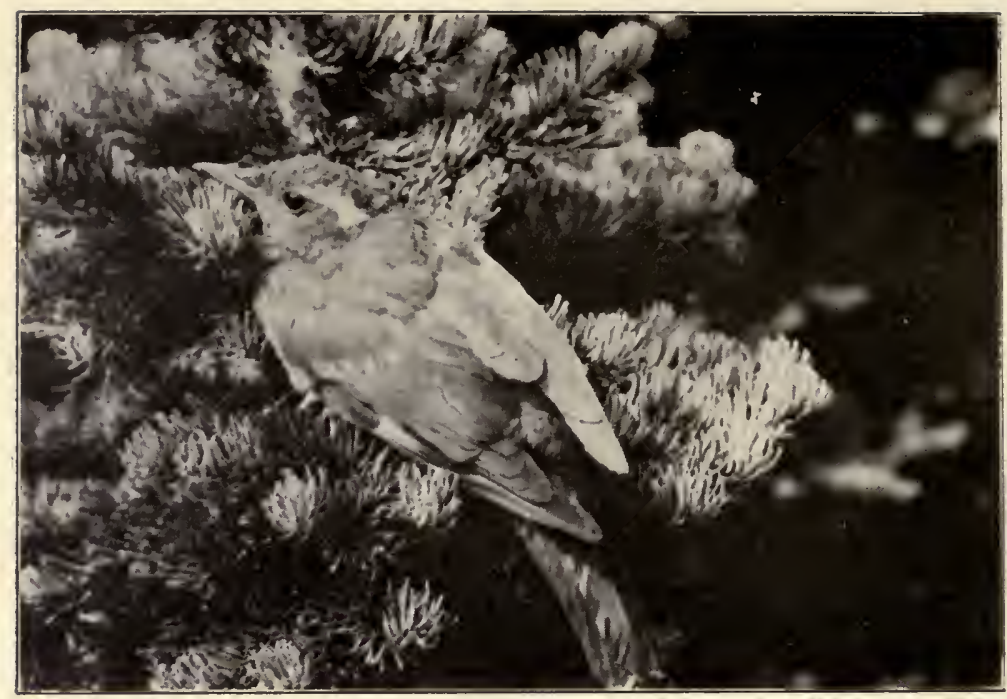

Fig. 143. VARIED THRUSH

(page 240)

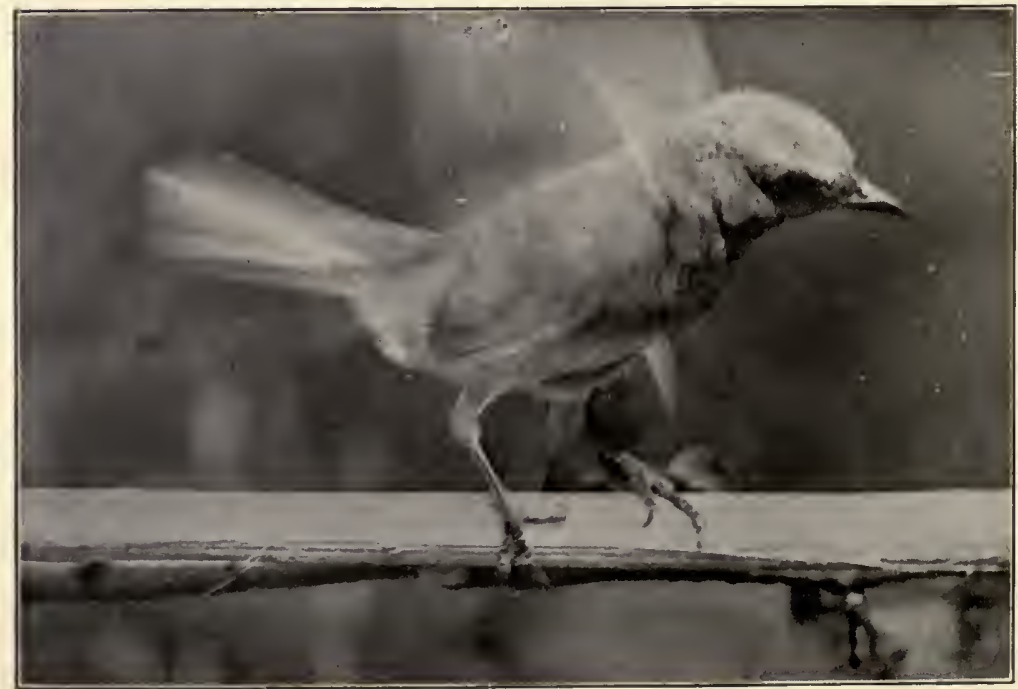

Fig. 144. BLUEBIRD

(page 210 ) 
crumbs that fall beneath Downy's table. Dee-dee, with its weak little bill, does not refuse the last-year's abandoned nest-hole of Downy for a nursery, which is willingly surrendered as Downy prefers a new apartment each spring.

Even before the most venturesome green thing has the courage to thrust its delicate shoot through the cold, damp leaf-mould, the spring song of the male mating Chickadee may be heard, as he busies himself on the under side of a leaning tree, or hangs from the branches in his search for little insects and their larvæ. He is a sociable little bundle of pale blue, gray and black, and an intimacy with him is easily established. I know of no bird more willing to meet you half-way in getting acquainted. Speak his language, "Dee, dee!" and you will receive a courteous reply, "Chic-a-dee-dee!" The formal introduction is now complete.

I have not found these birds as willing and tame posers for their pictures as the experience of some bird photographers would indicate. Chickadees are ever on the move and a quick shutter movement, one-fiftieth of a second, must be used to stop their restless motions while feeding. They are fond of suet and are easily enticed to the feeding platforms during the winter. 


\section{LXXXIX}

\section{Blue-Gray Gnatcatcher \\ 751. Polioptilla caerulea coerulea}

Next to the Hummingbird, the Blue-Gray Gnatcatcher, four and one-half inches long, is the smallest of our feathered friends. It is marked by a general pale blue body, with crown and forehead black and edges of eyelids white, and is whitish on belly and breast; the wings are dark brown, the tail black bordered with white, the bill is long and the body slender.

About the middle to the last of May, should you be bird-hunting in the dry uplands covered with evergreen, red-haw and other small trees, if you keep a close watch you are likely to see this mite of a bird, with its quiet demeanor and modest garb. This Gnatcatcher is a pygmy among birds and looks the part of a little all-dressed-up personage. Having once recognized the bird there is never again any doubt in your mind as to its identity. Its faint, lisping, "tsee, tsee, tsee!" will assist you in recognizing it even before you see it. It is an expert insect catcher and is ever on the alert for a passing moth or other flying insect.

It would seem that what this bird lacks in physical size it makes up in enthusiasm and bursting energy. Retiring in disposition and. sombre in color, the Gnateatcher is not easily seen unless in action, and its delicate subdued song is not audible very far. One can hardly believe that this little bunch of feathers makes a safe journey across the water to Cuba and the Bahamas, in its migration to the South. (Fig. 137.)

The nest is a masterpiece of bird architecture. For delicacy of lichens and downy lining it is excelled only by that of the Ruby-throated Hummingbird.

When I first heard the call of the Gnatcatcher I mistook it for that of the Chickadee. But on listening closely, I detected a delicacy and a faint character of tone that were very different from "Dee, dee." 
After sighting the Gnatcatcher I located the nest, within a few minutes. It was in a red-haw bush about ten feet from the ground. Such a beautiful, artistically moulded cup I have rarely seen made by a bird. The nest was snugly set in the crotch of three small twigs, with an arbor of live leaves shading the contents from the rays of the July sun. Scientifically constructed of thin scales of cherry bark, moss, lichens and a few hairs, it was so delicately put together that a gentle finger touch threatened to destroy its symmetry. Within the deep oval reposed three beautifully white eggs and an egg of a Cowbird was snugly tucked in their midst. The latter was fully double the size of those of the nestbuilders. (Fig. 139.)

The female came back within a few minutes, but was easily disturbed and returned very slowly after the third scare. I made some pictures of the nest and its contents, removed the slacker's egg, trusting that this act of courtesy would be appreciated and would redound to the interest of the prospective Blue-gray Gnatcatchers, and left the nest with no further disturbance. 


\section{$\mathrm{XC}$}

\section{Woon Thrush; Woop Robin 755. Hylocichla mustelina (Gmel.)}

The delicate shades of cinnamon brown on its back and tail and the white breast with its splotches of brown, make this Robin-sized bird one of the most beautiful and harmoniously colored of our woodland birds. Its subdued beauty of plumage should prepare one for the beauty of its song. As a rule, birds of gaudy plumage are the poorest musicians. The Hummingbird and the Painted Bunting are illustrations.

The Wood Thrush selects for its home-site deep shadowy ravines, where heavy timber and underbrush abound. The nest is usually placed from six to ten feet from the ground, and is composed of root fibres, old pieces of newspapers and, occasionally, a cast-off snake's skin, plastered firmly together with mud. There are usually four eggs of a bluish green color.

The Wood Thrush is more often heard than seen by those who do not know its ways and how to approach it and interpret its ventriloquist-like voice. It is a quiet, retiring bird, and does not flaunt its art by high and open perching or by the jerking of its tail, but remains modestly perched on a limb near the ground and close to the body of the tree.

The song of the Wood Thrush is that of a cultured musician; its modulations and phrasings are tones and expressions produced only by one who has practiced long under a master-teacher. No ragtime or jazz burlesquing is indulged in by this artist; its tones are pure, sweet and appealing. The harmonious and subdued notes are seemingly called forth as the shades of approaching night are drawn. The days of the Wood Thrush, spent in shadowy retreats free from the rays of the noonday sun, are days of continuous twilight, and the song is ever a song of evening, of a deliberate and melancholic character. This pensive sadness makes one like to linger in the gathering darkness and listen to its repetition. 
The song is always harmonized with the stage setting; for instance, if after a cool, refreshing rain, on a June or July evening, you visit the haunts of a Wood Thrush, in some deep, dark, wooded ravine, and remain quiet for a short period, you will hear the singer mingle its plaintive lay with the, drip-drip, of the raindrops from the freshly soaked foliage. Then you will realize that the song is a song of the deep woodland.

When most birds have selected their roosting perches, folded their wings and ceased their songs, save for a few goodnight notes, the Wood Thrush may be seen flying to its cloister for its evening hymns. Now, you must keep perfectly quiet or you will hear the suspicous call of its mate, "quit, quit!" If you fail to heed this warning note, you will see a nervous ruffling of feathers and, with a bobbing of its tail, the bird will fade away, apparently by dropping from its perch into the surrounding shadows. Then from their darkness you will hear its ventriloquist-like, faint, "Come to me!" in tones that are beyond description.

If you would really listen to the pensive song of the Wood Thrush, quietly linger in its shadowy ravine, near the nest-site, until the sun has disappeared and all nature's daylight activities have ceased and the cool breezes of approaching nightfall are gently and noiselessly waving the upper treetops and the nocturnal things are slyly peeping from their daylight retreats; then, if you are fortunate, you may hear the bird, in all the glory of its soft, inviting chimelike "Come to me! Come to me! uoli, uole, lee lee!" There is no other bird song of which I know that has a more heavenly appeal to one's very soul.

One afternoon, while watching a Yellow Warbler, I heard the beautiful, sad notes of the secluded Wood Thrush. On looking around I discovered the owner of the voice, sitting on a dead limb near the ground. The bird's pose was that of serious resignation to parental duties, while it went on busily weaving grasses, strings, twigs and tissue paper into a new home about eight feet from the ground, on a bending oak bush. I kept tab on the carpentry, as the builder finished the floor and sidewalls. I visited the vicinity of the home, spying on family affairs until two ugly little big-mouthed nestlings made 
their appearance; then it was time for the family group to have its picture taken. Owing to the deep shade all about the nest it was impossible to secure good fulltimed pictures; here I called to my assistance the Imp flash powder gun, and succeeded in getting some excellent negatives. (Fig. 138.)

While watching the pair I decided that no birds ever manifested more genuine affection for their young than do Wood Thrushes. It was indeed inspiring to witness the admiring attitude of this mother and father, and their display of affection at the side of the nest, where they both frequently fed their babies at the same time. They would actually stand on the rim, admiring the young for many minutes after the worm had been delivered into the open mouths of their ever-hungry offspring. These parents would unconcernedly let me come within four feet of them and change plate-holders in the camera. Even the flash gun with its calcium flare did not interrupt their frequent feedings.

On one occasion two small busybodies, House Wrens, came to investigate the state of affairs in this home, and the flash caught the Thrush with wings spread as she was driving the little intruders from the premises. 


\section{$\mathrm{XCI}$}

\section{American Robin \\ 761. Planesticus migratorius migratorius}

"I saw a Robin today," is often the glad message with which our friends and neighbors announce that the backbone of winter is broken and that spring is here; and our little red-breasted feathered friend rarely brings false tidings. It comes unannounced, just as an old friend would do. The first you hear of the Robin is its song from a limb of a tree in your front yard, or, perchance, you see the bird walking across your lawn as though it had returned to take charge of your bird affairs for the season. Watch it as it runs a few feet, then stops to look at you, as if to say, "Don't you remember me? I was here last year and pulled many an angleworm from this very lawn, and that, too, while you were watering the grass. Now, I know you must surely remember me, and we are going to work together another season." And you do.

The Robin does not return to us in early spring, exhausted by a long and hurried flight; its short northward journey is made in easy stages, just in the fresh footsteps of the departing winter.

Of all our broadly distributed birds the Robin probably holds first place; it is therefore the best-known bird. I have even found it nesting in northern British Columbia, far from human habitations; but from preference it selects the more settled parts of the country and the closer it is to a well-watered lawn or golf putting green, the more contented the bird is. There it finds an abundance of angleworms and also protection from most enemies, but not from the cursed house cat. (Fig. 140.)

I have found the Robin nesting in remote mountain ranges, where it was more shy than elsewhere. There it drew no safety zone but looked upon all strange objects as enemies and acted accordingly. In wild, unsettled localities, however, it ceases to be the pugnacious defender of its household but submits meekly, without a 
protest, to your near approach to its nest and young. Just try to invade the sanctity of its home in your dooryard, and notice the difference. Its voice, protest and physical bluff are in keeping with its feelings. As the Indian sign language is understood among the tribes, so is the distress signal of the Robin understood among all of its bird friends, regardless of species. Its language is precise and emphatic and easily understood. Familiarity here breeds contempt.

Some springs the Robin arrives a few days ahead of the season, when a late cold snap stops nest-building and angleworms become scarce. It is then that the Robin, of all birds, shows its disappointment in life's pursuits, and may be seen perched on a limb in some sunny place, with drooping tail and wings, and every aspect of disgust with the weather and a Robin's life in particular. No Song Sparrow spirit is shown in the actions of a disappointed Robin; but its "cheerie, cheer up! cheerie!" is soon heard again on the first warm day.

During the summer months the Robin is the optimist of the bird kingdom. Rain or shine it is the same cheerful singer. Have you not seen it and heard its words of good cheer when the rain was falling in torrents? The Robin belongs to the Thrush family of sweet singers and enters the competition in Class A of our best songsters, beside the Wood Thrush, and Verry. (Fig. 141.)

Do not be surprised if you find a Robin's nest in almost any locality, under a bridge, in the barn, in an oak or elm tree or even in a niche in a bank. The nesting material is usually composed of fine grasses and sticks, abundantly plastered with mud. Robins frequently repair and occupy a last-year's nest or they may hatch two broods in one season in the same nest. Why abandon a good home that has been occupied by four pale blue eggs for only two weeks and the young birds for ten or twelve days?

I know of no more interesting sight in a bird's life than that of a parent bird teaching its young how to provide for themselves. The Robin as it entices the nestling first out on a nearby limb, and finally to the ground, to give it instruction in "bait" digging, is an interesting example. Observe the parent bird as it runs a few feet, pauses, turns its head in an attitude of listening, with its 
eyes concentrated on a given spot near by, and seems to say: "Come, quick, and see how it is done!" Then, lighting into the task, it takes a head dive into the grass, with each assault throwing to one side a billfull of soil, and between each thrust, calls to the young bird; the little chubby, bobtailed fellow with its spotted first suit of Robin clothes, bobs over the lawn, as though it did not know what the fuss was about, until the parent bird offers the youngster a big, fat, juicy angleworm. This is greedily swallowed, while the young bird seems to say: "Where in the world did you get it?"

Robins in my yard have to do the worm digging for a number of English Sparrows. These pests go hopping along beside the Robin as it runs across the lawn. Sometimes there are as many as six English Sparrows after one Robin. As soon as the latter stops to listen or look for a worm the Sparrows collect in a circle within a few inches of it, and as it throws the dirt from about the worm, the little imposters quickly grab it and are off before the Robin has had even a chance at the prize. I have never seen the Robin protest against this injustice, though I have seen Sparrows actually pull the worm from between a Robin's bill. The automobiles in our cities have made worm and insect eaters out of these gramnivorous and seed eating Sparrows. 


\section{XCII}

\section{Varied Thrush; Oregon Robin 763. Ixoreus naevius}

In general shape and size the Varied Thrush resembles the common Robin, though its retiring disposition and the secluded locality selected for its breeding habitat are not in keeping with the bold familiarity of the other bird and the frontyard selection for its home site.

This beautiful thrush is easily identified, if one will only recall its distribution. It is a bird of the Pacific slope, breeding from southern Alaska to central California, and winters in practically the same area. I have found it nesting in the same locality as the Russet-backed Thrush (Hylocichla ustulata). (Fig. 143.)

Of much interest to me was this Thrush in its home surroundings along the sloping sides of Mt. Rainier (or Mt. Tacoma), the greatest volcanic cone of the United States. Within a few feet of the great ice river flowing from the summit and sides of the crystal-capped peak, amidst the irresistible onrushes of the avalanches and thunderous roar of the forming glacial crevasses, this bird builds its nest and rears its young, happy in its seclusion and boreal environs, still within a temperate zone. Why should it migrate within the Arctic Circle during the summer, when the frozen North and a trunda laden with food supply may be found a few miles from its winter resort?

The Varied Thrush is much of a ground-feeder, preferring a vegetable diet. However, it destroys many myriads of insects. Its song of long-drawn notes is in keeping with its isolation and shyness, but does not compare favorably with the sweet, liquid refrain of the Wood Thrush or Verry. The nest is bulky and is located in small trees, near the ground. The eggs are four in number and are a pale greenish-blue with brown specks. 


\section{XCIII}

\section{Bluebird; Blue Robin 766. Sialia sialis}

When the frost is about out of the ground, and the still, shallow pools have only a fringe of thin ice about their grassy borders, and the remains of snowdrifts are found only on the shaded sides of tall hedges or northern hillsides, then this little messenger, but seven inches in length, brings its tidings, apparently coming from the sky, with glorious azure still clinging to its outer garments.

The Bluebird soon makes its presence known by its modest acclaim from a nearby perch. It may be forced to retrace its journey a few miles south, because of an unlooked-for cold spell, but for only a few days, as the bird is a pretty accurate weather forecaster. The male usually arrives first, or else his modest mate remains in silent retirement until the proper time for her appearance, when, after a spirited courtship, they begin building their nest for their season's first brood.

This bird of early spring with its "cheery, cheery, cheer up!" and its lovely blue plumage is so familiar to all that little description is required to prove its identity. (Fig. 144.)

Bluebirds build in abandoned Woodpecker holes, knot holes, hollow stumps and often contest the ownership of the bird boxes on our premises. Both male and female are devoted parents; both incubate and feed their young and are pugnacious in the defense of their household. They rear two or three broods in a season, frequently using the same nest for second and third broods. The eggs number from five to six, and are of a pale blue color. 


\section{XCIV}

\section{Water Ouzel; American Dipper}

701. Cinclus mexicanus

If one is a trout fisherman and has "whipped" the clear, cold mountain streams of the United States-including the Rockies-and Canada, in general, no doubt he has seen this bird many times possibly without recognizing it and observing its peculiarities. It is about seven inches long, very plump, and of a pale cinnamon brown and grayish-white color, with waterproof plumage. Coues describes it, as "easily flying under the water." It feeds on water insects and small fishes. Its feet are not webbed, yet the bird is a good and fast swimmer, using its wings as a paddle. It has a habit of teetering while perched on a wet stone near the water's edge. (Fig. 142.)

The nest of the Water Ouzel is a large round one of green moss, stored away under some damp rocks near the rapids or, perchance, behind the veil of mist of a thundering waterfall. The bird sings loudest and longest when the floods of melting snow are at their crest. No storm, be it rain or snow, stops the song, which is that of a soloist, needing no chorus to sustain it save the musical rippling of its home cascades. It prefers solitude and is rarely seen in company with its kind.

Anyone seeing the Water Ouzel with its bluish-gray waterproof suit, as it darts in and out from behind the foam and spray of its home waterfall, cannot fail to think of its personality and admire its aquatic habits.

The Water Ouzel is to the clear mountain cascade and rapids what the Mud Hen is to the weed-overgrown mud flats. Where you find laughing, singing and thundering waterfalls, there you will find this peculiar bird. I have watched it for hours, as I stood on the banks of the glacial, water-fed streams of the Alaskan Peninsula, and the upper reaches of the Frazier River, in British Columbia, as well as along the streams flowing into Hudson's Bay, and I have found the personality of the bird the same over the entire area. 
One day, while perched on an isolated glacial boulder I was held spellbound by the beauties of Virgin Falls, just where the Nipigon River leaves Lake Nipigon. A Water Ouzel came flitting across the apron of the fall; like a flat stone "skipped" over the undulating water, it went skimming along. As the bird flew over the rapids within a few inches of the treacherous splashes, it seemed to ride on billows of air, the curves of which corresponded exactly to the undulations of the rushing waters.

Lighting on a stone within a few feet of where I stood, it bowed its head a couple of times, and apparently said: "Now that we have been introduced, I shall sing for you."

Such familiarity was truly reciprocal, and I joyfully and patiently listened to the lay, then watched the bird wade underneath a little clear pool of water, emerge and fly to its nest. On this invitation I visited its home to picture the nest in its hidden, damp, northern seclusion. Then, wishing the bird good luck, I bade my new friend farewell. 



\section{INDEX}

American Goldfinch ...... 171

American Brown Pelican ... 72

American Crow .......... 154

American Darter ......... 65

American Dipper ......... 242

American Herring Gull .... 57

American Least Tern ....... 69

American Night-jar ....... 133

American Osprey .......... 110

American Quail ........... 94

American Robin .......... 237

Anhinga ................ 65

Audubon Caracara ......... 109

Baltimore Oriole ......... 165

Bank Swallow ........... 198

Basket-Bird .............165

Bee-Bird .............. 142

Bee-Martin ............ 142

Bell's Vireo ............. 205

Belted Kingfisher ........ 120

Bird Personalities ........ 17

Bird Skins ............ 7

Bird Island ............ 51

Black Skimmer ......... 63

Black Vulture ........... 99

Blackbird, Red-winged ..... 159

Black-capped Chickadee .... 230

Black-capped Titmouse ....230

Black-throated Bunting .... 196

Blue Crane ........... 80

Blue-Gray Gnatcatcher ..... 232

Blue Jay .............. 150

Bluebird ............... 241

Bob-White ............ 94

Boat-tailed Grackle ....... 167

Breeding Rookeries ....... 46

Brown Creeper .......... 226

Bronze Grackle ........... 167

Brown Thrasher .......... 220

Bull Bat ............... 135

Buzzard, Turkey ......... 99

Camp Thief ............ 152

Canadian Jay ........... 152

Canary, Wild ........... 209

Caracara .............. 109
Cardinal .............. 189

Catbird .............. 218

Chalk-line .............. 91

Checkerboard ............ 122

Chewink ............... 187

Chickadee .............. 230

Chipping Sparrow ........ 180

Chippy ............... 180

Cock of the Woods ....... 124

Common Savanna Sparrow.. 173

Common Crow ........... 154

Cormorant, Florida ....... 70

Cow Blackbird ........... 156

Cowbird .............. 156

Cranes ............... 80

Creeper, Brown ......... 226

Crested Flycatcher, Great ... 144

Crow, Common .......... 154

Crow Blackbird ......... 167

Crow, Carrion ........... 99

Cuckoo, Yellow-billed ...... 116

Darter, American ......... 65

Demoiselle Egret ........ 84

Dickcissel .............. 196

Dipper .............. 242

Double-crested Cormorant .. 70

Dove, Mourning ......... 97

Dove, Turtle ........... 97

Downy Woodpecker ....... 122

Eagle, Bald ............. 104

Eagle, Golden ........... 102

Egret, Reddish .......... 54

Field Sparrow .......... 181

Field Lark ............. 163

Fire Bird .............. 165

Fish Hawk ........... 110

Flicker ............... 131

Florida Cormorant ....... 70

Flyeatcher, Great Crested ... 144

Fly-Up-the-Creek ......... 91

Fox Sparrow ............. 185

Frigate-Bird ........... 71

Gnateatcher, Blue-Gray .... 232

Golden Eagle ............ 102

Goldfinch, American ...... 171 
Golden-winged Woodpecker. 131 Grackle, Bronzed ......... 167 Grackle, Texas, Great Boattailed .............. 167

Great Blue Heron ........ 80

Great Crested Flycatcher ... 144

Green Heron .......... 91

Grosbeak, Rose-breasted .... 192

Ground Robin ........... 187

Gull, Herring $. . \ldots \ldots \ldots \ldots . .65$

Gull, Laughing $. \ldots \ldots \ldots \ldots . \quad 59$

Hang Nest ............. 165

Hair-Bird ............ 180

Harris's Sparrow ........ 175

Hawk, Sparrow ......... 107

Hawk, Fish ........... 110

Heron, Snowy $. . . \ldots \ldots . .84$

Heron, Great Blue ........ 80

Heron, Little Green ....... 91

Heron, Little Blue ....... 89

Heron, Louisiana ........ 88

Heron, Ward's ......... 80

Herring Gull ........... 57

High Hole .............. 131

Horned Lark ............ 148

House Wren ............ 223

Hummingbird, Ruby-throated 138

Ibis, White ............ 78

Identification ............ 22

Indigo Bunting .......... 194

Ivory-billed Woodpecker ... 124

Jay, Blue ............. 150

Jay, Mountain .......... 152

Jackdaw .............. 169

Junce ............... 182

Joree ................. 187

Kingbird .............. 142

Kingfisher, Belted ........ 120

Lady-of-the-Waters ....... 88

Laguna de la Madre ...... 51

Lark, Meadow ............ 163

Lark, Prairie Horned . ..... 148

Lark, Sparrow .......... 174

Laughing Gull .......... 59

Lazy-bird ............. 156

Least Tern ............. 61

Limpkin .............. 93

Little Blue Heron ........ 89

Log-Cock ............. 124

Long-eared Owl .......... 111

Louisiana Heron ........ 88

Man-0-war Bird ......... 71
Maryland Yellow-throat .... 214

Meadowlark ............ 163

Mexican Buzzard ......... 109

Migration .............. 19

Mockingbird ........... 216

Moose-bird ............. 152

Mountain Jay ............ 152

Mourning Dove ......... 97

Myrtle Bird ........... 212

Nest and Egg Collecting ... 23

Nest Building. ........... 23

Night-Hawk, Sennett's .... 135

Night-jar ............. 133

Oregon Robin ........... 240

Oriole, Baltimore ......... 165

Ospreys ................ 110

Ouzel $\ldots \ldots \ldots \ldots \ldots \ldots \ldots .242$

Owl, Long-eared .......... 111

Owl, Screech ............ 114

Passenger Pigeon ......... 96

Peabody Bird ........... 179

Pileated Woodpecker ...... 124

Pelican, American Brown .. 72

Phoobe Bird ............ 146

Photographic Equipment ... 39

Photographing Birds ....... 29

Pipilo ................. 39

Poor-will .............. 133

Prairie Horned Lark ....... 148

Preacher ............... 203

Prothonotary Warbler ..... 207

Quail ................ 94

Red-winged Blackbird ...... 159

Red-bellied Woodpecker .... 129

Redbird .............. 189

Red-headed Woodpecker .... 127

Red-shouldered Blackbird ... 159

Robin, American ........ 237

Rocky Mountain Jay ...... 152

Rose-breasted Grosbeak .... 192

Roseate Spoonbill ........ 76

Ruby-throated Hummingbird 138

Sand Martin ............ 198

Screech Owl ........... 114

Sennett's Night-Hawk .... 135

Shrike, White-rumped ....200

Skimmer, Black ......... 63

Slate-colored Junco ....... 182

Snake-Bird ............ 65

Snowbird ............. 182

Snowy Heron .......... 84

Song Sparrow .......... 184 
Sparrow, Chipping ....... 180 Sparrow, Common Savanna. 173 Sparrow, Fox ........... 185 Sparrow, Harris's ........ 175 Sparrow, Field .......... 181 Sparrow, Tree .......... 177 Sparrow, Lark .......... 174 Sparrow Hawk .......... 107 Sparrow, White-throated .. 179 Swallow, Bank .......... 198 Tent ................. 43

Tern, Least ............. 61

Tern, Aretic ............ 62

Thistle-Bird ............ 171

Thrasher, Brown ........ 220

Thrush, Varied ........... 240

Thrush, Wood ........... 234

Titmouse, Black-capped .... 230

Towhee ............... 187

Tree Sparrow .......... 177

Tricolor $\ldots \ldots \ldots \ldots \ldots \ldots .127$

Tufted Titmouse ......... 228

Turkey Buzzard .......... 99

Turkey, Water ............ 65

Turkey, Vulture ......... 99

Turtle Dove ............ 97

Varied Thrush .......... 240
Vireo, Bell's ........... 205

Vireo, Red-eyed .......... 203

Vulture, Black .......... 99

Warbler, Prothonotary .... 207

Warbler, Myrtle ........ 212

Warbler, Yellow ........ 209

Warbler, Golden ......... 209

Ward's Heron .......... 80

Water Ouzel ............. 242

Water Turkey ........... 65

Whiskey Jack .......... 152

Whip-poor-will ........... 133

White Ibis ........... 78

White-throated Sparrow .... 179

Wild Canary ............ 171

Woodpecker, Downy ....... 122

Woodpecker, Pileated ...... 124

Woodpecker, Red-headed ... 127

Woodpecker, Red-bellied ... 129

Wood Thrush ........... 234

Wren, House ............ 223

Yellow Warbler .......... 209

Yellow Summerbird ....... 209

Yellow-billed Cuckoo ...... 116

Yellow-Hammer ......... 131

Yellow-rumped Warbler .... 212

Yellow-throat, Maryland .... 213 




$\therefore$

4 



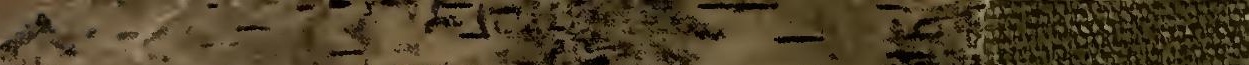

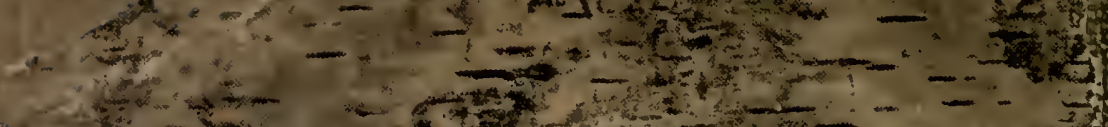

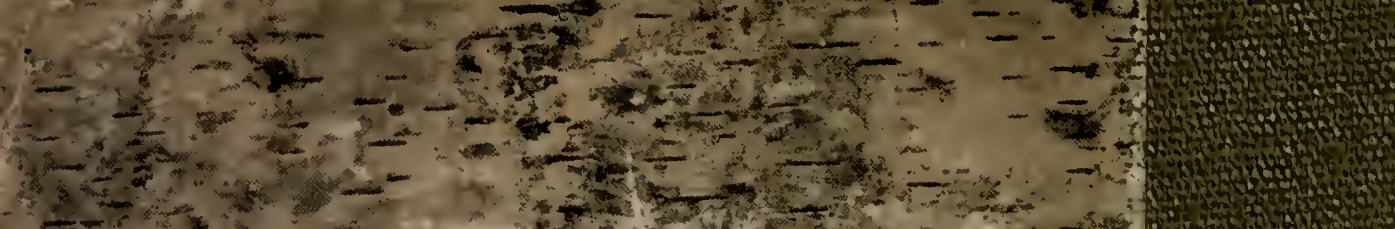

If

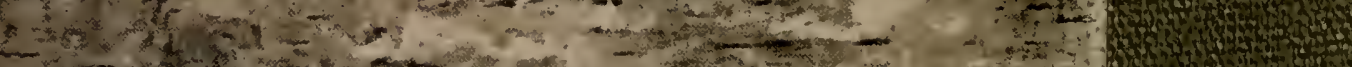

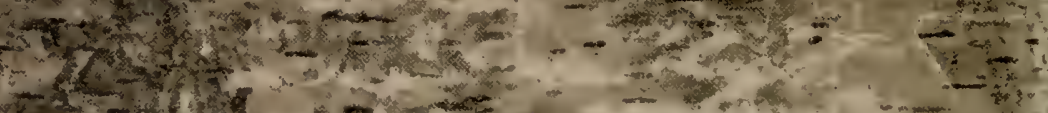

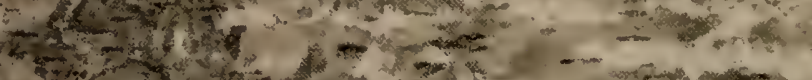

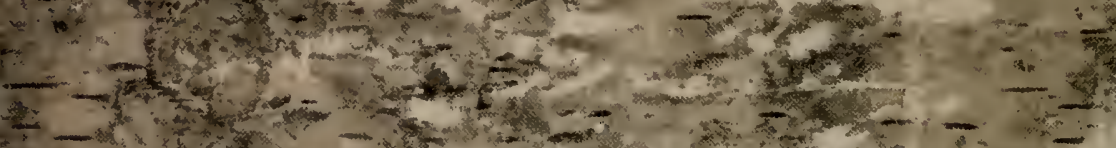

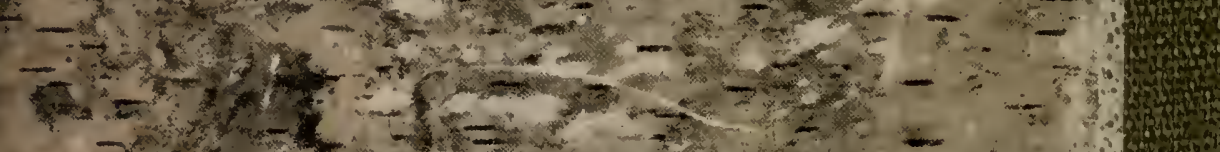

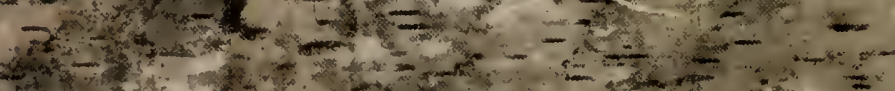

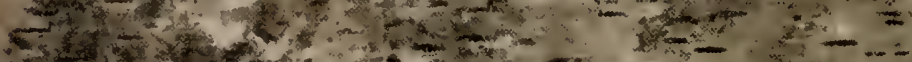

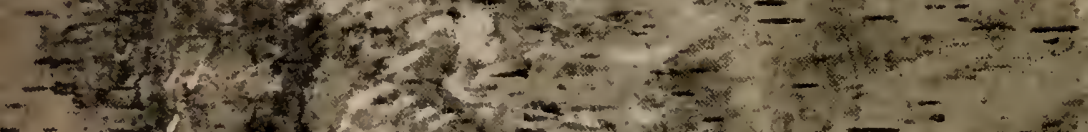

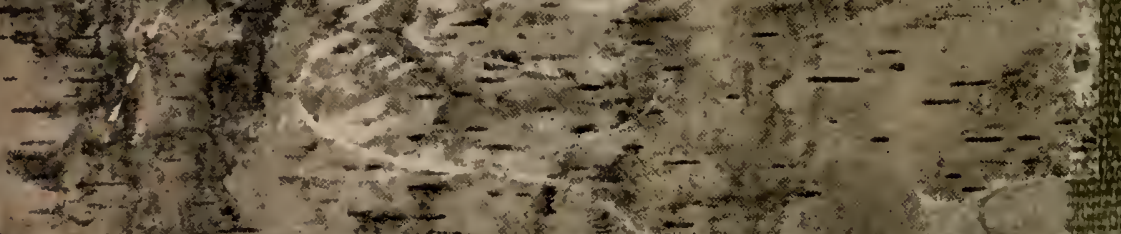

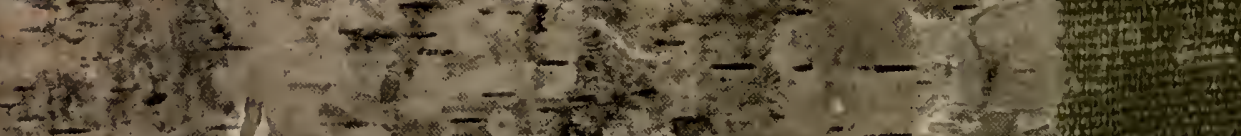

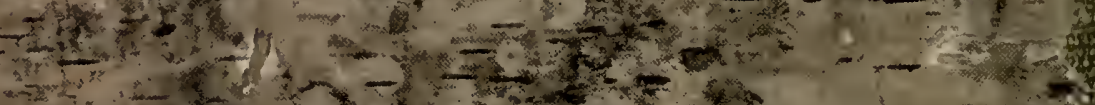

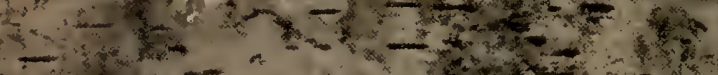

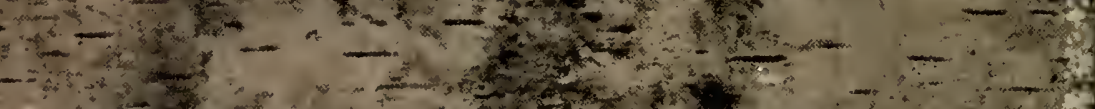

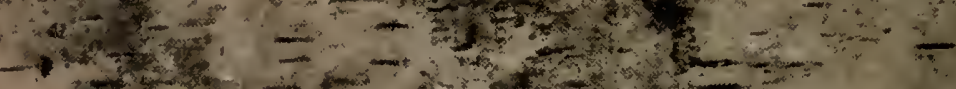

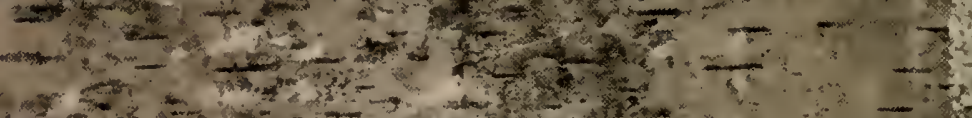

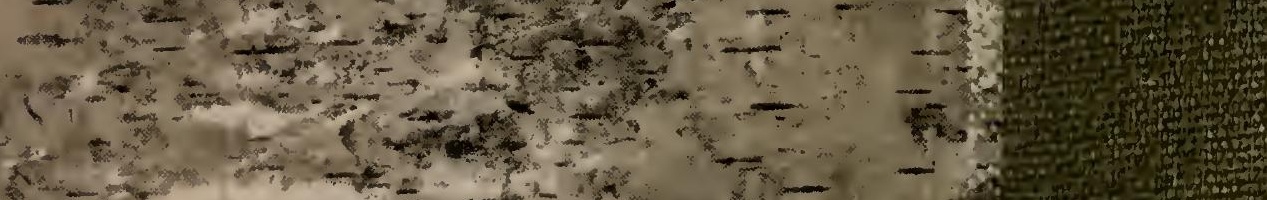

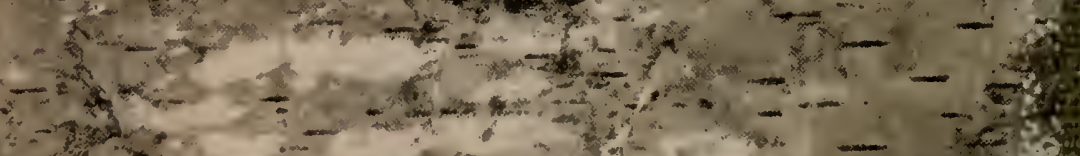

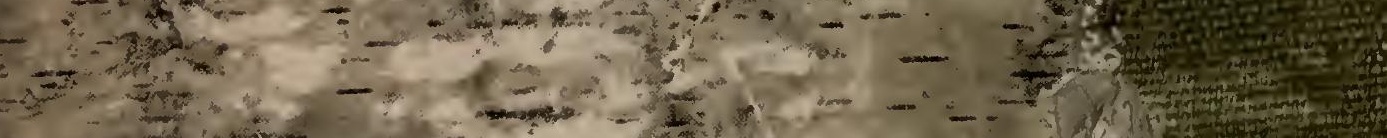

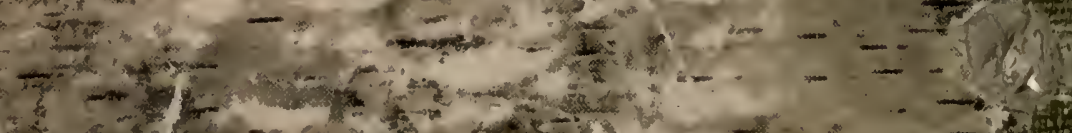

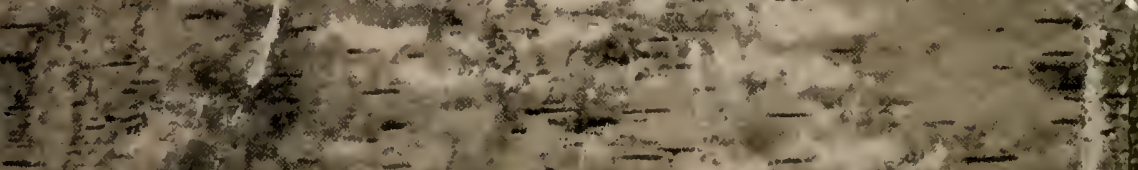

-

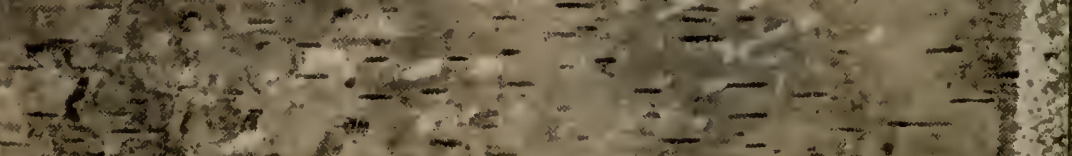

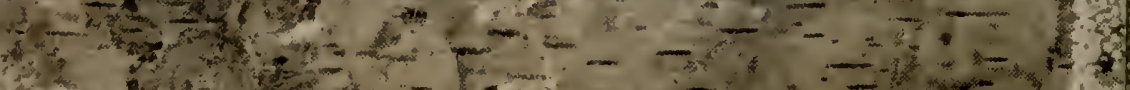

